Nikolaus Hagen, Tobias Neuburger (Hg.)

\title{
Antisemitismus in der Migrationsgesellschaft Theoretische Überlegungen, Empirische Fallbeispiele, Pädagogische Praxis
}



Nikolaus Hagen, Tobias Neuburger (Hg.)

\section{Antisemitismus in der Migrationsgesellschaft Theoretische Überlegungen, Empirische Fallbeispiele, Pädagogische Praxis}




\section{Nikolaus Hagen}

Wiener Wiesenthal Institut für Holocaust-Studien

\section{Tobias Neuburger}

Institut für Geschichtswissenschaften und Europäische Ethnologie, Universität Innsbruck

Diese Publikation wurde mit finanzieller Unterstützung des Forschungsschwerpunkts Kulturelle Begegnungen - Kulturelle Konflikte sowie des Vizerektorats für Forschung gedruckt.

Gefördertes Sonderprojekt der Österreichischen Hochschüler_Innenschaft.

(C) innsbruck university press, 2020

Universität Innsbruck

Alle Rechte vorbehalten.

www.uibk.ac.at/iup

ISBN 978-3-99106-015-4 


\section{Inhalt}

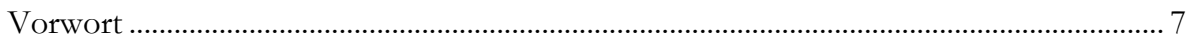

Antisemitismus der Anderen? - Einleitende Überlegungen .............................................. 9

Nikolaus Hagen und Tobias Neuburger

Das antisemitische Unbewusste. Zur politischen Psychologie des

Antisemitismus in der Bundesrepublik Deutschland

Wolfram Stender

Dekonstruktion ,jüdischer Souveränität“ als „ehrbarer Antisemitismus“.

Judith Butler liest Hannah Arendt

Gerhard Scheit

Antisemitismus - Ein blinder Fleck der intersektionalen Geschlechterforschung? ....... 51

Manuel Mayrl

Israelfeindschaft und Antisemitismus bei Hamas, Al-Qaida und

Islamischem Staat

Michel Wyss

Grundlagen und Formen der Annäherung zwischen dem Islamismus und der radikalen ,globalen Linken“ nach 9/11

Daniel Rickenbacher

Universalisierte Opferschaft. Über den Erfolg des islamischen

Antisemitismus in Europa.....

Soma Mohammad Assad 
Antisemitismus unter Geflüchteten aus Syrien und dem Irak.

Befunde einer qualitativen Erhebung.

Günther Jikeli

Im „Namen der guten Sache“. Palästina-Solidarität, Antizionismus und

Antisemitismus unter MuslimInnen im zeitgenössischen Frankreich.

Alexandra Preitschopf

Zum Umgang mit Antisemitismus und anderen Formen

Gruppenbezogener Menschenfeindlichkeit in der Berufsschule

Georg Lauss und Stefan Schmid-Heher

Nach der Erziehung zur Mündigkeit. Anmerkungen zu

Antisemitismus und Pädagogik

Michael Fischer

Opfergemeinschaften und Verschwörungsphantasmen. Reflexionen über pädagogische Praxis in der postnazistischen Gesellschaft

Enno Stïnkel

Autorinnen und Autoren 


\section{Vorwort}

\section{Nikolaus Hagen und Tobias Neuburger}

Dieser Band geht auf zwei Tagungen zurück, die im Oktober 2015 und im Oktober 2016 am Institut für Zeitgeschichte der Universität Innsbruck im Rahmen des Forschungsschwerpunkts „Kulturelle Begegnungen - Kulturelle Konflikte“ veranstaltet wurden. ${ }^{1}$ Die beiden Tagungen trugen den Titel „Antisemitismus in der Gegenwartsgesellschaft". Eine Auswahl der damaligen Vorträge, die von den Autorinnen und Autoren erweitert und aktualisiert wurden, liegt nun ergänzt um weitere Beiträge in diesem Band vor. Wir danken den Vortragenden und Diskutanten der damaligen Veranstaltungen, ebenso wie allen, die wir für weitere Beiträge, für Korrekturen und für Reviews zu den einzelnen Texten gewinnen konnten, herzlich für ihren Beitrag zur Realisierung dieser Publikation. Ziel der beiden Tagungen war es, den ,wissenschaftlichen Nachwuchs" mit Forschenden der Universität Innsbruck und einer interessierten Öffentlichkeit ins Gespräch zu bringen und das, aus unserer Sicht, stark vernachlässigte Feld der gegenwartsbezogenen Antisemitismusforschung zu beleben und sichtbar zu machen. In diesem Sinne basiert der Band auch nicht auf einem spezifischen Forschungsprogramm, er zeigt vielmehr ein breites Spektrum an durchaus heterogenen Ansätzen auf.

Die Drucklegung wurde ermöglicht durch Förderungen des Vizerektorats für Forschung der Universität Innsbruck und des Forschungsschwerpunkts „Kulturelle Begegnungen Kulturelle Konflikte“.

Wien/Hannover, Juli 2020

1 (Neuer) Antisemitismus in der Gegenwartsgesellschaft, Universität Innsbruck, 19.10.2015, [https://www.uibk.ac.at/fsp-kultur/veranstaltungen/dokumente/einladung-neuer-antisemitismus-in-dergegenwartsgesellschaft.pdf], eingesehen 14.7.2020; Antisemitismus in der Gegenwartsgesellschaft, Universität Innsbruck, 17.10.2016, [https://www.uibk.ac.at/zeitgeschichte/newsletter/2-2016/images/el-antisemitismus-in-dergegenwartsgesellschaft-2.pdf], eingesehen 14.7.2020. 



\title{
Antisemitismus der Anderen? - Einleitende Überlegungen
}

\author{
Nikolaus Hagen und Tobias Neuburger
}

Vor wenigen Jahren erschütterte eine tödliche Serie von Terroranschlägen Europa. Unter den Anschlagszielen befanden sich vor allem jüdische Einrichtungen (oder solche, die als „jüdisch“ wahrgenommen wurden), wie das Jüdische Museum Belgiens in Brüssel im Mai 2014, ${ }^{1}$ ein koscherer Supermarkt in Paris im Januar 2015 (zwei Tage nach dem Angriff auf die Redaktion des Satiremagazins Charlie Hebdo) ${ }^{2}$ und eine Synagoge in der dänischen Hauptstadt Kopenhagen im Monat darauf. ${ }^{3}$ Viele der Täter, darunter der Attentäter von Brüssel, bekannten sich offen zur dschihadistischen Gruppe „Islamischer Staat“ oder waren von deren Ideologie inspiriert. So sehr diese Anschläge allerdings die Öffentlichkeit schockierten: antisemitische Gewalt ist in Europa alles andere als eine Neuheit. Doch gerade die unheimliche Kontinuität des Antisemitismus gerät im Zuge der Skandalisierung allzu häufig aus dem Blick und wird geradezu durch sie verstellt.

Bereits in den 1970er-Jahren zielte der palästinensische Terrorismus ${ }^{4}$ - auch unter Beteiligung von Vertretern der europäischen Neuen Linken - auf jüdische und israelische Einrichtungen in Europa bzw. das, was die Terroristen für solche hielten. Besonders blutig war der Anschlag palästinensischer Terroristen auf die israelische Mannschaft bei den Olympischen Spielen 1972 in München, bei dem elf israelische Sportler und ein bayerischer Polizist starben. ${ }^{5}$ Niemals aufgeklärt wurde ein verheerender Brandanschlag, der sich zwei Jahre zuvor ebenfalls in München ereignet hatte: Am 13. Februar 1970 fielen sieben Shoah-Überlebende einem Brandanschlag auf das Jüdische Gemeindezentrum zum Opfer. Ermittelt wurde zu Beginn sowohl in rechten Kreisen als auch im Umfeld palästinensischer Terrorgruppen, im Anschluss auch im Umfeld linksterroristischer Organisationen - eine Aufklärung von Tat und Täterschaft konnten

\footnotetext{
${ }^{1}$ Gericht spricht Attentäter von Brüssel schuldig, in: Die Zeit, 7.3.2019, [https://www.zeit.de/gesellschaft/zeitgeschehen/2019-03/mehdi-nemmouche-anschlag-juedisches-museumbruessel-gericht-schuldig], eingesehen 1.2.2020.

2 Michael Thaidigsmann, Fünf Jahre nach dem Albtraum, in: Jüdische Allgemeine, 9.1.2020, [https://www.juedischeallgemeine.de/juedische-welt/ fuenf-jahre-nach-dem-albtraum/], eingesehen 1.2.2020.

3 Terror in Kopenhagen, in: Jüdische Allgemeine, 15.2.2015, [https://www.juedische-allgemeine.de/juedischewelt/terror-in-kopenhagen/], eingesehen 1.2.2020.

4 Siehe bspw. Thomas Riegler, Im Fadenkreuz: Österreich und der Nahostterrorismus 1973 bis 1985, Göttingen 2010; Ariel Merari/Shlomi Elad, The International Dimension of Palestinian Terrorism, New York 2019.

5 Eva Oberloskamp, Das Olympia-Attentat 1972. Politische Lernprozesse im Umgang mit dem transnationalen Terrorismus, in: Vierteljahrshefte für Zeitgeschichte 60 (2012), Heft 3, S. 321-352.
} 
auch Nachermittlungen der Bundesanwaltschaft, die 2017 ohne Ergebnis eingestellt wurden, nicht herstellen. ${ }^{6}$

Die gewalttätige Spur des Antisemitismus nach 1945 lässt sich auch nach Österreich verfolgen: Am jüdischen Neujahrsfest im September 1973 nahmen palästinensische Terroristen drei jüdische Geiseln am niederösterreichischen Grenzbahnhof Marchegg. Die Geiselnahme endete unblutig, zeitigte aber den gewünschten Erfolg: die österreichische Bundesregierung ging auf die Forderung der Täter ein und schloss ein Transitzentrum für jüdische Auswanderer aus der Sowjetunion. ${ }^{7}$ Im August 1981 war der israelitische Stadttempel in der Wiener Seitenstettengasse Ziel eines Terroranschlags, verübt von zwei Palästinensern. Dabei kamen zwei Personen ums Leben und zahlreiche andere wurden schwer verletzt. Schon zwei Jahre zuvor war die Synagoge Ziel eines Sprengstoffattentats geworden. ${ }^{8}$ Am 27. Dezember 1985 wurden die Schalter der israelischen Fluglinie EL AL an den Flughäfen Wien und Rom die Ziele tödlicher Angriffe. Insgesamt ermordeten Terroristen dabei 19 Personen. ${ }^{9}$

Auch Neonazis und Rechtsextremisten verübten immer wieder verheerende Anschläge auf jüdische Einzelpersonen und Einrichtungen. Im Dezember 1980 wurden der Rabbiner Shlomo Lewin und seine Lebensgefährtin in ihrer Privatwohnung in Erlangen von einem deutschen Neonazi ermordet. ${ }^{10}$ Neonazis und Rechtsextreme waren insbesondere in den 1990er und 2000er-Jahren für zahlreiche Mord-, Brand- und Sprengstoffanschläge auf Synagogen, jüdische Einrichtungen und Einzelpersonen verantwortlich. Teilweise konnten Anschläge kurz vor der Ausführung noch verhindert werden, wie ein geplanter Bombenanschlag von Neonazis anlässlich der Grundsteinlegung des neuen jüdischen Gemeindezentrums in München im November 2003. ${ }^{11}$

Diese Aufzählung antisemitischer Gewalttaten ist alles andere als erschöpfend - von ungezählten antisemitisch motivierten Übergriffen, Friedhofschändungen und Sachbeschädigungen an jüdischen Einrichtungen ganz zu schweigen. Sie verdeutlicht allerdings, dass der Antisemitismus auch nach 1945 eine blutige Spur nach sich zog und

${ }^{6}$ Der Generalbundesanwalt beim Bundesgerichtshof, Ermittlungen wegen des Brandanschlags auf die Israelitische Kultusgemeinde am 13. Februar 1970 in München mangels weiterer erfolgversprechender Ermittlungsansätze eingestellt, 23.11.2017,

[https://www.generalbundesanwalt.de/SharedDocs/Pressemitteilungen/DE/2017/Pressemitteilung-vom-23-11-

2017.html], eingesehen 1.2.2020.

7 Margit Reiter, Unter Antisemitismusverdacht. Die österreichische Linke und Israel nach der Shoah, Innsbruck 2001, S. 252-260.

8 Ursula Mindler-Steiner, Ermordung von Heinz Nittel - Anschlag auf den Stadttempel, o. D., [https://www.hdgoe.at/ermordung-nittel-anschlag-stadttempel], eingesehen 1.2.2020.

9 Lisa-Sophie Heinrich, Als der Terror nach Wien Schwechat kam, in: Die Presse, 26.12.2015, [https://www.diepresse.com/4892554/als-der-terror-nach-wien-schwechat-kam], eingesehen 1.2.2020.

10 Matthias Quent/Jan Rathje, Von den Turner Diaries über Breivik bis zum NSU: Antisemitismus und rechter Terrorismus, in: Samuel Salzborn (Hrsg.), Antisemitismus seit 9/11. Ereignisse, Debatten, Kontroversen, BadenBaden 2019, S. 165-178.

${ }^{11}$ Neonazis wollten jüdisches Zentrum sprengen, in: Süddeutsche Zeitung, 12.9.2003. 
weiterhin zieht. Zusammen mit den jüngsten Anschlägen der letzten Jahre ergibt sich ein Bild ungebrochener antisemitischer Gewalttaten - auch nach und trotz der militärischen Niederlage des Nationalsozialismus und seiner Verbündeten 1945. Womit die noch immer nachhallende Erzählung, der auf Vernichtung zielende Antisemitismus sei mitsamt dem Deutschen Reich 1945 untergegangen, bereits eindrücklich widerlegt ist. Die gesellschaftspolitische Transformation hin $\mathrm{zu}$ Liberaldemokratien westlichen Musters, die nicht nur postnazistische Gesellschaften wie Deutschland und Österreich kennzeichnet, führte offensichtlich nicht zum allmählichen Verschwinden des Antisemitismus. Bemerkenswert und erschütternd an den antisemitischen Gewalttaten ist nicht nur ihre Brutalität und ihre regelmäßige Wiederkehr, sondern auch die heterogene Täterschaft, die wiederum die soziale Streuung antisemitischer Einstellungen quer durch alle Schichten und Milieus spiegelt.

\section{Externalisierung und Universalisierung}

Die damals noch frischen Eindrücke der Anschlagsserie auf jüdische Einrichtungen sowie zahlreiche antisemitische Manifestationen auf Demonstrationen im Zuge des Gaza-Konflikts $2014^{12}$ haben uns im Frühjahr 2015 dazu bewogen, eine Tagung an der Universität Innsbruck zu Ausprägungen des gegenwärtigen Antisemitismus zu initiieren. ${ }^{13}$ Neben der auch heute noch gültigen Feststellung, dass der zeitgenössische Antisemitismus, trotz seiner verheerenden Auswirkungen, nicht die nötige Aufmerksamkeit in den Geistes-, Sozial- und Kulturwissenschaften erfährt, waren es auch öffentliche Reaktionen auf die Anschläge, die uns zu diesem Vorhaben motiviert hatten. Neben vereinzelten differenzierten und kritischen Beiträgen, schien die sich anschließende Debatte zugleich durch Externalisierung und - nur auf den ersten Blick gegenläufig, aber letztlich hiermit verwandt - Universalisierung der antisemitischen Gewalttaten geprägt.

Die Externalisierung folgt einem vertrauten Muster: während die Täter symbolisch ausgebürgert werden, entledigt man sich zugleich des Antisemitismus. Dieser sei folglich ein von außen nach Europa hereingetragenes Problem, bzw. ein Exportprodukt aus der islamischen Welt oder immer nur der Antisemitismus der Anderen. Die Rede vom „importierten Antisemitismus“ hat seither eine gewisse Konjunktur, insbesondere bei

12 Julia Edthofer, Debates on Islamized Antisemitism in Austria in the Wake of the Israel-Gaza Conflict 2014 (Kantor Center Position Papers), Tel Aviv 2016,

[https://en-humanities.tau.ac.il/sites/humanities_en.tau.ac.il/files/media_server/0001/Edthofer.pdf], eingesehen 1.2.2020.

13 Die Tagung trug den Titel „,Neuer) Antisemitismus in der Gegenwartsgesellschaft“ und fand am 19. Oktober 2015 an der Universität Innsbruck statt. Eine zweite Tagung mit dem Titel „Antisemitismus in der Gegenwartsgesellschaft“ fand im Oktober 2016 ebenfalls an der Universität Innsbruck statt. 
konservativen und rechtspopulistischen Politikern und Medien. ${ }^{14}$ Auf die Spitze trieb diese Behauptung 2019 der ungarische Premierminister Viktor Orbán, der seine restriktive Migrationspolitik als probates Mittel zum Schutz der jüdischen Gemeinschaft und gegen den ,importierten Antisemitismus aus der muslimischen Welt ${ }^{* 15}$ darstellte. Wiewohl er seit einigen Jahren selbst eine antisemitische Kampagne gegen den Philanthropen und Universitätsgründer George Soros führt, ${ }^{16}$ externalisierte er die antisemitische Gefahr mit den Worten: „Die jüdische Gemeinschaft lebt hier vielleicht am sichersten in ganz Europa. Das hängt auch damit zusammen, dass es hier keine großen muslimischen Gemeinschaften gibt und damit, dass die Regierung die jüdische Gemeinschaft entschlossen schützt.“"17

Teilweise führt diese Externalisierungsstrategie gar zur Leugnung des antisemitischen Gehalts von Gewalttaten: so zeigte sich ein deutsches Gericht im Februar 2015, das einen Brandanschlag auf die Wuppertaler Synagoge verhandelte, unfähig das Offensichtliche überhaupt zu erkennen. Stattdessen folgte das Gericht der Darstellung der angeklagten jungen Männer, konnte keine „Anhaltspunkte für eine antisemitische Tat" erkennen und argumentierte in der Urteilsbegründung diese hätten lediglich die „Aufmerksamkeit auf den Gaza-Konflikt lenken wollen“ “. ${ }^{18}$ Europa avanciert in solchen Deutungsmustern zum Nebenschauplatz fremder Auseinandersetzungen, der antisemitische Gehalt wird relativiert oder gar geleugnet und in eine begründete Aversion gegen den jüdischen Staat und seine vermeintlichen Statthalter in Europa verkehrt. ${ }^{19}$

Diese Externalisierung basiert auf der Vorstellung einer vom Antisemitismus geläuterten Gesellschaft und erhält das damit verbundene Selbstbild im Sinne einer sich selbsterfüllenden Prophezeiung zugleich am Leben. Neben dem Antisemitismus der Anderen kann auch die Rede vom Antisemitismus der „Ewiggestrigen“ eine solche Funktion übernehmen und als Versuch seiner scheinbaren Bannung in der Vergangenheit begriffen werden. Im Zentrum steht jeweils die Vorstellung, dass die demokratische Nachkriegsgesellschaft den Antisemitismus überwunden hat. Verbindungslinien, die

14 So behauptete etwa Anfang 2020 der österreichische Nationalratspräsident Wolfgang Sobotka in Österreich sei ein „starker, importierter Antisemitismus' zu beobachten“. Sobotka, Noch entschiedener gegen Antisemitismus vorgehen, in: katholisch.at, 29.1.2020, [https://www.katholisch.at/aktuelles/128662/sobotka-noch-entschiedener-gegenantisemitismus-vorgehen], eingesehen 1.6.2020.

15 Importierter Antisemitismus aus der muslimischen Welt, in: kath.net, 25.5.2019, [http://www.kath.net/news/68044], eingesehen 23.6.2019.

16 Roland Clark/Nikolaus Hagen, Kalergi Plan: The Undying „White Genocide” Conspiracy Theory, in: Rantt Media, 2.5.2020, [https://rantt.com/the-kalergi-plan-explained], eingesehen 4.6.2020.

17 Zit. n. Importierter Antisemitismus, in: kath.net, 25.5.2019.

18 Deniz Yücel, Antisemitismus? Ist abgeschafft, in: taz.de, 18.2.2015, [https://taz.de/Kolumne-Besser/!5019881], eingesehen 3.7.2020.

19 Diese Form der Externalisierung hat eine lange Tradition. Über die bundesdeutsche Reaktion auf das OlympiaAttentat 1972 schreibt Eva Oberloskamp: „Die Geiselnahme der israelischen Mannschaft wurde als rein palästinensische Form des Terrorismus perzipiert, die man von der Bundesrepublik auf Dauer fern halten wollte. [...] Dem entsprach die Einschätzung, dass die Bundesrepublik [...] als ,unschuldiges Opfer ${ }^{\star}$ in den Nahostkonflikt hineingezogen worden sei, für den sie keine Verantwortung trage.“ Overloskamp, Olympia-Attentat, S. 329-330. 
dieses geläuterte Selbstbild in Frage stellen und brüchig werden lassen, werden gekappt. Das führt im Extremfall sogar dazu, dass zeitgenössische Formen des Antisemitismus überhaupt gar nicht mehr als Antisemitismus erkannt werden.

Nachdem die Journalistin Jutta Ditfurth einen der Chefideologen der Neuen Rechten und Herausgeber des verschwörungstheoretischen Compact-Magąins, Jürgen Elsässer, als Antisemiten bezeichnet hatte, klagte dieser auf Unterlassung und bekam hierbei richterlichen Beistand. In einem Verfahren am Münchener Landgericht schloss die Richterin, „dass gerade vor dem Hintergrund der Verbrechen der Nazidiktatur sowie des Holocaust die Bezeichnung, glühender Antisemit ${ }^{\prime}$ in besonderer Weise geeignet ist, den so Bezeichneten herabzuwürdigen und in seiner Ehre zu verletzen. ${ }^{\text {20 }}$ In der richterlichen Position, dass die Bezeichnung Antisemit nur auf den Anwendung finden kann, der „die Überzeugungen teilt, die zu der Ermordung von 6 Millionen Juden unter der nationalsozialistischen Schreckensherrschaft geführt haben",21 artikuliert sich ein Unvermögen die Metamorphosen und Formwandlungen des Antisemitismus auch nur ansatzweise anzuerkennen.

Die Externalisierung des Antisemitismus funktioniert gut, weil sie Anknüpfungspunkte an unterschiedlichste Einstellungsmuster und Weltbilder bietet. Die gesellschaftliche „Mitte“ kann sich ihrer selbst versichern und den Antisemitismus wahlweise an Rändern und Extremen, bei Außenstehenden und Anderen verorten. Für die politische Rechte ist Antisemitismus neuerdings überhaupt eine Folge der Migration und werde entsprechend durch Einwanderungsstopp und Abschiebungen bekämpft. ${ }^{22}$ Während weite Teile der Linken insbesondere den israelbezogenen Antisemitismus - sofern der antisemitische Gehalt nicht überhaupt abgestritten wird - ohnehin als verständliche Reaktion auf Imperialismus und Kolonialismus rationalisieren. ${ }^{23}$ Sie verdrängen in diesem Zuge nicht nur die antikoloniale Entstehungsgeschichte des jüdischen Staates, sondern beschuldigen diesen gar als imperialistischen Brückenkopf und koloniales Übel.

Zweifelsohne hat in den letzten Jahren insbesondere die Deutung vom „importierten Antisemitismus“ - oder auch vom „Antisemitismus der Migranten“ - beinahe hegemonialen Charakter im öffentlichen Diskurs eingenommen. Der Antisemitismus wird auf diese Weise zwar nicht per se negiert, aber eben einer bestimmten Bevölkerungsgruppe überantwortet. Die kurzfristigen Vorteile dieser Verschiebung sind evident: Sie entlasten weite Teile der Gesellschaft nicht einfach nur, sondern sie kitten

${ }^{20}$ Landgericht München, Urteil vom 10.12.2014, 25 014197/14,

[https://www.juris.de/jportal/prev/JURE170032899], eingesehen 3.7.2020.

21 Ebd.

22 Siehe exemplarisch Alexander Häusler, Feindbild Moslem. Türöffner von Rechtsaußen hinein in die Mitte?, in: Gideon Botsch u. a. (Hrsg.), Islamophobie und Antisemitismus - ein umstrittener Vergleich, Berlin 2012, S. 169-190, hier S. 174 .

${ }^{23}$ Siehe exemplarisch Julia Edthofer, Vom antiimperialistischen Antizionismus zur aktuellen Boykottbewegung, in: Österreichische Zeitschrift für Soziologie 42 (2017), S. 407-424. 
zudem die Brüche im anti-antisemitischen Tabu der postnazistischen Gesellschaft ${ }^{24}$ und verhindern schmerzhafte (Selbst-) Reflexion.

In diesen Wirkungszusammenhang ist auch der Mechanismus der Universalisierung antisemitischer Gewalttaten einzuordnen. Indem die Anschläge auf jüdische Einrichtungen als Teil eines Kulturkampfes des Islamismus oder des Islam gegen den (jüdisch-)christlichen Westen verallgemeinert werden, verliert sich auch in diesem Deutungsmuster der spezifische antisemitische Gehalt solcher Gewaltsituationen. Einerseits ist diese Deutung nicht gänzlich von der Hand zu weisen, schließlich ist es geradezu Kernelement des Antisemitismus, dass dieser Jüdinnen und Juden als die Agenten gesellschaftlicher Modernisierungsprozesse und damit einhergehender Verwerfungen imaginiert und ins Visier nimmt. Dass Jüdinnen und Juden und insbesondere der jüdische Staat in der Ideologie diverser islamistischer Gruppierungen nicht einfach nur als Stellvertreter, sondern gar als heimliche Strippenzieher hinter den Vereinigten Staaten oder gleich dem gesamten Westen firmieren, steht genau in dieser antisemitischen Tradition. Andererseits wird diese Deutung dann problematisch, wenn der Antisemitismus im Narrativ vom allumfassenden Kulturkampf verschwindet.

Auf diese Weise wird der Antisemitismus universalisiert: „Jede Form des Antisemitismus", um eine Redewendung des deutschen Justizministers Heiko Maas aufzugreifen, wird dann zu einem „Angriff auf uns alle“. ${ }^{25}$ Diese Rhetorik unterschlägt aber das Wesentliche antisemitischer Gewalttaten, die eben nicht wahllos gegen „uns alle" gerichtet sind, sondern gegen Jüdinnen und Juden und - den Spuren des antisemitischen Wahns folgend - gegen deren „Kollaborateure“. ${ }^{26}$ Wird die Szenerie zu einem „Angriff auf uns alle“ verallgemeinert, dann ist am Ende möglicherweise gar nichts mehr zu erkennen: Als im November 2015 ein äußerst opferreicher Anschlag auf die Pariser Konzerthalle „Bataclan“ verübt wurde, spielte die offenkundige antisemitische Motivation der Täter im öffentlichen Diskurs kaum mehr eine Rolle - obwohl bekannt war, dass das Veranstaltungslokal wiederholt Gegenstand antisemitischer Schmähungen und Drohungen war. ${ }^{27}$

Neben diese beiden Mechanismen tritt in der politischen Arena eine problematische Pattstellung: Teile der politischen Rechten und der Linken schieben sich den Antisemitismus gegenseitig in die Schuhe, projizieren ihn auf andere oder leugnen ihn aus strategischen Gründen wahlweise. ${ }^{28}$ Letztlich führt das dazu, dass nicht nur der

24 Vgl. Juliane Wetzel, Judenfeindliche Stereotypisierungen: Das Beschneidungsurteil im öffentlichen Diskurs, in: Johannes Heil/Stephan J. Kramer (Hrsg.), Beschneidung: Das Zeichen des Bundes in der Kritik. Zur Debatte um das Kölner Urteil, Berlin 2012, S. 264-275, hier S. 265.

25 Heiko Maas, Jede Form von Antisemitismus, in: twitter.com, 10.12.2017,

[https://twitter.com/HeikoMaas/status/939985057174949888], eingesehen 9.7.2020.

${ }^{26}$ Siehe zur Logik des antisemitischen Selbstmordattentats insbesondere Gerhard Scheit, Suicide Attack. Zur Kritik der politischen Gewalt, Freiburg i. Br. 2004.

27 Alex Feuerherdt, Bataclan. Ein antisemitischer Anschlag, in: mena-watch.com, 17.11.2015, [https://www.menawatch.com/bataclan-ein-antisemitischer-anschlag], eingesehen 9.7.2020.

${ }^{28}$ Siehe dazu auch Julia Edthofer, Rassismus- oder Antisemitismuskritik? Eine antirassistische Perspektive auf den 
Antisemitismus der Mitte vollkommen aus dem Blick gerät, sondern darüber hinaus auch jener im eigenen politischen Lager.

\section{Antisemitismus in der Migrationsgesellschaft?}

2015 hatten wir für die erste unserer Tagungen ursprünglich den Titel „Antisemitismus in der Migrationsgesellschaft" ins Auge gefasst. Wir wollten damit der Tatsache Rechnung tragen, dass die mitteleuropäischen Gesellschaften in erheblichem Maße von und durch Migration geprägt sind. Einer OECD-Statistik zufolge waren mit Stand 2018 beinahe ein Drittel der schweizerischen, 19 Prozent der österreichischen und 16 Prozent der deutschen Wohnbevölkerung im Ausland zur Welt gekommen. Damit übertrifft die Schweiz sogar „klassische Einwanderungsländer“ wie Australien, Neuseeland, Kanada oder die Vereinigten Staaten in erheblichem Maße. Auch Österreich und Deutschland weisen nach dieser Erhebung Spitzenplätze noch vor den Vereinigten Staaten oder dem Vereinigten Königreich auf. ${ }^{29}$ Selbst unter Anwendung einer sehr engen Definition, wenn also beide Elternteile im Ausland zur Welt kamen, besitzt ein Viertel der österreichischen Bevölkerung einen sogenannten Migrationshintergrund. ${ }^{30}$

Mobilitäts- und Migrationserfahrungen bestimmen in zunehmendem Maße die Biografien weiter Teile der Bevölkerung. Hierin spiegelt sich nicht zuletzt die politische Förderung von grenzüberschreitender Mobilität, die aber vor allem dann als opportun gilt, sofern sie notwendiger Bestandteil von Bildungs- und Berufskarrieren ist. Trotz unbestreitbarer Migrationsrealitäten ist der Begriff „Migrationsgesellschaft“ allerdings bis heute politisch umstritten. Noch immer weigern sich maßgebliche politische Kräfte sowohl in Deutschland als auch in Österreich dies anzuerkennen. Wir halten den Begriff „Migrationsgesellschaft" demgegenüber für eine neutrale Tatsachenbeschreibung, die nicht zuletzt die soziale Wirklichkeit in den urbanen Ballungszentren beschreibt. In Wien, um eine der größten deutschsprachigen Städte beispielhaft heranzuziehen, waren Anfang 2018 laut amtlicher Statistik 41 Prozent der Bevölkerung im Ausland geboren oder besaßen eine andere als die österreichische Staatsbürgerschaft. ${ }^{31}$ Rechnet man die zweite bereits im Inland geborene Generation mit österreichischer Staatsbürgerschaft hinzu, so

Zusammenhang von Islamismus und Antisemitismus, 20.6.2015,

[https:// forschungsgruppefipu.wordpress.com/2015/06/20/gastbeitrag-rassismus-oder-antisemitismuskritik-julia-

edthofer/], eingesehen 1.2.2020.

${ }^{29}$ OECD Databases on Migration, o. D.,

[https://www.oecd.org/migration/mig/oecdmigrationdatabases.htm], eingesehen 1.6.2020.

30 Statistik Austria, Bevölkerung mit Migrationshintergrund im Überblick (Jahresdurchschnitt 2019), 18.3.2020,

[https://www.statistik.at/wcm/idc/idcplg?IdcService=GET_PDF_FILE\&RevisionSelectionMethod=LatestRelease $\mathrm{d} \& \mathrm{dD}$ ocName$=033240$ ], eingesehen 1.6.2020.

31 Stadt Wien, Daten und Fakten zur Migration 2019 - Wiener Bevölkerung, o. D.,

[https://www.wien.gv.at/menschen/integration/daten-fakten/bevoelkerung-migration.html], eingesehen 1.6.2020. 
kann man davon ausgehen, dass die absolute Mehrheit der Wiener Bevölkerung über familiäre Migrationserfahrung verfügt.

Die ideologische Fiktion eines homogenen Nationalstaates mit einem gemeinsamen „Geschichtsbewusstsein“ wird angesichts dieser Faktenlage immer brüchiger. ${ }^{32}$ Auf diesen Sachverhalt hätte insbesondere auch das Bildungssystem Rücksicht zu nehmen. Denn eine solche Fiktion und die mit ihr verbundenen Mythen sind keine adäquate Grundlage für die Analyse und Bekämpfung des Antisemitismus. Die vorherrschende Geschichtspolitik der letzten Jahrzehnte - die auch die Grundlage für die historischpolitische Bildungsarbeit geliefert hat - hat aber insbesondere in Deutschland und Österreich genau das Gegenteil getan. Zwar wird vordergründig häufig auf die Geschichte des Nationalsozialismus und den Holocaust rekurriert, beide Gesellschaften wurden und werden allerdings auf je unterschiedliche Weise als Opfer des Nationalsozialismus gedeutet. ${ }^{33}$ Als in Deutschland in den 1990ern ein nationaler Lernprozess („Geschichtsaufarbeitung“仿) einsetzte, kopierte man in Österreich mit einigen Jahren Verzug auch dieses geschichtspolitische Modell. Wie dieses geschichtspolitische Erfolgsmodell funktioniert, formulierte der ehemalige deutsche Bundeskanzler Gerhard Schröder vor 15 Jahren mit der Formel einer besonderen Verantwortung der Deutschen vor der Geschichte und einer hieraus resultierenden „moralischen Verpflichtung“, die zu einem „Teil unserer nationalen Identität“ geworden ist. ${ }^{34}$ Mit der Integration des Nationalsozialismus in das nationale Selbstbild und der Übernahme dieser besonderen Aufgabe befreit sich die Nation zugleich und implizit vom (eigenen) Antisemitismus. ${ }^{35}$

Jede Geschichtserzählung und Erinnerung stiftet im Sinne eines „Bindemittels“36 soziale Kohäsion und übernimmt damit eine integrierende Funktion. Einen Störfaktor in diesem Selbstbild von einer Gesellschaft, die aus dem Nationalsozialismus gelernt habe, stellen nicht erst seit heute Migranten und Migrantinnen dar. Deren Ausschluss ist bereits in den historischen Erzählungen entlang der Achse eines nationalen Narratives angelegt. Insofern ist es auch nicht überraschend, dass die ohnehin überforderten Bildungsinstitutionen im Angesicht von Migration beunruhigt sind und Lehrer und Lehrerinnen sich beklagen, dass sich (post-)migrantische Schüler und Schülerinnen nicht in die etablierte national-kulturelle Lernkultur, die ein Lernen aus Verantwortung

32 Dirk Rupnow, Deprovincializing Contemporary Austrian History. Plädoyer für eine transnationale Geschichte Österreichs als Migrationsgesellschaft, in: Zeitgeschicbte 40 (2013), Heft 1, S. 6-21.

33 In Österreich hallte lange die Vorstellung nach, das erste Opfer der deutschen NS-Aggression gewesen zu sein („Opferthese“). Zu Deutschland siehe Hannes Heer, Hitler war's. Die Befreiung der Deutschen von ihrer Vergangenheit, Berlin 2005.

34 Gerhard Schröder, „Wir stehen erst jetzt am Ende einer langen Nachkriegszeit“, in: Süddeutscher Zeitung, 7.5.2005.

35 „Wir wollen und wir werden nicht zulassen, dass Unrecht und Gewalt, dass Antisemitismus, Rassismus und Fremdenfeindlichkeit wieder eine Chance bekommen." (Ebd.)

${ }^{36}$ Carola Sachse/Edgar Wolfrum, Stürzende Denkmäler. Nationale Selbstbilder postdiktatorischer Gesellschaften in Europa - Einleitung, in: Carola Sachse/Edgar Wolfrum/Regina Fritz (Hrsg.), Nationen und ihre Selbstbilder. Postdiktatorische Gesellschaften in Europa, Göttingen 2008, S. 7-35, hier S. 13. 
gegenüber der „eigenen“ Geschichte postuliert, ${ }^{37}$ einfügen ließen. Und tatsächlich hat diese Feststellung - die realiter Symptom pädagogischer Unfähigkeit ist - letztlich ihr Wahres an sich: tatsächlich wurden und werden Migranten und Migrantinnen aus dieser Geschichte hinausgeschrieben. Erst langsam findet hier in den letzten Jahren ein Umdenken statt: der Inklusion von Migrationsgeschichte in die Geschichtsbücher müsste aber längst auch eine entsprechende Pädagogik folgen, die das Lernen aus der Geschichte - im Sinne von Verantwortung statt Identität - gerade nicht von einer spezifischen nationalen Herkunft abhängig macht.

Wir haben uns 2015 nach einigen Debatten letztlich für den Tagungstitel „Antisemitismus in der Gegenwartsgesellschaft“ entschieden und diesen auch für die Folgekonferenz 2016 verwendet. In der Zwischenzeit hatte sich nämlich ein Massenfluchtereignis ereignet, das eine neutrale Verwendung des Begriffs „Migrationsgesellschaft" beinahe unmöglich machte. Wir wollten in der Hitze der Debatten im Sommer 2015 den Eindruck vermeiden, vom „Antisemitismus der Anderen“ zu sprechen. Und tatsächlich stehen sich seit damals Proponenten einer „Willkommenskultur“ und Gegner jeder Einwanderung beinahe unversöhnlich gegenüber. Politisch haben letztere in vielen europäischen Ländern die Oberhand gewonnen: Seit Sommer 2015 sind zahlreiche europäische Binnengrenzen geschlossen oder erschwert passierbar, das Schengener Abkommen ist de facto ausgesetzt und die europäischen Außengrenzen, insbesondere jene im Mittelmeer, haben sich in Massengräber verwandelt. Der islamistische Terror wurde damit keineswegs gebannt, schließlich handelte sich bei den Attentätern von Brüssel, Kopenhagen oder Paris, die eingangs erwähnt wurden, nicht um Einwanderer, sondern um Personen, die in Europa zur Welt gekommen waren.

Die Mehrheitsbevölkerung schielt dennoch nach wie vor beinahe exklusiv und obsessiv auf den „Antisemitismus der Migranten“ und in der Zwischenzeit hat rechtsextremer Antisemitismus Fahrwasser bekommen. Das ist nur scheinbar ein Paradoxon. In Zeiten gesellschaftlicher Verwerfungen hat, wie die europäische Geschichte beweist, auch der Antisemitismus mit seiner ungebrochenen psychischen Attraktivität stets Konjunktur. Unter dem Schlagwort „Der große Austausch“ kultivieren rechte Agitatoren unterschiedlicher Couleur äußerst erfolgreich einen alten Verschwörungsmythos in modernisierter Form: Jüdinnen und Juden und ihre Verbündeten würden heimlich die Migrationsströme nach Europa lenken, um die ,autochthone“ europäische Bevölkerung zu ersetzen. ${ }^{38}$ Diese Erzählung ist letztlich ein Wiedergänger alter antisemitischer Mythen über einen jüdischen Plan zur Zerstörung Europas. Sie hat über den bereits erwähnten Viktor Orbán ihren Weg in den politischen Mainstream gefunden und wird auch von

${ }^{37}$ Astrid Messerschmidt, Geschichtsbewusstsein ohne Identitätsbesetzungen - kritische Gedenkstättenpädagogik in der Migrationsgesellschaft, in: bpb.de, 14.1.2016, [https://www.bpb.de/apuz/218720/kritischegedenkstaettenpaedagogik-in-der-migrationsgesellschaft?p=all], eingesehen 14.7.2020.

38 Clark/Hagen, Kalergi-Plan; A. Dirk Moses, „White Genocide“ and the Ethics of Public Analysis, in: Journal of Genocide Research 21 (2019), Heft 2, S. 201-213. 
Exponenten der FPÖ oder AfD regelmäßig aufgegriffen. Erst kürzlich glaubte die AfDAbgeordnete Beatrix von Storch die geheimen „Pläne für einen Massenaustausch“ gefunden $\mathrm{zu}$ haben, tatsächlich handelte sich um eine banale soziodemographische Studie. ${ }^{39}$

So absurd dieser Mythos sich auch anhört, so gefährlich und entschlossen sind seine Anhänger. In Kalifornien stürmte im April 2019 ein schwerbewaffneter 19-jähriger Täter namens John T. Earnest die Chabad-Synagoge in Poway, einer Vorstadt von San Diego. Er eröffnete das Feuer auf die dort versammelte jüdische Gemeinde, die gerade den letzten Feiertag des Pessachfests beging, und tötete eine Frau. ${ }^{40}$ Das erklärte Vorbild von Earnest war Brenton Harrison Tarrant, ein 28-jähriger Australier, der im Monat zuvor 51 Gläubige in einer Moschee im neuseeländischen Christchurch brutal massakriert hatte. Sowohl Earnest als auch Tarrant zeigten sich als überzeugte Anhänger des Verschwörungsmythos vom ,großen Austausch“, der Vorstellung nichteuropäische Völker wollten „die weiße Rasse“ vernichten. Nur geographisch weit von Europa entfernt wiesen diese Taten unmittelbare Bezüge mitten nach Europa auf: Tarrant korrespondierte und traf sich in Wien mit Vertretern der rechtsextremen „Identitären Bewegung Österreich" und spendete an deren Rädelsführer, Martin Sellner, wie später bekannt geworden ist, 1.500 Euro. ${ }^{41}$ Nur ein halbes Jahr nach den Anschlägen von Christchurch und Poway, im Oktober 2019, ermordete der deutsche Rechtsextremist Stephan Balliet, beim Versuch am jüdischen Feiertag Jom Kippur in die Synagoge in Halle einzudringen, eine Passantin und anschließend den Gast eines türkischen Imbisslokals. Auch Balliet bezog sich auf Tarrant und erklärte im Nachgang, so hieß es in Medienberichten, dass er bereue, „keine jüdischen Menschen und überhaupt nur so wenige Personen getötet zu haben" ${ }^{42}$ Zuletzt ermordete Tobias Rathjen, ein rechtsextremer Verschwörungstheoretiker, im Februar 2020 zehn Menschen im hessischen Hanau. Als Opfer wählte er gezielt Menschen aus, die er als Migranten zu erkennen glaubte. In einem Manifest, das er im Internet veröffentlichte, äußerte er genozidale Phantasien und rief unter anderem zur Vernichtung sämtlicher arabischer Staaten sowie Israels auf. ${ }^{43}$

39 Patrick Gensing, Legenden und Mythen. Keine Verschwörung ohne „Geheimplan“, in: tagesschau.de, 12.5.2020, [https://www.tagesschau.de/faktenfinder/verschwoerungen-geheimplaene-101.html], eingesehen 10.7.2020.

40 Earnest kündigte seine Tat in einem online veröffentlichten „Manifest“ an. Der Text findet sich online unter [https://archive.org/details/john-t-ernest-manifesto-8chan-pol-april-27-2019-an-open-letter], eingesehen 1.2.2020.

${ }_{41}$ Dokumentationsarchiv des österreichischen Widerstands, Die „Identitäre Bewegung Österreich“ nach Christchurch. Neues von ganz rechts, März 2019, [https://www.doew.at/erkennen/rechtsextremismus/neues-von-ganzrechts/archiv/maerz-2019/die-identitaere-bewegung-oesterreich-nach-christchurch], eingesehen 1.2.2020.

42 Geständnis über Anschlag von Halle, in: Deutsche Welle, 30.3.2020, [https://www.dw.com/de/berichtgest $\%$ C3\%A4ndnis- $\%$ C3\%BCber-anschlag-von-halle/a-52955191], eingesehen 1.4.2020.

43 Frank Jansen/Sven Lemkemeyer, Was über den Täter von Hanau bekannt ist, in: Der Tagesspiegel, 21.2.2020, [https://www.tagesspiegel.de/politik/wer-war-tobias-rathjen-was-ueber-den-taeter-von-hanau-bekannt-

ist/25566016.html], eingesehen 1.4.2020. 
Wir halten es heute für notwendiger denn je, über Antisemitismus in der Migrationsgesellschaft zu sprechen. Zur Migrationsgesellschaft gehören alle: schlechterdings auch die Antisemiten und Antisemitinnen aus unterschiedlichen politischen Lagern und der Mitte der sogenannten „Mehrheitsgesellschaft“ - und damit eben auch jene aus (post-)migrantischen Milieus. Mit dem Gesellschaftswandel der jüngeren Vergangenheit - der zwar nicht mit Migration gleichgesetzt werden kann, aber sehr wohl auch mit ihr zusammenhängt - nimmt ebenfalls der Antisemitismus neue Formen an. Der „alte“ und herkömmliche Antisemitismus ist damit nicht einfach verschwunden, sondern hat sich lediglich modernisiert. Die Gesellschaft ist in sich pluralistischer und diverser geworden, wofür auch der Begriff der Superdiversität ${ }^{44}$ geprägt wurde. Hiermit verbunden, so unsere These, sind auch die Ausdrucksformen des Antisemitismus vielgestaltiger und unübersichtlicher geworden - und damit mögliche antisemitische Bündnisse.

Scheinbar überwunden geglaubte antisemitische Verschwörungstheorien drängen heute wieder zurück in die politische Arena: die „Protokolle der Weisen von Zion“ als Erzählung vom „großen Austausch“, völkische Globalisierungs- und Kapitalismuskritik in Form von personalisierten antisemitischen Hetzkampagnen gegen George Soros und andere sogenannte „Globalisten“ und vermeintliche Strippenzieher. Neonazis und Rechtsextreme spüren in diesem Klima Aufwind und schreiten zur Tat. Auch linker Antisemitismus artikuliert sich wieder, wie jüngst das Beispiel der antisemitischen und antiisraelischen Kampagnen der britischen Labour-Parteiführung verdeutlicht, äußerst offen und unverstellt - ganz so als hätte es die innerlinke Kritik der vergangenen beiden Jahrzehnte niemals gegeben. Und nicht zuletzt hat der auch in Europa beheimatete islamistische Terrorismus, Jüdinnen und Juden sowie jüdische Einrichtungen zu bevorzugten Zielen seiner Gewaltexzesse erkoren. Diese Konstellationen erfordern zugleich ein besonnenes Augenmerk als auch entschiedenes Handeln gegen jede Form des Antisemitismus - unabhängig von strategischen Erwägungen.

${ }^{44}$ Steven Vetrovec, Super-diversity and its implications, in: Ethnic and Racial Studies 30 (2007), Heft 6, S. 1024-1054. 



\title{
Das antisemitische Unbewusste. Zur politischen Psychologie des Antisemitismus in der Bundesrepublik Deutschland
}

\author{
Wolfram Stender
}

Einer Studie der Anti-Defamation League aus dem Jahr 2014 zufolge gibt es weltweit über eine Milliarde Menschen mit antisemitischen Einstellungsmustern. Im Mittleren Osten und Nordafrika scheint die antijüdische Aversion besonders weit verbreitet. Durchschnittlich 74 Prozent der erwachsenen Bevölkerung stimmen dort den Phantasmen von der unheimlichen Macht, der Geldgier, dem Überlegenheitswahn und der Menschenfeindlichkeit der Juden zu. In Staaten wie Jordanien, Irak oder Algerien sollen es 90 Prozent sein, in der Westbank und im Gazastreifen 93 Prozent. Davon scheint Europa weit entfernt. Mit 4,4 Prozent weist Schweden im Jahr 2014 den niedrigsten Wert auf, Frankreich liegt bei 37 Prozent, Deutschland nimmt mit 27 Prozent einen Mittelplatz ein. Spitzenreiter ist Griechenland mit 69 Prozent, gefolgt von Rumänien mit 47 und Polen mit 45 Prozent. Bemerkenswert ist die Varianz des Phänomens. Der Zustimmungswert bei dem Item „Jews still talk too much about what happened to them in the Holocaust" ist in Westeuropa auffallend hoch - in Deutschland und Österreich liegt er jeweils bei 52 Prozent -, im Mittleren Osten und Nordafrika auffallend niedrig. Hingegen dominieren ökonomische und verschwörungsmythische Stereotype vor allem in Osteuropa. Dem Item ,Jews have too much power in the business world" stimmen in Rumänien 60, in Bulgarien 67 und in Ungarn 69 Prozent der Befragten zu. Spitzenreiter ist auch hier das krisengeschüttelte Griechenland mit 85 Prozent. ${ }^{1}$

Bezieht man die Ergebnisse der ADL-Studie auf die migrationsgesellschaftlichen Realitäten westeuropäischer Länder, scheint sich eine Befürchtung zu bestätigen, die Salomon Korn bereits vor 10 Jahren formulierte: „Der gleichzeitig von Südeuropa vordringende islamistische Antisemitismus und der aus dem Osten Europas in die bisherige Europäische Union einsickernde ,klassische' Antisemitismus werden eine ,Zangenbewegung' vollziehen, die den in Westeuropa vorhandenen sekundären und ,schuldreflexiven' Antisemitismus vermutlich stärken wird. Die Folge wäre womöglich eine Art „Kraftdreieck des Antisemitismus' - eine sich wechselseitig stützende Allianz unterschiedlich ausgeprägter Formen der Judenfeindschaft" ${ }^{2}$. Dafür spricht auch das

1 Alle Zahlen aus Anti-Defamation League (Hrsg.), The ADL Global 100. An Index of Anti-Semitism, 2014, [http://global100.adl.org], eingesehen 25.10.2018. - Zur Kritik an der Studie vgl. David Ranan, Muslimischer Antisemitismus. Eine Gefahr für den gesellschaftlichen Frieden in Deutschland?, Bonn 2018, S. 49ff.

2 Zit. n. Andrei S. Markovits, Amerika, dich hasst sich's besser. Antiamerikanismus und Antisemitismus in Europa, 
Bedrohungsgefühl vieler Jüdinnen und Juden, das in den letzten Jahren deutlich zugenommen zu haben scheint. So äußern 37 Prozent der befragten Jüdinnen und Juden in einer aktuellen Studie aus Deutschland, dass sie Angst vor körperlichen Angriffen haben, 58 Prozent vermeiden aus Sicherheitsgründen bestimmte Stadtteile und 70 Prozent tragen wegen erwarteter Stigmatisierung keine äußerlich erkennbaren Symbole. ${ }^{3}$ So realistisch also die Befürchtung Korns zu sein scheint, sind die Konstellationen des Antisemitismus komplizierter, als er annimmt. Es ist keineswegs nur so, dass sich wechselseitig stützende Allianzen bilden. Die viel zitierte „,neue Unübersichtlichkeit“ des Antisemitismus zeigt sich gerade darin, dass sich im lokalen Raum globalisierter Gesellschaftsverhältnisse unterschiedliche Varianten des Antisemitismus verknüpfen, aber auch in Konfrontation zueinander treten. Konfrontationen entstehen heute immer dann, wenn antisemitisch-proisraelische auf antisemitisch-antiisraelische Gruppen stoßen. Auch dies ließ sich 2014 gut beobachten. Während dschihadistische Islamisten gemeinsam mit rechten und linken Antiimperialisten in Europas Hauptstädten mit Parolen wie „Hamas, Hamas, Juden ins Gas!“ oder „Tod den Zionisten!“ durch die Straßen zogen, erklärten die völkischen Nationalisten aus der Neuen Rechten ihre Solidarität mit Israel, das sie als den wichtigsten Außenposten Europas im Krieg gegen die muslimischen Invasoren betrachten. Es handelt sich hier um ein nur scheinbar paradoxes Phänomen konträrer antisemitischer Wahnvorstellungen. Während radikalislamistische Gruppen propagieren, dass „die Juden“ einen globalen Vernichtungskrieg gegen die Gemeinschaft der muslimischen Gläubigen führen, ist die Neue Rechte Europas davon überzeugt, dass die phantasierte islamische Invasion nur ein weiterer Schritt ist hin zur totalen Vernichtung der europäischen Völker, die die vom ,jüdischen Geist“ (Carl Schmitt) besessenen „Liberalen“ und „Kulturmarxisten“ nach 1945 wieder konsequent betreiben.

In Deutschland ist die Konstellation noch einmal besonders. Aus dem singulären Verbrechenshintergrund dieses Landes ergeben sich politisch-psychologische Komplikationen ganz eigener Art. Dies wird immer dann besonders deutlich, wenn es um das „deutsch-jüdische Verhältnis“, vergangenheitspolitische Fragen oder öffentliche Debatten über Antisemitismus geht. Nach wie vor gilt hier das Gesetz der unmöglichen Tatsache, dass nicht sein kann, was nicht sein darf. Der beliebteste Abwehrtopos der Eliten aus Politik, Wissenschaft, Medienarbeit und Justiz anlässlich antisemitischer Vorfälle lautet, man müsse erst einmal definieren, was Antisemitismus überhaupt sei. Und bei dieser nicht enden wollenden Definitionsarbeit werden dann die unglaublichsten Verdrehungen und Verrenkungen vorgenommen, die schließlich immer wieder darauf hinauslaufen, dass es Antisemitismus vor 1945 gegeben hat, aber heute nicht mehr gibt. Er sei, so wird behauptet, in einem kollektiven Lernprozess überwunden worden, was

Hamburg 2008, S. 208.

${ }_{3}^{3}$ Bericht des Unabhängigen Expertenkreises Antisemitismus, 7.4.2017, Deutscher Bundestag, Drucksache 18/11970, S. 102ff., [http://dip21.bundestag.de/dip21/btd/18/119/1811970.pdf], eingesehen 25.10.2018. 
sich unter anderem in der prächtigen Erinnerungskultur dieses Landes zeige. Wenn überhaupt, dann trete Antisemitismus heute nur noch als Gefahr auf, die von außen das anti-antisemitisch geläuterte Gemeinwesen bedrohe - in Gestalt des Rechts- oder Linksextremismus oder als Importprodukt von meistens als „muslimisch“ markierten Migranten und Migrantinnen.

Dass das Narrativ vom anti-antisemitischen Lernprozess auf einer Realitätsabspaltung beruht, die zum Kern jener in Deutschland besonders ausgeprägten Form des Antisemitismus gehört, die als ,sekundär“ bezeichnet wird, ist eine These, die im Folgenden genauer begründet werden soll. ${ }^{4}$ Die nationalstaatliche Legende erzählt nur die halbe Wahrheit, die positive Geschichte der erfolgreichen Eindämmung des politischen Antisemitismus, nicht aber die verborgene, unterirdische, aber darum umso wirkungsmächtigere Geschichte der Tradierung der antisemitischen Erbschaft nach Auschwitz. Kennt man diese Geschichte nicht, bleiben einem einige Besonderheiten in der politischen Kultur der Bundesrepublik Deutschland völlig verschlossen.

\section{Sekundärer Antisemitismus und philosemitisches Syndrom: die Nachkriegszeit}

Aus Anlass des sogenannten Historikerstreits in den 1980er-Jahren - also des Versuchs mehrerer nationalkonservativer Historiker, qua „Geschichtsentsorgung“ (Jürgen Habermas) eine positive deutsch-nationale Identität wiederherzustellen - beschrieb Dan Diner „das Verhältnis von Deutschen und Juden nach Auschwitz“ als „negative Symbiose“. Er prognostizierte, dass mit zunehmender zeitlicher Distanz zum Ereignis dieses Verhältnis nicht einfacher, sondern schwieriger werde. ${ }^{5}$ Den Grund dafür sah er darin, dass Auschwitz für beide - nicht-jüdische Deutsche wie Juden - Ausgangspunkt ihres Selbstverständnisses geworden sei, allerdings in gegensätzlicher Perspektive. Leben im Schatten des Zivilisationsbruchs sei für das „Kollektiv der Opfer“ unerträglich, für das „Kollektiv der Täter“ unbehaglich. Während die Täter, Mittäter und Mitläufer und deren Nachgeborenen der Erinnerung ausweichen und Wege der Entlastung suchen, empfinden dies die überlebenden Opfer und deren Kinder als Anschlag auf das kollektive Gedächtnis. Ob aus der Psychodynamik des Unbehagens an der Vergangenheit ein neuer Antisemitismus werden könne, hielt Diner für eine plausible Fragestellung: „Und solche Manöver des Ausweichens [auf Seiten der Täter und ihrer Nachgeborenen; Anm. WS] wiederum vermögen angesichts ständigen jüdischen Gemahnens an das Grauen sich in

${ }^{4}$ Ich werde mich im Folgenden allein auf die Geschichte des Antisemitismus in der BRD beziehen, zur besonderen Geschichte der DDR siehe Thomas Haury, Antisemitismus von links. Kommunistische Ideologie, Nationalismus und Antizionismus in der frühen DDR, Hamburg 2002.

${ }^{5}$ Dan Diner, Negative Symbiose. Deutsche und Juden nach Auschwitz, in: Ders. (Hrsg.), Ist der Nationalsozialismus Geschichte? Zu Historisierung und Historikerstreit, Frankfurt a. M. 1987, S. 185-197, hier S. 195. 
blinde Wut zu steigern - Antisemitismus wegen Auschwitz?“.6 Die These eines Antisemitismus ,nicht trot\%, sondern wegen Auschwitz ${ }^{67}$ findet sich zeitgleich auch bei Henryk Broder. Mit Bezug auf das Theaterstück „Der Müll, die Stadt und der Tod“8 von Rainer Werner Fassbinder, das wegen seiner antisemitischen Inhalte in den 1980erJahren heftige Kontroversen auslöste, beschreibt er, wie aus unbewusster Beschämungsund Bestrafungsangst ein antisemitischer Hass entsteht: ,Jeder lebende und überlebende Jude ist Zeuge und Vorwurf zugleich. Wenn ,es ' in dem Antisemiten Hans von Gluck in Fassbinders Stück laut denkt: ,Und schuld ist der Jud, weil er uns schuldig macht, denn er ist da. Wär er geblieben, wo er herkam, oder hätten sie ihn vergast, ich könnte heute besser schlafen. Sie haben vergessen, ihn zu vergasen...', dann kommt in solchen Sätzen die Wut der Täter auf die Opfer zum Ausdruck, deren Immer-noch-da-Sein eine kaum erträgliche Provokation ist".?

Was Diner und Broder in den 1980er-Jahren beobachteten, war keine neue Entdeckung. Schon drei Jahrzehnte vorher war das Frankfurter Institut für Sozialforschung in seinen empirischen Studien auf den neuen, sekundären Antisemitismus gestoßen. Der Begriff findet sich zum ersten $\mathrm{Mal}$ in der kleinen empirischen Studie „Reaktionen auf die antisemitische Welle im Winter 1959/1960“von Peter Schönbach. Anlass für die Studie waren antisemitische Schmierereien an vielen Orten in der Bundesrepublik, die das nach 1945 mühsam errichtete „öffentliche Tabu des Antisemitismus“10 konterkarierten. Schönbach interessierten aber nicht die antisemitischen Vorfälle selbst, sondern die Reaktionen in der Bevölkerung, die er am Beispiel der Stadt Frankfurt untersuchte. Als besonders wertvoll erwies sich, dass die Forschungsergebnisse mit einer zeitgleich in den USA von Johan Galtung durchgeführten Studie ${ }^{11}$ verglichen werden konnten. Auch in den USA war es im Frühjahr 1960 zu einer Welle antisemitischer Handlungen gekommen, die nach Umfang und Verlauf mit der in der Bundesrepublik auffällig übereinstimmte. Während aber in der Frankfurter Befragung die als antisemitisch Eingestuften (ca. 16 Prozent) die Ereignisse mehrheitlich bagatellisierten und als „unpolitische Streiche von Halbstarken und dummen Jungen“ abtaten, war in den USA das genaue Gegenteil der Fall: die Vorfälle wurden als „politisch sehr bedeutsam“ aufgewertet. Mit der Beobachtung dieser Diskrepanz in den Reaktionen der Antisemiten waren die Forscher und Forscherinnen auf einen bedeutsamen Sachverhalt gestoßen: Je nach politisch-psychologischem Kontext, so lautete der Befund, fallen die antisemitischen Äußerungsformen unterschiedlich aus.

Das Besondere des bundesrepublikanischen Kontextes lag darin, dass sich der demokratische Neuanfang in der erfolgreichen Bekämpfung des Antisemitismus zu

\footnotetext{
${ }^{6}$ Diner, Negative Symbiose, S. 186.

${ }^{7}$ Henryk M. Broder, Der ewige Antisemit. Über Sinn und Funktion eines beständigen Gefühls, Berlin 2005, S. 37.

${ }^{8}$ Rainer Werner Fassbinder, Der Müll, die Stadt und der Tod. Nur eine Scheibe Brot, Frankfurt a. M. 1998.

${ }^{9}$ Broder, Der ewige Antisemit, S. $37 \mathrm{f}$.

${ }^{10}$ Peter Schönbach, Reaktionen auf die antisemitische Welle im Winter 1959/1960, Frankfurt a. M. 1961, S. 5.

${ }^{11}$ Johan Galtung, Anti-Semitism in Making. A Study of American High School Students, Oslo 1960.
} 
beweisen hatte. Antisemitismus durfte es offiziell nicht mehr geben, aber natürlich gab es ihn noch überall. Daraus entstand eine eigentümliche Doppelstruktur aus öffentlichem Tabu und antisemitischer Latenz. ${ }^{12}$ Konnten antisemitische Stereotype öffentlich nicht mehr geäußert werden, lebte das antijüdische Ressentiment auf der Ebene der Alltagskultur als nicht-öffentliche Meinung fort. Diese paradoxe Gleichzeitigkeit von öffentlicher Tabuisierung und alltagskultureller Reproduktion des Antisemitismus stand auch im Zentrum der Studie von 1961. Schönbach beobachtete, dass die Konfrontation mit den nationalsozialistischen Verbrechen bei gleichzeitiger offizieller Ächtung des weltanschaulichen Antisemitismus massive Schuldabwehr-Mechanismen bei vielen ehemaligen NS-Volksgenossen mobilisierte. In dem prekären Nebeneinander von Rechtfertigungs- und Leugnungsreaktionen der Befragten wurde eine „psychologische Aporie" sichtbar, in der sich Antisemiten in Deutschland nach 1945 befanden. Exakt auf diese Aporie bezog sich der Begriff des „,sekundären Antisemitismus“, mit dem die Studie zugleich eine generationengeschichtliche Perspektive für die Antisemitismusforschung eröffnete. ${ }^{13}$

Man habe vom Geschehenen damals nichts gewusst; schuld sei allein eine kleine Clique gewesen; andere hätten sich auch die Finger schmutzig gemacht; es müsse jetzt auch mal Schluss sein; die Juden seien letztlich an allem selber schuld; und wenn sie jetzt ständig Forderungen nach Entschädigung stellten, bräuchten sie sich nicht zu wundern, dass der Antisemitismus wiederauflebe: in solchen und ähnlichen Abwehräußerungen, vielfach dokumentiert in der großen empirischen Studie „Schuld und Abwehr"14 von Theodor W. Adorno aus dem Jahr 1955, trat das ideologische Syndrom des sekundären Antisemitismus deutlich hervor. Es ermöglichte dem Antisemiten, den Massenmord an den europäischen Juden zu relativieren, zugleich jede Mitschuld an ihm zu leugnen und in dieser Verleugnung antisemitische Stereotype zu reproduzieren. Die Attraktivität dieser Form des Antisemitismus lag darin, dass sie für die psychologische Aporie der ehemaligen NS-Volksgenossen unter postnazistischen politischen Rahmenbedingungen eine Lösung anbot: Man konnte sich gegenüber den neuen politischen Mächten konform geben, ohne die narzisstische Besetzung der eigenen (Familien-) Geschichte aufgeben zu müssen. Dem kam nicht nur die von Anfang an weit verbreitete Schlussstrichhaltung, sondern auch die von Teilen der politischen Führung wie ein Mantra rezitierte Beschwörungsformel entgegen, dass es Antisemitismus zwar vor 1945 gegeben habe, aber jetzt nicht mehr gebe: „Der Bazillus des Antisemitismus ist im deutschen

12 Werner Bergmann/Rainer Erb, Kommunikationslatenz, Moral und öffentliche Meinung. Theoretische Überlegungen zum Antisemitismus in der Bundesrepublik Deutschland, in: KZfSS 38 (1986), Heft 2, S. 223-246. Der Begriff des antisemitischen Unbewussten, der im Folgenden für den Antisemitismus im postnazistischen Deutschland vorgeschlagen wird, geht über die von Bergmann und Erb systemtheoretisch gefasste Kommunikationslatenz hinaus und umfasst auch Elemente einer psychoanalytisch-sozialpsychologischen Bewusstseinslatenz.

${ }^{13}$ Schönbach, Reaktionen auf die antisemitische Welle, S. 80.

14 Theodor W. Adorno, Schuld und Abwehr [1955], in: Ders., Gesammelte Schriften, Bd. 9.2, Frankfurt a. M. 1997, S. $121-324$. 
Volkskörper selbst nicht mehr virulent ", 15 formulierte im Jahr 1960 - also zeitgleich zur Schönbach-Studie - als einer von vielen der Staatsrechtler und prominente SPD-Politiker Carlo Schmid und bestätigte damit nur die ohnehin von der Mehrheit getragene Weigerung, sich in irgendeiner Weise mit dem fortbestehenden Problem des Antisemitismus auseinanderzusetzen.

Die Mechanismen des sekundären Antisemitismus hat Adorno in „Schuld und Abwehr“ und weiteren Aufsätzen aus den 1950er und 1960er-Jahren ${ }^{16}$ sehr genau analysiert. Deutlich erkannte er das „Neurotische“ vieler Deutscher im Verhältnis zur NSVergangenheit wie auch im Verhältnis zu noch lebenden Jüdinnen und Juden: „Gesten der Verteidigung dort, wo man nicht angegriffen ist; heftige Affekte an Stellen, die sie real kaum rechtfertigen; Mangel an Affekt gegenüber dem Ernstesten; nicht selten auch einfach Verdrängung des Gewussten oder halb Gewussten. So sind wir im Gruppenexperiment des Instituts für Sozialforschung häufig darauf gestoßen, dass bei Erinnerungen an Deportation und Massenmord mildernde Ausdrücke, euphemistische Umschreibungen gewählt werden oder ein Hohlraum der Rede sich darum bildet“". ${ }^{17}$ Bildet die Schuldabwehraggression gegen Jüdinnen und Juden den Kern des sekundären Antisemitismus in den ersten beiden Jahrzehnten nach Auschwitz, so sind es für Adorno vor allem vier Elemente, die die politische Psychologie dieser Form eines postnazistischen Antisemitismus bestimmen: das von außen erzwungene Kommunikationsverbot für antisemitische Äußerungen - Adorno spricht von den „offiziellen Tabus, die [...] über dem Antisemitismus liegen“18 _, das Fortbestehen nationaler Identifikationen und kollektiver Größenphantasien bei vielen ehemaligen NSVolksgenossen bei gleichzeitiger faktischer Schädigung des kollektiven Narzissmus, ${ }^{19}$

15 Zit. n. Werner Bergmann, Antisemitismus in öffentlichen Konflikten. Kollektives Lernen in der Bundesrepublik 1949-1989, Frankfurt a. M. 1997, S. 237. - Man könnte auch Adenauer, Kohl, Schmidt oder irgendeinen anderen bundesdeutschen Spitzenpolitiker nennen. In der Tendenz, Antisemitismus in der Gegenwart zu leugnen, bestand ein weitgehend parteiübergreifender Konsens.

16 Siehe u. a. Theodor W. Adorno, Was bedeutet: Aufarbeitung der Vergangenheit [1959], in: Ders., Gesammelte Schriften Bd. 10.2, Frankfurt a. M. 1997, S. 555-572; Ders., Meinung Wahn Gesellschaft [1961], in: Ders., Gesammelte Schriften, Bd. 10.2, Frankfurt a. M. 1997, S. 573-594; Ders., Zur Bekämpfung des Antisemitismus [1962], in: Ders., Gesammelte Schriften, Bd. 20.1, Frankfurt a. M. 1997, S. 360-383.

17 Adorno, Was bedeutet: Aufarbeitung, S. 556. Dass das „Neurotische“ im Verhältnis zu Jüdinnen und Juden sich bis heute fortsetzt, weiß jeder und jede, der/die einmal in Konflikte um antisemitische Vorfälle involviert war. Gesten der Verteidigung, wo man nicht angegriffen wurde, heftige Affekte an Stellen, die sie real kaum rechtfertigen - ,es“ denkt in den Kindern und Enkeln der NS-Volksgenossen immer sehr heftig, wenn sie mit Juden und Jüdinnen in Konflikt geraten. Beim Skandal um ein antisemitisches Seminar an der Hochschule für angewandte Wissenschaft und Kunst Hildesheim im Jahr 2016 konnte man dies exemplarisch an den Äußerungen der Hochschulpräsidentin beobachten, die meinte, der Öffentlichkeit mitteilen zu müssen, dass sie ihren Kindern jüdische Vornamen gegeben habe, sich aber nicht „von einflussreichen Kreisen“ des Antisemitismus bezichtigen lasse. Wozu habe ich meinen Kindern jüdische Vornamen gegeben, dass ich mich jetzt von den Juden fertig machen lassen muss!, so denkt „es“ in ihr.

18 Adorno, Zur Bekämpfung des Antisemitismus, S. 361.

${ }^{19}$ Die These Adornos, dass alle Indikatoren, die auf ein Zerbrechen der kollektiven Identifikationen hätten hindeuten können, nach 1945 fehlten - weder waren Anflüge von Panik noch von Depressionen bei den ehemaligen NSVolksgenossen zu erkennen - und deshalb davon auszugehen sei, dass diese ,insgeheim, unbewusst schwelend und darum besonders mächtig“ (Adorno, Was bedeutet: Aufarbeitung, S. 564) fortbestanden, trifft sich mit den 
diffuse Gefühle von Schuld und Scham, die durch die Erinnerung an Auschwitz hervorgerufen werden, und schließlich die tradierte antijüdische Aversion selbst, die kulturell so tief verankert ist, dass sie nach 1945 unmöglich ihre Wirkung verloren haben konnte. Im Kraftfeld dieser widerstrebenden politisch-psychologischen Tatsachen konstituierte sich ein antisemitisches Unbewusstes ${ }^{20}$ in der politischen Kultur der Bundesrepublik, dessen generationenübergreifende Virulenz bis heute nachweisbar ist ${ }^{21}$ und das in dem „Neurotischen“ (Adorno) des deutsch-jüdischen Verhältnisses immer wieder zum Ausdruck drängt. Je umfassender das antisemitische Kommunikationsverbot etabliert war, umso erfinderischer wurden die Wege, um das Verbotene - das antisemitische Ressentiment - unerkannt in die Sprache und das Handeln zu schmuggeln - unerkannt durchaus, wenn auch keineswegs immer, auch für die antisemitischen Subjekte selbst. Nur in Konflikten - Augenblicken der Wahrheit - brach es mitunter offen und unwillkürlich aus den zum Verbot Gezwungenen heraus, die Geschichte der Bundesrepublik ist reich an Beispielen davon. ${ }^{22}$ Dabei ähnelten die Äußerungsformen des antisemitischen Unbewussten, das man später paradox auch als „Antisemitismus ohne Antisemiten“23 umschrieb, in ihrer inneren Struktur jenen Kompromiss- und Ersatzbildungen, die Freud ja nicht nur für den Traum, sondern auch für die Psychopathologie des Alltagslebens konstatiert hatte. ${ }^{24}$

Beobachtungen Hannah Arendts (Hannah Arendt, Besuch in Deutschland [1950], in: dies., Zur Zeit. Politische Essays, Berlin 1986, S. 43-70.) ebenso wie mit den Überlegungen der Mitscherlichs (Alexander Mitscherlich/Margarete Mitscherlich, Die Unfähigkeit zu trauern. Grundlagen kollektiven Verhaltens, München 1985 [1967].).

20 Es muss zwischen dem Unbewussten des Antisemiten und dem antisemitischen Unbewussten unterschieden werden. Die psychoanalytische Theorie kann die unbewussten Abwehrmechanismen erklären, die der antijüdischen Aversion zugrunde liegen. Fenichel hat diese als konformistische Rebellion beschrieben: „Im Unbewussten der Antisemiten verkörpern die Juden gleichzeitig das, wogegen sie gern rebellieren möchten, und die rebellische Tendenz in ihnen selbst“. (Otto Fenichel, Elemente einer psychoanalytischen Theorie des Antisemitismus, in: Ernst Simmel (Hrsg.), Antisemitismus, Frankfurt a. M. 1993 [engl. 1946], S. 35-57, hier S. 45.) - Das antisemitische Unbewusste hingegen besteht in der Unbewusstmachung der antijüdischen Aversion selbst. Es entsteht überall dort, wo die Regeln der politischen Kultur die antisemitische Kommunikation in die Latenz zwingen. Man hat es hier also mit einer doppelten Unbewusstheit zu tun: Der Antisemit täuscht sich über die unbewussten Motive seiner antijüdischen Aversion; der postnazistische Antisemit, der kein Antisemit mehr sein will, täuscht sich über seine unbewusste antijüdische Aversion, die seiner Israelobsession zugrunde liegt.

${ }^{21}$ Hier erweist sich einmal mehr der besondere Wert der Psychoanalyse für die Antisemitismusforschung, die am Material der analytischen Therapie den Nachweis eines antisemitischen Unbewussten erbracht hat. (Siehe u. a. Anna Maria Jokl, Zwei Fälle zum Thema „Bewältigung der Vergangenheit“, Frankfurt a. M. 1997; Ilka Quindeau, Schuldabwehr und nationale Identität - Psychologische Funktionen des Antisemitismus, in: Matthias Brosch u. a. (Hrsg.), Exklusive Solidarität. Linker Antisemitismus in Deutschland, Berlin 2007, S. 157-164.)

22 Siehe u. a. Bergmann, Antisemitismus in öffentlichen Konflikten; Lars Rensmann, Demokratie und Judenbild. Antisemitismus in der politischen Kultur der Bundesrepublik Deutschland, Wiesbaden 2005, S. 334ff.

23 „Er ist ein ,Antisemitismus ohne Antisemiten‘. Dieser Begriff bezeichnet ein Massenvorurteil ohne Legitimation, ohne öffentliches Subjekt, ohne propagandistische Träger, ohne das Selbstbewusstsein und das Selbstverständnis einer Ideologie [...]. Darüber hinaus ist es als Massenvorurteil durch kulturelle Verfestigung ins, kollektive Unbewusste abgesunken; es wird häufig ohne Absicht und Bewusstsein im alltäglichen Sprachgebrauch reproduziert, ,hinter dem Rücken der Subjekte, über ,Sprachzerstörung' durch bewusstlose Individuen hindurch wirkend.“ (Bernd Marin, Antisemitismus ohne Antisemiten. Autoritäre Vorurteile und Feindbilder, Wien 2000, S. 112.)

24 Sigmund Freud, Zur Psychopathologie des Alltagslebens, in: Ders., Gesammelte Werke. Vierter Band, Frankfurt a. M. 1999. 
Adorno erläutert die Mechanismen antisemitischer Latenz an verschiedenen Formvarianten. Die gängigste Form bestand in der Kryptisierung des Antisemitismus. Im „Krypto-Antisemitismus“,25 wie Adorno es nennt, wird der Judenhass nicht aufgegeben, sondern insgeheim, im Verborgenen fortgesetzt. Der Antisemit verhält sich in der Öffentlichkeit politisch korrekt, verbreitet aber im nicht-öffentlichen Raum weiter seine antisemitischen Ansichten und gibt sich als Widerständler gegen die angeblich von außen aufgezwungene Meinungsdiktatur: „Man darf ja gegen Juden heute nichts sagen“, ${ }^{26}$ lautete ein häufig zu hörender Satz, dessen antisemitischen Gehalt Adorno analysiert: „Es wird sozusagen gerade aus dem öffentlichen Tabu über dem Antisemitismus ein Argument für den Antisemitismus gemacht: wenn man nichts gegen die Juden sagen darf, dann - so läuft die assoziative Logik weiter - sei an dem, was man gegen sie sagen könnte, auch schon etwas daran. Wirksam ist hier ein Projektionsmechanismus: dass die, welche die Verfolger waren und es potentiell heute noch sind, sich aufspielen, als wären sie die Verfolgten. " ${ }^{27}$ Eine zweite Variante bestand darin, dass die Erinnerung an Auschwitz den Juden zum Vorwurf gemacht wurde und in diesem Vorwurf antisemitische Stereotype reproduziert wurden. Typisch dafür waren neben der Schlussstrich-Rhetorik und der Auschwitz-Dresden-Gleichsetzung („die Bombennächte von Dresden waren für uns ja mindestens genauso schlimm wie Auschwitz für die Juden“"28) die Unterstellung, die Juden würden ihren Status als Opfer der NS-Zeit ausnutzen, ${ }^{29}$ um sich finanzielle Vorteile zu verschaffen. Die Relativierung, Minimierung und Bagatellisierung von Auschwitz und die Selbststilisierung der Täter als Opfer stehen im Mittelpunkt dieser Form der Abwehr. In einer dritten Variante schließlich wurde ,der Jude’ ,zu dem Feind, den man lieben muss". ${ }^{30}$ Auch hier ist das Versprechen auf Gewalt, das sich gegen Juden richtet, gut verhüllt: „Auch der sogenannten positiven Stereotypenbildung wäre entgegenzuwirken, hinter der die negative Stereotypie dicht lauert. Sagt einer: ,Die Juden sind alle so gescheit', dann ist er, auch wenn er es lobend sagt, schon nahe bei ,nun ja, und deshalb wollen sie uns betrügen"“. 31

In einer umfassenden Studie hat Frank Stern die dritte Variante der unbewussten Schuldentlastung als „philosemitisches Syndrom“32 analysiert. Seine These lautet, dass Philosemitismus nicht einfach mechanisch als ein auf den Kopf gestellter Antisemitismus zu interpretieren sei. Der philosemitische Habitus, der sich nach 1945 in den Westzonen herausbildete und später zu einem festen Bestandteil der politischen Kultur der

\footnotetext{
25 Adorno, Zur Bekämpfung des Antisemitismus, S. 361.

${ }^{26}$ Heute wird das Wort „Jude“ durch „Israel“ ersetzt, was an dem antisemitischen Gehalt nichts ändert: „Man darf ja gegen Israel heute nichts sagen“.

27 Adorno, Zur Bekämpfung des Antisemitismus, S. 368.

${ }_{28}$ Die Rechte spricht heute vom „Dresdener Bombenholocaust“.

${ }^{29}$ Adorno, Zur Bekämpfung des Antisemitismus, S. 368.

${ }^{30}$ Hermann Greive, Geschichte des modernen Antisemitismus in Deutschland, Darmstadt 1988, S. 184.

31 Adorno, Zur Bekämpfung des Antisemitismus, S. 378.

32 Frank Stern, Im Anfang war Auschwitz. Antisemitismus und Philosemitismus im deutschen Nachkrieg, Gerlingen 1991, S. 351.
} 
Bundesrepublik wurde, habe vielmehr von Anbeginn eine Doppelfunktion gehabt, in der das Verhältnis von Kontinuität und Diskontinuität im deutschen Nachkrieg zum Ausdruck komme. Im Spannungsfeld von offiziellem Antisemitismusverbot, auf dessen Einhaltung die Siegermächte mit Nachdruck pochten, und tiefsitzenden antisemitischen Ressentiments vollzog sich in einem statistisch nicht irrelevanten Teil der deutschen Bevölkerung ein ambivalenter sozialpsychologischer Prozess, in dem es zu einer Metamorphose von antisemitischen in philosemitische Stereotype kam. ${ }^{33}$ Nach Stern war dies keineswegs nur Teil der individuellen Anpassung an die neuen Machtverhältnisse, sondern hatte auch eine „kathartische Funktion“.34 Die philosemitische Metamorphose des Antisemitismus schuf Distanz zum antisemitischen Konsens der NS-Gesellschaft und damit auch zur eigenen Verstrickung in diesen. Stern betont die pragmatische Tendenz, sieht aber auch die irrational-unbewusste Dimension in diesem Verwandlungsprozess. Deutsche begannen ihren neugeborenen Kindern jüdische Vornamen zu geben, suchten nach jüdischen Vorfahren, (er)fanden jüdische Freunde oder Nachbarn, schufen sich also ein projüdisches Phantasma, nicht nur weil sie sich dadurch Vorteile in der neuen Zeit erhofften, sondern auch weil ihnen dies seelische Entlastung brachte. Und genau aus diesem Grund drehten sie auch die antisemitischen Stereotype um, ohne sich je mit ihrem eigenen Antisemitismus auch nur eine Sekunde auseinandergesetzt zu haben. Die Entstehung des Topos vom jüdischen Beitrag zur deutschen Kultur, der bis heute nachhallt, fällt in diese Zeit: „Das in wahrem Crescendo erklingende Lob des jüdischen Beitrags zu deutscher Kultur, Wissenschaft und Wirtschaft wird zu einem festen Topos in der politischen Kultur. Dies traf gleichermaßen zu auf die Ebene sozialer Beziehungen. Mit einem Juden befreundet zu sein, oder derartige Beziehungen aus der Erinnerung zu rekonstruieren, rückte den Betreffenden quasi automatisch an die Seite der Sieger, ließ ihn vermeintlich zu den ehemaligen NSParteigenossen auf Distanz gehen. Die Haltung zu Juden nahm zunehmend den Charakter eines unterschiedslos, ja stereotyp, alles Jüdische positiv wertenden gesellschaftlichen Phänomens an. Und was nicht in dieses überhöhte Bild vom Juden, von jüdischer Eigenart und jüdischem Beitrag passte, fiel schlicht unter Amnesie“. ${ }^{35}$ Eine zweite, in der Gründungsphase der Bundesrepublik zunehmend wichtiger werdende Funktion hatte der Philosemitismus auf der politischen Ebene. Hier diente er der

33 Auch das Frankfurter Institut für Sozialforschung war in dem im Winter 1950/51 durchgeführten „Gruppenexperiment“ - einer Untersuchung zum politischen Bewusstsein der westdeutschen Bevölkerung in 121 Gruppendiskussionen mit insgesamt 1.635 Personen - auf das Phänomen des Philosemitismus gestoßen. Es zeigte sich, dass 18 Prozent der Interviewten philosemitische Positionen einnahmen. Auch Pollock, der die Untersuchung leitete, und seinen Mitarbeitern entging nicht, dass die projüdischen Äußerungen zum Teil große Strukturähnlichkeit mit den antisemitischen Stereotypen aufwiesen und deshalb keineswegs generell positiv zu bewerten seien. (Friedrich Pollock, Gruppenexperiment. Ein Studienbericht (Frankfurter Beiträge zur Soziologie 2), Frankfurt a. M. 1955, S. 128.) 34 Frank Stern, Philosemitismus statt Antisemitismus. Entstehung und Funktion einer neuen Ideologie in Westdeutschland, in: Wolfgang Benz (Hrsg.), Zwischen Antisemitismus und Philosemitismus. Juden in der Bundesrepublik, Berlin 1991, S. 47-61, hier S. 52.

35 Stern, Im Anfang war Auschwitz, S. 16. 
moralischen Legitimierung der westdeutschen Demokratie. Er wurde als Symbol für die Glaubwürdigkeit des demokratischen Erneuerungswillens der Bundesrepublik politisch funktionalisiert.

Philosemitismus ist bis heute ein wichtiges Element in der politischen Kultur Deutschlands geblieben und gilt als „unausgesprochene Staatsdoktrin“36. Auf der Alltagsebene hatte diese Schuldentlastungsform ihre große Zeit in den ersten beiden Jahrzehnten des Nachkriegs. Ihr Niedergang setzte in den 1960er-Jahren ein. Der Wendepunkt lässt sich ziemlich genau bestimmen. Es war der Sechstagekrieg 1967, in dem sich Israel gegen eine Übermacht arabischer Armeen behauptete. Mit ihm veränderte sich der Blick auf Israel und in der Folge zeigte sich, wie rasch die Metamorphose umgekehrt und aus dem Philosemitismus wieder ein Antisemitismus werden kann - in den Worten Frank Sterns: „In gesellschaftlichen Konfrontationen hat der Philosemitismus keinen Bestand: denn in ihm werden die Juden [...] romantisiert, monumentalisiert, respektabel neutralisiert und damit kulturell erneut stigmatisiert und ausgegrenzt. Auch die vermeintlich positive Umkehrung des Antisemitismus macht die Juden zu Fremden; nur dass der gelbe Fleck jetzt geschönt ist, freundlich glänzt" “ ${ }^{37}$

\section{Israelfeinde: der „ehrbare“ Antisemitismus von links in den 1970er und 1980er-Jahren}

Niemand hat so früh und so treffend die antisemitische Kehrseite des Antizionismus auf den Begriff gebracht wie Jean Améry in dem Zeit-Artikel „Der ehrbare Antisemitismus“ von 1969: „Fest steht: der Antisemitismus, enthalten im Anti-Israelismus oder AntiZionismus wie das Gewitter in der Wolke, ist wiederum ehrbar. Er kann ordinär reden, dann heißt das, Verbrecherstaat Israel'. Er kann es auf manierlichere Art machen und vom ,Brückenkopf des Imperialismus' sprechen, dabei so nebstbei allenfalls in bedauerndem Tonfall hinweisen auf die missverstandene Solidarität, die so ziemlich alle Juden, von einigen löblichen Ausnahmen abgesehen, an den Zwergstaat bindet, und kann es empörend finden, dass der Pariser Baron Rothschild die Israel-Spenden der jüdische Bevölkerung Frankreichs als eine Steuer einfordert“.38 Der Sechstagekrieg von 1967 wirkte in Westdeutschland wie ein Fluoreszenzindikator, der blitzartig die antisemitischen Erbschaften auch dort sichtbar machte, wo man sie nicht unbedingt vermutete. Während in der westorientierten, konservativen „Mitte“ der Gesellschaft

36 Wolfgang Benz, Zur Geschichte der organisierten Abwehr des Antisemitismus, in: Jabrbuch für Antisemitismusforschung 20 (2011), S. 15-35, hier S. 17.

${ }^{37}$ Frank Stern, Philosemitismus in Deutschland. Die kulturelle Ambivalenz der Bilder von Juden, in: Heike Catrin Bala/Christian Scholz (Hrsg.), Deutsch-jüdisches Verhältnis? Fragen, Betrachtungen, Analysen, Essen 1997, S. 73-87, hier S. 84 .

38 Jean Améry, Der ehrbare Antisemitismus. Die Barrikade vereint mit dem Spießer-Stammtisch gegen den Staat der Juden, in: Die Zeit, Nr. 30, 25.7.1969. 
zunächst nach bewährter philosemitischer Schuldentlastungsmanier Israels militärische Schlagkraft bejubelt wurde und Vergleiche zwischen Wüstenfuchs Rommel und Mosche Dajan gezogen wurden, vollzog der Sozialistische Deutsche Studentenverbund (SDS) als wichtigste Organisation der außerparlamentarischen Opposition bereits im September 1967 eine deutliche Abkehr vom bis dahin pro-israelischen Konsens der bundesdeutschen Linken. ${ }^{39}$ Die sich danach - begleitet von innerlinken Konflikten herausbildende antizionistische Weltanschauung wurde für zwei Jahrzehnte zum Markenzeichen großer Teile der radikalen Linken, reichte aber auch bis weit in das Alternativmilieu und die Partei „Die Grünen“, die sich 1980 gründete. ${ }^{40}$

Der linke Antizionismus in Westdeutschland entstand im Schnittfeld verschiedener politischer Kraftlinien, zu der nicht zuletzt die massive antikommunistische und mit deutlich antisemitischen Untertönen durchsetzte Hetze des dezidiert pro-israelischen Springer-Konzerns und seiner Medien gegen die Studentenbewegung gehörte. Der bis aufs Äußerste zugespitzte Konflikt der „Protestgeneration" 41 mit der NSTätergeneration, die sehr schnell nach 1945 wieder politische und gesellschaftliche Machtpositionen besetzt hatte, ist für das Verständnis der politisch-psychologischen Dynamik, die der Herausbildung des linken Antizionismus zugrunde lag, von zentraler Bedeutung. Der Antizionismus hatte politisch-psychologisch die Funktion eines „Massenmediums“42, in dem die widersprüchlichsten Wünsche, Projektionen und Identifikationen zusammengeführt werden konnten. Er gab Teilen der „Protestgeneration“ das gute Gefühl, auf der Seite der Schwachen und Unterdrückten zu stehen und die Menschenrechte $\mathrm{zu}$ verteidigen, sich von den im Schweigen und Verdrängen sich einkapselnden und sich selber als Opfer stilisierenden Eltern vehement abgrenzen und zugleich die von den Eltern übertragenen, unbewussten Schuld- und Schamgefühle in latenten oder auch sehr manifesten Aggressionen gegenüber den Juden ausleben zu können. ${ }^{43}$ Das antisemitische Ressentiment konnte in ein

${ }^{39}$ Siehe u. a. Martin Kloke, Israel und die deutsche Linke, Frankfurt a. M. 1994, S. 113ff.; Ders., Israel - Alptraum der deutschen Linken?, in: Brosch (Hrsg.), Exklusive Solidarität, S. 301-323, hier S. 303.

40 Siehe u. a. Lars Rensmann, Demokratie und Judenbild, S. 315; Broder, Der ewige Antisemit, S. 124ff.

41 „Die Studenten haben so ein wenig die Rolle der Juden übernommen“, formulierte Adorno in einer Erklärung aus Anlass des Todes des Studenten Benno Ohnesorg, der am Rande der Anti-Schah-Demonstration am 2. Juni 1967 von der Polizei erschossen wurde. Dass sich in dem Hass gegen die revoltierenden Studenten etwas von dem Hass gegen die Juden wiederholte, entging Adorno ebenso wenig wie das Scheinhafte der studentischen Revolte, dessen antisemitisches Potenzial er in einem Brief an Herbert Marcuse im Sommer 1969 deutlich benannte: „Nachdem man in Frankfurt den israelischen Botschafter niedergebrüllt hat, hilft die Versicherung, das sei nicht aus Antisemitismus geschehen [...], nicht das mindeste. [...] Du müsstest nur einmal in die manisch erstarrten Augen derer sehen, die, womöglich unter Berufung auf uns selbst, ihre Wut gegen uns kehren“. (Adorno zit. n. Wolfgang Kraushaar, Abspaltung und Potenzierung. Zum Verhältnis von Antizionismus und Antisemitismus in der militanten Linken der Bundesrepublik Deutschland, in: Brosch (Hrsg.), Exklusive Solidarität, S. 325-346, hier S. 331f.) - Die Verdienste der 68er-Bewegung für die Demokratisierung der politischen Kultur der Bundesrepublik stehen außer Frage. Hier geht es allein um die antisemitischen Tendenzen im linken Antizionismus und deren politisch-psychologischer Genese.

42 Adorno, Zur Bekämpfung des Antisemitismus, S. 366.

43 Auch die unbewusste Übertragung des antisemitischen Erbes an die zweite Generation ist psychoanalytisch mittlerweile gut erforscht. (Siehe u. a. Jan Lohl, Gefühlserbschaft und Rechtsextremismus. Eine sozialpsychologische 
antiimperialistisches Feindbild eingebaut und mit klassentheoretischen und kapitalismusbezogenen Freund-/Feindschemata verknüpft werden. Israel wurde so als „Speerspitze“ oder „Brückenkopf des Imperialismus“ imaginiert, als Zentrum der imperialistischen Weltverschwörung, das zusammen mit den USA die Welt beherrscht oder zu beherrschen anstrebt. Folgerichtig solidarisierten sich die antizionistischen Antiimperialisten mit dem als homogen und ethnisch vorgestellten ,palästinensischen Volk“ oder den „arabischen Völkern“, unterstellten dem phantasierten jüdischen Täterkollektiv eine besondere Nähe zur feindlichen Klasse, dem Kapitalismus und den zu bekämpfenden Ideologien des Rassismus, Nationalismus und Faschismus und taten alles, um die „unterdrückten Völker“ in ihrem bewaffneten Kampf gegen die „Zionisten“ und „Imperialisten“ zu unterstützen. ${ }^{44}$

Im Prozess der Antizionisierung eines großen Teils der radikalen Linken entstand nicht nur eine zunehmend enthemmte antisemitische Propaganda, sondern es kam auch zu einer Reihe von antisemitischen Gewalttaten, wie man sie bis dahin nur aus dem rechten Spektrum kannte. Schon 1969 schändeten radikale Linke Gedenkstätten, fast zeitgleich folgten der Versuch eines Bombenattentats auf das Jüdische Gemeindehaus in Westberlin und Agitationen gegen israelische Wissenschaftler mit Parolen wie „Schlagt die Zionisten tot - macht den Osten rot". ${ }^{45}$ Auch in den Jahren darauf kam es immer wieder zu linken Gewaltattacken gegen Jüdinnen und Juden, die ihren Höhepunkt in der „Selektion von Entebbe “46 im Jahr 1976 fanden. ${ }^{47}$ Der Auschwitzüberlebende Yitzhak David, der sich an Bord des entführten Flugzeugs befand, traf etwas Richtiges, als er den

Studie zur Generationengeschichte des Nationalsozialismus, Gießen 2010, S. 193ff.; Ders./Angela Moré (Hrsg.), Unbewusste Erbschaften des Nationalsozialismus. Psychoanalytische, sozialpsychologische und historische Studien, Gießen 2014.)

${ }_{44}$ Claudia Globisch hat die semantische Struktur des antizionistischen Antiimperialismus an Texten aus der radikalen Linken detailgenau analysiert. (Claudia Globisch, Radikaler Antisemitismus. Inklusions- und Exklusionssemantiken von links und rechts in Deutschland, Wiesbaden 2013, S. 257ff.)

45 Siehe u. a. Rensmann, Demokratie und Judenbild, S. 310ff; Thomas Haury, Der neue Antisemitismusstreit der deutschen Linken, in: Doron Rabinovici/Ulrich Speck/Natan Sznaider (Hrsg.), Neuer Antisemitismus? Eine globale Debatte, Frankfurt a. M. 2004, S. 143-167; Thomas Haury, Der Antizionismus der Neuen Linken in der BRD. Sekundärer Antisemitismus nach Auschwitz, in: Arbeitskreis Kritik des deutschen Antisemitismus (Hrsg.), Antisemitismus - die deutsche Normalität. Geschichte und Wirkungsweise des Vernichtungswahns, Freiburg i. Br. 2015, S. 217-229; Wolfgang Kraushaar, Abspaltung und Potenzierung; Wolfgang Kraushaar, „Wann endlich beginnt bei Euch der Kampf gegen die heilige Kuh Israel?", München 1970; Ders., Über die antisemitischen Wurzeln des deutschen Terrorismus, Hamburg 2013.

${ }^{46}$ Kraushaar, Abspaltung und Potenzierung, S. 343.

${ }^{47}$ Mit der Entführung des Air-France-Flug 139 von Tel Aviv nach Paris am 27. Juni 1976 wollte das „Kommando Che Guevara“ der „Volksfront für die Befreiung Palästinas“ (PFLP) unter der Führung des ehemaligen Frankfurter Soziologiestudenten Wilfried Böse die Freilassung von 53 „Freiheitskämpfern“ für die „palästinensische Sache“ erzwingen, darunter auch Gefangene der RAF und der Bewegung 2. Juni. Nach der Landung auf dem Flughafen Entebbe in Uganda nahmen die Entführer eine Selektion zwischen den jüdischen und nichtjüdischen Geiseln vor: Die 147 nichtjüdischen Geiseln wurden freigelassen, die 70 israelischen und 34 weitere jüdische Passagiere mussten an Bord bleiben: „Die Geiselnehmer drohten, das Flughafengebäude zu sprengen und alle Geiseln umzubringen, wenn ihrer Forderung nach Freilassung der inhaftierten ,Kampfgenossen' nicht nachgegeben würde“. (Kraushaar, Abspaltung und Potenzierung, S. 344.) In einer Kommandoaktion der israelischen Armee konnten viele Geiseln befreit werden, einige starben. 
deutschen Flugzeugentführer und ehemaligen Frankfurter Soziologiestudenten Böse mit dem Satz konfrontierte: „I was mistaken when I told my children that there is a different Germany. When I see what you and your friends are doing to women, children and the elderly, I see that nothing has changed in Germany".48 Tatsächlich schien der bundesdeutsche Linksterrorismus nahtlos an die Exekutionspraktiken der NSTätergeneration anzuknüpfen, nur dass der zu vernichtende „Jude“ nun „Zionist“ hieß, man selber sich nicht mehr Antisemit, sondern Antiimperialist nannte und die Identifikation mit dem als „Opfer der jüdischen Weltverschwörung“ imaginierten völkisch-deutschen Kollektiv durch die Identifikation des als „Opfer des Weltzionismus“ imaginierten heldenhaften völkisch-palästinensischen Kollektivs ersetzt wurde. Auf der unbewussten Ebene des Generationenverhältnisses aber stellen sich die Dinge komplizierter und widersprüchlicher dar. Wenn die psychoanalytischsozialpsychologische These zutrifft, dass die auf den NS folgende Generation mit den verdrängten Schuldgefühlen der Elterngeneration „unausweichlich, weil unbewusst“49 identifiziert war, dann liegt es nahe, dass es sich bei dem militanten deutschen Antizionismus auch um eine besonders verdrehte Form unbewusster Schuldentlastung und „Wiedergutmachung“ gehandelt haben muss. In der Solidarisierung mit den vermeintlichen Opfern der Opfer und deren Kampf gegen Israel holten die Nachgeborenen nach, was sie sich von ihren Eltern gegenüber dem NS gewünscht hätten. Zugleich musste es für sie psychisch enorm entlastend gewesen sein, dass im antizionistischen Weltbild die ehemaligen Opfer zu mindestens ebenso schlimmen Tätern geworden waren wie ihre Nazi-Eltern. Dass sie mit dieser Täter-OpferVerkehrung die antisemitische Erbschaft ihrer Eltern übernahmen, war ihnen selbst vermutlich am wenigsten bewusst.

Der linke Antizionismus hatte seine große Zeit in den 1970er-Jahren, in der es quasi keine linksradikale Gruppe gab, die nicht antizionistisch war. ${ }^{50}$ Sein Niedergang begann bereits in den 1980er-Jahren und dann forciert im Nachgang zum zweiten Golfkrieg im Jahr 1990/91. In heftigen innerlinken Debatten spaltete sich die radikale Linke in eine weiterhin scharf antiisraelische Szene und eine dezidiert prozionistische Strömung, in der die - sich selbst so nennenden - „Antideutschen“ besonders hervorstachen. Den weltweiten Kommunismus als messianisches Fernziel propagierend, zelebrierte diese Gruppierung für die Zeit auf dem Weg dorthin eine „Form der Israelbegeisterung, die sich mit den Maximalpositionen der israelischen Rechten deckt".51 Trotz seines Bedeutungsverlustes hat der antizionistische Antisemitismus von links Wirkungen bis

48 Yossi Melman, Setting the Record Straight: Entebbe was not Auschwitz, in: Haaretz, 8.7.2011.

${ }^{49}$ Quindeau, Schuldabwehr und nationale Identität, S. 163.

50 „In ihrem sogenannten Antizionismus war sich die ansonsten häufig zerstrittene Linke - maoistische K-Gruppen, moskautreue DKP, antiautoritäre Linke, antiimperialistische Dritte-Welt-Solidaritätsgruppen bis hin zu den terroristischen ,Gruppen des bewaffneten Kampfes’ - während der gesamten 1970er Jahre überaus einig“. (Haury, Der neue Antisemitismusstreit, S. 205; siehe auch Kloke, Israel und die deutsche Linke.)

${ }^{51}$ Kloke, Israel - Alptraum der deutschen Linken, S. 315. 
weit über die Grenzen des eigenen Milieus hinaus erzielt. Fast ein Drittel der deutschen Bevölkerung ist heute der Meinung, dass das, „was der Staat Israel heute mit den Palästinensern macht, im Prinzip auch nichts anderes ist als das, was die Nazis im Dritten Reich mit den Juden gemacht haben“. Und der Aussage „Israel führt einen Vernichtungskrieg gegen die Palästinenser" stimmen aktuell sogar 40 Prozent der Befragten zu. ${ }^{52}$

\section{Falsche Israelfreunde: der „ehrbare“ Antisemitismus von rechts seit 1989}

Im Zuge des Vereinigungsprozesses der beiden deutschen Staaten nach 1989 und noch einmal verstärkt nach den islamistischen Terroranschlägen vom 11. September 2001 lassen sich drei Entwicklungen beobachten, in denen sich der Zusammenhang von Schuldentlastung und sekundärem Antisemitismus in der Bundesrepublik Deutschland neu konstelliert: der Aufstieg des antimuslimischen Rassismus in der sogenannten Mitte der Gesellschaft, der - nur scheinbar paradox - zugleich eine sekundärantisemitische Funktion übernimmt; der taktische Proisraelismus der Neuen Rechten, die gleichzeitig aggressiv geschichtsrevisionistisch agiert, und das Wiedererstarken des linken Antizionismus im Rahmen der Anti-Globalisierungsbewegung und eines weltweiten Anti-Israel-Kampfes, der sich unter anderem in der sogenannten BDS-Kampagne organisiert.

An der ideologischen Struktur des linken Antizionismus, der mit der Zweiten Intifada Anfang der 2000er-Jahre wieder an Aufwind gewann, hat sich wenig verändert. Neu sind aber die Bündniskonstellationen, die es in den 1970er und 1980er-Jahren noch nicht gab. ${ }^{53} \mathrm{Da}$ auch islamistische Terrorgruppen wie der Islamische Dschihad oder die Hamas, die offen Sympathie für den NS äußern und vernichtungsantisemitische Propaganda betreiben, als Teil des antiimperialistischen Befreiungskampfes betrachtet werden, gelten sie den deutschen Antizionisten als willkommene Bündnispartner. ${ }^{54}$ Zugleich wird der Staat der Auschwitzüberlebenden als „Verbrecherstaat“ dämonisiert und mit dem Nationalsozialismus gleichgesetzt. Die tausendfach im Internet, auf AntiIsrael-Demonstrationen und im antizionistischen Propagandamaterial $\mathrm{zu}$ findende Gleichsetzung des Davidsterns mit dem NS-Hakenkreuz transformiert die alte antisemitische Vorstellung vom ,Juden“ als dem absolut Bösen in die Gegenwart. Als Motor antisemitischer Propaganda erweist sich dabei immer mehr die BDS-Kampagne gegen Israel. ${ }^{55}$

52 Bericht des Unabhängigen Expertenkreises Antisemitismus, 7.4.2017.

53 Siehe auch den Beitrag von Daniel Rickenbacher in diesem Band.

54 Haury, Der neue Antisemitismusstreit, S. 149f.

55 „Boycott, Divestment and Sanctions“ (abgekürzt BDS) ist eine weltweite propalästinensisch-antizionistische Kampagne, die Israel wirtschaftlich, kulturell und politisch isolieren und ruinieren will. 
Gibt es über den antizionistischen Teil der deutschen Linken kaum Neues zu berichten, so versuchen sich die Neuen Rechten nach 1989 verstärkt in der Etablierung eines „ehrbaren“ Antisemitismus eigener Art, der sie endlich wieder reputationsfähig machen soll. In maximaler Distanzierung vom NS stilisieren sie sich als die wahren Antifaschisten. Von der Wirmer-Flagge über den Stauffenberg-Kult bis hin zu IsraelSolidaritätsbekundungen auf Pegida-Demonstrationen - alles baut in der Neuen Rechten auf dem Mythos von den „konservativen Revolutionären“ auf, die zwischen 1933 und 1945 heldenhaften Widerstand gegen die Nazis geleistet hätten und deren Erben heute ebenso entschlossen dem „Islamo-Faschismus“ entgegenträten. Tatsächlich aber ist diese Rechte auch heute genau das, was sie schon immer war: nationalistisch und antisemitisch. Für die Neue Rechte nämlich sind - dies hat Volker Weiß in seinem Buch „,Die autoritäre Revolte“56 herausgearbeitet - das Muslim-Bashing wie auch die Israel-Solidarität nur taktische Mobilisierungsressourcen, inhaltlich aber sind sie Nebenschauplätze. Im Zentrum steht der „Ethnozid am deutschen Volk“. Dieser drohe nicht durch den Islam, sondern durch den ,großen Austausch“, wie es im neurechten Jargon heißt, also durch Einwanderung. Und hinter dieser stehe der eigentliche, der innere Feind. Um diesen Gedankengang zu verstehen, ist es notwendig, sich den großen Einfluss des - von Waldemar Gurian sarkastisch so genannten - „Kronjuristen des Dritten Reiches“, Carl Schmitt, im neurechten Denken klar zu machen. ${ }^{57}$ In Carl Schmitts „Theorie des Partisanen“58 wird zwischen ,wirklichem“ und ,absolutem Feind“ unterschieden. Der „wirkliche Feind“ ist sichtbar, berechenbar, der Krieg gegen ihn ist führbar, also auch kontrollierbar. Die ,absolute Feindschaft“ hingegen zielt auf die totale Vernichtung des Gegners. Genau damit haben wir es aus Sicht der Neuen Rechten heute zu tun. Die Vernichtung des „Eigenen“ beginne mit der „Amerikanisierung“ Westdeutschlands nach 1945, setze sich fort in der „Kulturzerstörung von 1968“ und gipfele im „linksliberalen Eine-Welt-Gender-Multikulti-Albtraum“ von heute. Hinter diesem Vernichtungswerk aber stehe das Prinzip universalistischer Nicht-Identität. Der Vordenker der Nouvelle Droite, Alain de Benoist, formulierte dies in einem Gespräch mit der neonazistischen Zeitschrift Hier \& Jetət im Jahr 2010 so: „Die größte Bedrohung unserer Identität ist keine andere Identität, sondern der politische Universalismus in allen seinen Formen, der die Volkskulturen und unterschiedlichen Lebensstile bedroht, und der sich anschickt, die Erde in einen homogenen Raum zu verwandeln. "59 Von hier aus wird auch klar, warum die Feindschaft gegen den Islam nur taktischer Art ist. Denn in der Logik des neurechten Ethnopluralismus sind alle Völker im Prinzip Waffenbrüder, auch das deutsche Volk und die arabischen Völker. Und so verbindet die völkischen Nationalisten Europas und die

56 Volker Weiß, Die autoritäre Revolte. Die Neue Rechte und der Untergang des Abendlandes, Stuttgart 2017.

${ }^{57}$ Siehe hierzu Samuel Salzborn, Angriff der Antidemokraten. Die völkische Rebellion der Neuen Rechten, WeinheimBasel 2017, S. 63ff.

58 Carl Schmitt, Theorie des Partisanen. Zwischenbemerkung zum Begriff des Politischen, Berlin 1963.

${ }^{59}$ „Auf den Trümmern des bürgerlichen Individualismus.“, Arne Schimmer, Interview mit Alain de Benoist, in: Hier おetz̧t 15 (2010), S. 26-35, hier S. 30f. 
islamischen Fundamentalisten von heute eine „Hassliebe“ (Volker Weiß), weil aus Sicht der Rechten beide ja letztlich nichts anderes wollen, als das Vernichtungswerk der Moderne aufzuhalten.

Von hier ist es dann nur noch ein kleiner Schritt, dem ,absoluten Feind“ einen Namen und eine Gestalt zu geben. Was bei den Neuen Rechten krypto-antisemitisch meistens versteckt bleibt und nur in Andeutungen sichtbar wird, wird in der alten Rechten offen ausgesprochen. Einen ,geistigen Giftpilz der Gemeinschaftszersetzung“ hat der NPDKader und Autor der „Deutschen Stimme“, Jürgen Gansel, den Philosophen des NichtIdentischen, Adorno, zu dessen 35. Todestag im Jahr 2004 genannt. ${ }^{60}$ Für ihn ist Adorno der Inbegriff ,des entwurzelten jüdischen Intellektuellen“. Und auch aktuell fehlt fast nie der Hinweis auf die „Kulturmarxisten“ von der „Frankfurter Schule“, wenn von der „Vergiftung des deutschen Volkes“ nach 1945 die Rede ist. Adorno steht dabei nur stellvertretend für den ,jüdischen Geist“ (Carl Schmitt), dem es aus Sicht der Neuen Rechten durch die Etablierung eines „Dauer-Schuldkults“ gelungen sei, die „deutsche Identität" fast völlig zu zerstören. Wendet man also den Blick von der Agitations- auf die Ideologieebene - dem Hauptfeld neurechten Schaffens -, so ist klar, dass der für die Rechte konstitutive Zusammenhang von Nationalismus und Antisemitismus sich keineswegs aufgelöst hat, wie manchmal behauptet wird. Ganz im Gegenteil: Er hat sich - und dies hat der von der alten wie der neuen Rechten gehasste Adorno schon früh sehr genau gesehen - nach Auschwitz sogar noch verschärft.

Völkischer Nationalismus lässt sich, so Adorno, sozialpsychologisch als kollektiver Narzissmus begreifen, der die Funktion einer Ersatzbefriedigung für die gesellschaftlich freigesetzten, zugleich aber unbefriedigt bleibenden narzisstischen Bedürfnisse vieler Einzelner hat. In den Masseninszenierungen des NS sei dieser kollektive Narzissmus ins Unermessliche gesteigert worden. Wurde die Niederlage Deutschlands von den völkischen Nationalisten als massive narzisstische Kränkung erfahren, so „lauert“ - wie Adorno es formuliert ${ }^{61}$ - ihr beschädigter kollektiver Narzissmus nur darauf, repariert zu werden. Was dies allerdings immer wieder verhindert, ist die mit Juden und dem Staat Israel verknüpfte Erinnerung an die eigene Verbrechensgeschichte. Juden werden im völkisch-nationalistischen Bewusstsein als entäußerte moralische Instanz und ewiger Störenfried der Erinnerung imaginiert und gehasst. Deshalb gilt, so Adorno: „Überall dort, wo man eine bestimmte Art des militanten und exzessiven Nationalismus predigt, wird der Antisemitismus gleichsam automatisch mitgeliefert".62 Genau dieser Zusammenhang lässt sich auch heute ohne große Mühe an vielen Äußerungen von AfDPolitikern, Pegida-Anhängern, Identitären und anderen Neurechten nachweisen, und zwar nicht nur, wenn die der NS-Propaganda entnommene Parole „Lügenpresse, halt die Fresse“ in die offen antisemitische ,Judenpresse, auf die Fresse“ umschlägt (wie auf einer

${ }^{60}$ Globisch, Radikaler Antisemitismus, A.1.2 Primärquellen.

61 Adorno, Was bedeutet: Aufarbeitung, S. 564.

62 Adorno, Zur Bekämpfung des Antisemitismus, S. 361. 
Pegida/Hogesa-Demonstration in Wuppertal im März 2015), sondern auch wenn davon Rede ist, dass Deutschland kein „souveränes Land“ sei, sondern die „Befehle aus Tel Aviv und Washington“ bekomme und die „USA von einer jüdischen Lobby“ regiert werde. ${ }^{63}$

\section{Zur sekundärantisemitischen Funktion des antimuslimischen Rassismus}

Bildet der auf die Restitution des Nationalstolzes ausgerichtete Geschichtsrevisionismus nach wie vor den Kern der Ideologiebildung der Rechten, so verstehen es ihre Agitatoren in geschickter Weise, durch Muslim-Bashing und Israel-Solidaritätsbekundungen Anschluss an den offiziellen Anti-Antisemitismus in der gesellschaftlichen Mitte zu finden. Sie beuten dabei das Entlastungsbedürfnis aus, das die öffentliche Anerkennung der Schuld sozialpsychologisch hervorbringt. Wie dies funktioniert, hat Ilka Quindeau in ihrer These eines modifizierten Sekundärantisemitismus skizziert. Quindeau sieht „die Leistung der [auf die NS-Tätergeneration nachfolgenden; Anm. WS] zweiten und dritten Generation in einer Anerkennung der Schuld [...], die in mühsamen, leidvollen kollektiven Prozessen einer ethisch-politischen Selbstverständigung errungen wurde“".64 Der psychologische Gewinn der Schuldanerkennung besteht zunächst darin, dass sie geradezu umkehrt zur schuldabwehrenden Tätergeneration - die Chance kollektiver narzisstischer Gratifikation eröffnet. Sie ermöglicht nämlich die kollektive Selbststilisierung als moralisch integre, demokratische Nation, der weltweit eine vorbildliche Auseinandersetzung mit ihrer Vergangenheit attestiert wird. Schuldbekenntnis und Erlösungserwartung, so Quindeau, gehen Hand in Hand und äußern sich in quasi religiösen Inszenierungen. Sie weist auf die Goldhagen-Debatte hin, in der so etwas wie eine Lust an der Schuld bei vielen Deutschen zu beobachten gewesen sei. ${ }^{65}$ Diese resultierte daraus, dass mit dem Bekenntnis zu einem spezifisch deutschen Vernichtungsantisemitismus das Versprechen auf Absolution einherging, das Goldhagen dann auch bereitwillig bediente. Das Selbstbild der geheilten, vom Antisemitismus

\footnotetext{
${ }^{63}$ Nachzuhören in der auf der ARD-Mediathek zugänglichen Panorama-Dokumentation „Pegida: Die Interviews in voller Länge“. (Siehe auch Salzborn, Angriff der Antidemokraten, S. $101 \mathrm{ff}$.) - Der von Julijana Ranc eingeführte Begriff der „Vergegenwärtigungsabwehr“ trifft ziemlich genau die Bewusstseins-/Unbewusstseinslage, die viele Anhänger von Pegida und AfD kennzeichnet: abgewehrt werden unlustvolle Gedanken und Gefühle, dabei handelt es nicht nur um „das Unbehagen am Holocaust und an der Schuld und dem Versagen der eigenen Eltern- und Großelterngeneration“, sondern auch um ,kulturell viel tiefer verankerte Gefühle wie etwa des Unheimlichen gegenüber Juden“. (Julijana Ranc, „Eventuell nichtgewollter Antisemitismus“. Zur Kommunikation antijüdischer Ressentiments unter deutschen Durchschnittsbürgern, Münster 2016, S. 161.)

${ }^{64}$ Quindeau, Schuldabwehr und nationale Identität, S. 164.

${ }^{65}$ Ebd., S. 163. - Lars Rensmann entgegnet aber zu Recht, dass mindestens ebenso so viel Schuldabwehraggression in den Reaktionen auf Goldhagens Buch zu beobachten war, was auch hier für eine Überlagerung verschiedener Formen des Sekundärantisemitismus spricht, mit der wir es heute zu tun haben könnten. (Rensmann, Demokratie und Judenbild, S. 336ff.)
} 
befreiten Nation aber gerät immer dann in Gefahr, wenn es zu manifester antisemitischer Gewalt kommt. Diese Gefahr kann nur durch eine rigorose Abspaltung gebannt werden. Genau hier bietet die Dramatisierung des migrationsbedingten Imports eines „muslimischen Antisemitismus“ einen Ausweg. Obwohl der größte Teil der antisemitischen Straftaten in Deutschland, wie die Statistiken zeigen, ${ }^{66}$ nach wie vor von völkischen Nationalisten verübt wird, wird in großen Teilen der medialen Öffentlichkeit die Hauptgefahr bei den „muslimischen Migranten“ verortet. Empirisch belegt ist dies nach wie vor kaum, ${ }^{67}$ aber sozialpsychologisch von großer Attraktivität. Indem der Antisemitismus auf ein Problem von „muslimischen Migranten“, zu denen kurzerhand dann auch die seit Generationen in Deutschland lebenden, ehemaligen türkischen Arbeitsmigranten und Arbeitsmigrantinnen gemacht werden, verkürzt wird, kann sich die „Wir"-Gruppe der Kinder und Enkel der ehemaligen NS-Volksgenossen in die Position moralischer Überlegenheit setzen und dadurch die Auseinandersetzung mit den eigenen antisemitischen Tendenzen vermeiden. Zugleich verknüpft die kulturalisierende, „religionisierende“ Wahrnehmung eines „muslimischen Antisemitismus“ den Kampf gegen eine angebliche Islamisierung Europas mit dem kategorischen Imperativ des „Nie wieder Auschwitz!“ ${ }^{68}$ In der patenten Formel vom „muslimischen Antisemitismus“ lässt sich ein kausaler Zusammenhang zwischen Islam und Antisemitismus behaupten. Antisemitismus wird zum Wesensmerkmal des Islam erklärt. Dadurch wird jeder Muslim und jede Muslima unter Antisemitismusverdacht gestellt. Sofern sie noch keine manifesten Antisemiten sind, sind sie es jedenfalls latent. Aber schlimmer noch: Die Muslime befinden sich in großer Zahl bereits in „unserem“ Land, und mit jedem neu ankommenden Muslim wächst die antisemitische Gefahr auch in Deutschland wieder. Historische Verantwortungsübernahme heißt dann - und hier liegt die Agitationschance, die die Neue Rechte nutzt -, sich der AfD als der einzigen politischen Kraft, die der Islamisierung und damit der Antisemitisierung Europas entschlossen entgegentritt, anzuschließen. ${ }^{69}$ Die Entsorgung des gesellschaftlichen Problems des Antisemitismus

66 Bericht des Unabhängigen Expertenkreises Antisemitismus, 10.11.2011, Deutscher Bundestag, Drucksache 17/7700, S. 14ff., [http://dipbt.bundestag.de/doc/btd/17/077/1707700.pdf], eingesehen 25.10.2018. - Selbstverständlich kann es sein, dass die vorhandenen Statistiken aufgrund mangelhafter oder einseitiger Erhebungstechniken die Realität verzerren und das Problem antisemitischer Gewalt, die von Muslimen ausgeht, unterschätzen, nur wäre auch dies zunächst einmal nachzuweisen.

${ }^{67}$ Auch die neueste Untersuchung von Günther Jikeli zum Antisemitismus bei Geflüchteten aus Syrien und dem Irak reicht dazu nicht aus. (Vergleich dazu den Beitrag Günther Jikelis in diesem Band, sowie Ders., Einstellungen von Geflüchteten aus Syrien und dem Irak zu Integration, Identität, Juden und Shoah. Forschungsbericht Dezember 2017, [https://ajcberlin.org/sites/default/files/ajc_studie_gefluechtete_und_antisemitismus_2017.pdf], eingesehen 25.10.2018; siehe auch Wolfram Stender, Konstellationen des Antisemitismus, in: Ders. u. a. (Hrsg.), Konstellationen des Antisemitismus. Antisemitismusforschung und sozialpädagogische Praxis, Wiesbaden 2010, S. 7-38, hier S. 19ff.) ${ }^{68}$ Dass die Reduzierung des Antisemitismus auf ein Importprodukt von „muslimischen Migranten“ sich schon längst in kulturrassistische Perspektiven verstrickt hat, zeigt sich z. B., wenn rechtspopulistische Initiativen wie „Pro Köln“ zur Gegenwehr gegen den ,importierten Antisemitismus“ aufrufen. (Alexander Häusler, Feindbild Moslem: Türöffner von Rechtsaußen hinein in die Mitte?, in: Gideon Botsch u. a. (Hrsg.), Islamophobie und Antisemitismus - ein umstrittener Vergleich, Berlin 2012, S. 169-190, hier S. 183f.)

${ }^{69}$ Exakt dieses Argumentationsmuster findet sich auch in den Gruppendiskussionen, die ein Forschungsteam der 
qua Projektion auf die von außen kommenden „Anderen“ lässt sich politischpsychologisch als Entlastungsstrategie interpretieren, die durch die migrationsgesellschaftlichen Entwicklungen möglich wird und die zugleich der von Quindeau analysierten Modifikation des sekundären Antisemitismus in der zweiten und dritten Generation nach Auschwitz entspricht. Der antimuslimische Rassismus gewinnt so, ohne dass dies den deutschen Islamfeinden bewusst sein muss, eine sekundärantisemitische Funktion. ${ }^{70}$

Das Fatale daran ist nicht nur die Verleugnung der antisemitischen Tendenzen in der Mehrheitsgesellschaft, sondern auch die Bagatellisierung des islamisierten modernen Antisemitismus durch die praktische Formel vom „muslimischen Antisemitismus“. Das Wissen von der gesellschaftlichen Transformation der traditionellen, religiösen Judenfeindschaft in den modernen Antisemitismus, ein Begleitprodukt der gesellschaftlichen Säkularisierung, gehört seit langem zum festen Bestandteil der Antisemitismusforschung. Die Reduzierung der islamisierten Variante des modernen Antisemitismus auf ein ausschließlich religiöses Phänomen aber ignoriert dies und abstrahiert damit auch von dessen spezifischer Vernichtungsqualität. Dies alles ist so gut erforscht und so bekannt, dass man auch bei den Verfechtern des Konstrukts „muslimischer Antisemitismus“ in der Wissenschaft den Eindruck nicht loswird, dass sie zum Zwecke eines billigen Muslim-Bashing die Bagatellisierung des modernen Antisemitismus wider besseren Wissens in Kauf nehmen. Statt sich dieser für Israel und alle Jüdinnen und Juden der Welt tödlich realen Gefahr zu stellen, was eine Auseinandersetzung mit der gesellschaftsgeschichtlichen Genese des islamisierten modernen Antisemitismus implizieren würde, gefällt man sich - im Wissenschaftsbetrieb nicht anders als in großen Teilen der Medien - in der Diffamierung einer Religion.

Der moderne Antisemitismus, der als Gegenbewegung zur politischen Emanzipation der Juden zwischen 1750 und 1850 entstand, ist zu einem globalen Phänomen geworden, das auch im einundzwanzigsten Jahrhundert eine geradezu unheimliche Aktualität hat. Sein Gravitationszentrum liegt heute in der arabischen Welt, seine Virulenz in Europa aber ist ungebrochen. Seine Besonderheiten in Deutschland wurden hier in groben Zügen skizziert. Antisemitismus lässt sich nicht erkennen, wenn man nur auf den Antisemitismus blickt. Notwendig ist die Erkenntnis der Gesellschaft, die ihn hervorbringt. Weder kann politische Psychologie kritische Gesellschaftstheorie ersetzen, noch ist sie ohne diese möglich. ${ }^{71}$ Eine politische Psychologie des Antisemitismus aber

Universität Göttingen mit „Pegidisten“ geführt hat. (Lars Geiges/Stine Marg/Franz Walter, Pegida. Die schmutzige Seite der Zivilgesellschaft, Bielefeld 2015, S. 125f.)

${ }^{70}$ Siehe u. a. Jan Lohl, „Ein total besiegtes Volk“. Tiefenhermeneutische Überlegungen zum Komplex „Geschichte, völkischer Nationalismus und Antisemitismus" im Rechtspopulismus, in: Meron Mendel/Astrid Messerschmidt (Hrsg.), Fragiler Konsens. Antisemitismuskritische Bildung in der Migrationsgesellschaft, Frankfurt a. M. 2017, S. 281303, hier S. 294ff.; Wolfram Stender, Ideologische Syndrome. Zur Aktualität des sekundären Antisemitismus in Deutschland, in: Markus Brunner u. a. (Hrsg.), Volksgemeinschaft, Täterschaft und Antisemitismus. Beiträge zur psychoanalytischen Sozialpsychologie des Nationalsozialismus und seiner Nachwirkungen, Gießen 2011, S. 240.

71 Zur gesellschaftskritischen Analyse des modernen Antisemitismus siehe u. a. Detlev Claussen, Grenzen der 
kann dabei helfen, über die unbewusste Tradierung antisemitischer Ressentiments in spezifischen politisch-kulturellen Kontexten aufzuklären. ${ }^{72}$ Für die Bekämpfung des Antisemitismus kann sie von großem Nutzen sein, folgt sie doch der Maxime, die Max Horkheimer bereits 1943 in einem Vortrag in der Jüdischen Gemeinde von Los Angeles formulierte: „Der Erfolg jedes Versuchs, den Antisemitismus zu bekämpfen, beruht weitgehend auf der Erkenntnis seiner verschiedenen Abarten, die im täglichen Leben oft nicht unterscheidbar sind. Wir müssen die soziale und psychologische Genese jeder einzelnen Variante erforschen “ ${ }^{73}$

Aufklärung. Die gesellschaftliche Genese des modernen Antisemitismus, Frankfurt a. M. 2005; Moishe Postone, Antisemitismus und Nationalsozialismus, in: Ders., Deutschland, die Linke und der Holocaust. Politische Interventionen, Freiburg i. Br. 2015, S. 165-194.

72 Grundlegend hierzu Rensmann, Demokratie und Judenbild, 2005; zum Verhältnis von Kritischer Theorie und kritischer politischer Psychologie siehe Alfred Krovoza/Christian Schneider, Politische Psychologie in der Bundesrepublik: Positionen und methodische Probleme, in: Helmut König (Hrsg.), Politische Psychologie heute (Leviathan Sonderheft 9/1988), Opladen 1988, S. 13-35.

73 Max Horkheimer, Zur Psychologie des Antisemitismus [1943], in: Ders., Gesammelte Schriften, Bd. 12, Frankfurt a. M. 1985, S. 172-183, hier S. 178. 


\title{
Dekonstruktion , jüdischer Souveränität“ als ,ehrbarer Antisemitismus“. Judith Butler liest Hannah Arendt
}

\author{
Gerhard Scheit
}

\section{Israel und der Welthegemon}

1946 schreibt Gershom Scholem an Hannah Arendt, dass ihm „das Staatsproblem vollkommen schnuppe“ sei, da er nicht glaube, dass „die Erneuerung des juedischen Volkes von der Frage seiner politischen, ja sogar von der Frage seiner sozialen Organisation abhaengt. Mein politischer Glaube ist, wenn er irgendetwas ist anarchistisch." Im Hinblick auf das politische Verhalten der Briten und der Araber schließe er sich jedoch den ,zionistischen Politikern“ an, denen es vor allem um die Errichtung eines Staates geht, der die Juden schützen kann und ihnen die Einwanderung ermöglicht, schweren Herzens würde er für den binationalen Staat ebenso stimmen wie für „Partition“. „Ich selbst habe gewiss zur Gegenseite gehoert, als alter Brith-ShalomMann“, aber die arabischen Gegner seien, so Scholem, nicht ,an unseren moralischen Gesinnungen interessiert, sondern an der Frage, ob wir ueberhaupt vorhanden sind oder nicht". 1

Diese Darstellung des eigenen Wegs ist gegen Arendts neue Auffassungen über zionistische Politik gerichtet, die Scholem als ihr „Assortiment von antizionistischen Argumenten“ schließlich so zusammenfasst: „Die reaktionaere Natur Herzls, die schamlose Ausbeutung des Antisemitismus fuer zionistische Propaganda, die gottverlassene Theorie von der Ewigkeit des Antisemitismus“, um seinerseits etwas wie eine Rückkehr zu Herzl zu bekennen: „Ich muss ihnen sagen, dass ich die Schriften von Herzl heute nicht ohne Erschuetterung lesen kann und dass es mich tief ergreift, wie in einem Menschen als realer Einheit eben Torheit und Groesse beieinander wohnen können. Auf Herzl zu schimpfen ist so ungeheuer leicht, dass ich es mir abgewoehnt

${ }^{1}$ Gershom Scholem, Brief an Hannah Arendt, 28.1.1946, in: Marie Luise Knott (Hrsg.), Hannah Arendt, Gershom Scholem. Der Briefwechsel, Frankfurt a. M. 2010, S. 91-100, hier S. 94. - Micha Brumlik hat in seiner „Kritik des Zionismus“ den „vernünftigen Sinn“ von Scholems Wendung anerkannt und folgendermaßen zusammengefasst: Wenn schon „der Versuch einer normativen Neugründung des Judentums durch den Zionismus [...] früh gescheitert“ sei, und das heiße: „widerlegt“ worden sei, bleibe „doch ein realpolitisches Experiment, dem man sich unter Beibehaltung moralischer Prinzipien ohne jeden utopischen Überschwang zu stellen hat. Vernünftiger konnte man sich im 20. Jahrhundert zu einem normativ-utopischen Entwurf tatsächlich nicht verhalten. “ Und so begründet auch Brumlik in seiner Deutung von Scholems Weg die Staatsbildung, spricht aber vom dürrsten aller Motive: „Es ist kein Zufall, dass sie alle, Martin Buber, Robert Weltsch und Gershom Scholem, Felix Rosenblüth, Kurt Blumenfeld und Hans Kohn, letzten Endes nationalstaatskritische Universalisten waren, die sich - wenn überhaupt - zur jüdischen Staatsbildung nur aus dem dürrsten aller Motive bereit fanden: dem unmittelbaren Schutz von Leib und Leben einer bedrängten Minderheit.“ (Micha Brumlik, Kritik des Zionismus, Hamburg 2007, S. 110.) 
habe. [...] Wer heute gegen die Einsichten Herzls aus seinen naivsten Schritten heraus argumentieren zu können glaubt, hat nichts von uns verstanden. Ich bin nicht fein genug, die Unbeflecktheit meiner Sekte um jeden Preis durchhalten zu wollen. Und, um auch dies gebuehrend und hochachtungsvoll anzumerken, der Zynismus, mit dem die erhabenen und progressiven Argumente gegen eine Sache, die fuer das juedische Volk lebenswichtig ist, bei Ihnen vorgebracht werden, ist gar nicht dazu angetan, mich zu veranlassen, mich von ihr loszusagen. Ich hatte nie geglaubt, dass es mir leichter sein wuerde, mich mit Ben Gurion zu verstaendigen als mit Ihnen!“2 Wenn er Arendts Argument zur Sprache bringt, die Auffassung sei überholt, „dass die Organisation einer Gemeinschaft als Staat sogar in einer Periode der Foederationen noch einen Sinn haben mag“, trifft er den Kern ihrer Kritik des Zionismus, die von einer neuen Theorie vom Ende der Souveränität herrührt: Die Nation „oder besser der Nationalstaat als Organisation von Voelkern“ sei tot. „Dies duerfte jedem Historiker, der weiss, dass die Nation von ihrer Souveraenitaet abhaengt und von der Identitaet von Staat, Volk und Territorium, klar sein." ${ }^{\text {3 }}$

An die Stelle des Nationalstaats sieht Arendt eine den Staaten übergeordnete Macht treten und zwar in Gestalt der neuen hegemonialen Stärke der USA, wie sie aus dem Zweiten Weltkrieg hervorgegangen ist: Entscheidend sei, „daß es im Interesse amerikanischer Außenpolitik zu liegen scheint, einen neuen Weg zur Lösung von Völkerkonflikten anzubahnen, welcher darauf hinauslaufen würde, kleineren Nationen mit Hilfe der eigenen Macht jenen Boden zu bereiten, von welchem aus sie weiterhin von sich aus in relativer Unabhängigkeit Politik machen können. Diese Real- und Machtpolitik unterscheidet sich von imperialistischer Machtpolitik dadurch, daß sie nicht darauf aus ist, auf Grund der bestehenden Macht unbegrenzt mehr und mehr Macht zu akkumulieren. [...] Die offenbar von Roosevelt angebahnte Lösung des palästinensischen Konfliktes versucht gerade, ihn aus der tragischen Hölle der Unlösbarkeit, welche die Folge auch des gemäßigtsten Imperialismus ist, heraus in die Sphäre jener Humanität zu heben, in welcher manchmal bessere und manchmal schlechtere und meistens Kompromiß-Lösungen gefunden werden. “4

Während es Gershom Scholem im Verlauf seiner Erfahrungen in Palästina immer bewusster wurde, was Utopie im messianischen Sinn ist - eine Welt, die staatlicher Herrschaft nicht mehr bedarf - und was sie nicht sein kann: der Aufbau eines jüdischen Staats, verleiht Hannah Arendt ihrer utopischen Hoffnung den Charakter eines sofort realisierbaren politischen Programms, legt aber nur eine weitere Utopie im ursprünglichen Sinn des Wortes vor und denkt einen Staat ohne Ort. Das Problem, das sich hier zuspitzt, lautet im Grunde, dass die Kritik des Staats, die eine Welt ohne Staaten

2 Scholem, Brief an Hannah Arendt, 28.1.1946, S. 92 u. 99.

${ }^{3}$ Hannah Arendt, Brief an Gershom Scholem, 21.4.1946, in: Knott (Hrsg.), Der Briefwechsel, S. 105-111, hier S. 109.

${ }^{4}$ Hannah Arendt, Völkerverständigung im Nahen Osten - eine Basis jüdischer Politik [16.3.1945], in: Marie Luise Knott (Hrsg.), Hannah Arendt. Vor Antisemitismus ist man nur noch auf dem Monde sicher. Beiträge für die deutschjüdische Emigrantenzeitung „Aufbau“ 1941-1945, München-Zürich 2000, S. 177-180, hier S. $178 f$. 
als petitio principii voraussetzt, die wirkliche Bedeutung des Judenstaats für die Gegenwart einschließen muss: Zufluchtsort der Juden zu sein. Arendt jedoch sieht in Israel einen Staat wie jeden anderen, doch gilt ihr im Sinne der menschheitlichen Utopie des ewigen Friedens staatliche Souveränität bereits als obsolet, weil die neue hegemoniale Macht der USA den Staaten selbst eine friedliche Existenz garantieren könnte wie ein wirklicher Souverän seinen Bürgern. So übergeht sie, worin jener eine Staat sich von den anderen $\mathrm{zu}$ unterscheiden hat, weil doch diese hegemoniale Macht so wenig wie irgendeine andere ein über den Staaten selbst regierender Souverän sein kann, sondern nur ein besonders mächtiger in ihrer Reihe.

\section{Vom Welthegemon zum Weltsouverän}

In ihrer Dekonstruktion des Souveränitätsbegriffs knüpft heute Judith Butler an die Position an, die Hannah Arendt im Briefwechsel mit Gershom Scholem einnahm. Dabei unterstellt sie in einer Art antizionistischem Manifest mit dem Titel „Parting Ways“, dass Scholem zwischen seiner messianischen Geschichtsauffassung und seiner Parteinahme für den Zionismus zu unterscheiden nicht imstande sei, jene vielmehr ein historisches „Erlösungsnarrativ für die Gründung des Staates Israel“ beinhalte, dem wiederum Arendt widersprochen habe. ${ }^{5}$ Während Arendt aber noch den Hegemon konkret adressieren konnte, wie groß ihre Illusionen auch waren, die sie mit ihm verband, wendet Butler diese Illusionen gegen die USA selbst, indem sie statt von einer wirklichen hegemonialen Macht, die selbst nur ein Staat mit Territorium sein kann, von einem „international socius“ ausgeht, dessen Vorbild offenkundig die Vereinten Nationen sind, deren Verhältnis zu den Staaten sie jedoch damit auf den Kopf stellt: „kein ,selbst‘, auch kein nationales Subjekt" soll „unabhängig“ von diesem ,internationalen Sozius“ existieren. Das Existenzrecht, das allein er verleihe, möge aber an kein Territorium mehr gebunden sein: Es gehe darum, dass die „Nation“ sich „von der Idee des Territoriums“ lossage. 6

Sie sei, wie sie schon 2003 in ihrem Buch „Precarious Life“ betont, für nationale „Selbstbestimmung“" ${ }^{\text {, }}$ meint damit einerseits Selbstbestimmung jedes Volkes - und setzt so einen allgemeinen Begriff von Volk allerdings nur voraus, um den Juden ein besonderes Recht auf Selbstbestimmung, das sich doch aus der Geschichte der Verfolgung und dem gegenwärtigen Antisemitismus ergeben müsste, abzusprechen. Andererseits soll diese Selbstbestimmung aber auch für andere Völker durchaus keine Souveränität bedeuten: „Der Modus dieser Selbstbestimmung irgendeines Volkes ist, ungeachtet seines aktuellen staatlichen Status, nicht dasselbe wie die außergesetzliche

${ }^{5}$ Judith Butler, Am Scheideweg. Judentum und die Kritik am Zionismus. Frankfurt a. M.-New York 2013, S. 147.

${ }^{6}$ Ebd., S. 172.

7 Judith Butler, Gefährdetes Leben [2003], Frankfurt a. M. 2005, S. 119. 
Ausübung von Souveränität zum Zweck der willkürlichen Außerkraftsetzung von Rechten. Folglich kann es keine legitime Ausübung von Selbstbestimmung geben, die nicht durch eine internationale Konzeption der Menschenrechte bedingt und eingeschränkt ist, insofern diese den verbindlichen Rahmen für staatliches Handeln bereitstellt. “8 Indem sie sich selbst in der Position des ,international socius“ imaginiert, hat sie dann keine Probleme damit, „die gegenwärtige Gestalt von Israel in Frage“ zu stellen um „eine bessere Form für dieses Staatswesen zu finden“: „Eine Form, die beliebig viele Möglichkeiten einschließen könnte“ - vor allem ein „Aufgehen Israels in einem größeren Israel/Palästina“. $?$

Die Frage, wer, welche organisierte Gewalt, dann verhindern könnte, dass eine dieser beliebig vielen Möglichkeiten als Bedrohung von Leib und Leben der Juden realisiert würde und die Menschenrechte auch in dieser Hinsicht eingehalten werden, stellt sich Butler nicht nur nicht - denn es sei für die Juden ,am besten [...], Formen der radikalen Demokratie zu befürworten, die das, was am besten ist, auf alles ausdehnen, seien die betreffenden nun jüdisch oder nicht". ${ }^{10}$ Sie leugnet vielmehr, dass es eines anerkannten Gewaltmonopols bedarf, das jener Bedrohung sich entgegensetzt. Ihr Begriff von radikaler Demokratie läuft darauf hinaus, alles zu boykottieren, was sie als ein „Wiedererstehen einer gewalttätigen und selbstverherrlichenden staatlichen Souveränität" bezeichnet, ${ }^{11}$ und dieses Wiedererstehen sieht sie wie selbstverständlich in den USA von George W. Bush und in Israel unter Sharon und Netanjahu am weitesten getrieben.

Was bei Arendt noch als Illusion durchsichtig bleibt in der Abhängigkeit ihrer Konzeption von der wirklichen Hegemonie der USA nach dem Zweiten Weltkrieg, schlägt bei Butler in den „Wahn vom Weltsouverän“12 um. Sei es die Rede vom „,international socius“ und davon, dass kein nationales Subjekt unabhängig von diesem Sozius existieren möge; oder die reine Ethik, auf die sie sich stützt - im Namen von Emmanuel Lévinas, aber im Widerspruch zu dessen prononcierter Parteinahme für Israel - und die im Politischen die Souveränität ersetzen soll: auf Israel angewandt ist immer die Entwaffnung der Juden die Konsequenz. Butler lehnt zwar Gewalt in jedem Fall ab, indem sie aber Hamas und Hisbollah als „,fortschrittlich“ bezeichnet und als „Teil der globalen Linken“ und „Bewegungen gegen Kolonialismus und Imperialismus“ versteht, ${ }^{13}$ entpuppt sich ihre Dekonstruktion der Souveränität als eine Art gewaltfreier Djihad, der dem wirklichen Vorschub leistet. Warum Butler diese Propaganda betreibt, spricht sie selber indirekt an, wenn sie ihr Verhältnis zu den nichtjüdischen antizionistischen

${ }^{8} \mathrm{Ebd}$.

${ }^{9}$ Ebd., S. $143 \mathrm{f}$.

10 Ebd., S. 134.

11 Ebd., S. 121.

12 Siehe hierzu Gerhard Scheit, Der Wahn vom Weltsouverän. Zur Kritik des Völkerrechts, Freiburg i. Br. 2009.

${ }_{13}$ Siehe hierzu Stephan Grigat, Die Einsamkeit Israels. Zionismus, die israelische Linke und die iranische Bedrohung, Hamburg 2014, S. 128. 
Aktivisten beschreibt: Sie wird offenkundig von der Angst getrieben, in den Augen der anderen Linken mit Israel identifiziert zu werden, weil sie Jüdin ist. ${ }^{14}$ Von diesen Linken geht offenbar ein stets wachsender Druck aus, dem Butler immer mehr nachgegeben hat, sodass sie schließlich zur Gallionsfigur der ganzen BDS-Bewegung avancierte. Niemand kann sie unverdächtiger und respektabler repräsentieren als eine Philosophin jüdischer Herkunft - umso mehr, wenn sie auch noch das Epitheton jüdisch ganz allgemein in Frage stellt. Und tatsächlich macht Butler auch noch diesen Schritt und liefert damit etwas wie die Gegenprobe zum Urteil Jean Amérys, der den Antizionismus einmal polemisch als den „ehrbaren Antisemitismus“ bezeichnete..$^{15}$ Dabei zeigt sich gerade bei Butler mit besonderer Klarheit, dass der Antizionismus nicht nur irgendeine weitere, sozusagen modernisierte Form des Antisemitismus ist, sondern gleichsam dessen Speerspitze, insofern er auf die Bewaffnung der vom Antisemitismus Verfolgten zielt.

Diaspora heißt für Butler zwar zunächst ,hineingeworfen sein in eine Welt der NichtJuden, in der man ethisch und politisch seinen Weg inmitten einer unumkehrbaren Heterogenität finden muss, [...] eine Bevölkerung und sogar eine ,Macht', die von der Kohabitation mit den Nicht-Juden abhängt und die zionistische Verknüpfung von Volk und Land vermeidet“. ${ }^{16}$ Als wäre jedoch der Ausdruck „Kohabitation“, den Butler verwendet, nicht schon historisch aussagekräftig genug, schreitet die Dekonstruktion ganz bewusst weiter zu dem Ziel, auch die Verknüpfung von Jude und Jude zu boykottieren: Jüdischsein sei hinfort eben als ,anti-identitäres Projekt zu verstehen“. ${ }^{17}$ Darin wird nun deutlich, dass Butler eine jüdische Antisemitin im vollen Wortsinn ist: Sie macht etwa nicht wie die vielen jüdischen Gegner des Zionismus in Vergangenheit und Gegenwart halt bei einer Trennung von gewaltfreiem Diaspora-Judentum und gewaltsamer Israel-Souveränität. Denn sie fürchtet sogar, dass das Judentum noch in der Kritik an Israel sich erneuern könnte. Darum schreibt sie den Satz hin, der für sich betrachtet eigentlich auf Delirium schließen lässt: „Ich will auch nicht einfach sagen, Juden seien zur Kritik am Staat Israel verpflichtet, obgleich ich tatsächlich der Auffassung bin, dass sie - oder vielmehr wir - dazu verpflichtet sind [...]“. Dass sie es nicht „einfach“ sagen will, heißt aber nur, dass sie es zugleich auch noch gegen das Judentum selbst wenden will: Die „Herausstellung progressiver Juden“, das heißt: israelkritischer Juden, sei nämlich „mit der Gefahr verbunden, dass man in identitären und kommunitaristischen Annahmen" verharre ${ }^{18}$ - sodass letztlich doch wieder Erfahrungen möglich wären, die es nahelegen könnten, sich zu bewaffnen. „Jüdischsein“ bedeutet jedoch in Butlers Denken, gegen die Juden sein - gerade auch dort, wo sie sich gegen ihre Feinde zusammenschließen: ein „,anti-identitäres Projekt“; es bedeutet: „die

14 Butler, Gefährdetes Leben, S. 145.

15 Jean Améry, Der ehrbare Antisemitismus, in: Irene Heidelberger-Leonard (Hrsg.), Jean Améry, Werke, Bd. 7, Stuttgart 2005, S.131-140.

16 Butler, Am Scheideweg, S. $25 \mathrm{f}$.

17 Ebd., S. 140 f.

18 Ebd., S. 140. 
Loslösung von einem jüdisch zentrierten Bezugsrahmen [...] und die Betrachtung des Jüdischseins im Moment seiner Begegnung mit dem Nicht-Jüdischen und der sich daraus ergebenden Zerstreuung des Selbst“. ${ }^{19}$ Die „Israelkritik“ soll letztlich eine Einheit des Judentums als solche unmöglich machen: sie in einem Judesein auflösen, das sich wiederum selbst auflöst. ${ }^{20}$ Butlers Antizionismus ist so konsequent, dass er sich demaskiert: Er zielt zuletzt auf jede Vereinigung von Juden, weil darin noch etwas von Selbstverteidigung erkannt werden könnte, und sei es auch nur darin, sich selbst als Jude oder Jüdin zu bezeichnen, was immer der- oder diejenige unter dieser Zugehörigkeit auch verstehen mag.

So zielstrebig Butlers „Israelkritik“ auch vorgeht, sie ist nur möglich dank der Beliebigkeit im moralphilosophischen Urteil, die sich ihr durch die schon seit langem eingeübte Dekonstruktion des Subjekts eröffnet hat. Das zeigt sich nicht zuletzt an Butlers Auseinandersetzung mit Arendts berühmten Buch über „Eichmann in Jerusalem“.

\section{Eichmann-Prozess und jüdische Souveränität}

Hannah Arendts Ressentiment gegenüber dem Zionismus resultierte wohl aus einer Enttäuschung - Enttäuschung darüber, dass der Judenstaat seiner über den Staat hinausreichenden, menschheitlichen Mission nicht gerecht würde, die in Wahrheit einer übermenschlichen im Sinne Nietzsches gleichzukommen scheint: Arendt hatte es 1944 im Hinblick auf den zu gründenden Staat als eine ,gute Botschaft“ angesehen, „daß in dem furchtbaren Morden, das die Nazis angerichtet haben, die Überlebenden zu den Besten gehören werden. Denn die Widerstandslosen und Gefügigen erwartete der sichere Tod.“21 Diese Botschaft ist das genaue Gegenteil des späteren „Law of Return“, das jedem Juden und jeder Jüdin das Recht gewährt, nach Israel zu kommen. Unter den herrschenden Bedingungen war und ist dieses Gesetz die einzig mögliche, konsequente politische Praxis nach der Shoah, Praxis auch in emphatischer Bedeutung, denn sie gibt der Shoah nachträglich keinen Sinn, sondern hat den ihren allein darin, die Wiederholung von Auschwitz zu verhindern und das Überleben der Jüdinnen und Juden zu sichern. In der ,guten Botschaft" aber findet sich bereits ein Motiv für Arendts spätere Bemerkungen zu den Judenräten - jene Bemerkungen, die von vielen Verfolgten des Naziregimes als unerträglich empfunden wurden. Es ist die Verachtung jener „Gefügigen“, die womöglich überlebt hatten. Das berühmt gewordene Buch über den Eichmann-Prozess sollte schließlich ignorieren, in welcher realen Situation sich die Judenräte befanden, so etwa mit der Behauptung, den Judenräten wäre von den Nazis

${ }^{19}$ Ebd., S. 39.

${ }^{20}$ Siehe hierzu Ljiljana Radonić, „Deutsche Therapie ist irgendwie universell.“ Von der friedfertigen Antisemitin zur queer-theoretischen Post-Zionistin, in: sans phrase (2014), Heft 4, S. 48-62, hier S. 61.

${ }^{21}$ Hannah Arendt, Eine Lehre in sechs Schlüssen [11.8.1944], in: Marie Luise Knott (Hrsg.), Hannah Arendt. Vor dem Antisemitismus, S. 154-157, hier S. 156. 
„eine enorme Macht“ in die Hände gelegt worden und sie hätten, wie ihre Manifeste bezeugten, ,ihre neue Macht genossen““. ${ }^{22}$ In der englischen Erstausgabe versteigt sich Arendt sogar dazu, Leo Baeck „the Jewish Führer“ zu nennen. Immer wieder wird in „Eichmann in Jerusalem“ die „Trennungslinie zwischen Verfolgern und Opfern“, die ihre Artikel aus den frühen vierziger Jahren noch scharf gezogen hatten, verwischt: die Rolle des Kaposystems in den Lagern und die Funktion der jüdischen Sonderkommandos wird isoliert betrachtet, um deren Repräsentanten moralisch zu verurteilen; dabei spricht Arendt dem eigentlich Angeklagten selbst noch ein „Gran von Wahrheit" zu, wenn dieser in seiner Aussage die innerhalb der SS gepflegte Teamarbeit auch als eine zwischen Tätern und Opfern darzustellen sucht, um sich zu entlasten: „wenn der Betreffende es nicht - nicht gern macht, dann leidet ja die gesamte Arbeit darunter". ${ }^{23}$ Die Frage, unter welchen Bedingungen jemand etwas ,gerne macht", welche Alternativen die Judenräte hatten, als sie die Macht über Leben und Tod übernahmen, stellt sich Arendt in diesem Zusammenhang nicht. ${ }^{24}$

Schon der Vorbehalt, den Arendt gegen den Prozess formulierte, dass es nämlich besser gewesen wäre, wenn Eichmann von einem internationalen Strafgericht der Prozess gemacht worden wäre, verweist auf ihre frühere Wendung gegen den Zionismus. Der Auffassung, dass Israel nur einspringen musste, weil es ein solches Gericht noch nicht gibt, dass es sich also lediglich um eine Notlösung handelte, ist - abgesehen von der dahinterstehenden Theorie obsolet gewordener Souveränität - insofern zu widersprechen, als sie den Blick auf die Verbrechen verzerrt: Sie richteten sich in Arendts Augen gegen die Menschheit als Ganzes, die sie aber als die „Pluralität der Existenz“ verschiedener Völker, nicht verschiedener Individuen, verstehen möchte, und eben deshalb hält sie ein internationales Gericht für einzig angemessen. So ist es möglich, dass die Autorin die besondere Lage der Juden als Verfolgte gegenüber der „Pluralität der Existenz" aller anderen Verfolgten so wenig wie die je individuelle der Judenräte wahrzunehmen gewillt ist: Als wäre nicht der Weltverschwörungswahn ausschlaggebend für den Antisemitismus, behauptet Arendt, die Juden seien nur zufällig zum Objekt der Vernichtung geworden. Gershom Scholem wiederum hat eben das mit der nötigen Schärfe kritisiert und auch gespürt, wieviel „Hohn auf den Zionismus“ in Arendts Formulierung steckt, dass Eichmann durch die Lektüre von Herzls Judenstaat für immer zum Zionismus konvertiert sei. ${ }^{25}$ Aber er vermag die Position Arendts nur als fehlende „Ahabath Israel“, „Liebe zu den Juden“ zu kritisieren, ${ }^{26}$ worauf Arendt mit einem gewissen Recht antwortet, sie könne nur Individuen und keine Kollektive lieben. Solidarität mit den Juden und ihrem Staat ist tatsächlich keine Liebe, sondern die

22 Hannah Arendt, Eichmann in Jerusalem. Ein Bericht von der Banalität des Bösen [1963], Leipzig 1990, S. 220 f.

${ }^{23}$ Ebd., S. 228.

24 Doron Rabinovici, Instanzen der Ohnmacht. Wien 1938-1945, Der Weg zum Judenrat, Frankfurt a. M. 2000.

25 Gershom Scholem, Brief an Hannah Arendt, 23./24.6.1962, in: Knott (Hrsg.), Der Briefwechsel, S. 428-437, hier S. 433 .

26 Ebd., S. 429. 
Erkenntnis, wie die Vernichtung von Individuen zu verhindern ist. Es hängt wohl mit den alten anarchistischen und kulturzionistischen Vorstellungen zusammen, die Scholem vermutlich nie ganz aufgegeben hat, dass er an diesem Punkt Arendt nicht auf der ihr gemäßen Ebene des Politischen entgegnen kann. Ebenso signifikant ist, dass Scholem einerseits dafür plädierte, das Todesurteil gegen Eichmann nicht zu vollziehen, andererseits meinte, Benjamin Murmelstein, der zu jenen Judenräten gehört hatte, habe „verdient, von den Juden gehängt zu werden“. ${ }^{27}$ (Im Gespräch mit Claude Lanzmann am Ende des Films „Der Letzte der Ungerechten“, der dieses Urteil eindrucksvoll revidierte, sagt Murmelstein, er finde hier die Argumentation von Scholem „kapriziös“.) Eichmann hätte, so Scholem, deshalb nicht erhängt werden sollen, um „den Deutschen die Auseinandersetzung mit ihrer Vergangenheit nicht durch den Tod Eichmanns so zu erleichtern, wie wir es gemacht haben“. ${ }^{28}$ Arendt hingegen hat in ihrem Buch für die Vollstreckung des Urteils plädiert: Niemandem könne „zugemutet“ werden, „,mit denen, die solches wollen und in die Tat umsetzen, die Erde zusammen zu bewohnen“, und im Brief an Scholem ergänzte sie, dass ein Gnadenakt den Mörder begnadigt, weil er mehr sein könne als seine Tat, was aber bei Eichmann nicht zutreffe, und ihn am Leben zu lassen, ohne ihn zu begnadigen, sei rein juristisch unmöglich. ${ }^{29}$ Die Schwäche von Scholems Kritik an Arendt rührt daher, dass er mit ihren Auffassungen noch immer etwas teilt: Im Fall Eichmanns erscheint ihm der Staat Israel eher als moralische Anstalt für die Deutschen, statt in seiner Funktion als Schutz der Verfolgten; im Fall Murmelsteins wiederum will er die Öffentlichkeit im Judenstaat gerade nicht als eine moralische Anstalt betrachtet wissen, der durch die Hinrichtung die ihr und Murmelstein gemäße Auseinandersetzung mit der Lage und dem Verhalten jedes einzelnen Mitglieds der Judenräte entzogen würde.

\section{Verdrängung, Wiederkehr und Delegitimierung jüdischer Souveränität}

Auf eigentümliche Weise verschoben kehrt demnach in Arendts Plädoyer für den Vollzug der Todesstrafe an Eichmann wieder, was sie in ihrer Polemik gegen den Prozess selbst verdrängt hatte: die Notwendigkeit eines jüdischen Souveräns. ${ }^{30}$ Hier nun bewährt

\footnotetext{
${ }^{27}$ Ebd., S. 431.

${ }^{28}$ Gershom Scholem, Brief an Hannah Arendt, 12.8.1963, in: Knott (Hrsg.), Der Briefwechsel, S. 449_453, hier S. 452.

${ }^{29}$ Hannah Arendt, Brief an Gershom Scholem, 10.7.1963, in: Knott (Hrsg.), Der Briefwechsel, S. 438-446, hier S. $443 \mathrm{f}$.

${ }^{30}$ Geht es - wie in ihren großen historischen Arbeiten über die „Elemente und Ursprünge totaler Herrschaft“ oder über die Französische und Amerikanische Revolution („,On Revolution“) - nicht um ein Urteil über den Zionismus und die israelische Politik, dann vermag Arendt die Fragen der Souveränität mitunter ziemlich klar und ohne solche Verschiebungen zu stellen, so auch in ihrer Polemik gegen Carl Schmitts Großraumtheorie und dessen „Polemik gegen den ,gerechten Krieg“" : „Die amerikanische Auffassung vom gerechten Krieg ist wesentlich - nicht, a war to end wars“ oder , a war to make the world safe for democracy“ - von der Kriminalisierung des Angriffskriegs als Angriff, als Friedens- und Vertragsbruch bestimmt, wobei nach angelsächsischer Auffassung der Vertragsbruch schwerer wiegt als der Friedensbruch. Verwischt man diese Sache, wie Schmitt es konsequenterweise tut, so hat man aus Vertrag und
} 
sich bei Judith Butler die Hellsicht der antizionistischen Ranküne. Die Darstellung Eichmanns in dem Buch von Arendt missversteht sie als Beispiel für die Dekonstruktion des Subjekts, umso mehr ist sie irritiert, wenn im Votum für die Todesstrafe plötzlich das Subjekt in Gestalt des Souveräns auftaucht: Arendt sei bereit gewesen, „der Todesstrafe zuzustimmen, weil sie zu dem Schluss gelangte, dass keine Person mehr da war, dass Eichmanns Handeln (oder Nichthandeln) effektiv die Vorbedingungen seines eigenen Personenseins zerstört hatte“. ${ }^{31}$ In diesem Zusammenhang zitiert sie den Satz aus Arendts „Responsibility and Judgement“: „Im bodenlosen Bösen ist keine Person mehr da, der man je vergeben könnte“.32 Wenn Arendt also die Stimme des Richters annimmt, um Eichmann zum Tode zu verurteilen, so verstört das Butler sichtlich und nachhaltig. Sie kann sich nicht damit beruhigen, dass es sich doch nur, wie sie beteuert, um ein „Texttheater“ handle oder dass die Todesstrafe selbst nur ein „Sprechakt“ sei, all diese aus ihrer Theorie stammenden Jargonwörter können den Dissens, den sie hier mit Arendt hat, nicht auslöschen. „Einerseits beschwört sie die Gestalt einer souveränen Autorität außerhalb aller Gesetze herauf; andererseits führt sie performativ eine Norm ein, anhand derer sich auf radikal egalitärer Basis gerechte von ungerechten Gesetzen unterscheiden ließen [...]. Es gibt aber keinen Grund zu der Annahme, dass der einzige Weg zur Opposition gegen das Recht oder zur Aussetzung des Rechts der Rückgriff auf eine außerrechtliche Souveränität ist." 33 Beinahe desperat versucht sie darum, Arendt in die Nähe zu Carl Schmitt zu rücken, um sich von ihr an diesem Punkt loszusagen. Sie ist sogar bereit, ihre Polemik gegen den Primat der Selbstverteidigung und Selbsterhaltung fallenzulassen, wenn diese nicht Israel sondern einen Nazimörder betreffen, und gibt bei dieser Gelegenheit auch das Fundament ihres Genderbegriffs preis, um sich auf „das Leben des Körpers“, dessen „Hunger“, „Bedürfnisse nach Unterkunft und Schutz vor Gewalt" zu berufen. ${ }^{34}$ So können ihr dann Hamas und Hisbollah im selben Maß als fortschrittlich gelten wie das Urteil der Richter im Eichmannprozess als rückschrittlich. Der Unterschied zu Arendt tritt hier deutlich wie nirgendwo hervor: Alles wird dieser

Frieden eine ,causa iusta ' gemacht, die sie nicht sind. Erst wenn Frieden ideologisiert wird, also von der Realität gelöst, so dass es einer klaren Gefahr und Bedrohung nicht mehr bedarf, um die Welt zu pazifizieren, wird er zur ,causa '." (Ursula Ludz/Ingeborg Nordmann (Hrsg.), Hanna Arendt. Denktagebuch 1950 bis 1973, München 22003, S. 217.)

31 Butler, Am Scheideweg, S. 201.

32 Zit. n. ebd.

33 Ebd., S. 204 f.

34 Gegen das Todesurteil von Eichmann argumentiert sie mit der Mannigfaltigkeit des menschlichen Lebens, worin aber selbst der anthropozentrische Horizont zu überschreiten wäre: „Wenn Denken - oder gutes Denken - den Schutz der Mannigfaltigkeit des menschlichen Lebens beinhaltet, dann denken wir, wenn wir denken, die Heterogenität. Wir müssen aber an dieser Stelle auch festhalten, dass diese Heterogenität in einem ausschließlich anthropozentrischen Horizont gedacht wird. Das Leben, das erhaltenswert ist, ist, auch wenn es sich auf das menschliche beschränkt, in ganz wesentlicher Hinsicht mit dem nichtmenschlichen Leben verbunden; das ergibt sich aus dem Gedanken des menschlichen Tieres. Denken wir also gut und verpflichtet uns unser Denken auf die Bewahrung des Lebens in der einen oder anderen Form, dann hat das zu bewahrende Leben körperliche Form. Umgekehrt bedeutet das, dass das Leben des Körpers - sein Hunger, seine Bedürfnisse nach Unterkunft und Schutz vor Gewalt - sämtlich zentrale Fragen der Politik würden.“ (Ebd., S. 205.) 


\section{Gerhard Scheit}

Art Theorie beliebig, wenn nur eines als gesichert gelten kann: dass es keine jüdische Souveränität mehr geben soll. 


\title{
Antisemitismus - Ein blinder Fleck der intersektionalen Geschlechterforschung?
}

\author{
Manuel Mayrl
}

Bereits Ende der 1970er-Jahre wurde innerhalb zeitgenössischer Debatten der feministischen Theoriebildung auch Kritik an antisemitischen Denkmustern laut. Jüdische Feministinnen wie Judith Plaskow und Annette Daum kritisierten die Reproduktion antjüdischer Klischess in der damals formulierten Patriarchatskritik und forderten demgegenüber differenziertere Analysen ein. ${ }^{1}$ Dennoch scheint diese frühe Kritik kaum Eingang in die feministische Reflexion gefunden zu haben. Auch heute noch lassen Feministinnen und Feministen wie auch Geschlechterforscherinnen und Geschlechterforscher wiederholt mit antisemitischen Äußerungen oder Unterstützungsbekundungen für die antisemitische BDS-Kampagne ${ }^{2}$ aufhorchen, darunter Koryphäen wie Judith Butler, Laurie Penny und Angela Davis. Wie kommt es, dass feministische Denkerinnen, die sich zum Teil in der Tradition der Kritischen Theorie verorten, Antisemitismus ausblenden und - „on basis of intersectionality “3 durch eine einseitige Positionierung gegen den israelischen Staat dessen Delegitimierung forcieren?

Mit „intersectionality“ (dt. Intersektionalität) konzeptualisierte Kimberlé Crenshaw die Mechanismen des Zusammenwirkens mehrerer Ungleichheitsdimensionen, jenseits eines simplen Aufaddierens. Konkret untersuchte sie das Zusammenwirken von „race“ und „gender" im Kontext des US-amerikanischen Rechtssystems. Allerdings betonte sie schon früh, das Konzept könne und solle erweitert werden. ${ }^{4}$ Mit Edward Said kann diese Anmerkung Crenshaws verstanden werden als „kritische Einsicht, daß keine Theorie imstande ist, alle Situationen abzudecken, einzugrenzen und vorherzusagen, für die sie nützlich sein könnte“. ${ }^{5}$

1 Charlotte Kohn-Ley/Ilse Korotin (Hrsg.), Der feministische „Sündenfall“? Antisemitische Vorurteile in der Frauenbewegung, Wien 1994, S. 9f.

2 Das Akronym BDS steht für Boycott, Divestment and Sanctions und ist ein „Beispiel für eine einflussreiche antisemitische Kampagne gegen Israel, die strukturell von Kritik unterschieden werden kann." Samuel Salzborn, Israelkritik oder Antisemitismus? Kriterien für eine Unterscheidung, in: Kirche und Israel. Neukirchener Theologische Zeitschrift 28 (2013), Heft 1, S. 5-16, hier S. 11.

${ }^{3}$ Karin Stögner, A Critical Theory of Nationalism, Post-Nationalism and anti-Zionism, Vortrag auf der International Scholars Conference Anti-Zionism, Antisemitism, and the Dynamics of Delegitimization, Bloomington, 2.-6.4.2016, [https://youtu.be/cnDxmsau-dY], eingesehen 11.10.2017.

${ }^{4}$ Kimberlé Crenshaw, Mapping the Margins. Intersectionality, Identity Politics, and Violence Against Women of Color, in: Stanford Law Review 43 (1991), Heft 6, S. 1241-1299, hier Fußnote 9 (S. 1245).

${ }^{5}$ Edward Said, Theorien auf Wanderschaft, in: Ders. (Hrsg.), Die Welt, der Text und der Kritiker, Frankfurt a. M. 1997, S. 263-292, hier S. 283. 
Dieser Beitrag geht von der grundlegenden Offenheit von Crenshaws Konzept aus und schließt sich Saids impliziter Forderung an, theoretische Konzepte an die jeweiligen Kontexte anzupassen. Auf diese Weise soll das konflikthafte Verhältnis zwischen intersektionaler und antisemitismuskritischer Analyse näher beleuchtet werden. Davon ausgehend wird nachgezeichnet, in welchem Kontext sich das ursprüngliche Konzept intersectionality entwickelte und wie es im deutschsprachigen Raum rezipiert wurde. ${ }^{6}$ Dies geschieht auf Grundlage von Edward Saids Anmerkungen zu „traveling theories“ und entsprechend des darin explizit nahegelegten historischen Ansatzes: „[T] is always informed by the past, by past hopes and promises, but also by past horror and injustice. “7 Durch diesen Ansatz soll „[d]as kritische Bewusstsein“ als „ein Wissen um die Unterschiede zwischen den Situationen“8 entwickelt werden, das den Ausgangspunkt für konkrete Konzeptualisierungen von Antisemitismus als Bestandteil von Intersektionalität markieren soll.

\section{Historischer Entstehungskontext in den Vereinigten Staaten}

Der ideengeschichtliche Ursprung von intersectionality wird gemeinhin in den 1960er und 1970er-Jahren in den Vereinigten Staaten von Amerika verortet. Der soziale Kontext dieser Zeit war maßgeblich von ethnisch segregierten Lebenswelten und antirassistischen Bürgerrechtsbewegungen geprägt. Diese Bewegungen kämpften - unter anderem mit ihrem wohl prominentesten Protagonisten Martin Luther King - für ein Ende des bis dahin geltenden juristischen Grundsatzes „separate but equal“", welcher eine Trennung zwischen „weißen“ und „schwarzen“ Amerikanerinnen und Amerikanern legitimierte. Der Civil Rights Act von 1964 und der Voting Rights Act von 1965, als konkrete Erfolge der antirassistischen Bewegungen, beendeten schließlich formal die Segregation und die Benachteiligung schwarzer Personen bei der Wählerregistrierung. Eng mit der Bürgerrechtsbewegung verzahnt war auch die US-amerikanische Studierendenbewegung. Konkrete Überschneidungen zu den Kampagnen und Forderungen der schwarzen Bürgerrechtsbewegung lassen sich etwa am Beispiel des Student Nonviolent Coordinating Committee (SNCC) illustrieren, zu dessen bekanntesten Mitgliedern Angela Davis und Stokely Carmichael zählten. ${ }^{9}$ Anhand des SNCC und dessen zeitweisen Vorsitzenden Stokely Carmichael sollen im Folgenden theoretische Grundlagen,

${ }_{6} \mathrm{Um}$ die unterschiedlichen historischen und gesellschaftlichen Kontexte und die Transformation des Konzepts sprachlich sichtbar zu machen, wird im weiteren Verlauf des Beitrags zwischen intersectionality - für den USamerikanischen Kontext - und Intersektionalität - für den deutschsprachigen Raum - unterschieden. Siehe auch Lucy Chebout, Wo ist Intersectionality in bundesdeutschen Intersektionalitätsdiskursen? - Exzerpte aus dem Reisetagebuch einer Traveling Theory, in: Sandra Smykalla/Dagmar Vinz (Hrsg.), Intersektionalität zwischen Gender und Diversity. Theorien, Methoden und Politiken der Chancengleichheit, Münster 2011, S. 43-57.

${ }^{7}$ Karin Stögner, A Critical Theory.

${ }^{8}$ Edward Said, Theorien auf Wanderschaft, S. 284.

${ }^{9}$ Peniel E. Joseph, Stokely: A Life, New York 2014. 
internationale Vernetzungen und politische Parteinahmen - vor allem in Bezug auf Israel - skizziert werden.

Stokely Carmichael war von 1966 bis Ende 1967 Vorsitzender des SNCC, eine Zeit in der sich seine politischen Positionen zu internationalisieren und zu radikalisieren begannen. Dieser Prozess ging mit einer Zuwendung hin zur Black Power Bewegung und einer Entfremdung von Martin Luther Kings Positionen einher. ${ }^{10} \mathrm{Im}$ Juli 1967 hielt Carmichael in Havanna eine vielbeachtete Rede auf der OLAS Konferenz - einer Nachfolgeorganisation der ein Jahr zuvor gegründeten „Tricontinentalen“, der auch die Palestine Liberation Organisation (PLO) angehörte. Fidel Castro begrüßte ihn dort als „one of America's ,most distinguished' civil rights leaders.“" Wenige Tage zuvor trat Carmichael als Redner bei der Konferenz „Dialectics of Liberation“ in London auf, an der auch Herbert Marcuse und Angela Davis teilnahmen. Sich vom konventionellen Marxismus abgrenzend, identifizierte Carmichael auf dieser Konferenz neben dem Kapitalismus den Rassismus als globales Unterdrückungssystem und forderte eine Solidarisierung mit der sogenannten Dritten Welt: „What we're talking about around the United States today, and I believe around the Third World, is the system of international white supremacy coupled with international capitalism. "12 Entsprechend seiner an Frantz Fanon angelehnten Argumentation, der Befreiungskampf der schwarzen Bevölkerung könne nur in konsequenter Abgrenzung zu - und nicht mit - weißer Unterstützung geführt werden, fasste das SNCC Ende 1966 den Beschluss, sich von seinen weißen Mitgliedern zu trennen. Durch diesen - denkbar knappen - Beschluss wurden auch viele bis dahin aktive jüdische Mitglieder ausgeschlossen, was zu einer beginnenden Entfremdung zwischen vormals vielseitig kooperierenden schwarzen und jüdischen Interessensgruppen führte. ${ }^{13}$

Einen wichtigen theoretischen Bezugspunkt für Carmichael und die der Black Power Bewegung zugewandten Teile der US-amerikanischen Bürgerrechts- und Studierendenbewegungen, stellte Fanons Arbeit zu Gewalt und Kolonialismus dar. Vor dem Hintergrund des Algerienkrieges beschreibt Frantz Fanon in seinem Werk „Die Verdammten dieser Erde" sowohl die Kolonisation als auch die Dekolonisation als notwendig gewaltförmig. Der Status Quo der Kolonisation könne „nur durch die absolute Gewalt in Frage gestellt werden". ${ }^{14}$ Neben einer Affirmation der Gewalt von Kolonisierten, lässt sich in Fanons Arbeit auch eine antimilitaristische Haltung erkennen. Fanon nahm damit eine implizite Unterscheidung zwischen emanzipatorischem Guerillakampf von antikolonialen Befreiungsbewegungen einerseits und negativ

${ }_{10}$ David J. Garrow, Bearing the Cross. Martin Luther King Jr. and the Southern Christian Leadership Conference, New York 1986.

${ }^{11}$ Joseph, Stokely, S. 134.

12 Zit. n. ebd., S. 132.

${ }_{13}$ Jewish Virtual Library, Modern Jewish History: The New Left, o. D., [http://www.jewishvirtuallibrary.org/the-newleft], eingesehen 7.10.2017.

${ }^{14}$ Frantz Fanon, Die Verdammten dieser Erde, Sonderausgabe, Frankfurt a. M. 2008, S. 29. 
konnotierten staatlichem Militarismus andererseits vor. Diese Unterscheidung des Partikularen - der emanzipatorischen Gewalt der Kolonialisierten - gegenüber dem Universalen - dem Unterdrückungsregime und dessen Militarismus - lässt sich auch bei Angela Davis wiederfinden. Sie beschreibt Israel als abstrakten und künstlichen Staat, der in diesem Sinne für das Universale und eine weiße, männliche Herrschaft einstehe. Demgegenüber stellt sie die arabischen Gemeinschaften, die noch authentisch und verwurzelt wären. ${ }^{15}$ Nicht nur wird hierbei das dialektische Verhältnis zwischen dem Besonderen und dem Allgemeinen ,zugunsten antikolonialer ,Eindeutigkeit"“16 verkannt. Ebenso greifen die impliziten wie expliziten Dichotomien wurzellos/verwurzelt, konkret (authentisch)/abstrakt (künstlich), Gemeinschaft/Gesellschaft klassische Strukturelemente des modernen Antisemitismus auf. ${ }^{17}$

Im Laufe der Zeit verschärfte sich Carmichaels antisemitische Rhetorik und gipfelte 1985 in der Aussage: „The only good Zionist is a dead Zionist." 18 Hier wird ein konkreter Konfliktpunkt zu Martin Luther King deutlich, der bereits 1968 den sich ausbreitenden Antizionismus in der amerikanischen Linken als Antisemitismus entlarvte: „When people criticize Zionists, they mean Jews. You're talking anti-Semitism. “19

Die „Studentenbewegung selber war [...] mit ihren Themen und ihren Herangehensweisen ein wichtiges Fundament für die neue Frauenbewegung " ${ }^{20}$ und folglich auch für die konzeptionelle Entwicklung von intersectionality. ${ }^{21}$ Neben die antirassistische Bürgerrechtsbewegung und die antiimperialistische Studierendenbewegung trat eine an Geschlechtergerechtigkeit orientierte Frauenbewegung. Die im anglo-amerikanischen Raum bis heute dominierende Konzeptualisierung von intersectionality (race, class, gender) ist das Ergebnis eines historischen Integrationsprozesses dieser sozialen Bewegungen im Rahmen eines Analysekonzepts. ${ }^{22}$

Dass die theoretischen Auseinandersetzungen der beiden zuvor skizzierten Bewegungen auch an der inhaltlichen Ausrichtung der Frauenbewegung nicht spurlos vorübergegangen sind, wurde spätestens bei der ersten UN-Weltfrauenkonferenz 1975

15 Karin Stögner, New Challenges in Feminism: Intersectionality, Critical Theory, and Anti-Zionism, in: Alvin H. Rosenfeld (Hrsg.), Anti-Zionism and Antisemitism. The Dynamics of Delegitimation. Bloomington 2018, S. 84-112. ${ }^{16}$ Martin Kloke, Antizionismus und Antisemitismus als Weltanschauung? Tendenzen im deutschen Linksradikalismus und -extremismus, in: Bundesministerium des Inneren (Hrsg.), Texte zur inneren Sicherheit. Extremismus in Deutschland. Erscheinungsformen und aktuelle Bestandsaufnahmen, Berlin 2004, S. 163-196, hier S. 170.

17 Claudia Globisch, Radikaler Antisemitismus. Inklusions- und Exklusionssemantiken von links und rechts in Deutschland, Wiesbaden 2013.

${ }^{18}$ Henry Louis Gates Jr./Evelyn Brooks Higginbotham, African American Lives, Oxford-New York 2004, S. 142.

19 Zit. n. Seymour Martin Lipset, The Socialism of Fools. The Left, the Jews, and Israel, New York 1969, S. 7.

${ }^{20}$ Frigga Haug, Perspektiven eines sozialistischen Feminismus. 20 Jahre Frauenbewegung in Westdeutschland und West-Berlin, in: Autonome Frauenbewegung (Hrsg.), Westeuropa (Frauenbewegungen in der Welt 1), Berlin 1988, S. 25-52, hier S. 27.

${ }^{21}$ Sara Salem, Intersectionality and its discontents: Intersectionality as traveling theory, in: European Journal of Women's Studies (2016), S. 1-16, hier S. 10.

${ }^{22}$ Eve Mitchell, I am a woman and a human. A Marxist feminist critique of intersectionality theory, 12.9.2013, [https://libcom.org/library/i-am-woman-human-marxist-feminist-critique-intersectionality-theory-eve-mitchell], eingesehen 9.10.2017. 
sichtbar. Durch eine Mehrheit aus kommunistischen und arabischen Staaten wurde eine Deklaration verabschiedet, die sich gegen jede Form der Unterdrückung richtet und Frauen als ,natural allies in the struggle against [...] colonialism, neocolonialism, Zionism, racial discrimination and apartheid" deklarierte. ${ }^{23}$ Dieser Passus, der später informell als „Zionism is racism resolution“ bezeichnet wurde, sollte kurze Zeit später auch von der UN-Generalversammlung in der Resolution 3379 verabschiedet werden. Bemerkenswerterweise wurde der Vorstoß von Delegierten aus Neuseeland, Sexismus ebenfalls der Aufzählung hinzuzufügen, von eben dieser Mehrheit abgelehnt. ${ }^{24}$ Gerade in Bezug auf die Weltfrauenkonferenz gilt es anzumerken, dass die Frauen, die an den offiziellen Treffen als Repräsentantinnen ihrer Regierungen teilnahmen, letztlich unter der Kontrolle männlicher Politiker in ihren Heimatländern standen. ${ }^{25}$ Es ist daher wenig überraschend, dass auch innerhalb der US-Delegation nicht alle Feministinnen mit der Gegenstimme zur „Zionism is racism resolution“ einverstanden waren. ${ }^{26}$ Vor allem Women of Color identifizierten sich zum Teil mit den Palästinenserinnen und Palästinensern, mit der Begründung, diese seien ,people of color struggling for the liberation of their homeland." 27

Nicht nur in offiziellen Delegationen wurden zu diesem Zeitpunkt die Stimmen von Women of Color überhört. Auch innerhalb der Bürgerrechtsbewegung gerieten die spezifischen Bedürfnisse und Erfahrungen schwarzer Frauen zugunsten einer möglichst großen und homogen auftretenden Interessengruppe häufig in den Hintergrund. Auf der anderen Seite fühlten sich viele schwarze Frauen auch von der damals ebenfalls an Einfluss gewinnenden zweiten Welle des Feminismus, der vorwiegend von weißen Mittelschichtsfrauen getragen wurde und in seinen Forderungen an deren Lebensrealitäten ansetzte, nicht entsprechend repräsentiert. Um sich der jeweils einseitigen Vereinnahmung einer dieser beiden sozialen Bewegungen zu entziehen, gingen schwarze Feministinnen dazu über, eigene Organisationen zu gründen. ${ }^{28}$ Das Combahee River Collective gilt als eine der bekanntesten und einflussreichsten Gruppierungen jener Zeit. Es konstituierte sich 1974 in Boston und veröffentlichte drei Jahre später das vielrezipierte „Combahee River Collective Statement“. Darin formulierte das Kollektiv seinen Anspruch „racial, sexual, heterosexual, and class oppression“ zu bekämpfen, da es davon ausging, dass , [t] $[$ he synthesis of these oppressions creates the

${ }^{23}$ UN Documents, Declaration of Mexico on the Equality of Women and their Contribution to Development and Peace, 2.7.1975, [http://www.un-documents.net/mex-dec.htm], eingesehen 8.10.2017.

${ }^{24}$ Betty Friedan, It changed my life: Writings on the Women's Movement, Cambridge, Massachusetts 1998.

${ }^{25}$ Kristen Ghodsee, Revisiting the United Nations decade for women: Brief reflections on feminism, capitalism and Cold War politics in the early years of the international women's movement, in: Women's Studies International Forum 33 (2010), S. 3-12, hier S. 5.

${ }^{26}$ Hannah Milstein, The United Nation Women's Decade and Jewish Feminist Identity, in: Ex Post Facto 25 (2016), S. 199-222.

${ }_{27}$ Barbara Smith, The Truth That Never Hurts. Writings on Race, Gender, and Freedom, New Brunswick (N.J.) 1985, S. 149.

${ }^{28}$ Patricia Hill Collins/Sirma Bilge, Intersectionality, Cambridge 2016. 
conditions of our lives“. ${ }^{29}$ Obwohl die Gruppe den Begriff intersectionality noch nicht verwendete, ist das später von Kimberlé Crenshaw ausgearbeitete Konzept bereits deutlich erkennbar.

Ende der 1980er-Jahre führte die Rechtswissenschaftlerin Kimberlé Crenshaw schließlich den Begriff intersectionality ein. ${ }^{30}$ Sie konzeptualisierte damit einen juristischen Fall, in dem eine Diskriminierung schwarzer Frauen aufgrund ihrer spezifischen Situation von der US-amerikanischen Rechtsprechung nicht erfasst werden konnte. Der Gesetzeslage lag zu diesem Zeitpunkt ein eindimensionaler Ordnungsrahmen zugrunde, basierend auf der Annahme, dass eine Person entweder aufgrund der Rasse (race) oder aufgrund des Geschlechts (gender) diskriminiert werden könne. Eine Diskriminierung aufgrund der Gleichzeitigkeit dieser beiden Kategorien war dabei konzeptionell nicht vorgesehen. Intersectionality ist eine komplexe Metapher, die darauf abzielt, genau dieses Zusammenwirken von zwei oder mehreren Unterdrückungskategorien sichtbar $\mathrm{zu}$ machen und $\mathrm{zu}$ benennen. Das Konzept baut auf der grundlegenden Erkenntnis auf, dass soziale Ungleichheit und lebensweltliche Erfahrungen durch multiple und ineinander verschränkte Achsen sozialer Einteilung geprägt sind, die zusammenwirken und sich gegenseitig beeinflussen. ${ }^{31}$

Crenshaws Überlegungen zur intersectionality besonders im Kontext US-amerikanischer Rechtsprechung, fand auch andernorts großen Zuspruch. Sara Salem spricht gar von einer neuen Phase in der Geschlechterforschung, die damit eingeleitet wurde. ${ }^{32}$ Die Übernahme und Übersetzung von intersectionality in anderen fachlichen und regionalen Gebieten wird häufig als Fall einer ,traveling theory“ genannt. ${ }^{33}$ Damit wird in Anschluss an Edward Saids Ausführungen theoretisiert, dass sich Theorien, Konzepte und Ideen im Zuge einer regionalen, zeitlichen oder fachlichen Aneignung verändern können. Said geht davon aus, dass Ideen und Theorien wandern, „,von Mensch zu Mensch, von Situation zu Situation, von einer Epoche zur anderen“.34 Im Zuge dieser Wanderung können sich diese Ideen verändern, denn der Übergang geschieht nie reibungslos. Häufig diskutiert wurde die Veränderung von intersectionality im Zuge der Übernahme im deutschsprachigen Kontext etwa in Bezug auf die angemessene Bezeichnung der Kategorie „race“.

29 Text abrufbar über die Webseite der Yale University: The Combahee River Collective Statement, o. D. [https://americanstudies.yale.edu/sites/default/files/files/Keyword\%20Coalition_Readings.pdf], eingesehen 2.10.2017.

30 Kimberlé Crenshaw, Demarginalizing the Intersection of Race and Sex: A Black Feminist Critique of Antidiscrimination Doctrine, Feminist Theory and Antiracist Politics, in: University of Chicago Legal Forum 1 (1989), S. 139-167.

31 Collins/Bilge, Intersectionality, S. 2.

32 Salem, Intersectionality.

${ }^{33}$ Gudrun-Axeli Knapp, Race, Class, Gender. Reclaiming Baggage in Fast Traveling Theories, in: European Journal of Women's Studies 12 (2005), Heft 3, S. 249-265; Chebout, Wo ist Intersectionality; Salem, Intersectionality.

${ }^{34}$ Said, Theorien, S. 263. 
Nachdem bislang die Gegebenheiten am Ursprungsort des Konzeptes behandelt wurden, wird im Folgenden nun - entsprechend Saids Anspruch eines historischen Ansatzes zur Erklärung der Genese und Transformation von Konzepten - der geschichtliche Kontext im deutschsprachigen Raum skizziert.

\section{Historischer Kontext im deutschsprachigen Raum}

Auschwitz - als Symbol für die nationalsozialistische Judenvernichtung - markiert eine „Epochenscheide der Antisemitismusgeschichte“. ${ }^{35}$ Vor allem die Nachfolgestaaten des Nationalsozialismus sahen sich mit der Notwendigkeit konfrontiert, den Antisemitismus öffentlich zu ächten, sich von ihm zu distanzieren und ihr Verhältnis zu Jüdinnen und Juden neu zu ordnen. ${ }^{36}$ Dass die Tabuisierung in der politischen Kultur nicht auch zu einem radikalen Wandel tiefsitzender Einstellungsmuster führte, belegt unter anderem das 1954 veröffentlichte „Gruppenexperiment“ des kurz zuvor wiedereröffneten Frankfurter Instituts für Sozialforschung. Die Studie legte den insbesondere unter Akademikerinnen und Akademikern immer noch weit verbreiteten Antisemitismus offen und folgerte, „daß zwar die nationalsozialistische Ideologie als einheitlich organisierter Zusammenhang nicht mehr existiert, [...] daß aber zahlreiche Einzelelemente des faschistischen Denkens [...] noch gegenwärtig sind “. ${ }^{37}$ Vor dem Hintergrund solcher Befunde ist es wohl kein Zufall, dass die Vertreterinnen und Vertreter der Kritischen Theorie zu den vehementesten Unterstützerinnen und Unterstützern eines souveränen jüdischen Staates zählten. ${ }^{38}$

Die Erfahrung der Shoah und der anhaltende Antisemitismus in weiten Teilen Europas bestärkten Sympathien in der öffentlichen Wahrnehmung für die Notwendigkeit dieses Staates. Nach der Staatsgründung konnte ein Rückgang des Antisemitismus in westeuropäischen Ländern verzeichnet werden. Bedingt unter anderem durch den Eichmann-Prozess, der Veröffentlichung des Tagebuchs der Anne Frank und historischen Forschungen, rückten - vor allem in der Bundesrepublik Deutschland - die eigene Mitschuld und die jüdischen Opfer der Shoah langsam in die Medienberichterstattung und ins öffentliche Bewusstsein. ${ }^{39}$ Zentrales Moment der öffentlichen Aufarbeitung in Deutschland stellte die 68er Bewegung und ihre Kritik an der Nichtauseinandersetzung der postnazistischen Gesellschaften mit den NSVerbrechen dar.

${ }^{35}$ Herbert A. Strauss, Der Holocaust als Epochenscheide der Antisemitismusgeschichte: historische Diskontinuitäten, in: Werner Bergmann/Rainer Erb (Hrsg.), Antisemitismus in der politischen Kultur nach 1945, Opladen 1990, S. 38-56.

${ }^{36}$ Globisch, Radikaler Antisemitismus.

${ }^{37}$ Friedrich Pollock, Gruppenexperiment. Ein Studienbericht, Frankfurt a. M. 1955, S. 397.

38 Stögner, A Critical Theory.

39 Werner Bergmann, Geschichte des Antisemitismus, Beck 42010. 
Verstärkt durch das anfängliche sozialistische Selbstverständnis des jüdischen Staates, solidarisierte sich ein Teil der Linken (auch der Studierendenbewegung) mit Israel, dessen „Existenz der stärkste Beleg für die Verbrechen von Nationalsozialismus und Faschismus war" ${ }^{\prime 40}$. Die von linken Studierenden in Israel gesetzte Hoffnung wurde mit dessen zunehmender Integration in die kapitalistische Weltwirtschaft allerdings enttäuscht und die Sympathien begannen zu schwinden. ${ }^{41}$ Einen „Vertrauensverlust“ hatte Israel in Teilen der Linken schon Mitte der 1950er-Jahre erlitten, als sich der junge Staat an der Seite der Kolonialmächte Großbritannien und Frankreich am Suezkrieg beteiligte.

In dieser Phase internationaler linker Theoriebildung, in der „sozialistische Befreiungsbewegungen" als antiimperialistische Speerspitzen einer globalen Revolution angesehen wurden, unternahm Israel Anfang Juni 1967 einen erfolgreichen Präventivschlag gegen die militärischen Provokationen und Drohgebärden des - von der Sowjetunion unterstützten und ausgerüsteten - ägyptischen Militärs. ${ }^{42}$ Durch seine Allianz mit den Kolonialmächten Frankreich und Großbritannien im Suezkrieg und der Solidarisierung der USA im Zuge des Sechstagekrieges konnte Israel im dichotomen Denken der 68er nicht länger als unterdrücktes und subalternes Kollektiv firmieren. Israel wurde ab diesem Zeitpunkt als imperialistischer Aggressor identifiziert, mit sehr realen Folgen auch für die noch im Westen lebenden Jüdinnen und Juden. Ganz im Sinne der ,politische[n] und organisatorische[n] Zusammenarbeit zwischen den revolutionären Befreiungsbewegungen in der Dritten Welt und den Widerstandsbewegungen in den USA und in den westeuropäischen Ländern" wurden unter anderem Vorträge gestört und jüdische Einrichtungen angegriffen. ${ }^{43}$

Dieser Wandel in der Einstellung gegenüber Israel hatte auch Auswirkungen in der neuen Frauenbewegung. Denn obwohl diese nicht unmittelbar aus den 68ern heraus entstand, können personelle und normativ-ideelle Überschneidungen und Rückgriffe auf bewährte Aktions- und Organisationsformen ausgemacht werden. ${ }^{44}$

Noch während der Hochphase der 68er war das Verhältnis der eigenen Organisationen zu den darin tätigen Frauen widersprüchlich. Das stets betonte Emanzipationsinteresse reduzierte die Interessen der Frauen auf einen Nebenwiderspruch und reproduzierte beständig tradierte Geschlechterrollen. Frauen konnten sich in Debatten kaum Gehör verschaffen und waren vor allem für administrative Aufgaben - wie Kaffee kochen,

40 Anton Pelinka, Israel. Ausnahme- oder Normalstaat, Wien 2015, S. 151.

41 Ebd.

42 Timo Stein, Zwischen Antisemitismus und Israelkritik. Antizionismus in der deutschen Linken, Wiesbaden 2011.

43 Infopartisan, Die Schlußerklärung der Internationalen Vietnam-Konferenz, o. D., [http://www.infopartisan.net/archive/1967/266763.html], eingesehen 5.10.2017.

44 Kristina Schulz, Wende im Geschlechterverhältnis? Feminismus und Frauenbewegung, in: Jens Kastner/David Mayer (Hrsg.), Weltwende 1968? Ein Jahr aus globalgeschichtlicher Perspektive (Globalgeschichte und Entwicklungspolitik 7), Wien 2008, S. 38-53, hier S. 49. 
Flugblätter abtippen und dergleichen - zuständig. Um die Interessen der Frauen vermehrt in den Fokus zu rücken, bildeten sich deshalb eigene Frauenorganisationen. ${ }^{45}$ Die europäische Frauenbewegung der 1970er-Jahre war maßgeblich durch den USamerikanischen Diskurs beeinflusst. Schlüsselkonzepte aus den USA, wie die Patriarchatsanalysen von Kate Millett, haben die „kognitive Orientierung des europäischen Feminismus“ wesentlich geprägt. ${ }^{46}$ Interdependenztheorien, ähnlich zur Intersektionalität, waren allerdings auch im deutschsprachigen Raum nichts gänzlich Neues. Katharina Walgenbach führt mit Clara Zetkin und Mathilde Vaerting zwei einflussreiche, deutschsprachige Denkerinnen an, die sich bereits in den 1920er-Jahren mit den Zusammenhängen von Klasse und Geschlecht auseinandersetzten. ${ }^{47}$ Des Weiteren skizziert sie die Perspektive jüdischer Frauen auf den feministischen Diskurs im deutschsprachigen Raum. Cathy Gelbin beschreibt diesbezüglich sowohl die gemeinsame „Erfahrung einer diskursiven Ausgrenzung auch im Kontext der deutschen Frauenbewegung" migrantischer, schwarzer und jüdischer Frauen, als auch die Konflikte unter eben diesen Gruppen. ${ }^{48}$ So weist sie auch darauf hin, dass jüdische Themen verworfen wurden, da sie im multikulturalistischen Diskurs als $\mathrm{zu}$ dominant wahrgenommen wurden. Jüdinnen wurden als „weiß“ markiert und damit als Teil der Mehrheitsgesellschaft ausgemacht. Diese scheinbare nicht-Subalternität hing nach Gelbin mit der sichtbaren Repräsentation jüdischer Themenbereiche in Form einer aktiven Erinnerungskultur zusammen, während paradoxerweise doch gerade diese Form der Repräsentation zu einer ,,verdrängte[n] Wahrnehmung einer jüdischen Gegenwart im Nachkriegsdeutschland“ führte. ${ }^{49}$

Maria Baader beschrieb in den 1990er-Jahren ihr „Unbehagen am Nachkriegsdeutschland“, das auch mit dem Fehlen jüdischer Feministinnen in der Öffentlichkeit zusammenhing. Dieser Mangel führte 1984 in Berlin auch zur Konstituierung des sogenannten „Schabbeskreis“. ${ }^{50}$ Der Kreis bestand aus einem Zusammenschluss jüdischer und nicht-jüdischer, migrantischer und nicht-migrantischer Frauen, die sich „für jüdische Themen und gegen Antisemitismus engagieren wollten“. 51 Ein Anliegen, das in der deutschen Frauenbewegung auch auf Widerstand stieß. Als (vermeintliche)

${ }^{45}$ Haug, Perspektiven, S. 27.

46 Schulz, Wende, S. 41.

${ }^{47}$ Katharina Walgenbach, Gender als interdependente Kategorie, in: Katharina Walgenbach u. a. (Hrsg.), Gender als interdependente Kategorie. Neue Perspektiven auf Intersektionalität, Diversity und Homogenität, Opladen 2007, S. 23-64.

${ }^{48}$ Cathy S. Gelbin, Die jüdische Thematik im (multi)kulturellen Diskurs der Bundesrepublik, in: Cathy S. Gelbin u. a. (Hrsg.), AufBrüche. Kulturelle Produktion von Migrantinnen, Schwarzen und jüdischen Frauen in Deutschland, Taunus 1999, S. 87-111, hier S. 87f.

49 Ebd., S. 91.

${ }^{50}$ Maria Baader, Zum Abschied. Über den Versuch als jüdische Feministin in der Berliner Frauenszene einen Platz zu finden, in: Ika Hügel u. a. (Hrsg.), Entfernte Verbindungen. Rassismus, Antisemitismus, Klassenunterdrückung, Berlin 21999, S. 82-94.

${ }^{51}$ Gelbin, Die jüdische Thematik, S. 97. 
Jüdinnen, so berichtet Baader, reichte „[d]er Name unserer Gruppe im Programmheft“52, um Anfeindungen ausgesetzt zu werden und zudem als Projektionsfläche für den Hass gegen den jüdischen Staat zu dienen: „Wollten wir etwa die Berührungspunkte zwischen neuen Mütterlichkeitsidealen und antisemitischen Weltbildern aufzeigen, so wurden wir zu unserer Haltung bezüglich der israelischen Politik in den besetzten Gebieten befragt. “53 Zumindest in dieser Zeit konnten jüdische Aktivistinnen somit ausschließlich als Frau, ohne eine betont jüdische Identität, in der Frauenbewegung aktiv sein oder aber sie drohten - im anderen Fall - als Jüdin zur Projektionsfläche eines israelbezogenen Antisemitismus zu werden. ${ }^{54}$ Diese Konflikte führten schließlich zu einem Rückzug jüdischer Feministinnen aus multikulturalistischen Zusammenhängen. ${ }^{55}$ Charlotte KohnLey brachte dies folgendermaßen auf den Punkt: „Es ist für eine jüdische Frau unmöglich, sich ohne Selbstverleugnung feministischen Gruppierungen in Deutschland und Österreich anzuschließen“. ${ }^{6}$ Die bereits zuvor wenig erfolgreichen Bemühungen „eine konkrete Analyse des Antisemitismus als spezifische Unterdrückungsform einzufordern" 57 und in Folge die Betrachtung ihrer Intersektion mit anderen Herrschaftsverhältnissen, kamen damit zum Erliegen.

\section{(Dis)Kontinuität von Antisemitismus in postnazistischen Gesellschaften}

„Nicht einmal der Bruch der Zivilisation, die Realisierung des Antisemitismus in der nationalsozialistischen Judenvernichtung konnte - nicht im Land der Täter - die Kontinuität des Antisemitismus durchbrechen. Der gegenwärtige Antisemitismus ist trotz mannigfaltiger Modifikationen strukturell gleich dem Antisemitismus, der in die Vernichtung der Juden führte“, stellte Klaus Holz Mitte der 1990er fest. ${ }^{58}$ Dass Antisemitismus im deutschsprachigen Raum nach wie vor alltägliche Wirklichkeit ist, das bestätigen unter anderem die jährlich erscheinenden Berichte der Recherche- und Informationsstelle Antisemitismus (RIAS) in Berlin. RIAS registrierte im Jahr 2017 alleine in Berlin 947 antisemitische Vorfälle. ${ }^{59}$ Auch die öffentliche Debatte um die Verbreitung von Antisemitismus im deutschsprachigen Rap, ausgelöst durch die

52 Baader, Zum Abschied, S. 85.

${ }^{53}$ Ebd., S. 86.

54 Ebd.

55 Gelbin, Die jüdische Thematik.

${ }^{56}$ Charlotte Kohn-Ley, Antisemitische Mütter - Antizionistische Töchter?, in: Charlotte Kohn-Ley/Ilse Korotin (Hrsg.), Der feministische „Sündenfall“? Antisemitische Vorurteile in der Frauenbewegung, Wien 1994, S. 209-230, hier S. 229.

57 Gelbin, Die jüdische Thematik, S. 98

58 Klaus Holz, Antisemitismus als Ideologie? Zur Struktur des antisemitischen Selbst- und Gesellschaftsbildes, in: Hansjörg Bay/Christoph Hamann (Hrsg.), Ideologie nach ihrem ,Ende‘. Gesellschaftskritik zwischen Marxismus und Postmoderne, Opladen 1995, S. 149-164, hier S. 151.

${ }_{59}$ Recherche- und Informationsstelle Antisemitismus Berlin, Antisemitische Vorfälle 2017, 2018, [https://reportantisemitism.de/media/bericht-antisemitischer-vorfaelle-2017.pdf], eingesehen 7.5.2019. 
Verleihung des Musikpreises Echo an die Rapper Kollegah und Farid Bang im April 2018, führt vor Augen, dass Antisemitismus weder überwunden, noch das alleinige Problem von isolierten rechtsextremen Gruppierungen ist. Auch im politisch linken Spektrum ist Antisemitismus, etwa in Form einer regressiven Kapitalismuskritik, keineswegs erledigt. ${ }^{60}$ Vielmehr lassen sich antisemitische Einstellungsmuster, wie die Leipziger Mitte-Studien belegen, quer durch alle gesellschaftlichen Schichten und Milieus beobachten. ${ }^{61}$ An öffentlicher Aufmerksam nimmt neuerdings, im Windschatten des langen Sommers der Migration, die Debatte um die Spezifik und Ausprägung eines womöglich „importierten“ Antisemitismus zu. Dieser vermeintliche „neue Antisemitismus der Anderen“62 stellt eine Engführung der Debatte auf den Antisemitismus von Migrantinnen und Migranten dar und ist als Ausdruck einer Externalisierungs-strategie zu verstehen.

\section{Intersektion mit anderen gesellschaftlichen Machtverhältnissen}

Im Folgenden soll ein Überblick über die - in ihrer Anzahl überschaubaren - Ansätze zur Integration von Antisemitismus in intersektionale Betrachtungen gegeben werden. Die bislang intensivste Auseinandersetzung hierzu fand in der Analyse des Zusammenspiels mit Geschlecht statt. Beginnend mit der Auseinandersetzung um die (Mit-)Täterinnenschaft von Frauen während des Nationalsozialismus wurden unter anderem die Spezifika von Frauen als Antisemitinnen ${ }^{63}$, Frauen als „Opfer“ aufgrund ihres Jüdisch-seins ${ }^{64}$ und geschlechterreflektierte Formen der Antisemitismusprävention $^{65}$ in den Blick genommen. „Die verschiedenen historischen und gegenwärtigen Erscheinungsformen des Antisemitismus“, argumentiert Heike Radvan, „waren und sind immer auch vergeschlechtlicht." 66

Eine weitere Überkreuzung, die eher implizit thematisiert wird, ist jene mit kapitalistischen Ausbeutungsverhältnissen. Dieses Verhältnis scheint von Grund auf intersektional zu sein: „Der bürgerliche Antisemitismus hat einen spezifischen ökonomischen Grund: die Verkleidung der Herrschaft in Produktion“. ${ }^{67}$ Jüdinnen und

60 Globisch, Radikaler Antisemitismus.

${ }^{61}$ Oliver Decker/Johannes Kiess/Elmar Brähler, Die enthemmte Mitte. Autoritäre und rechtsextreme Einstellungen in Deutschland, Gießen ${ }^{2} 2016$.

${ }^{62}$ Sina Arnold, Der neue Antisemitismus der Anderen? Islam, Migration und Flucht, in: Christian Heilbronn/Doron Rabinovici/Nathan Sznaider, Neuer Antisemitismus? Fortsetzung einer globalen Debatte, Berlin 2019, S. 128-158.

${ }^{63}$ Ljiljana Radonić, Die friedfertige Antisemitin? Kritische Theorie über Geschlechterverhältnisse und Antisemitismus, Frankfurt a. M. 2004.

${ }^{64}$ Jessica Jacobi/Lwanga Gotlinde Magiriba, Was „sie“ schon immer über Antisemitismus wissen wollten, aber nie zu denken wagten, in: Beiträge zur feministischen Theorie und Praxis (1990), Heft 211, S. 95-105.

65 Heike Radvan, Antisemitismus und Geschlecht. Überlegungen hinsichtlich einer geschlechterreflektierten Prävention, in: Jahrbuch für Antisemitismusforschung 22 (2013), S. 123-142.

${ }^{66}$ Ebd., S. 126.

${ }^{67}$ Max Horkheimer/Theodor W. Adorno, Elemente des Antisemitismus. Grenzen der Aufklärung, in: Helmut König 
Juden sind - verallgemeinert gesprochen - in der aktuellen Phase des Kapitalismus im deutschsprachigen Raum nicht strukturell, das heißt ökonomisch-institutionell ausgegrenzt ${ }^{68}$, wie dies etwa bei schwarzen Frauen in den USA der Fall ist. Allerdings dienen sie als Projektionsfläche eben jener ökonomisch-institutionellen Ausgrenzung, wie sie in Zuschreibungen wie „Spekulanten“, „Heuschrecken“ und „Machtelite“ deutlich werden. Die Verschränkung von Kapitalismus - bzw. dessen inhärenter Krisendynamik - und Antisemitismus wird insbesondere dadurch evident, dass der Antisemitismus seit dem ausgehenden 19. Jahrhundert immer dann an Brisanz gewann, „,wenn der Börsenkurs fiel““ ${ }^{69}$

Mit ihrer Arbeit zur „Intersektionalität von Ideologien“ legte Karin Stögner vor Kurzem ein Intersektionalitätskonzept vor, das den Antisemitismus als Analysekategorie zentral integriert. ${ }^{70}$ Stögner positioniert Antisemitismus dabei als eine Art Masterkategorie. Sie spricht von Antisemitismus als die, intersektionale Ideologie schlechthin, indem sie sichtbar macht, dass die Wirkmächtigkeit des Antisemitismus als verquere Welterklärung auch von seiner Durchdringung durch andere Ideologien wie Sexismus, Rassismus und Nationalismus herrührt“. ${ }^{71}$ Ein derartiger Anspruch einer Art „Masterkategorie“ findet sich allerdings auch in anderen Disziplinen, etwa in den Disability Studies, und führt nach Gudrun-Axeli Knapp zu keinen produktiven Auseinandersetzungen: „Eine bestimmte Auswahl der in Betracht zu ziehenden Verhältnisse in einer Konstellation [...] lässt sich nicht allgemein und normativ setzen, sondern nur materialiter und immer nur in je bestimmten Hinsichten". 72

Klaus Holz beschreibt Antisemitismus als ein „ideologisches Bewußtsein“"73 über die „Gesellschaft und sich selbst“, stets bedingt durch „die derzeitige Gesellschaftsform“. ${ }^{74}$ Der Antisemitismus erfüllt dabei die Funktion, mittels Projektionen ,sich die Welt zu erklären oder um Erklärungsmuster für die eigenen Marginalisierungserfahrungen zu finden, die es erlauben, sich nicht mit sich selbst auseinandersetzen zu müssen“. ${ }^{75}$ Derartige Marginalisierungserfahrungen werden zwar auf der individuellen Ebene erfahren, können in ihren Auswirkungen und (antisemitischen) Artikulationsformen aber

(Hrsg.), Elemente des Antisemitismus. Kommentare und Interpretationen zu einem Kapitel der Dialektik der Aufklärung von Max Horkheimer und Theodor W. Adorno, Weilerswist 2016, S. 21-52, hier S. 26.

68 Gelbin, Die jüdische Thematik.

69 Zit. n. Jan Weyand, Das Konzept der Kommunikationslatenz und der Fortschritt in der soziologischen Antisemitismusforschung, in: Jabrbuch für Antisemitismusforschung 26 (2017), S. 36-58, hier 39.

${ }^{70}$ Karin Stögner, Intersektionalität von Ideologien - Antisemitismus, Sexismus und das Verhältnis von Gesellschaft und Natur, in: Psychologie \& Gesellschaftskritik 41 (2017), Heft 2, S. 25-45.

${ }^{71}$ Ebd., S. 25.

${ }^{72}$ Gudrun-Axeli Knapp, Von Herkünften, Suchbewegungen und Sackgassen: Ein Abschlusskommentar, in: Sabine Hess/Nikola Langreiter/Elisabeth Timm (Hrsg.), Intersektionalität revisited. Empirische, theoretische und methodische Erkundungen, Bielefeld 2011, S. 249-272, hier S. 267.6

${ }^{73}$ Holz, Antisemitismus.

74 Ebd., S. 164.

75 Astrid Messerschmidt, Antisemitismuskritik im Kontext migrationsgesellschaftlicher und geschlechterreflektierter Bildung, in: Jabrbuch für Antisemitismusforschung 22 (2013), S. 99-122, hier S. 108. 
nur auf einer Makro-Ebene adäquat analysiert werden und letztlich zeigen „how these categories are created, how they exploit and not simply oppress, and why they intersect". ${ }^{76}$ In diesem Sinne ist auch die antisemitismuskritische Bildungsarbeit, die bei der eigenen Diskriminierungserfahrung ansetzt - wie sie unter anderem von Astrid Messerschmidt eingefordert wird ${ }^{77}$-, lediglich als eine Form der Symptombehandlung zu verstehen, da sie die gesellschaftlichen Verhältnisse, welche den modernen Antisemitismus hervorbringen, unangetastet lassen.

Auch gegenwärtige Formen der Rassifizierung sind Produkt zeitgenössischer Gesellschaftsformen. Volkhard Mosler bezeichnet Rassismus als „eine ,von oben“ konstruierte Ideologie, ein Beispiel dafür, dass, wie Marx und Engels es formulierten, die ,Gedanken der herrschenden Klasse [...] in jeder Epoche die herrschenden Gedanken sind““. ${ }^{78}$ Wie Silvia Federici in ihrem Buch „Caliban und die Hexe“ nachzeichnet, dient auch der Rassismus als bürgerliche Ideologie der Aufrechterhaltung der bestehenden Verhältnisse. ${ }^{79}$ Die Auffassung von intersektionalen Verhältnissen als Ideologien, wie von Stögner vorgeschlagen, eröffnet die Möglichkeit der Analyse und Kritik gesellschaftlicher Verhältnisse, die rassistische, sexistische und antisemitische Vorstellungen immer wieder auf das Neue aus sich selbst hervorbringt, und die zu deren Stabilisierung beständig beitragen. Gerade auch die Überkreuzungen dieser Weltbilder können auf diese Weise treffend erfasst werden.

\section{Zusammenfassung}

Dieser Beitrag ging der Frage nach, warum Antisemitismus bis heute lediglich eine marginale Rolle in den Debatten zur Intersektionalität spielt. Nach Said schreiben Forschende „,sowohl für eine Situation als auch in einer Situation“. ${ }^{80}$ Wie gezeigt wurde, sind zentrale Unterschiede zwischen den USA und dem deutschsprachigen Raum zu verzeichnen: vor allem hinsichtlich historischer Entwicklungen und (Dis)Kontinuitäten der gesellschaftlichen Verhältnisse, zu deren Kritik das Konzept der intersectionality/ Intersektionalität entwickelt wurde und in die dieses eingebettet war.

Ausgehend von Edward Saids Konzeption einer „traveling theory“ und der Annahme, dass ein ,zentraler Bezug auf ein in der Vergangenheit lokalisiertes Ereignis als bestimmend für die Identität ${ }^{\text {"81 }}$ wirkt, wurde nachgezeichnet, warum am Ursprungsort von intersectionality Antisemitismus kein zentraler Bestandteil der einschlägigen

${ }^{76}$ Salem, Intersectionality, S. 6.

${ }_{77}$ Messerschmidt, Antisemitismuskritik.

78 Volkhard Mosler, Rassismus im Wandel. Vom Sozialdarwinismus zum Kampf der Kulturen, in: theorie21 2 (2012),

S. 19-52, hier S. 20.

${ }^{79}$ Silvia Federici, Caliban und die Hexe. Frauen, der Körper und die ursprüngliche Akkumulation, Wien 2012.

80 Said, Theorien, S. 277.

81 Gelbin, Die jüdische Thematik, S. 94. 
Debatten war. Der historische Bezugspunkt am Entstehungsort des Konzeptes war die im Nachhall der Sklaverei begründete Bürgerrechtsbewegung und eine von der Studierendenbewegung mitgeprägte Frauenbewegung. Aus dem Konflikt mit diesen beiden Bewegungen begannen schwarze Frauen, sich selbständig zu organisieren und auf ihre spezifischen Erfahrungen und Benachteiligungen aufmerksam $\mathrm{zu}$ machen. Benachteiligungen, die sich auch juristisch bemerkbar machten, und die Kimberlé Crenshaw anhand von intersectionality in der bis heute dominierenden Trias race, class und gender ausarbeitete.

Entsprechend Saids Argumentation wurde auch der historische Kontext der neuen Umgebung skizziert. Im deutschsprachigen Raum charakterisierten die nationalsozialistische Vergangenheit und die Shoah die Auseinandersetzungen der 68erund der Frauenbewegung und führte paradoxerweise gerade deshalb lange Zeit zur Ausblendung von Antisemitismus als Unterdrückungsform und zu dessen fehlender Integration in das Analysekonzept Intersektionalität. 


\title{
Israelfeindschaft und Antisemitismus bei Hamas, Al-Qaida und Islamischem Staat
}

\author{
Michel Wyss
}

Während seiner Rede auf der jährlichen UN-Generalversammlung Ende September 2014 sorgte der israelische Ministerpräsident Benjamin Netanjahu für Aufregung. Nur wenigen Wochen nach Ende des jüngsten Waffengangs zwischen Israel und der Hamas in Gaza und einige Monate nachdem der Islamische Staat Mossul und weite Teil des Iraks unter seine Kontrolle gebracht hatte, erklärte Netanjahu vor versammelter Weltöffentlichkeit:

„Last week, many of the countries represented here rightly applauded President Obama for leading the effort to confront ISIS, and yet weeks before, some of these same countries, the same countries that now support confronting ISIS, opposed Israel for confronting Hamas. They evidently don't understand that ISIS and Hamas are branches of the same poisonous tree. [...] So when it comes to their ultimate goals, Hamas is ISIS and ISIS is Hamas. And what they share in common, all militant Islamists share in common. Boko Haram in Nigeria, Al-Shabab in Somalia, Hezbollah in Lebanon, AlNusra in Syria, the Mahdi army in Iraq, and the Al-Qaida branches in Yemen, Libya, the Philippines, India and elsewhere. “1

Bereits vor dem UN-Gipfel hatten Netanjahu und das israelische Außenministerium die Kernbotschaft „Hamas ist ISIS und ISIS ist Hamas“ sowohl in den sozialen Medien als auch bei öffentlichen Auftritten lanciert und beispielsweise die Massenermordung schiitisch-irakischer Soldaten im Camp Speicher bei Tikrit durch den Islamischen Staat mit der Tötung von vermeintlichen Kollaborateuren in Gaza durch die Hamas verglichen. ${ }^{2}$ Während seine Regierungskoalition applaudierte, wurde Netanjahus Gleichsetzung von verschiedenen Seiten vehement kritisiert. ${ }^{3}$ Einer der gängigen Vorwürfe lautete, Netanjahu wolle politisch punkten und würde die Gräueltaten des Islamischen Staates auf Kosten der Hamas instrumentalisieren. Die Hamas wiederum

1 Transcript of Benjamin Netanyahu's Address to the 2014 UN General Assembly, in: Haaretz, 29.9.2014, [http://www.haaretz.com/israel-news/1.618308], eingesehen 13.8.2017.

2 Yoni Kempinski/Gil Ronen, Netanyahu: Hamas is ISIS, ISIS is Hamas, in: Arutz. Sheva, 21.8.2014, [http://www.israelnationalnews.com/News/News.aspx/184288], eingesehen 13.8.2017; Israel's Foreign Affairs Min., Hamas is ISIS - ISIS is Hamas, in: YouTube, 25.8.2014, [https://youtu.be/Eza9OtoH60A], eingesehen 13.8.2017.

3 Washington rejects Netanyahu's comparison of Iran and Hamas to ISIS, in: Middle East Monitor, 30.9.2014, [https://www.middleeastmonitor.com/20140930-washington-rejects-netanyahus-comparison-of-iran-and-hamas-toisis/], eingesehen 13.8.2014; Yossi Mekelberg, No Mr. Netanyahu, Hamas is not ISIS, in: Al-Arabiya, 17.9.2014, [https://english.alarabiya.net/en/views/news/middle-east/2014/09/17/No-Mr-Netanyahu-Hamas-is-not-

ISIS.html], eingesehen 13.8.2017; Max Fisher, Hamas isn't ISIS. Here's why Netanyahu says it anyway, in: Vox, 25.8.2014, [https://www.vox.com/2014/8/25/6064467/no-netanyahu-hamas-is-not-isis-isis-is-not-hamas], eingesehen 13.8.2017. 
protestierte ebenfalls energisch und Politbüro-Chef Khaled Meshaal ließ in einem Interview mit Yahoo News verlauten, dass die de facto Machthaberin in Gaza keine gewalttätige religiöse Organisation sei. ${ }^{4}$ Bis auf einige wenige Ausnahmen, machten sich Netanjahus Kritiker und Kritikerinnen allerdings nicht die Mühe, sich inhaltlich mit seiner These auseinanderzusetzen und zu erörtern, ob und inwiefern Hamas, der Islamische Staat und weitere dschihadistische Organisation miteinander gleichzusetzen seien. ${ }^{5}$ Ziel dieses Beitrags ist es deshalb, mittels einer vergleichenden Fallstudie sowohl Gemeinsamkeiten als auch Gegensätze zwischen Hamas und Islamischem Staat herauszuarbeiten. Neben Hamas und Islamischem Staat wird die Fallstudie mit Al-Qaida auch die Mutterorganisation der Globalen Dschihad-Bewegung einbeziehen, da sie mit den beiden erstgenannten Organisationen langjährige, komplexe Beziehungen aufweist, welche permanent zwischen Kooperation und Konkurrenz pendeln. Aus Gründen der Vergleichbarkeit fokussiert die Studie damit ausschließlich auf sunnitischdschihadistische Gruppierungen und berücksichtigt keine schiitischen Organisationen wie Hezbollah oder Mahdi-Armee, welche zweifelsohne einer separaten Betrachtung wert wären. Im Einklang mit dem thematischen Schwerpunkt dieses Sammelbands legt die Fallstudie ein besonderes Augenmerk auf die Bedeutung von Antisemitismus und Antizionismus für Hamas, Al-Qaida und Islamischen Staat. Dieser Fokus bietet sich aus mehreren Gründen an. Zum einen sind Juden- und Israelfeindschaft zweifelsohne ein zentrales Element islamistischer und dschihadistischer Ideologie. ${ }^{6}$ Zum anderen eignet sich diese Schwerpunktsetzung besonders gut, um einige der grundsätzlichen Unterschiede zwischen Hamas, Al-Qaida und Islamischem Staat anhand zweier spezifischer Merkmale zu illustrieren. Wie sich im Folgenden zeigen wird, ist die Forschungsfrage, ob und inwiefern Hamas, Al-Qaida und Islamischer Staat miteinander gleichzusetzen sind, weniger eindeutig zu beantworten als sich dies Gegner wie Befürworter von Netanjahus „ISIS ist Hamas, Hamas ist ISIS“-These wünschen würden. Zum Zweck dieses Beitrags wird Antisemitismus als „Feindschaft gegen Juden als Juden“ definiert. $^{7}$ Antizionismus wiederum ist ,the denial of the right of Jews to be part of a worldwide community or to constitute an independent political unit in Israel" ${ }^{\text {" }}$, beziehungsweise, in den Worten von Shlomo Avineri, ,a fundamental refusal to accept the legitimacy of Israel“"?

\footnotetext{
${ }^{4}$ Michael Isikoff, Hamas leader: Don't compare us to ISIL, in: Yaboo News, 22.8.2014, [https://www.yahoo.com/news/hamas-leader--don-t-compare-us-to-isil-193125056.html], eingesehen 13.8.2017. ${ }_{5}$ Eine der wenigen fundierten Auseinandersetzungen fand sich in der Times of Israel: Lazar Berman, Is Hamas Really ISIS, in: The Times of Israel, 27.8.2014, [http://www.timesofisrael.com/is-hamas-really-isis/], eingesehen 14.8.2017.

6 Bassam Tibi, Religion, Prejudice and Annihilation. The Case of Traditional Islamic Judeophobia and Its Transformation into the Modern Islamist Antisemitism, in: Anthony McElligott/Jeffrey Herf (Hrsg.), Antisemitism Before and Since the Holocaust. Altered Contexts and Recent Perspectives, Cham 2017, S. 115-145.

${ }^{7}$ Armin Pfahl-Traughber, Antisemitismus als Feindschaft gegen Juden als Juden, in: Der Bürger im Staat 63 (2013), Heft 4, S. 252-261.

8 Yehuda Bauer, Antisemitism and Anti-Zionism - New and Old, in: Robert S. Wistrich (Hrsg.), Anti-Zionism and Antisemitism in the Contemporary World, London 1990, S. 195-207, hier S. 198-199.

${ }^{9}$ Shlomo Avineri, Western Anti-Zionism. The Middle Ground, in: Robert S. Wistrich (Hrsg.), Anti-Zionism and
} 
Mittlerweile gibt es eine Reihe an ausführlichen Studien zu Hamas, Al-Qaida und insbesondere dem Islamischen Staat, sowohl auf Deutsch als auch Englisch. ${ }^{10}$ Vergleichende Fallstudien zu den drei Organisationen sind aber selten zu finden, insbesondere nicht auf Deutsch. ${ }^{11}$ Auch gibt es kaum Arbeiten zum Thema, die explizit auf die Bedeutung von Antisemitismus und Antizionismus für die jeweilige Gruppierung fokussieren, insbesondere nicht bei Al-Qaida und dem Islamischen Staat. ${ }^{12}$

Dieser Beitrag ist in fünf Abschnitte unterteilt. Der erste Abschnitt zeichnet in aller Kürze die Entwicklung des politischen Islam seit Ende des 19. Jahrhunderts bis zur Entstehung der Globalen Dschihad-Bewegung in den 1980er-Jahren nach. Die folgenden Abschnitte sind den eigentlichen Fallstudien von Antizionismus und Antisemitismus bei Hamas, Al-Qaida und dem Islamischen Staat gewidmet (in dieser Reihenfolge). Die Fallstudien beginnen mit einem kurzen historischen Überblick der jeweiligen Organisation und fokussieren danach auf die Bedeutung von Antizionismus und Antisemitismus für die entsprechende Gruppierung, sowohl für deren Ideologie als auch bezüglich konkreten israelfeindlichen oder antisemitisch motivierten Aktivitäten (die von Rhetorik und Propaganda bis zu Terroranschlägen und Guerillakriegsführung reichen). Der Beitrag schließt mit einem Vergleich und abschließenden Überlegungen.

Antisemitism in the Contemporary World, London 1990, S. 171-177, hier S. 171.

${ }_{10}$ Joseph Croituru, Hamas. Der Islamische Kampf um Palästina, München 2007; Matthew Levitt, Hamas. Politics, Charity, and Terrorism in the Service of Jihad, New Haven 2006; Peter Wichmann, Al-Qaida und der Globale Djihad. Eine vergleichende Betrachtung des transnationalen Terrorismus, Wiesbaden 2014; Bruce Hoffman/Fernando Reinares (Hrsg.), The Evolution of the Global Terrorist Threat. From 9/11 to Osama Bin Laden's Death, New York 2014; Barak Mendelsohn, The al-Qaeda Franchise. The Expansion of Al-Qaeda and Its Consequences, New York 2016; Guido Steinberg, Kalifat des Schreckens. IS und die Bedrohung durch den islamistischen Terror, München 2015; Christoph Reuter, Die Schwarze Macht. Der „Islamische Staat“ und die Strategen des Terrors, München 2015; Behnam T. Said, Islamischer Staat. IS-Miliz, al-Qaida und die deutschen Brigaden, München 2015; Wilfried Buchta, Terror vor Europas Toren. Der Islamische Staat, Iraks Zerfall und Amerikas Ohnmacht, Frankfurt a. M.-New York 2015; Peter Neumann, Die neuen Dschihadisten. ISIS, Europa und die nächste Welle des Terrorismus, Berlin 2015; Jessica Stern/J.M. Berger, ISIS. The State of Terror, New York 2015; Michael Weiss/Hassan Hassan, ISIS. Inside the Army of Terror, London-New York 2015; William McCants, The ISIS Apocalypse. The History, Strategy, and Doomsday Vision of the Islamic State, New York 2015; Patrick Cockburn, The Rise of Islamic State. ISIS and the New Sunni Revolution, Brooklyn 2015; Joby Warrick, Black Flags: The Rise of ISIS, New York 2015; Daniel Byman, Al Qaeda, the Islamic State, and the Global Jihad Movement. What Everybody Needs to Know, New York 2015; Fawaz A. Gerges, ISIS. A History, Princeton 2016.

${ }^{11}$ Eine der wenigen Ausnahmen ist Reuven Paz' Vergleich von Hamas und Al-Qaida, siehe Reuven Paz, Jihadis and Hamas, in: Assaf Moghadam/Brian Fishman (Hrsg.), Self-Inflicted Wounds. Debates and Divisions within Al-Qa'ida and its Periphery, West Point 2010, S. 183-201.

$12 \mathrm{Zu}$ Antisemitismus bei der Hamas, siehe Meir Litvak, The Antisemitism of Hamas, in: Palestine-Israel Journal 12 (2005), Heft 2/3, S. 41-46; Günther Jikeli, A Framework for Assessing Antisemitism. Three Case Studies (Dieudonné, Erdoğan, and Hamas), in: Alvin Rosenfeld (Hrsg.), Deciphering the New Antisemitism, Bloomington 2015, S. 43-76. 


\section{Von der Muslimbruderschaft zum Globalen Dschihad: Die Evolution des politischen Islam}

Gegen Ende des 19. Jahrhunderts stand die islamische Welt - insbesondere in ihrem Kerngebiet, dem Nahen Osten - vor einem Trümmerhaufen. Wenige Jahrhunderte zuvor Europa noch in fast allen Bereichen überlegen, hatte sie nun militärisch, technologisch wie kulturell das Nachsehen. ${ }^{13}$ Muslimische Intellektuelle wie Jamal AlDin Al-Afghani, Muhammad Abdu, sowie zu Beginn Abdus Schüler Rashid Rida waren überzeugt davon, dass eine Modernisierung des Islam nicht bloß von wörtlicher Interpretation und blinder Imitation religiöser Praktiken Abstand nehmen, sondern auch vom Westen lernen musste, insbesondere im Bereich der Wissenschaften. ${ }^{14} \mathrm{Nach}$ Abdus Tod wandte sich Rida allerdings einer puritanischen Version des Islam zu, d. h. einer strikten wörtlichen Interpretation von Koran und Sunna im Stile Ibn Taymiyyas, bis heute einem der wichtigsten Stichwortgeber für dschihadistische Ideologie und Ideologen. ${ }^{15}$ Rida war auch einer der ersten muslimischen Intellektuellen, die sich mit dem Zionismus beschäftigten. ${ }^{16}$ Seine anfängliche Bewunderung für die Juden und den Zionismus, als Vorbild für die islamische Gemeinschaft, schlug allerdings wenige Jahre später in offene Feindschaft um. ${ }^{17}$ So war Rida zunehmend davon überzeugt, dass es sich beim Kampf zwischen Zionisten und Arabern um einen religiösen Krieg handelte, den die Muslime gegen die „verräterischen Juden“ letzten Endes gewinnen würden. ${ }^{18}$ Ridas Überlegungen zum Zionismus beeinflussten den gerade in seiner Entstehung begriffenen politischen Islam nachhaltig und wurden etwa von Hassan Al-Banna übernommen. ${ }^{19} \mathrm{Al}-$ Banna, der 1928 in Ismailiyya die ägyptische Muslimbruderschaft gründete, kann mit Fug und Recht als einer der Urväter des politischen Islam bezeichnet werden. Al-Bannas Programm war simpel und effektiv: „Der Islam ist die Lösung.“ Die islamische Welt könne ihre einstige Vormachtstellung erst dann zurückerhalten, wenn sich die Muslime auf die Lehren des Islam besinnen würden. ${ }^{20}$ Al-Banna verstand es, eine einfache Sprache mit sozialer Wohlfahrt und religiöser Indoktrinierung $\mathrm{zu}$ verbinden, was die Muslimbruderschaft insbesondere für die ärmeren und weniger gebildeten Schichten Ägyptens attraktiv machte - eine Art „Islamisierung von unten“. Doch obwohl religiöse Bekehrung (arab. Da'wa, der „Ruf zum Islam“) seit jeher zum wichtigsten Instrument der Muslimbruderschaft zählte, beschränkte sie sich auch zu Zeiten Al-Bannas nicht darauf. Al-Banna selbst betonte die Bedeutung von gewalttätigem Dschihad für die

${ }^{13}$ Bernard Lewis, What Went Wrong. The Clash Between Islam and Modernity in the Middle East, New York 2003.

${ }^{14}$ Bernard Haykel, On the Nature of Salafi Thought and Action, in: Roel Mejer (Hrsg.), Global Salafism. Islam's New

Religious Movement, Oxford 2014, S. 33-57, hier S. 45-46.

15 Ebd., 46.

${ }^{16}$ Uriya Shavit, Zionism as told by Rashid Rida, in: Journal of Israeli History 34 (2015), Heft 1, S. $23-44$.

${ }^{17}$ Shavit, Zionism as told by Rashid Rida, S. 29-32.

18 Ebd., S. 38.

${ }^{19}$ Ebd., S. 39-40.

${ }^{20}$ Richard Paul Mitchell, The Society of the Muslim Brothers, New York 1993, S. 232. 
Verteidigung des Islam und erlaubte zu Beginn der 1940er-Jahre den Aufbau einer geheimen paramilitärischen Truppe, der nizam al-khass (Spezialabteilung) bzw. al-jihaz al-sirri (Geheimorganisation). ${ }^{21}$ Mitglieder der Geheimorganisation waren mutmaßlich verantwortlich für zahlreiche Gewaltakte wie etwa Bombenattentate, die Ermordung von politischen Rivalen sowie Angriffe auf britische Truppen. ${ }^{22}$ Diese Umtriebe führten 1948 zum ersten von mehreren Verboten der Muslimbruderschaft. Doch trotz Al-Bannas Dschihad-Rhetorik und seinem Bestreben, in Ägypten eine islamische Ordnung basierend auf der Scharia zu etablieren, bzw. „im islamischen Vaterland frei von ausländischem Einfluss einen islamischen Staat $\mathrm{zu}$ schaffen“, lehnte die Muslimbruderschaft Konzepte wie den modernen Nationalstaat oder Demokratie nicht $\mathrm{ab}$, sondern argumentierte, dass diese mit der islamischen Lehre vereinbar seien (allerdings interpretierte Al-Banna Konzepte wie Demokratie und Patriotismus gemäß seinem Islamverständnis um). ${ }^{23}$ Al-Banna nahm selbst an den ägyptischen Präsidentschaftswahlen teil (die er verlor) und die Ableger der Muslimbruderschaft in verschiedenen islamischen Ländern formten Parteien und nahmen an Wahlen teil (allerdings gab es durchaus Unterschiede; die Muslimbruderschaft in Syrien war etwa wesentlich radikaler als die Ennahda in Tunesien). Die Muslimbruderschaft und ihre Ableger erkannten damit nicht nur die Legitimität von Nationalstaaten an, sie sprachen sich auch meist für einen „Dialog mit dem Westen“ aus (ohne dies genauer zu konkretisieren). Explizit davon ausgenommen war Israel, gegen das auch vermeintlich „moderate“ Islamisten wie Rachid Ghannouchi, der Vorsitzende der Ennahda-Partei in Tunesien, wiederholt zum Dschihad aufriefen. ${ }^{24}$ Die - zumindest vorgebliche Akzeptanz der auf nationalstaatlicher Souveränität beruhenden Weltordnung und Dialogbereitschaft mit dem Westen sind die entscheidenden Unterschiede zwischen der Muslimbruderschaft und der globalen Dschihad-Bewegung. ${ }^{25}$ Letztere lehnt beide Ideen, wie überhaupt jegliche Art von Politik, die nicht allein auf der Scharia basiert, konsequent ab. Einzig und allein der bewaffnete Kampf sowie religiöse Bekehrung zur Etablierung eines globalen Kalifates sind für sie akzeptabel. ${ }^{26}$ Ironischerweise war es aber ausgerechnet ein Muslimbruder, der die Entstehung der globalen Dschihad-Bewegung maßgeblich mitbeeinflusste. Sayyid Qutb, Literaturkritiker und Lehrer, hatte zwei Jahre in den USA verbracht, um das dortige Erziehungssystem zu studieren, zeigte sich aber von den amerikanischen Umgangsformen angewidert und schockiert. ${ }^{27} \mathrm{Nach}$ seiner

${ }^{21}$ Ebd., S. 30.

22 Ebd., S. 58-65.

23 Nelly Lahoud, The Evolution of Modern Jihadism, in: The Oxford Research Encyclopdia of Religion, August 2016, [http://doi.org/10.1093/acrefore/9780199340378.013.68], eingesehen 13.8.2017.

24 The Global Muslim Brotherhood Daily Watch, Rachid Ghannouchi, o. D.,

[https://www.globalmbwatch.com/rachid-ghannouchi/], eingesehen 21.9.2017.

${ }^{25}$ Lahoud, The Evolution of Modern Jihadism.

26 Ebd.

${ }^{27}$ Sayyid Qutb, The America I Have Seen. In the Scale of Human Values, 1951,

[https://archive.org/stream/SayyidQutb/The\%20America\%20I\%20have\%20seen_djvu.txt], eingesehen 4.11.2017; 
Rückkehr nach Ägypten trat er in den frühen 1950er-Jahren in die Muslimbruderschaft ein und wurde zu einem der einflussreichsten Theoretiker des politischen Islam. Qutb argumentierte, dass sich die islamische Gemeinschaft in einer erneuerten Phase der „jahiliyya“ (arab. Ignoranz, der Begriff bezeichnete auch die vor-islamische Periode) befinde, da sie in Ländern lebe, die nicht der Scharia folgten. Gemäß Qutb hätten einzig die Gesetze Allahs Legitimität, alle anderen widersprächen hingegen dessen Souveränität. ${ }^{28}$ Qutb bestand darauf, dass der Koran ewige Gültigkeit habe und nicht in einem bestimmten historischen Kontext verstanden werden müsse. Aus diesem Grunde würden auch die Beschreibungen von Juden als feige und verräterisch heute noch genauso zutreffen wie zu den Zeiten Muhammads. ${ }^{29}$ Schließlich argumentierte Qutb, dass Dschihad der allumfassende (physische wie mentale) Kampf gegen alles sei, was der Anbetung Allahs widerspreche. Dieser Kampf ist gemäß Qutb nicht nur gegen Ungläubige zu führen, sondern auch gegen jene Muslime, die vom „rechten Glauben“ abgefallen sind. Qutb ging noch einen Schritt weiter und erklärte die Tötung von muslimischen Staatsoberhäuptern für rechtens, wenn diese nicht gemäß der Scharia regierten. Die Exkommunikation (takfir) von Muslimen als Rechtfertigung für ihre Tötung wurde von späteren Theoretikern der Dschihad-Bewegung von Staatsoberhäuptern auf sämtliche Muslime ausgeweitet, bleibt aber umstritten. ${ }^{30}$

Aufgrund seiner radikalen Ansichten wurde Qutb 1954 (nach einem fehlgeschlagenen Attentat gegen Präsident Gamal Abdel Nasser) verhaftet und schließlich, nach zehnjähriger Haft, Freilassung und der erneuten Festnahme, am 29. August 1966 hingerichtet. Qutbs Anhänger (unter ihnen sein Bruder Muhammad) flüchteten in den 1960er-Jahren nach Saudi-Arabien. Das saudische Königshaus empfing die Muslimbrüder mit offenen Armen, in der Hoffnung, dadurch den saudischen PanIslamismus, ein Gegenkonzept zum säkular-nationalistischen Pan-Arabismus, zu stärken. Die Muslimbrüder spielten eine entscheidende Rolle bei der 1962 gegründeten Muslimischen Weltliga, sowie der Weltversammlung der islamischen Jugend, die zehn Jahre später etabliert wurde. ${ }^{31}$ In Saudi-Arabien vermischte sich der Polit-Aktivismus der Muslimbruderschaft mit der saudischen Staatsdoktrin des Wahhabismus, einer puritanischen und extrem konservativen Auslegung des Islam, welche Feindschaft gegenüber allen Nichtmuslimen (sowie anderen muslimischen Strömungen wie Schiiten,

David von Drehle, A Lesson in Hate, in: Smithsonian Magazine, Februar 2006,

[https://www.smithsonianmag.com/history/a-lesson-in-hate-109822568/], eingesehen 4.11.2017.

${ }_{28}$ William E. Shepard, Sayyid Qutb's Doctrine of Jahiliyya, in: International Journal of Middle East Studies 35 (2003), Heft 4, S. 521-545; Sayed Khatab, „Hakimiyyah“ and ,Jahiliyya“ in the thought of Sayyid Qutb, in: Middle Eastern Studies 38 (2002), Heft 3, S. 145-170.

${ }_{29}$ Bassam Tibi, From Sayyid Qutb to Hamas. The Middle East Conflict and the Islamization of Antisemitism (The Yale Initiative for the Interdisciplinary Study of Antisemitism Working Paper Series 5), Yale 2010, S. 12-14.

${ }^{30}$ Camilla Adang u. a. (Hrsg.), Accusations of Unbelief in Islam. A Diachronic Perspective on Takfir, Leiden 2017.

31 Peter Mandaville, Muslim Networks and Movements in Western Europe, in: Pew Forum on Religion \& Public Life, September 2010, S. 27-32. 
Sufis oder Ahmadiyyas) propagiert. ${ }^{32}$ Während sich das saudische Königshaus das Netzwerk der Muslimbruderschaft zunutze machte, um die wahhabitische Ideologie weltweit in muslimischen Gemeinschaften (insbesondere auch westlichen Diasporas) zu fördern, betrachtete es den politischen Aktivismus der Muslimbrüder schon nach kurzer Zeit mit Argwohn. Angesichts der islamischen Revolution im Iran zu Beginn des Jahres 1979 und der Besetzung der Großen Moschee von Mekka durch Extremisten, die den Sturz des Königshauses forderten, zögerte Saudi-Arabien nach dem Einmarsch der Sowjetunion in Afghanistan deshalb nicht lange, sich als den primären Verteidiger des Islam darzustellen. Gemeinsam mit dem pakistanischen Geheimdienst ISI organisierte Saudi-Arabien finanzielle und logistische Unterstützung für arabische Freiwillige, die aus zahlreichen Ländern in den Dschihad gegen die ,gottlose Sowjetunion“ zogen. ${ }^{33}$ Zentrale Figuren in den saudischen Bemühungen waren Osama Bin Laden und Abdallah Azzam, die beiden Gründer von Al-Qaida. Mit tatkräftiger saudischer Unterstützung wurde der antisowjetische Dschihad zur Geburtsstunde der Globalen DschihadBewegung, die sich nach wenigen Jahren auch gegen das saudische Königshaus wandte. Ihr Ziel ist die Befreiung aller muslimischer Länder aus der Hand der Ungläubigen und der „Apostaten“-Regimes sowie die Etablierung eines globalen islamischen Kalifats. ${ }^{34}$ In den folgenden Abschnitten werden die Gemeinsamkeiten und Unterschiede sowie die komplexen Beziehungen zwischen Muslimbruderschaft und der Globalen DschihadBewegung weiter verdeutlicht.

\section{Hamas}

Die Wurzeln der Hamas reichen zurück bis in die Zeit des britischen Mandats für Palästina vor der Staatsgründung Israels. Im Jahr 1935 kam es zu einem Treffen von Abdel Rahman Al-Banna, dem Bruder Hassan Al-Bannas, mit dem für seine spätere Kollaboration mit dem Nationalsozialismus berüchtigten Jerusalemer Mufti Hajj Amin Al-Husseini. Dabei stimmte Hassan Al-Banna der Etablierung eines Zentralkomitees zur Unterstützung Palästinas zu, das gegen die britische Präsenz protestieren und die palästinensischen Nationalbestrebungen unterstützen sollte. ${ }^{35}$ Schließlich gründete Said Ramadan, der Vater von Tariq und Hani Ramadan und die zentrale Figur beim Aufbau des Muslimbruderschaft-Netzwerks im Westen, 1945 in Jerusalem eine Filiale der Muslimbruderschaft. ${ }^{36}$ Bereits zwei Jahre später verfügte die Muslimbruderschaft über

32 Carol E. B. Choksy/Jamsheed K. Choksy, The Saudi Connection. Wahhabism and Global Jihad, in: World Affairs Journal, Mai/Juni 2015, [http://www.worldaffairsjournal.org/article/saudi-connection-wahhabism-and-global-jihad], eingesehen 4.11.2017.

33 Thomas Hegghammer, Jihad in Saudi Arabia. Violence and Pan-Islamism since 1979, New York 2010, S. 26-30.

${ }^{34}$ Hegghammer, Jihad in Saudi Arabia.

35 Levitt, Hamas, S. 20.

36 Robert Dreyfuss, Cold War, Holy Warrior, in: Mother Jones, Januar/Februar 2006,

[http://www.motherjones.com/politics/2006/01/cold-war-holy-warrior/], eingesehen 5.11.2017; Ian Johnson, A 
25 Zweigstellen im Mandatsgebiet und zwischen 12.000 bis 20.000 Mitglieder. ${ }^{37}$ Während zwischen 1948 und 1967 die Muslimbruderschaft-Strukturen in Gaza in die ägyptische Mutterorganisation und jene im Westjordanland in den jordanischen Ableger integriert waren, führte der israelische Sieg im Sechstagekrieg und der damit einhergehende Gebietsgewinn zu einer Vereinheitlichung und zu einem deutlich gesteigerten Aktivismus der Muslimbrüder. ${ }^{38}$ Israel tolerierte diese Aktivitäten, da es sich ein Gegengewicht zum Terror der nominell säkularen Terrorgruppen, wie der Palästinensischen Befreiungsfront (PLO) und der Volkfront für die Befreiung Palästinas (PFLP), erhoffte. Anders als letztere waren die Muslimbrüder nicht an einer gewalttätigen Konfrontation interessiert, sondern auf die Islamisierung der palästinensischen Gesellschaft fokussiert. ${ }^{39}$ Der Ausbruch der Intifada im Dezember 1987 bestärkte allerdings eine radikale Fraktion der palästinensischen Muslimbrüder in der Überzeugung, dass der bewaffnete Kampf die einzige Lösung sei. Die Hamas war entstanden. In den folgenden Jahren entführte und tötete diese Organisation mehrere israelische Soldaten und wurde daraufhin von Israel verboten. ${ }^{40}$ Ironischerweise stärkte dieses Verbot die Glaubwürdigkeit der Hamas unter den Palästinensern, die der Organisation zuvor aufgrund der Tolerierung durch Israel misstraut hatten. Nachdem Ministerpräsident Yitzhak Rabin im Jahr 1992 über 400 Mitglieder der Hamas und des Palästinensischen Islamischen Dschihad (PIJ) in den Südlibanon deportieren ließ, nutzte die Hamas die Gelegenheit, um ihre militärischen Kapazitäten und Terrortaktiken in Ausbildungscamps der Hisbollah und einer PFLPFraktion (PFLP-Generalkommando von Ahmad Dschibril) weiterzuentwickeln. ${ }^{41}$ In den folgenden Jahren versuchte die Hamas gemeinsam mit dem PIJ und anderen radikalen PLO-Fraktionen, den Friedensprozess durch Terroranschläge zu torpedieren. Nicht zuletzt aufgrund ihrer kompromisslosen Haltung gegenüber Israel gewann sie Zuspruch unter den Palästinensern. Zugleich nutzte sie die 1990er-Jahre, um ihre Strukturen weiter auszubauen und ihren Einfluss, insbesondere in Gaza, zu konsolidieren. Der Ausbruch der Zweiten Intifada im Jahr 2000 war der Beginn einer beispielslosen Kampagne von Selbstmordanschlägen in Israel, von denen die meisten auf das Konto der Hamas gingen. ${ }^{42}$ Nach dem unilateralen Rückzug Israels aus dem Gaza im Jahr 2005, den viele Palästinenser der Hamas zuschrieben, beteiligte diese sich erstmalig an den palästinensischen Legislativwahlen - und gewann diese im Januar 2006 prompt. ${ }^{43}$ Doch nach anhaltenden Feindseligkeiten und Interessenskonflikten zwischen Hamas und der

Mosque in Munich. Nazis, the CIA, and the Rise of the Muslim Brotherhood in the West, San Diego 2011.

${ }^{37}$ Levitt, Hamas, S. 20.

38 Ebd., S. 21.

${ }^{39}$ Croituru, Hamas, S. 43-44.

40 Croituru, Hamas, S. 112-113.

${ }^{41}$ Croituru, Hamas, S. 127; Jonathan Schanzer, Hamas and Fatah. The Struggle for Palestine, New York 2008, S. 39.

42 Assaf Moghadam, Palestinian Suicide Terrorism in the Second Intifada. Motivations and Organizational Aspects, in: Studies in Conflict and Terrorism 26 (2003), Band 2, S. 65-92.

43 Peter Philipp, Zehn Jahre Hamas in Gaza, in: Deutschlandfunk, 25.1.2016, [http://www.deutschlandfunk.de/nahostkonflikt-zehn-jahre-hamas-in-palaestina.724.de.html?dram:article_id=343620], eingesehen 11.11.2017. 
Fatah unter der Führung von Mahmud Abbas, dem Präsidenten der Palästinensischen Autonomiebehörde (PA), übernahm die Hamas im Juni 2007 gewaltsam die Macht im Gazastreifen. ${ }^{44}$ Seither ist sie, trotz wiederholter innerpalästinensischer Versöhnungsversuche, die Alleinherrscherin in Gaza und bildet eine Parallelregierung zur PA im Westjordanland. ${ }^{45}$

\section{Antizionismus bei der Hamas}

Der bewaffnete Kampf bis zur Zerstörung Israels ist der raison d'être der Hamas. Bereits in der Einleitung ihres Gründungsdokuments lässt sie keinen Zweifel offen an ihrer Zielsetzung und zitiert Hassan Al-Banna: „Israel will exist and will continue to exist until Islam will obliterate it, just as it obliterated others before it. "46 Damit stellt die Hamas klar, dass es sich beim Kampf gegen Israel nicht einfach um einen territorialen Konflikt handelt, sondern um einen Krieg religiöser Natur, in der Tradition der Überlegungen von Rida, Al-Banna und Qutb. In Artikel 6 ihrer Gründungscharta heißt es: „Die Hamas strebt danach, das Banner des Islam über jedem Zentimeter Palästinas zu hissen “ und Artikel 11 beschreibt Palästina als „,islamisches Waqf“" (heiliges Land nur für Muslime) bis zum „Tag des Jüngsten Gerichts“. ${ }^{47}$ Die Hamas beschreibt den Kampf gegen Israel an mehreren Stellen als individuelle Pflicht (fard ayn, wie etwa das Beten und Fasten) eines jeden Moslems. Während der (defensive) Dschihad als individuelle Pflicht unter muslimischen Theologen schon immer umstritten war, popularisierte Abdullah Azzam, einer der Gründer von Al-Qaida, dieses Konzept in den 1980er-Jahren. ${ }^{48}$ Die HamasCharta ist zudem ein Musterbeispiel für die Verbindung von da’wa, also dem „Ruf zum Islam“, mit dem bewaffneten Kampf. Artikel 16 betont die Bedeutung einer islamischen Erziehung mit dem Studium von Koran, Sunna und islamischer Geschichte, aber auch „des Feindes, seiner Stärken und Schwächen, seinen Verbündeten, sowie seiner

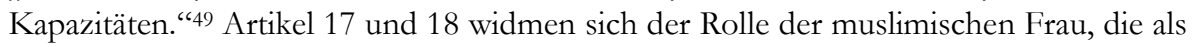
Schöpferin der Männer für die Erziehung der nächsten Generationen verantwortlich sei. ${ }^{50}$ In Artikel 19 wiederum ist die Rede von islamischer Kunst, die sich von der vorislamischen (jahili) Kunst unterscheide. Laut Hamas sind alle Formen von Kunst, egal

44 Ebd.

45 Jonathan Cook, Will Hamas-Fatah reconciliation deal succeed?, in: Al Jazeera, 13.10.2017,

[http://www.aljazeera.com/indepth/features/2017/10/hamas-fatah-reconciliation-deal-succeed-

171013064803703.html], eingesehen 11.11.2017.

${ }^{46}$ Hamas Covenant 1988. Yale Law School, The Avalon Project,

[http://avalon.law.yale.edu/20th_century/hamas.asp], eingesehen 11.11.2017.

47 Ebd.

48 Vgl. Majid Khadduri, War and Peace in the Law of Islam, Baltimore 1955, S. 60; Andrew McGregor, ,Jihad and the Rifle Alone." "Abdullah 'Azzam and the Islamist Revolution, in: The Journal of Conflict Studies 23 (2003), Band 2, [https://journals.lib.unb.ca/index.php/jcs/article/view/219/377], eingesehen 11.11.2017.

${ }^{49}$ Hamas Covenant 1988.

50 Ebd. 
ob Buch, Artikel, Predigt, Gedicht, Lied oder Theaterstück ein Mittel zur „,ideologischen Mobilisierung“". ${ }^{51}$ Der bewaffnete Kampf gegen Israel geht für die Hamas folglich einher mit einer umfassenden Islamisierung der palästinensischen Gesellschaft. Sie führt nicht nur regelmäßig Krieg gegen Israel, sondern erzieht Jugendliche in Gaza gemäß ihren Vorstellungen. ${ }^{52}$ In ihren Sommerlagern werden bereits Kinder auf den bewaffneten Kampf und den „glorreichen Märtyrertod“ vorbereitet. ${ }^{53}$ Daneben führt die Hamas ihren Kampf auch auf der politischen Ebene, sowohl in der palästinensischen Arena als auch international, wo sie unter anderem in der Europäischen Union kontinuierliche Lobbyarbeit betreibt. ${ }^{54}$ Seit Jahren behaupten Hamas-Unterstützer in Europa, die Organisation habe der Vernichtung Israels seit langem abgeschworen. Im Frühling 2017 präsentierte die Organisation eine neue Charta, die keine Referenzen mehr zu „Juden“ enthält und die Möglichkeit eines palästinensischen Staates in den Grenzen von 1967 andeutet. ${ }^{55}$ Nur wenige Tage später stellte Hamas-Mitbegründer Mahmoud Zahrar allerdings klar, dass die gewaltsame Befreiung „aller palästinensischen Gebiete“, worunter auch das israelische Kernland subsummiert wird, noch immer das Ziel der Organisation sei. ${ }^{56}$ Weitere Hamas-Anführer erklärten infolge, sie würden weder einer Entwaffnung, noch der Anerkennung Israels zustimmen. ${ }^{57}$

\section{Antisemitismus bei der Hamas}

Auch Antisemitismus spielt eine entscheidende Rolle in der Ideologie der Hamas. Ihre Judenfeindschaft speist sich dabei aus unterschiedlichen Quellen. Einerseits übernimmt die Hamas die Topoi einer jüdischen Weltverschwörung, die auch im Vernichtungs-

51 Ebd.

52 David Patrikarakos, Hamas Is Ready for War with Israel, in: Foreign Policy, 7.6.2016,

[http://foreignpolicy.com/2016/06/07/hamas-is-ready-for-war-with-israel-gaza-strip/], eingesehen 11.11.2017; Fares Akram/Jodi Rudoren, To Shape Young Palestinians, Hamas Creates Its Own Textbooks, in: The New York. Times, 3.11.2013, [http://www.nytimes.com/2013/11/04/world/middleeast/to-shape-young-palestinians-hamas-createsits-own-textbooks.html], eingesehen 11.11.2017.

53 Adnan Abu Amer, Thousands of teens enroll in Hamas summer camps, in: Al-Monitor, 18.8.2015, [http://www.almonitor.com/pulse/originals/2015/08/palestine-summer-camps-hamas-qassam-brigades-israel.html], eingesehen 11.11.2017.

54 The Global Muslim Brotherhood Watch Daily, European Hamas Support Group Announces Lobbying And Advocacy Course In Rotterdam, 21.1.2016, [https://www.globalmbwatch.com/2016/01/21/european-hamassupport-group-announces-lobbying-and-advocacy-course-in-rotterdam/], eingesehen 11.11.2017; CEPR und das europäische Netzwerk der Hamas, in: Audiatur-Online, 20.1.2014, [http://www.audiatur-online.ch/2014/01/20/ceprund-das-europaeische-netzwerk-der-hamas/], eingesehen 11.11.2017.

${ }^{55}$ Hamas in 2017. The document in full, in: Middle East Eye, 1.5.2017, [http://www.middleeasteye.net/news/hamascharter-1637794876], eingesehen 11.11.2017; Jack Khoury, Hamas Presents New Charter Supporting Palestinian State Along 1967 Borders, in: Haaretz, 1.5.2017, [https://www.haaretz.com/middle-east-news/palestinians/1.786754], eingesehen 11.11.2017.

56 Dov Lieber, Hamas assures critics Israel's destruction still its goal, in: The Times of Israel, 10.5.2017, [https://www.timesofisrael.com/hamas-assures-critics-israels-destruction-still-a-goal/], eingesehen 11.11.2017.

57 Jack Khoury, Hamas Leader in Gaza: We Will Neither Disarm nor Recognize Israel, in: Haaret\%, 19.10.2017, [https://www.haaretz.com/middle-east-news/palestinians/1.818235], eingesehen 11.11.2017. 
antisemitismus der Nazis zu finden waren. Andererseits wird die Judenfeindschaft aber religiös begründet, beispielsweise unter Berufung auf die berüchtigte Gharqad-Hadith, die in Artikel 7 ihrer Charta zitiert wird: „The Day of Judgement will not come about until Moslems fight the Jews (killing the Jews), when the Jew will hide behind stones and trees. The stones and trees will say O Moslems, O Abdulla, there is a Jew behind me, come and kill him. Only the Gharkad tree, (evidently a certain kind of tree) would not do that because it is one of the trees of the Jews. "58 Zudem heißt es in der Charta, dass „Israel, das Judentum und die Juden“ den Islam und die Muslime herausforderten (Art. 28) und dass ,islamische Gruppen“ (d. h. Gruppen wie die Hamas, im Gegensatz zu „säkularen“ Organisationen) am besten geeignet sind für den Kampf gegen die „kriegstreibenden Juden“ (Art. 32). ${ }^{59}$ Neben diesen religiösen Motiven finden sich in der Charta auch viele Elemente, die ihre Wurzeln im europäischen Antisemitismus des späten 19. und frühen 20. Jahrhunderts haben. Die „Zionisten“ hätten die Freimaurer, Rotarier und den Lions Club infiltriert (Art. 17) und würden hinter der französischen Revolution, dem Kommunismus sowie den beiden Weltkriegen stecken (Art. 22). ${ }^{60}$ Der offensichtliche Bezug auf die „Protokolle der Weisen von Zion“ - eine antisemitische Fälschung - wird in Artikel 32 explizit gemacht, der besagt, dass die Protokolle die „Pläne des Weltzionismus“ verkörpern würden. ${ }^{61}$ Der Antisemitismus der Hamas beschränkt sich nicht auf ihre Charta. Hamas-Mitbegründer Abdelaziz Al-Rantisi behauptete im Jahr 2003, der „falsche Holocaust“ sei die größte Lüge überhaupt, welche von den Zionisten erfunden wurde, um die Juden einzuschüchtern und so zur Emigration nach Palästina zu zwingen. ${ }^{62}$ Al-Rantisi argumentiert zudem, dass der Vergleich von Zionisten mit Nazis eine Beleidigung für letztere sei, da deren Verbrechen nur einen Bruchteil vom „Terror der Zionisten gegen das palästinensische Volk“ ausmachten. ${ }^{63}$ Ein weiteres klassisches Motiv in der antisemitischen Rhetorik der Hamas ist die Behauptung, Juden würden Christenblut für die Herstellung von Pessach-Matzot verwenden. Hamas-Sprecher Osama Hamdan stellte diese Behauptung im Juli 2014 auf und erklärte zudem, dies sei der Grund, weshalb die Israelis insbesondere Kinder ins Visier nehmen würden - es sei in ihrer zionistischen Psyche verankert. ${ }^{64}$ Ebenfalls im Juli 2014 bekräftigte ein HamasGeistlicher bei einer öffentlichen TV-Ansprache, dass man ,alle Juden vernichten“ werde. ${ }^{65}$

58 Hamas Covenant 1988.

59 Ebd.

60 Ebd.

61 Ebd.

62 Abdelaziz Al-Rantisi, The False Holocaust. The Greatest Lies Funded By The Zionists, in: Al-Risala, 21.11.2003, [https://www.memri.org/reports/hamas-leader-rantisi-false-holocaust-greatest-lies-funded-zionists], eingesehen 11.11.2017.

63 Ebd.

${ }^{64}$ Top Hamas Official: Jews Use Blood in their Passover Matzos, in: Israel National News, 31.7.2014, [http://www.israelnationalnews.com/News/News.aspx/183541], eingesehen 11.11.2017.

65 Palestinian Media Watch, Hamas cleric: We will “exterminate” the Jews "until the last one", in: YouTube, 30.07.2014, [https://youtu.be/UJNdDzweqbY], eingesehen 11.11.2017. 


\section{Al-Qaida}

Al-Qaida entstand Ende der 1980er-Jahre in Afghanistan unter der Führung von Osama Bin Laden und Abdullah Azzam. Bin Laden war der Sohn eines saudisch-jemenitischen Unternehmers, der über gute Kontakte zur saudischen Königsfamilie verfügte. ${ }^{66}$ Azzam wurde 1941 in der Nähe von Jenin geboren und zog nach dem Sechstagekrieg nach Jordanien, wo er sich 1969 der Muslimbruderschaft anschloss. ${ }^{67}$ Später erlangte er in Kairo ein Doktorat in islamischem Recht und begann, nach einem kurzen Aufenthalt in Saudi-Arabien in den frühen 1980er-Jahren, an der Islamischen Universität Islamabad in Pakistan zu unterrichten. ${ }^{68} 1984$ gab er diese Stelle auf, um sich auf den Jihad im benachbarten Afghanistan zu konzentrieren. Gemeinsam mit Bin Laden gründete Azzam in Peshawar das Makhtab Kadamat al-Mujaheddin, das Dienstleistungsbüro für Mujaheddin, welches arabische Jihadisten in Afghanistan finanziell und logistisch unterstützte. ${ }^{69}$ Nach Lawrence Wright gründeten Azzam, Bin Laden und weitere Anführer des Ägyptischen Islamischen Dschihads am 11. August 1988 Al-Qaida, wobei der Name der Organisation für mehrere Jahre geheim gehalten wurde. ${ }^{70} \mathrm{Zu}$ diesem Zeitpunkt war die Niederlage der Sowjetunion bereits absehbar und die arabischen Dschihadisten drängte es nach der „Befreiung“ aller muslimischer Länder. Allerdings waren sie sich nicht einig, wo der nächste Jihad zu führen sein würde. Während für Azzam die Befreiung Palästinas die höchste Priorität einnahm, betonte Ayman AlZawahiri, ein Anführer des Ägyptischen Islamischen Dschihads und der heutige Anführer Al-Qaidas, in Einklang mit der Lehre Sayyid Qutbs und der Takfir-Ideologie, die Notwendigkeit des Kampfes gegen „Apostaten-Regimes“, insbesondere demjenigen in seiner Heimat Ägypten. Sowohl Azzam als auch Zawahiri kämpften um die Gunst Bin Ladens, der Dank seinem Vater über beträchtliche finanzielle Mittel verfügte. ${ }^{71}$ Nachdem Azzam im November unter ungeklärten Umständen bei einem Bombenanschlag verstarb, fokussierte sich Al-Qaida anfänglich vor allem auf den von Zawahiri favorisierten „,nahen“ Feind und bekämpfte etwa die kommunistische Regierung im Jemen. ${ }^{72}$ Al-Qaida-Mitglieder und Sympathisanten beteiligten sich zudem an den Kriegen im Balkan. ${ }^{73}$ Spätestens gegen Mitte der 1990er-Jahre nahm Al-Qaida aber zunehmend den „fernen Feind“, also den Westen und insbesondere die USA, ins Visier. Al-Qaidas Anführer spekulierten, dass die arabischen „Apostaten-Regimes“ sich nur durch die

${ }^{66}$ Michael Scheuer, Osama Bin Laden, New York 2011, S. 21-22.

${ }^{67}$ Asaf Maliach, Abdullah Azzam, al-Qaeda, and Hamas. Concepts of Jihad and Istishhad, in: Military and Strategic Affairs 2 (2010), Band 2, S. 79.

${ }^{68}$ Ebd., S. 80.

${ }^{69}$ Ebd.

${ }^{70}$ Lawrence Wright, The Looming Tower. Al-Qaeda and the Road to 9/11, New York 2006, S. 131.

${ }^{71}$ Ebd. S. 8-9.

72 Byman, Al Qaeda, the Islamic State and the Global Jihadist Movement, S. 14.

73 Shaul Shay, Islamic Terror and the Balkans, New Brunswick 2009. 
Unterstützung der Vereinigten Staaten an der Macht halten konnten. ${ }^{74}$ Einen Rückzug der USA aus der Region würde demnach ihren Sturz zur Folge haben. Am 23. Februar 1998 veröffentlichten Bin Laden, Zawahiri sowie drei weitere Jihadisten aus Ägypten, Pakistan und Bangladesch einen Appell der „Weltislamischen Front“, der zum „Heiligen Krieg gegen Juden und Kreuzfahrer aufrief. ${ }^{75}$ In den Jahren darauf erfolgten die Anschläge gegen die US-Botschaften in Nairobi und Daressalam (1998), den Zerstörer USS Cole im Golf von Aden (2000), sowie Al-Qaidas größter Erfolg, die Anschläge vom 11. September 2001. Doch statt sich aus dem Nahen Osten zurückzuziehen, zerstörten die USA stattdessen die Infrastruktur von Al-Qaida in Afghanistan. In der Folge wandelte sich Al-Qaida von einer relativ hierarchisch strukturierten Organisation in eine weltweite Bewegung, mit Ablegern und Partnerorganisationen in zahlreichen Ländern. ${ }^{76}$ Seit Osama Bin Ladens Tod im Mai 2011 ist Ayman Al-Zawahiri Al-Qaidas neuer Anführer.

\section{Antizionismus bei Al-Qaida}

Der Jihad zur „Befreiung Palästinas“ war ein konstantes Thema für Bin Laden und Thomas Hegghammer hat bereits 2007 darauf hingewiesen, dass Palästina eine zentrale Rolle in der Strategie Al-Qaidas einnimmt. ${ }^{77}$ Operativ hingegen war Israel nie eine Priorität, doch dies lag nicht in seiner vermeintlich geringen Bedeutung begründet. Vielmehr sollten mit der Vertreibung der USA aus der Region und dem Sturz der arabischen Regimes überhaupt erst die Bedingungen geschaffen werden, um Palästina zu befreien. Von Bin Laden ist die Anekdote überliefert, dass er die Frage seines Sohnes Omar, warum Al-Qaida die USA statt Israel bekämpfe, wie folgt beantwortete: Israel und die USA seien wie ein Fahrrad mit einem hölzernen und einem eisernen Rad. Israel sei letzteres und deshalb sei es einfacher, zuerst das hölzerne Rad, d. h. die USA, zu zerstören. ${ }^{78}$ Tatsächlich halten sich dokumentierte Angriffe Al-Qaidas gegen israelische Ziele in Grenzen. Der vermutlich schwerste ereignete sich am 28. November 2002 während des Hanukkah-Fests in Kenia, als bei einem Selbstmordanschlag gegen ein Hotel mit israelischem Besitzer dreizehn Personen starben, darunter drei Israelis. ${ }^{79}$

\footnotetext{
74 Byman, Al Qaeda, the Islamic State and the Global Jihadist Movement, S. 16-17.

75 World Islamic Front, Jihad Against Jews and Crusaders, 23.2.1998, [https://fas.org/irp/world/para/docs/980223fatwa.htm], eingesehen 11.11.2017.

${ }^{76}$ Rick "Ozzie" Nelson/Thomas M. Sanderson, A Threat Transformed. Al-Qaeda and Associated Movements in 2011, 8.2.2011, [https://www.csis.org/analysis/threat-transformed], eingesehen 11.11.2017.

77 Maggie Michael, Bin Laden: Palestinian cause at heart of al-Qaeda's mission, in: USA Today, 16.5.2008, [http://usatoday30.usatoday.com/news/world/2008-05-16-bin-laden_N.htm], eingesehen 11.11.2017; Thomas Hegghammer, Osama bin Laden's true priorities, in: The Guardian, 3.12.2007,

[https://www.theguardian.com/commentisfree/2007/dec/03/osamabinladenstruepriorities], eingesehen 11.11.2017. 78 Scheuer, Bin Laden, S. 111-112.

${ }_{79}$ Marc Lacey/Benjamin Weiser, After Attack, Kenya Traces Qaeda's Trail in East Africa, in: The New York. Times, 1.12.2002, [http://www.nytimes.com/2002/12/01/world/after-attack-kenya-traces-qaeda-s-trail-in-east-africa.html], eingesehen 11.11.2017.
} 
Zeitgleich feuerten Terroristen eine Rakete auf ein Flugzeug der israelischen Fluggesellschaft Arkia ab, verfehlten aber ihr Ziel. Umstritten ist das Selbstmordattentat gegen die Mike's Place-Bar in Tel Aviv im Jahr 2003. Zwar bekannte sich die Hamas zu dem Anschlag, aber es gibt Hinweise darauf, dass die beiden britischen Selbstmordattentäter mit pakistanischem Hintergrund von Al-Qaida rekrutiert worden waren. ${ }^{80} 2005$ planten zudem Mitglieder der Salafistische Gruppe für Gebet und Kampf (GSPC), eine Partnerorganisation von Al-Qaida und der Vorgänger von Al-Qaida im Islamischen Maghreb (AQIM), ein El Al-Flugzeug beim Start in Genf abzuschießen, setzten ihr Vorhaben aber nie um. ${ }^{81}$

\section{Antisemitismus bei Al-Qaida}

Auch Antisemitismus spielt eine zentrale Rolle bei Al-Qaida. Im Appell der Weltislamischen Front vom Februar 1998 behauptet Al-Qaida, dass Juden die USA kontrollieren würden. ${ }^{82}$ Bin Laden wiederholte diese Behauptung in zahlreichen Interviews und verkündete zudem, die Juden würden auch die britische Regierung kontrollieren. ${ }^{83}$ Juden waren stets eines der wichtigsten gegnerischen Ziele für Al-Qaida und die Organisation rief wiederholt zum „Jihad gegen Juden“ auf. Inspire, das englischsprachige Magazin von Al-Qaida in der Arabischen Halbinsel, forderte im Mai 2012 dazu auf, Ziele anzugreifen, „wo sich Juden versammeln, ihre Anführer und wichtigsten Institutionen in Europa“". ${ }^{84}$ Zudem erklärte das Magazin, Juden seien neben „Polytheisten“ die ,größten Feinde“ des Islam. ${ }^{85}$ Brynjar Lia hat festgestellt, dass die Juden die einzige ,gegnerische“ Gruppe seien, die von Al-Qaida nie positiv erwähnt, bzw. denen nie ein Friedensangebot gemacht wurde. ${ }^{86}$ Al-Qaida führte zudem mehrere Anschläge gegen jüdische Ziele durch, etwa gegen die Synagoge von Djerba im September 2002 sowie gegen jüdische Gemeindezentren in Casablanca und Istanbul ein Jahr darauf. ${ }^{87}$ Auch der Anschlag von Mohammed Merah auf eine jüdische Schule in Toulouse im Jahr 2012 hat einen Bezug zu Al-Qaida. Obwohl Merah oftmals als sogenannter „Lone Wolf“ beschrieben wurde, trainierte er in Pakistan mit Jund Al-

80 Jonathan Schanzer, The Prospects of Al-Qaeda in Hamas-Controlled Gaza, in: Jewish Policy Center, 31.8.2007, [https://www.jewishpolicycenter.org/2007/08/31/the-prospects-of-al-qaeda-in-hamas-controlled-gaza/], eingesehen 11.11.2017.

81 Terrorists planned to blow up El Al plane, in: Ynetnews, 19.5.2006, [https://www.ynetnews.com/articles/0,7340,L3252772,00.html, eingesehen 11.11.2017.

82 World Islamic Front, Jihad Against Jews and Crusaders.

${ }^{83}$ Rahimullah Yusufzai, A Conversation with Terror, in: Time, 11.1.1999, [http://content.time.com/time/printout/0,8816,17676,00.html], eingesehen 11.11.2017.

84 Anti-Defamation League, Inspire Magazine Highlights "Jewish Enemy" To Recruit Jihadists, 31.5.2013, [https://www.adl.org/blog/inspire-magazine-highlights-jewish-enemy-to-recruit-jihadists], eingesehen 11.11.2017.

85 Ebd.

${ }^{86}$ Assaf Moghadam/Brian Fishman, Debates and Divisions within and around Al-Qa'ida, in: Moghadam/Fishman (Hrsg.), Self-Inflicted Wounds., S. 1-18, hier S. 9.

${ }^{87}$ Aaron Y. Zelin, Fifteen Years After the Djerba Synagoge Bombing, in: CTC Sentinel 10 (2017), Band 4. 
Khilafa, einer Al-Qaida-nahestehenden Gruppierung. Deren Anführer Moez Garsallaoui war anscheinend Merahs Mentor und ermutigte diesen, einen Anschlag in Frankreich durchzuführen. ${ }^{88}$

\section{Al-Qaida und Hamas}

Al-Qaida und Hamas verfügten zu ihren Anfangszeiten über ein Bindeglied in der Person von Abdallah Azzam, der bekannt war für seine Sympathien gegenüber der palästinensischen Terrororganisation und ihrem Gründer Scheich Ahmad Yassin. ${ }^{89}$ In einem Buch über die Hamas argumentierte er, nur diese sei in der Lage, Palästina zu befreien. ${ }^{90}$ Azzam unterstützte die Hamas auch finanziell und sammelte dafür Gelder während seiner USA-Reisen, wo er für die Unterstützung des antisowjetischen Jihads warb. ${ }^{91}$ Im Gegenzug führte die Hamas im Dezember 1989 einen Generalstreik durch, aus Protest gegen die Ermordung Azzams. ${ }^{92}$ Zudem benannte sie verschiedene Einrichtungen und Einheiten nach ihm, etwa ihren militärischen Flügel im Westjordanland (später vereinheitlicht in Al-Qassam-Brigaden) sowie die Shahid Dr. Abdullah Azzam-Militärakademie, die 2006 in Gaza eröffnet wurde. ${ }^{93}$ Allerdings hat sich in den vergangenen fünfzehn Jahren das Verhältnis zwischen der Hamas und Al-Qaida sehr verschlechtert. Al-Qaida kritisierte erstere für deren Beteiligung an den palästinensischen Legislativwahlen im Jahr 2006 sowie ihren positiven Bezug auf den palästinensischen Nationalismus. ${ }^{94}$ An dieser Stelle wird der Unterschied zwischen der Hamas als Vertreterin der Muslimbruderschaft und der salafistisch-jihadistischen AlQaida deutlich. Al-Qaida warf der Hamas darüber hinaus vor, das palästinensische Volk zu verraten, da sie bereit sei, Waffenstillstände mit Israel einzugehen. ${ }^{95}$ Zudem kritisierte Al-Qaida die Hamas für ihren mangelnden Antiamerikanismus, die höchstens partielle Einführung der Scharia in Gaza sowie ihre Zusammenarbeit mit dem Iran und der Hisbollah. ${ }^{96}$ Umgekehrt wirft die Hamas Al-Qaida vor, dass ihre Unterstützung für die Palästinenser außer wohlfeilen Erklärungen wenig Konkretes zu bieten habe. ${ }^{97}$ Die Hamas war stets darauf bedacht, den Einfluss von Al-Qaida und den ihr nahestehenden

88 Delphine Byrka, On a retrouvé le mentor taliban de Mohamed Merah, in: Paris Match, 12.9.2012,

[http://www.parismatch.com/Actu/Societe/On-a-retrouve-le-mentor-taliban-de-Mohamed-MeRah-161129], eingesehen 11.11.2017.

${ }^{89}$ Maliach, Abdullah Azzam, al-Qaeda, and Hamas, S. 87-88.

${ }^{90}$ Ebd., S. 88.

${ }^{91}$ Ebd.; Thomas Hegghammer, 'Abdallāh 'Azzām and Palestine, in: Welt des Islams 53 (2013), Band 3/4, S. $377-378$.

92 Maliach, Abdullah Azzam, al-Qaeda, and Hamas, S. 88.

93 Ebd., S. 89.

$94 \mathrm{Paz}$, Jihadis and Hamas, S. 188-189.

95 Ebd., S. 192-193.

${ }^{96}$ Ebd., S. 189-192.

97 Ebd., S. 200. 
Gruppierungen im Gazastreifen einzuschränken. Wiederholt ging sie massiv gegen salafistisch-dschihadistische Organisationen vor, oftmals mit tödlichem Ausgang. ${ }^{98}$

\section{Islamischer Staat}

Spätestens seit der Islamische Staat (IS) bei seiner Offensive im Juni 2014 Mossul, eine der größten Städte des Iraks, einnahm, ist er zum berüchtigtsten und medial am meist beachteten Vertreter der globalen Dschihad-Bewegung avanciert. Seine Geschichte geht aber viel weiter zurück. Im Jahr 1999 etablierte der jordanische Dschihadist Abu Musab Al-Zarqawi, nachdem er im Rahmen einer Generalamnestie freigekommen war, mit der finanziellen Unterstützung Osama bin Ladens ein Trainingscamp im afghanischen Herat. ${ }^{99}$ Nach der US-Invasion in Afghanistan floh Zarqawi via Iran in den Irak, von wo er sein Netzwerk namens Jama'at Tawhid w'al Jihad (Organisation für Monotheismus und Dschihad) ausbaute. Dazu gehörte unter anderem auch die sogenannte TawhidGruppe, welche in Deutschland Anschläge auf jüdische und israelische Ziele plante, diese Pläne aber nie umsetzte. ${ }^{100}$ Nach dem US-Einmarsch im Irak waren Zarqawi und sein Netzwerk nach kurzer Zeit einer der zentralen Akteure unter den zahlreichen Dschihadistengruppen. ${ }^{101}$ Obwohl Zarqawi auch im Irak auf finanzielle Hilfe durch AlQaida zählte, bestand er auf seiner Unabhängigkeit und weigerte sich, seine Gruppe AlQaida offiziell anzuschließen. ${ }^{102}$ Erst im Oktober 2004 schwor er den Treueeid auf Bin Laden und benannte seine Gruppe offiziell in Al-Qaida in Irak (AQI) um. ${ }^{103}$ Allerdings führte Zarqawis Fokus auf das Entfachen eines konfessionellen Kriegs mit den irakischen Schiiten zu Konflikten mit der Al-Qaida-Führung, die Angriffe auf die USund Koalitionstruppen bevorzugte. Zawahiri kritisierte Zarqawis Brutalität, die sich auch gegen sunnitische Irakis richtete, in einer privaten Korrespondenz. ${ }^{104}$ Zarqawi zeigte sich davon wenig beeindruckt und nachdem er bei einem US-Angriff 2006 ums Leben kam, hielten seine Nachfolger an seiner Strategie fest und benannten die Organisation in Islamischer Staat im Irak (ISI) um. ${ }^{105}$ Die willkürliche Gewalt führte letztlich zu einer Gegenreaktion unter vielen sunnitischen Stämmen, dem sogenannten Anbar Erwachen, welches gemeinsam mit der US-amerikanischen Truppenaufstockung 2007, den ISI in

98 Peter Beaumount, Hamas destroys al-Qaida group in violent Gaza battle, in: The Guardian, 16.8.2009, [https://www.theguardian.com/world/2009/aug/15/hamas-battle-gaza-islamists-al-qaida], eingesehen 11.11.2017.

${ }_{99}$ Brian Fishman, The Master Plan. ISIS, Al-Qaeda, and the Jihadi Strategy for Final Victory, New Haven 2016, S. 8 und 19-21.

100 Fishman, The Master Plan, S. 27-28.

${ }^{101}$ Byman, Al Qaeda, the Islamic State and the Global Jihadist Movement, S. 166.

102 Ebd.

103 Ebd.

104 Zawahiri's Letter to Zarqawi (English Translation), in: Combating Terrorism Center, o. D., [https://ctc.usma.edu/wpcontent/uploads/2013/10/Zawahiris-Letter-to-Zarqawi-Translation.pdf], eingesehen 11.11.2017.

105 Byman, Al Qaeda, the Islamic State and the Global Jihadist Movement, S. 166. 
die Defensive drängte. ${ }^{106}$ Der Abzug der US-Truppen 2011 und die darauffolgende Repression Bagdads gegen die sunnitische Bevölkerung des Irak sowie der Ausbruch des syrischen Bürgerkriegs eröffneten dem ISI neue Möglichkeiten. Sein neuer Anführer, Abu Bakr Al-Baghdadi, entsandte einige ISI-Kämpfer unter der Führung von Abu Mohammed Al-Jolani nach Syrien, um dort eine Präsenz zu etablieren. ${ }^{107}$ Jabhat AlNusra, so der Name des syrischen Ablegers, avancierte in Kürze zu einer der effektivsten Rebellengruppen. Im April 2013 erklärte Baghdadi, Jabhat Al-Nusra sei ein Teil des ISI und verkündete die Vereinigung beider Gruppen zum Islamischen Staat im Irak und in Syrien (ISIS). ${ }^{108}$ Das lehnten sowohl die Jabhat Al-Nusra, welche sich als offizieller AlQaida-Ableger in Syrien verstand, als auch die Kern-Al-Qaida unter der Führung von Zawahiri ab. Dies entfachte einen brutalen Konflikt zwischen ISIS und Jabhat Al-Nusra, in welchem ersterer zumindest einstweilen die Oberhand gewann. ${ }^{109}$ Die ISIS-Offensive im Jahr 2014 brachte der Organisation massive Gebietsgewinne sowohl im Irak als auch in Syrien. Baghdadi änderte den Namen der Organisation zu Islamischer Staat (IS) und erklärte sich selbst zu dessen Kalifen und dem Anführer aller Muslime. Seit 2014 hat der IS zahlreiche Ableger in verschiedenen Ländern etabliert, darunter viele ehemalige Partnerorganisationen von Al-Qaida, welche die Seite wechselten. Als er in seinem Kerngebiet militärisch immer stärker unter Druck geriet, entfesselte der IS weltweit eine beispielslose Terrorwelle, die auch nach - mittlerweile massiven - Gebietsverlusten anhält. ${ }^{110} \mathrm{Ob}$ und wie sich der IS von seiner militärischen Niederlage im Irak und in Syrien erholen wird, bleibt abzuwarten.

\section{Antizionismus beim Islamischen Staat}

Ähnlich wie bei Bin Laden spielte der israelisch-palästinensische Konflikt eine wichtige Rolle in der Rhetorik Zarqawis, demzufolge der „Islamische Staat im Irak das Tor zur Befreiung des gestohlenen Palästinas" sei. ${ }^{111}$ Die zweite Ausgabe von Dabiq, einem englischsprachigen Online-Magazin des IS, verkündete ,it is only a matter of time and patience before it reaches Palestine to fight the barbaric jews and kill those of them hiding behind the gharqad trees - the trees of the jews". ${ }^{112}$ Allerdings beschränken sich die antiisraelischen Aktivitäten des IS ausschließlich auf Rhetorik. Im Vergleich zu Al-Qaida nimmt Israel beim IS eine geringere Priorität ein. In einer Audiobotschaft Abu Bakr AlBaghdadis vom November 2014, in der dieser unter anderem die wichtigsten Feinde des

\footnotetext{
106 Austin Long, The Anbar Awakening, in: Survival 50 (2008), Band 4, S.67-94.

107 Byman, Al Qaeda, the Islamic State and the Global Jihadist Movement, S. 166-167.

108 Ebd, S. 168.

109 Ebd., S.168-169.

110 Andrew Watkins, Losing Territory and Lashing Out. The Islamic State and International Terror, in: CTC Sentinel 9 (2016), Band 6, S. 14-18.

111 Paz, Jihadis and Hamas, S. 196.

112 Foreword, in: Dabiq (2014), Heft 2, S. 4.
} 
IS aufzählte, wurde Israel nicht einmal erwähnt. ${ }^{113}$ Stattdessen standen an erster Stelle die Schiiten, gefolgt von den arabischen „Apostaten-Regimes“ und schließlich den „Kreuzfahrern“, also dem Westen. Erst im Dezember 2015 drohte Baghdadi in einer Audiobotschaft, er habe die Juden nicht vergessen und Palästina werde ihr Friedhof sein. ${ }^{114}$ Zwei Monate zuvor hatte die Organisation erstmals ein Video auf Hebräisch veröffentlicht, in dem ein IS-Kämpfer ankündigte, der IS würde die Al-Aqsa Moschee als Eroberer betreten. ${ }^{115}$ In einem Artikel im arabischsprachigen Al-Naba Magazin stellte der IS im März 2016 allerdings klar, dass der Jihad in Palästina keine wichtigere Rolle einnehmen würde als der Jihad andernorts. ${ }^{116}$ Diese geringe Priorität zeigt sich ebenfalls in der Abwesenheit von IS-Angriffen gegen Israel. Eine der wenigen Ausnahmen ist ein Gefecht an der Grenze zu Syrien im November 2016, in dessen Verlauf israelische Soldaten vier Kämpfer der Khalid Ibn Al-Walid-Armee, einer dem IS-nahestehenden Organisation, töteten. ${ }^{117}$ Abgesehen davon ist davon auszugehen, dass einige ISAnhänger in Gaza seit dem Sommer 2014 in sporadische Raketenangriffe gegen Israel involviert waren. Auch diese dürften aber ohne Absprache mit der IS-Führung erfolgt sein. Eine höhere Gefahr geht möglicherweise vom IS-Ableger auf der Sinai-Halbinsel aus. Israelische Sicherheitskräfte gingen im September 2016 davon aus, dass dieser in der nahen Zukunft einen Angriff gegen Israel durchführen würde. ${ }^{118}$

\section{Antisemitismus beim Islamischen Staat}

Analog zu Hamas und Al-Qaida ist die IS-Rhetorik geprägt von antisemitischen Elementen. Dessen mittlerweile getöteter Sprecher Abu Muhammad al-Adnani bezeichnete in einer Audiobotschaft von September 2014 Präsident Obama als ein „Maultier der Juden“ und behauptete, die Juden hätten gemeinsam mit den Kreuzfahrern hunderttausende Muslime getötet. ${ }^{119}$ Zudem zitierte er eine Stelle im Koran, gemäß der

113 Even If The Disbelievers Despise Such - Baghdadi's latest speech (Transcript), in: Terrorism Research and Analysis Consortium, o. D., [https://www.trackingterrorism.org/chatter/even-if-disbelievers-despise-such-baghdadis-latestspeech-transcript], eingesehen 11.11.2017.

114 Denver Nicks, ISIS Leader Reportedly Warns Israel. „We Are Getting Closer to You“, in: TIME, 26.12.2015, [http://time.com/4161623/isis-leader-baghdadi-message-israel/], eingesehen 11.11.2017.

115 Daniel J. Roth, Watch: Hebrew-Speaking ISIS-Jihadi Threatens Israel, Jews Worldwide in New Video, in: The Jerusalem Post, 23.10.2015, [http://www.jpost.com/Arab-Israeli-Conflict/Hebrew-speaking-ISIS-jihadi-threatensIsrael-Jews-worldwide-in-new-video-429884], eingesehen 11.11.2017.

116 ISIS: Jihad In Palestine Does Not Take Precedence Over Jihad Elsewhere, in: MEMRI, 22.3.2016, [https://www.memri.org/reports/isis-jihad-palestine-does-not-take-precedence-over-jihad-elsewhere\#_edn3], eingesehen 11.11.2017.

117 Judah Ari Gross, First IDF-Islamic State clash sends Israeli message: Don't mess with us, in: The Times of Israel, 27.11.2016, [http://www.timesofisrael.com/first-idf-islamic-state-clash-unlikely-a-gamechanger-experts-say/], eingesehen 11.11.2017.

118 Israel 'bracing for attack' by IS in Sinai in next 6 months, in: The Times of Israel, 10.9.2016, [http://www.timesofisrael.com/israel-bracing-for-attack-by-is-in-sinai-in-next-6-months/], eingesehen 11.11.2017.

119 Yara Bayoumy, Islamic State urges attacks on U.S., French citizens, taunts Obama, in: Reuters, 22.9.2014, [http://www.reuters.com/article/us-iraq-crisis-adnani/islamic-state-urges-attacks-on-u-s-french-citizens-taunts- 
die Juden versuchen würden, die Muslime von ihrem Glauben abzubringen. Auch das bereits erwähnte IS-Video in hebräischer Sprache ist geprägt von Antisemitismus. Der hebräischsprachige IS-Kämpfer kündigt darin an, dass der Islamische Staat die ganze Welt von der „Krankheit“ der Juden reinigen werde. ${ }^{120}$ Wenig verwunderlich finden sich auch in den IS-Publikation wie Dabiq antisemitische Topoi wie die Gharqad-Hadith und zahlreiche Verschwörungstheorien, wonach Juden die US-Regierung kontrollieren würden. ${ }^{121}$ Allerdings nehmen die Juden im Vergleich mit der IS-Propaganda gegen Schiiten, Apostaten und Christen eine fast schon untergeordnete Rolle ein. Dies hat ISAnhänger in Europa allerdings nicht davon abgehalten, gezielte Terrorakte gegen jüdische Ziele zu begehen, etwa gegen das jüdische Museum in Brüssel 2014, den Hyper Cacher-Supermarkt in Paris im Januar 2015 sowie gegen eine Synagoge in Kopenhagen im Februar 2015. ${ }^{122}$ Zudem habe laut anonymen Quellen mindestens einer der Attentäter des Anschlags am Brüsseler Flughafen im März 2016 gezielt orthodoxe Juden ins Visier genommen. ${ }^{123}$

\section{Der Islamische Staat und die Hamas}

Das Verhältnis zwischen dem IS und der Hamas ist mindestens so kompliziert wie jenes zwischen letzterer und Al-Qaida. Der IS kritisierte die Hamas wiederholt für ihren Nationalismus und ihre unzureichende Umsetzung der Scharia in Gaza. Verglichen mit jener Al-Qaidas an der Hamas fällt die Kritik aber noch schärfer aus und in verschiedenen Publikationen wurden Hamas und Muslimbruderschaft als „Apostaten“ und „Verräter gegenüber dem Islam“ bezeichnet. ${ }^{124}$ Während dem Gaza-Krieg von 2014 verbrannten ISIS-Kämpfer in Syrien Palästinenserflaggen, ein klarer Affront gegenüber der Hamas. ${ }^{125}$ Im Gegenzug verurteilte die Hamas den Anschlag auf die Charlie Hebdo-Redaktion im Januar 2015, wobei sie die jüdischen Opfer des Hyper Cacher Anschlags unerwähnt ließ, sowie die multiplen Terrorakte in Paris im November 2015. ${ }^{126}$ Der Hamas-nahe

obama-idUSKCNOHH1MB20140922], eingesehen 11.11.2017.

120 Roth, Hebrew-Speaking ISIS-Jihadi Threatens Israel.

121 Anti-Defamation League, Anti-Semitism: A Pillar of Islamic Extremist Ideology, 2015, S. 3-4,

[https://www.adl.org/sites/default/files/documents/assets/pdf/combating-hate/Anti-Semitism-A-Pillar-of-

Islamic-Extremist-Ideology.pdf], eingesehen 11.11.2017.

122 Ebd., S. 4.

123 Lachlan Carmichael, Brussels airport bombers targeted Jews, Americans, investigators say, in: The Times of Israel, 24.1.2017, [http://www.timesofisrael.com/brussels-airport-bombers-targeted-jews-americans-investigators-say/], eingesehen 11.11.2017.

124 Cole Bunzel, From Paper State to Caliphate: The Ideology of the Islamic State (The Brookings Project on U.S. Relations with the Islamic World Analysis Paper 19), Washington D.C. 2015, S. 10.

125 Ali Mamouri, Why Islamic State has no sympathy for Hamas, in: Al-Monitor, 29.7.2014, [https://www.almonitor.com/pulse/originals/2014/07/islamic-state-fighting-hamas-priority-before-israel.html],

eingesehen 11.11.2017.

126 Nidal al-Mughrabi, Hamas condemns France attacks, says no justification for ,killing innocents', in: Reuters, 11.1.2015, [http://www.reuters.com/article/us-france-shooting-hamas/hamas-condemns-france-attacks-says-nojustification-for-killing-innocents-idUSKBNOKJOMP20150111], eingesehen 11.11.2017; Hamas, Islamic Jihad 
Muslimbruderschaft-Geistliche Scheich Yussuf Al-Qaradawi erklärte bereits 2014 das ISKalifat für illegitim. ${ }^{127}$ Zudem geht die Hamas, wie schon früher gegen Al-QaidaSympathisanten, entschlossen gegen IS-Anhänger vor. Im Mai 2015 zerstörte sie eine Salafistenmoschee in Gaza und verhaftete wiederholt IS-Sympathisanten. IS-Anhänger in Gaza erklärten infolge, die Hamas sei schlimmer als Israel. ${ }^{128}$ Auf der anderen Seite arbeitet die Hamas eng mit dem IS-Ableger auf der Sinai Halbinsel zusammen. Dessen Kämpfer erhielten etwa medizinische Versorgung in Gaza sowie militärisches Training durch die Qassam-Brigaden. ${ }^{129}$ Die Hamas erlaubte dem IS-Ableger zudem die Eröffnung eines Propaganda-Büros in Gaza, beliefert dessen Kämpfer mit Waffen und besteuert IS-Schmuggeltunnels zwischen Gaza und Ägypten. ${ }^{130}$

\section{Schlussfolgerung}

Wie dieser Beitrag aufgezeigt hat, spielen Antisemitismus und Antizionismus sowohl bei Hamas als auch bei Al-Qaida und IS eine wichtige Rolle in Ideologie und Praxis. Zugleich lassen sich bei den drei Organisation erhebliche Unterschiede ausmachen, insbesondere bei konkreten antisemitischen oder antizionistischen Aktivitäten (die Rhetorik dagegen ist bei allen mehr oder weniger dieselbe). Für die Hamas bleibt die Zerstörung Israels ihr ultimatives Ziel und folglich fokussiert das Gros ihrer Anstrengungen, d. h. sowohl ihre politischen als auch militärischen Kapazitäten, darauf. Zugleich ist sie bemüht, trotz fundamental antisemitischer Rhetorik, ihre Angriffe seit Ende der zweiten Intifada auf ihrer Ansicht nach - „legitime“ Ziele, d. h. im Allgemeinen „Zionisten“ und dabei insbesondere Soldaten und Siedler, zu beschränken. So ist bei der Hamas, anders als bei den säkularen palästinensischen Terrorgruppen, kein Anschlag außerhalb des israelischen bzw. palästinensischen Gebiets bekannt. Während das Konzept des Juden als des totalen Feindbilds im kosmischen Kampf zwischen Gut und Böse zwar durchaus eine Rolle spielt, zeichnen sich die Aktivitäten der Hamas durch einen gewissen Pragmatismus aus, der ihr in den Augen der Weltöffentlichkeit Legitimation für ihre Sache verleihen soll.

condemn Paris attacks, in: The Times of Israel, 14.11.2015, [http://www.timesofisrael.com/hamas-islamic-jihadcondemn-paris-attacks/], eingesehen 11.11.2017.

127 Shafik Madhai, Muslim leaders reject Baghdadi's caliphate, in: Al Jazeera, 7.7.2014,

[http://www.aljazeera.com/news/middleeast/2014/07/muslim-leaders-reject-baghdadi-caliphate-

20147744058773906.html], eingesehen 11.11.2017.

128 Joanna Paraszczuk, As Tensions Rise, Pro-IS Group In Gaza Complains Hamas ,Worse Than Israel', in: Radio Free Europe/Radio Liberty, 5.5.2015, [https://www.rferl.org/a/islamic-state-group-in-gaza-says-hamas-worse-thanisrael/26995991.html], eingesehen 11.11.2017.

129 Michel Wyss, Hamas und der Islamische Staat. Zwischen Kooperation und Repression, in: Audiatur-Online, 27.1.2016, [http://www.audiatur-online.ch/2016/01/27/hamas-und-der-islamische-staat-zwischen-kooperationund-repression/], eingesehen 11.11.2017.

130 Avi Issacharoff, Hamas, Islamic State resume close cooperation despite pressure from Cairo, in: The Times of Israel, 15.1.2017, [http://www.timesofisrael.com/hamas-islamic-state-resume-close-cooperation-despite-pressure-fromcairo/], eingesehen 11.11.2017. 
Al-Qaida und IS dagegen kümmern sich nicht um solche - für die Hamas politisch relevanten - Distinktionen. Stattdessen haben beide gemäß ihrer antisemitischen Rhetorik bislang vorwiegend jüdische Ziele außerhalb Israels ins Visier genommen (selbstverständlich liegt auch dies teilweise einem operationellen Pragmatismus zugrunde, da solche Ziele einfacher anzugreifen sind). Interessant ist dabei, dass für den IS sowohl die Juden als auch Israel als Feindbilder eine geringere Rolle spielen als bei Al-Qaida, bei der diese zentral waren. Dies dürfte einerseits mit einem Bedürfnis nach Abgrenzung gegenüber Al-Qaida zusammenhängen, andererseits aber auch mit der operationellen Ausrichtungen der beiden Organisation: der „ferne Feind“ bei Al-Qaida, bzw. der „nahe Feind" beim IS. Schließlich lassen sich anhand dieses Vergleichs die Unterschiede und Gemeinsamkeiten zwischen der Muslimbruderschaft, vertreten von der Hamas, und der globalen Dschihad-Bewegung, repräsentiert durch Al-Qaida und IS, nachvollziehen. Die Hamas fokussiert (einstweilen) auf ein örtlich beschränktes Ziel und verbindet zu dessen Erreichung Nationalismus und Islam. Neben dem Einsatz von Gewalt gibt sie sich politisch pragmatisch und partizipiert gar an demokratischen Prozessen. Für Al-Qaida und den IS hingegen gibt es, in den Worten Abdallah Azzams, ,nur das Gewehr und den Dschihad“. Jegliches politische Engagement außerhalb des bewaffneten Kampfs gilt für sie als unislamisch und der salafistischen Doktrin widersprechend. Folglich sind für AlQaida und IS die Hamas und überhaupt die Muslimbruderschaft Verräter an ihrer Religion (was aber, wie aufgezeigt, taktische Kooperationen zwischen beiden Seiten nicht verunmöglicht). Einig sind sich alle drei einzig und allein in ihrer Feindschaft gegen Israel und das Judentum. 



\title{
Grundlagen und Formen der Annäherung zwischen dem Islamismus und der radikalen ,globalen Linken“ nach $9 / 11$
}

\author{
Daniel Rickenbacher
}

\section{Einführung}

Die Annäherung zwischen linken und islamistischen Gruppierungen im Jahrzehnt nach dem 11. September 2001 war eine für viele überraschende und kontroverse Entwicklung. Sie hatte sowohl ideologische Grundlagen, etwa die gemeinsame Ablehnung Israels und den Hang zu einem dichotomen, anti-westlichen Weltbild, als auch taktische Gründe. So argumentierten linke Aktivisten, durch die Bündnisse mit islamistischen Gruppierungen ließen sich Muslime für linke Politik gewinnen. Wie eine kurze Auflistung zeigt, waren solche links-islamistischen Bündnisse keine isolierten Ausreißer, sondern ein weit verbreitetes internationales Phänomen. So entstand in England aus den Protesten gegen den dritten Irakkrieg im Jahr 2003 die Respect Party, ein Joint Venture britischer Islamisten und Linker. ${ }^{1}$ In Ägypten vereinte die 2002 ins Leben gerufene KairoKonferenz linke Gruppierungen und Parteien aus Europa sowie Islamisten aus dem Nahen Osten. An den sechs Tagungen der Kairo-Konferenz nahmen unter anderem auch die Muslimbruderschaft, ihr palästinensischer Ableger Hamas sowie die libanesische Hisbollah teil, bis die Konferenz 2009 vom Mubarak-Regime gewaltsam aufgelöst wurde. ${ }^{2}$ Auf der internationalen Bühne wurde das linkspopulistische Regime von Hugo Chávez in Venezuela, das auch unter der europäischen Linken Zustimmung bis tief ins sozialdemokratische Milieu fand, zum bevorzugten Verbündeten des schiitischislamischen Regimes im Iran. ${ }^{3}$ In Frankreich begannen politische Beobachter und Wissenschaftler daher Anfang der 2000er-Jahre, von einem rot-grünen Bündnis zwischen Islamisten und Sozialisten zu sprechen. ${ }^{4}$ Jedoch erhob sich früh - gerade auch innerhalb der politischen Linken - Kritik an diesen Allianzen. Fred Halliday, ein Nahost-

${ }^{1}$ Eran Benedek, Britain's Respect Party. The Leftist-Islamist Alliance and Its Attitude toward Israel, in: Jewish Political Studies Review 19 (2007), Heft 3/4, S. 153-163.

${ }^{2}$ Emmanuel Karagiannis/Clark McCauley, The emerging Red-Green alliance. Where political Islam meets the radical left, in: Terrorism and Political Violence 25 (2013), Heft 2, S. 167-182, hier S. 172.

3 Siehe z. B. Franco Cavalli, Was in Venezuela wirklich geschieht, in: WOZ, 9.4.2014, [https://www.woz.ch/-4daf], eingesehen 5.10.2017. - Franco Cavalli, ehemaliger Fraktionschef der SP Schweiz, gehört zu den profiliertesten Verteidigern des venezulanischen Regimes und ist sogleich als antiisraelischer Aktivist bekannt.

${ }^{4}$ Alexandre del Valle, La convergence des totalitarismes, ou les nouveaux visages rouge-bruns-verts de l'antisémitisme, in: Observatoire du monde Juif, 5.9.2002; Pierre-André Taguieff, L'émergence d'une judéophobie planétaire: islamisme, antiimpérialisme, antisionisme, in: Outre-Terre (2003), Heft 3/2, S. 189-226. 
Wissenschaftler und selbst ein erfahrener antiimperialistischer Aktivist, gehörte zu den prominentesten innerlinken Warnern vor dem „falschen Bewusstsein, das so viele sogenannte Linke in die Arme der Dschihadisten treibt" ${ }^{5}$ Derartige Warnungen verhallten allerdings meist ungehört.

In den letzten Jahrzehnten konnte man verschiedene intensivere und weniger intensive Formen der Zusammenarbeit zwischen linken und islamistischen Gruppen beobachten. Die Politikwissenschaftler Ackermann und Bale unterscheiden dabei vier Kategorien: Gegenseitige rhetorische Unterstützung, gemeinsame politische Mobilisierung, sowie schließlich operative paramilitärische und logistische Zusammenarbeit. ${ }^{6}$ Dieser Beitrag befasst sich mit der gewaltfreien Zusammenarbeit beider Richtungen in den ersten beiden Bereichen, wobei das Themenfeld des Terrorismus ebenfalls kurz gestreift werden soll. Ferner wird untersucht, wie das Paradigma der links-islamistischen Einheitsfront (engl. United Front) nach dem 11. September 2001 durch linke Intellektuelle popularisiert und schließlich in Großbritannien und Ägypten zu einer Zusammenarbeit auf lokaler Ebene führte. Der Aufsatz analysiert die rhetorische Konstruktion des Islam und islamistischer Bewegungen als natürliche strategische Verbündete in linken Diskursen. Schließlich behandelt der Artikel die gemeinsamen Deutungsmuster und Weltanschauungen, welche die Zusammenarbeit zwischen der extremen Linken und dem politischen Islam erst möglich machen.

\section{Die Einheitsfront: Die antiimperialistische Antwort auf den 11. September und das Ende der Menschenrechte}

Die islamistischen Anschläge vom 11. September 2001 waren ein einschneidendes Ereignis für das linke Verhältnis zum Islam. Der Islam hatte bis dahin bestenfalls eine periphere Stellung in linken Diskursen eingenommen. Der Antiimperialismus, den die Neue Linke seit den 1960ern popularisierte, war eine nationalistische Ideologie mit einem reduktiven Freund-Feind Schema. Konflikte in der Dritten Welt und im Nahen Osten galten darin als Ausdruck eines Hegemonialstrebens der Vereinigten Staaten und ihrer Verbündeten, das sich gegen einheimische, „progressive“ nationalistische Bewegungen richtete. Religion spielte dabei eine untergeordnete Rolle. Dieser antiimperialistische Rahmen war nicht nur inadäquat, um die Konflikte während des Kalten Krieges zu verstehen, insbesondere den arabisch-israelischen Konflikt, sondern erwies sich nach dessen Ende als noch ungeeigneter. Dennoch prägte dieser antiimperialistische Rahmen die Reaktion linker Aktivisten und Intellektueller auf den Terroranschlag auf das World

${ }^{5}$ Fred Halliday, The left and the jihad, in: Open Democracy 8 (2006), [http://thedivineconspiracy.org/Z5203D.pdf], eingesehen 12.5.2015.

6 Gary A. Ackerman/Jeffrey M. Bale, The potential for collaboration between Islamists and Western left-wing extremists: A theoretical and empirical introduction, in: Dynamics of Asymmetric Conflict 5 (2012), Heft 3, S. 151-171, hier S. 152-153. 
Grundlagen und Formen der Annäherung zwischen dem Islamismus und der radikalen ,globalen Linken“

Trade Center und den anschließenden „Krieg gegen den Terror“. Der marxistische Historiker Moishe Postone kritisierte 2006 unter anderem, die linke Analyse von 9/11 habe die Ideologie der Attentäter ignoriert und sei apologetischer Natur. Statt einer erkenntnisorientierten Analyse habe die Linke ihren eigenen Verständnisrahmen, insbesondere ihre Kritik an US-amerikanischer und israelischer Politik, den Ereignissen aufgezwungen. ${ }^{7}$ Generell wurden die Angriffe in weiten Teilen der Linken als irregeleitete, aber verständliche Reaktion auf den westlichen Imperialismus gewertet.

Statt den Islamismus zu konfrontieren, entwickelten radikale Elemente der britischen und der amerikanischen Linken nach 9/11 das Konzept einer Einheitsfront mit dem Islamismus. Ein führender Akteur dieses Projektes war die britische Socialist Workers Party (SWP). Die Wissenschaftlerin und linke Aktivistin Camilla Bassi, die damals selbst der SWP angehörte, schilderte die Diskussionen innerhalb der SWP nach dem 11. September in einem aufschlussreichen Dokument. Ihre Darstellung bestätigt Postones Kritik. Die Parteimitglieder verurteilten bei einem Treffen unmittelbar nach 9/11 zwar den Anschlag, aber nur aus taktischen Gründen. Intern hielten sie diese Taten für gerechtfertigt. In einer öffentlichen Diskussion im November 2001 lehnte die Mehrheit der SWP Camilla Bassis Forderung ab, sowohl den amerikanischen Krieg in Afghanistan und als auch die Taliban gleichermaßen zu verurteilen und stattdessen afghanische progressive Kräfte zu unterstützen. Bassis Gegner argumentierten, die Bekämpfung des größeren Übels, d. h. der USA und Großbritanniens, hätte Priorität. ${ }^{8}$ Dabei gälte es zu vermeiden, die ,entfremdeten Massen desillusionierter, wütender britisch-muslimischer Jugendlicher, die die Sozialisten für sich gewinnen müssten“ zu verärgern. ${ }^{9}$ Es wird hier ein Widerspruch zwischen öffentlichem und internem Diskurs in der SWP offenbar. Während die SWP öffentlich betonte, dass ein Großteil der Muslime keine Sympathien für die Terroristen hätte, ging ihr wahlpolitisches Kalkül von der entgegengesetzten Annahme aus. Das SWP-Zentralkomitee verkündete daher die „Einheit der Basis der Opposition gegen den [...] Krieg allein, ohne den Zusatz anderer Leitlinien (z. B. Verurteilung des Terrorismus), die einige wichtige potentielle Verbündete ausschließen können und implizieren, dass der Hauptfeind jeder außer dem westlichen Imperialismus ist $[. . .]^{\text {“ } .10}$ Wie wir sehen war, die Inklusion islamistischer, gewalttätiger Gruppierungen im Kampf gegen den „,westlichen Imperialismus“ daher bewusste Politik der von der SWP angeführten Koalition.

Eine Reihe linker Intellektueller verfolgte das Projekt, diese links-islamistische Einheitsfront von der lokalen auf die globale Ebene auszudehnen. Zu ihnen gehörte die

${ }^{7}$ Moishe Postone, History and helplessness: mass mobilization and contemporary forms of anticapitalism, in: Public Culture 18 (2006), Heft 1, S. 93-110, hier S. 97-98.

${ }^{8}$ Camila Bassi, ,The Anti-Imperialism of Fools“. A Cautionary Story on the Revolutionary Socialist Vanguard of England's Post-9/11 Anti-War Movement, in: ACME. An international E-journal for Critical Geographies 9 (2010), Heft 2, S. 113-137, hier: S. 113.

${ }^{9}$ Ebd., S. 114.

${ }^{10}$ Ebd., S. 126. 
amerikanische Philosophin Susan Buck-Morss. In ihrem Essay „Can there be a Global Left?" diskutierte Buck-Morss die Schaffung einer weltweiten Allianz, die auf der Verbindung der Modernitätskritik der Frankfurter Schule und jener Said Qutbs basieren würde. Ein solches „deutsch-jüdisches und arabisch-muslimisches“ Bündnis sei zwar bislang keine Realität, ,,aber schon der Gedanke an ein solches Bündnis, ein Angriff von innen und außen, suggeriert die Macht, die eine neue Linke in der Weltöffentlichkeit heute zu haben beginnt". ${ }^{11}$ Antinazistische Modernekritik nach Frankfurter Schule und antiwestlicher, antisemitischer Islamismus als gemeinsames Projekt. Für Buck-Morss war es daher die Aufgabe der zeitgenössischen Linken, „nach einem Pfad zu suchen, der kritische Diskurse, die sich in Teilkontexten entwickelt haben, miteinander verknüpft, um sie für eine noch zu konstituierende, globale progressive Linke nutzbar zu machen“. ${ }^{12}$ Eine ähnliche Vision äußerte Judith Butler bei einem Sit-In an der Universität Berkeley im Jahr 2006, als sie betonte, wie wichtig es sei, Hamas und Hisbollah als soziale Bewegungen zu verstehen, „die progressiv sind, die links stehen, die Teil der globalen Linken sind" und die es daher auf eine kritische Weise einzubeziehen gälte. ${ }^{13}$ Sowohl Buck-Morss als auch Judith Butler sehen sich als Vertreterinnen der Frankfurter Schule. Der Politikwissenschaftler Stephan Grigat wies jedoch darauf hin, dass sich Butlers proislamistische und damit auch gegenüber dem Antisemitismus implizit tolerante Einstellung kaum mit Adornos in der „Negativen Dialektik“ formuliertem kategorischen Imperativ vertrage. Dieser fordert, ,alles Handeln und Denken so einzurichten, dass Auschwitz sich nicht wiederhole, nichts Ähnliches geschehe“". ${ }^{4}$ Schon damals wurde klar, dass die Vision einer globalen Linken, die linken und islamistischen Antiimperialismus verband, nur realisierbar war durch einen Verzicht auf die Universalität der Menschenrechte und durch eine implizite Toleranz gegenüber Antisemitismus und Terror. Buck Morss argumentierte in diesem Sinne konsequent, „westlich definierte Freiheiten“ wie die universalen Menschenrechte dürften in einem „postkolonialen Kontext“ keine große Rolle spielen. Als Alternative schlug sie das Konzept der Würde vor: „Es geht hier nicht um Freiheit, sondern um Würde. Und im postkolonialen Kontext ist Würde wichtig. Besser ausgedrückt, Würde ist Freiheit in einem anderen Sinne, nämlich als Befreiung von der westlichen Hegemonie. [...] Wenn die Übernahme westlich definierter Freiheiten die Unterwerfung unter die westliche Macht mit sich bringt, wird das angestrebte Ziel durch die Mittel der Selbstentfremdung untergraben. "15 Offenbar war Buck-Morss bereit, die Menschenrechte, jedenfalls jene der

\footnotetext{
${ }^{11}$ Susan Buck-Morss, Thinking Past Terror. Islamism and Critical Theory on the Left, New York 2003, S. 99.

12 Ebd., S. 101.

13 Iakovos Alhadeff, Judith Butler on Hamas, Hezbollah \& the Israel Lobby (2006), in: radicalarchives, 28.3.2010, [http://radicalarchives.org/2010/03/28/jbutler-on-hamas-hezbollah-israel-lobby/], eingesehen 28.1.2016.

${ }^{14}$ Stephan Grigat, Die Einsamkeit Israels. Zionismus, die israelische Linke und die iranische Bedrohung, Hamburg 2014.

15 Buck-Morss, Thinking Past Terror, S. 46.
} 
Grundlagen und Formen der Annäherung zwischen dem Islamismus und der radikalen ,globalen Linken“

Menschen in nicht-westlichen Staaten und Gesellschaften, zum Nutzen einer linksislamistischen Einheitsfront aufzulockern.

Nur durch ein manichäisches, bipolares Weltbild ist eine solche Haltung moralisch begründbar. Dies bedingt die Konstruktion eines Westens, repräsentiert durch die USA und Israel, als des absoluten Bösen. Gegenüber diesem sei jede Art von Gewalt moralisch und politisch gerechtfertigt. Dieses Weltbild schließt die Möglichkeit einer unabhängigen linken Position, die liberale Anliegen vertritt, aus. Die linkspopulistische kanadische Aktivistin Naomi Klein argumentierte genau in dieser Art, als sie 2004 „Progressive“ dazu aufrief, den amerikanischen Militäreinsatz gegen die Milizen des irakischen schiitischen Geistlichen Muktada al-Sadr, die den Aufbau eines islamischen Staates verfolgten, zu bekämpfen, weil letzterer eine hohe Popularität genieße und sich gegen die Amerikaner stellte. Obwohl sie Sadrs ,gefährlichen Fundamentalismus“ zur Kenntnis nahm, gab es für Klein nur zwei Optionen. Entweder man sprach sich für eine manipulierte Demokratie aus, welche die USA und ihre „Schufte“ begünstigen würde, oder man war für eine „richtige“ Demokratie, die zwar die Islamisten begünstigte, aber eben auch weltliche und progressive Kräfte. ${ }^{16}$ Diese linke Parteinahme für den Islamismus war daher auch Ausdruck einer schwächelnden Linken, deren einziges Mittel es war, auf den islamistischen Zug aufzuspringen, um wenigstens die Hoffnung auf politische Macht aufrechtzuerhalten. Auch andere Linksintellektuelle sahen in der Parteinahme für islamistische Akteure ein probates Mittel, um westliche Staaten zu bekämpfen. So besuchte der Linksintellektuelle Noam Chomsky im Mai 2006 das Hauptquartier der Hisbollah und verteidigte die auch im Libanon kritisierte verfassungswidrige militärische Bewaffnung der Gruppe, weil diese eine abschreckende Wirkung gegenüber Israel entfaltete. Kaum zwei Monate später provozierte die Hisbollah einen Krieg mit Israel und widerlegte damit Chomskys These. ${ }^{17}$ Vor die Wahl zwischen westlichen oder mit islamistischen Akteuren gestellt, solidarisierten sich linke amerikanische Aktivisten und Intellektuelle in verlässlicher Weise mit letzteren.

Wie bereits erwähnt, geht das Projekt einer globalen links-islamistischen Allianz einher mit einer Kritik an aufklärerischen Überzeugungen, insbesondere der Universalität der Menschenrechte oder der Idee zivilisatorischen Fortschritts. Judith Butler etwa kritisiert ein Narrativ, welches die westliche Geschichte als eine Entwicklung in Richtung größerer individueller Freiheit darstellt. Dieses Narrativ, so Butler, bedinge die Ablehnung eines antimodernen islamischen Anderen. ${ }^{18}$ In Folge traten vermehrt rechtsgerichtete und konservative Bewegungen als Vertreter traditionell aufklärerischer Positionen auf. In den USA wurde diese Entwicklung von den Neokonservativen eingeleitet, einer Gruppe

\footnotetext{
${ }^{16}$ Naomi Klein, The making of a hero, in: The Guardian, 7.10.2004, [http://www.theguardian.com/world/2004/oct/07/iraq.comment], eingesehen 6.6.2016.

17 U.S. Linguist Noam Chomsky Meets With Hizbullah Leaders in Lebanon, in: MEMRI, 16.5.2006, [http://www.memri.org/report/en/0/0/0/0/0/0/1690.htm], eingesehen 16.4.2016.

18 Judith Butler, Frames of War. When Is Life Grievable?, London-New York 2009, S. 102, zit. n. Birgit Schippers, The Political Philosophy of Judith Butler, New York 2014, S. 100.
} 
ursprünglich antistalinistischer Linker, die in den 1980ern zu Reagans Republikanern überliefen, weil sie ihre Werte nicht länger durch die Demokratische Partei vertreten sahen. Nach 9/11 verstärkte sich diese Entwicklung. Moishe Postone kritisierte die amerikanische Linke dafür, dass sie „,[...] der amerikanischen neokonservativen Rechten in der Bush-Administration erlaubt haben, das, was traditionell die Sprache der Linken war, zu übernehmen und sogar zu monopolisieren [... “. ${ }^{19}$ Er resümierte daher, dass „,der gesamte Diskurs des Wandels an die Rechte abgegeben wurde“.${ }^{20}$ Der linke Umgang mit dem 11. September 2001 und der Aufstieg des Islamismus lösten daher wohl eine der größte Krisen innerhalb der Linken seit dem Kalten Krieg aus. In vielerlei Hinsicht war die Krise vergleichbar mit der Desillusionierung, die linke Intellektuelle angesichts der Entzauberung des Kommunismus durch die stalinistischen Schauprozesse und ähnliche Ereignisse empfanden. Bekannte, ehemals dezidiert linke Stimmen wie Christopher Hitchens, Nick Cohen oder Melanie Philipps, um nur einige zu nennen, verließen in der Folge den Mainstream der Linken oder wurden „exkommuniziert“. Die damalige Entwicklung zeitigte ein eigenes Genre, in dem sich die Autorinnen und Autoren damit auseinandersetzten, wie die Linke von ihrem Weg abgekommen sei. Dahinter stand das Bemühen, die Werte einer aufgeklärten Linken, wie sie das Anliegen der Autoren war, zu retten. In ihrem Wesen erinnert diese Gattung stark an die Werke jener Intellektuellen, die ihren Bruch mit dem Kommunismus verarbeiteten. ${ }^{21} \mathrm{Oft}$ verbinden diese Bücher die Analyse der politischen Begebenheiten mit einer autobiografischen Darstellung der allmählichen Entfremdung des Autors von der Linken. ${ }^{22}$ In der Tat verstärkte 9/11 den schon lange andauernden Niedergang der Nachkriegs-Sozialdemokratie. Durch ihre Abgrenzung vom Sowjetkommunismus hatte sie sich eindeutig zum aufklärerischen Fortschrittsprojekt und zur Demokratie bekannt. Solche Inhalte standen nun vermehrt zur Disposition. Die Vision einer links-islamistischen Allianz war nur ein Ausdruck davon.

Kooperation zwischen Linken und Islamisten: Die „Stop the War Coalition" in Großbritannien und die Kairo-Konferenz

Im Folgenden sollen die Zusammenarbeit zwischen Linken und Islamisten in Großbritannien sowie die Argumente, um diese gegenüber Kritikern zu rechtfertigen, analysiert werden. Nur zehn Tage nach den Anschlägen vom 11. September wurde die Stop the War Coalition (SWC) ins Leben gerufen als eine Plattform gegen den von den USA angeführten „War on Terror“. Die Koalition hatte durchschlagenden Erfolg, als

19 Postone, History and Helplessness, S. 103.

20 Ebd.

${ }^{21}$ Siehe z. B. Arthur Koestler/Ignazio Silone/André Gide, Ein Gott, der keiner war, München 1962.

22 Siehe z. B. Paul Berman, Terror and Liberalism, New York 2004; Nick Cohen, What's Left? How the Left Lost its Way, How Liberals Lost Their Way, London 2007. 
Grundlagen und Formen der Annäherung zwischen dem Islamismus und der radikalen ,globalen Linken“

Hunderttausende in London und anderen britischen Städten an den von ihr organisierten Protesten gegen die britische Beteiligung am Dritten Golfkrieg im Jahr 2003 teilnahmen. Dominiert wurde die SWC von der trotzkistischen Socialist Workers Party (SWP). Die SWP kooperierte im Rahmen der SWC mit der Muslim Association of Britain (MAB), der örtlichen Zweigstelle der Muslimbruderschaft, um die verschiedenen Proteste zu koordinieren. ${ }^{23}$ Diese Kooperation zog die Kritik einiger linker Organisationen sowie von Einzelpersonen und Blogger auf sich. Die Alliance for Worker's Liberty zum Beispiel bezeichnete die MAB als „Faschisten“. ${ }^{24}$ Einer der prominentesten linken Kritiker war sicherlich der Guardian Kolumnist Nick Cohen. Nachdem die MAB eine Zeitung verteilt hatte, die zum Mord an Ex-Muslimen aufrief, bemerkte er sarkastisch: „Im Interesse des Multikulturalismus ignorierte die SWP die Proteste der zimperlichen Linken und ließ das durchgehen. Die Trotzkisten sind schließlich keine Islamfeinde. Die einzigen Muslime, gegen die sie eine Phobie haben, sind säkulare irakische Muslime, die schockierenderweise an die Menschenrechte glauben." 25 Nach einer Reihe von Gesprächen, die im November 2003 begonnen hatten, gründeten Mitglieder der SWC am 24. Januar 2004 die Respect Party (RP). ${ }^{26}$ Sie stellte weitgehend eine Allianz zwischen der trotzkistischen SWP und der islamistischen MAB dar, die jedoch als unabhängige Gruppierungen bestehen blieben. ${ }^{27}$

Die RP profitierte anfänglich von reichlichen Spenden und einer allgemeinen Enttäuschung über die Irak-Politik der Labour Party, insbesondere unter den muslimischen Wählern. Die Partei bemühte sich stark um dieses Wählersegment auf der Basis einer muslimischen Identitätspolitik. Bei den Europawahlen 2004 bezeichnete sie sich daher als „die Partei für Muslime“ und kämpfte gegen Irakkrieg und AntiterrorGesetzgebung. ${ }^{28}$ Die RP erzielte einen Achtungserfolg und erhielt eine Viertelmillion Stimmen oder 1,5 Prozent der Stimmen. Sie war damit siebtstärkste Kraft, holte jedoch keine Sitze. In zwei stark muslimisch geprägten Bezirken im Osten Londons erhielt die RP gar mehr als $20 \%$ der Stimmen und wurde stärkste Partei. Gleichwohl schnitt sie nicht in allen Bezirken mit einer bedeutenden muslimischen Bevölkerung erfolgreich ab. ${ }^{29}$ Der denkwürdigste Erfolg der RP ereignete sich 2005, als der Labour-Renegat George Galloway den parlamentarischen Sitz der Labour Amtsinhaberin Oona King errang. King, die jüdischer und afroamerikanischer Herkunft ist, sah sich im Wahlkampf

23 Zur Geschichte der MAB siehe Lorenzo Vidino, The New Muslim Brotherhood in the West, New York 2010, S. 140-146.

${ }^{24}$ Peter Ullrich, Die Linke, Israel und Palästina. Nahostdiskurse in Großbritannien und Deutschland, Berlin 2008, S. 219.

${ }^{25}$ Nick Cohen, The Left isn't listening, in: The Guardian, 16.2.2003,

[http://www.theguardian.com/politics/2003/feb/16/foreignpolicy.iraq], eingesehen 7.11.2015.

26 Timothy Peace, All I'm Asking, Is For a Little Respect: Assessing the Performance of Britain's Most Successful

Radical Left Party, in: Parliamentary Affairs 66 (2013), Heft 2, S. 405-424, hier S. 407.

${ }^{27}$ Benedek, At Issue.

${ }^{28}$ Peace, All I'm Asking, S. 415.

${ }^{29}$ Ebd., S. 408-416. 
wiederholt antisemitischen Angriffen ausgesetzt. U. a. drängten RP-Mitglieder die Wähler, aufgrund Kings jüdischer Identität nicht für diese zu stimmen. ${ }^{30}$ Galloways Kandidatur profitierte auch von der Unterstützung durch islamistische Organisationen. $\mathrm{Zu}$ diesen gehörte das Islamic Forum Europe. Diesem schrieb Galloway in seiner Dankesrede eine entscheidende Rolle bei seinem Sieg zu. Die Gruppe strebt die Errichtung eines Kalifats auf der Grundlage der Scharia an und hatte ihren Sitz in der East London Moschee. ${ }^{31}$ George Galloways Wahlsieg zeigte, dass es möglich war, basierend auf einer islamisch-identitären Plattform erfolgreich Politik zu betreiben.

Die RP war die prominenteste, aber nicht die einzige linke Initiative zur damaligen Zeit, die zum Ziel hatte, britische Muslime für die extreme Linke zu mobilisieren. Einer ähnlichen Strategie bediente sich auch der linkspopulistische Labour-Bürgermeister von London Ken Livingstone. 2004 und 2005 fungierte er als Gastgeber des spirituellen Führers der Muslimbruderschaft, Yussuf al Qaradawi, den er als „progressive Persönlichkeit" beschrieb. ${ }^{32}$ Kritiker, die auf die Unterstützung des Klerikers für Selbstmordattentate und dessen gut bezeugten antisemitischen, frauenfeindlichen und homophoben Äußerungen aufmerksam machten, wurden von Livingstone und seinen Gefolgsleuten der Verleumdung und der „Islamophobie“ beschuldigt. ${ }^{33} \mathrm{Nach}$ den Erfolgen der RP im Jahr 2005 setzte auch die SWP ihre Annäherungspolitik an den Islamismus fort. So bezogen sich 2006 auf der jährlichen SWP-Marxismus-Konferenz mehrere Redner auf die Verschwörungstheorie eines „Krieges gegen den Islam“, die zu den Kernelementen der islamistischen Weltanschauung gehört, und riefen zu dessen Verteidigung auf. ${ }^{34}$ Muslimbruderschaft-Aktivist Azzam Tamimi erhielt heftigen Applaus während seiner Rede, als er gestand: „Ich war mein ganzes Leben lang Mitglied der Muslimbruderschaft. Ich bin ein treuer Anhänger der Hamas. Und ich bin stolz darauf.“35 Die linksislamistische Allianz übte auch Einfluss auf die Hochschulpolitik aus. Studentengruppen der SWP unterstützten die Föderation Islamischer Studenten-

${ }^{30}$ Ebd., S. 409.

31 Andrew Gilligan, IFE: not harmless democrats, in: The Guardian, 4.3.2010,

[http://www.theguardian.com/commentisfree/belief/2010/mar/04/islamic-forum-europe-dispatches-gilligan], eingesehen 9.11.2015; Ders., The infiltration of Labour, in: Telegraph, 28.2.2010,

[http://www.telegraph.co.uk/news/politics/labour/7333470/The-infiltration-of-Labour.html], eingesehen 9.11.2015.

${ }^{32}$ Mayor justifies cleric's welcome, in: BBC Online, 11.1.2005, [http://news.bbc.co.uk/2/hi/4165691.stm], eingesehen 28.5.2018.

33 Peter Tatchell, Ken apologises (sort of), in: The Guardian, 7.4.2008,

[http://www.theguardian.com/commentisfree/2008/apr/07/kenapologisessortof], eingesehen 28.5.2018; Jeremy Havardi, Refuting the Anti-Israel Narrative. A Case for the Historical, Legal and Moral Legitimacy of the Jewish State, Jefferson (NC) 2016, S. 209-210.

34 Siehe dazu auch Daniel Rickenbacher, Der jüdisch-westliche „Krieg gegen den Islam“. Genealogie und Aktualität einer islamistischen Verschwörungstheorie, in: Marc Grimm/Bodo Kahmann (Hrsg.), Antisemitismus im 21. Jahrhundert. Virulenz einer alten Feindschaft in Zeiten von Islamismus und Terror, Berlin-Boston 2018, S. 157-178.

35 Ullrich, Die Linke, S. 220. 
Grundlagen und Formen der Annäherung zwischen dem Islamismus und der radikalen ,globalen Linken“

gesellschaften beispielsweise in ihrer Opposition gegen den internationalen HolocaustGedenktag. ${ }^{36}$

Antizionismus war ein wichtiges Standbein der RP. Der antiimperialistische Antizionismus der SWP und der antisemitische Antizionismus der MuslimbruderschaftAktivisten erwiesen sich dabei als kongruent. Der Libanon-Krieg im Jahr 2006 bot der RP die Gelegenheit, mit antiisraelischer Agitation unter britischen Muslimen um Unterstützung zu werben. In ihren Stellungnahmen drückte die RP ihren Wunsch nach der Zerstörung Israels aus und solidarisierte sich mit dessen terroristischen Feinden. So äußerte Lindsey German, eine führende RP-Aktivistin, bei einer Kundgebung, „dass, welche Meinungsverschiedenheiten ich auch immer mit Hamas und Hisbollah habe, ich lieber in ihrem Lager sein würde [...] sie wollen Demokratie. Demokratie im Mittleren Osten ist Hamas, ist Hisbollah“. ${ }^{37}$ Die RP-Führer trafen sich noch im selben Jahr mit der Hamas- und Hisbollah-Führung. ${ }^{38}$

RP erzielte in den Jahren 2005 bis 2007 bei Kommunal- und Parlamentswahlen weitere Erfolge. Insbesondere in den Bezirken mit den höchsten muslimischen Bevölkerungsanteilen im Vereinigten Königreich war die RP erfolgreich. Dieser Erfolg war jedoch zweischneidig. Es gelang der Partei letztlich nicht, islamistisch gesinnte Muslime für eine linke Politik zu gewinnen. Vielmehr driftete die RP immer mehr selbst in eine islamistische Richtung. Die RP spaltete sich schließlich 2007 in eine SWP-geführte und eine muslimisch geführte Teilpartei auf. Ein Grund für die Spaltung war das unterdurchschnittliche Abschneiden der nicht-muslimischen SWP-Kandidaten bei den Wahlen. Obwohl RP sowohl muslimische als auch nicht-muslimische Kandidaten auf ihre Wahllisten setzte, waren alle erfolgreichen Kandidaten muslimischer Herkunft. Dies unterstreicht die Tatsache, dass der Erfolg der RP größtenteils auf die Unterstützung muslimischer Wähler zurückzuführen war. ${ }^{39}$ Linke, nicht-muslimische Kandidaten konnten sich dagegen nicht durchsetzen.

Die durch die Stop the War Coalition (SWC) verkörperte links-islamistische Allianz hatte auch eine internationale Komponente. Ihre Ursprünge reichen in die Zeit nach dem Ausbruch der zweiten Intifada (auch: Al-Aqsa-Intifada) im September 2000 zurück. Zur Unterstützung des Aufstandes gründeten linke Organisationen im Oktober 2000 das Egyptian Popular Committee for Solidarity with the Palestinian Intifada EPCSPI (deutsch: Ägyptisches Volkskomitee für Solidarität mit der palästinensischen Intifada). Bald schlossen sich dem EPCSPI aber auch von der Muslimbruderschaft (MB) dominierte Berufsverbände und Gewerkschaften sowie Nasseristen an. ${ }^{40}$ Das EPCSPI entfaltete eine Reihe von Aktivitäten: Es rief u. a. zu einem Boykott amerikanischer und

36 Ebd., S. 219-220.

37 Benedek, At Issue.

38 Ebd.

${ }^{39}$ Peace, All I'm Asking, S. 417.

40 Maha Abdelrahman, „With the Islamists? - Sometimes. With the State? - Never!“ Cooperation between the Left and Islamists in Egypt, in: British Journal of Middle Eastern Studies 36 (2009), Heft 1, S. 37-54, S. 42. 
israelischer Waren auf, organisierte Demonstrationen und reichte eine Petition zur Schließung der israelischen Botschaft in Ägypten ein. ${ }^{41}$ Im September 2002 gründete die ägyptische Anwaltskammer, die von der Muslimbruderschaft kontrolliert wurde, die Egyptian Popular Campaign to Confront US Aggression (EPCCUA), um die Proteste gegen den Irak-Krieg zu koordinieren. ${ }^{42}$ Via EPCSPI und EPCCUA übte die MB wesentlichen Einfluss auf die organisierte antiamerikanische und antiisraelische „Antikriegsbewegung“ in Ägypten und später auch weltweit aus. Am 18. und 19. November 2002 organisierte die EPCCUA die erste Kairo-Konferenz, zu der neben Vertretern zahlreicher linker Organisationen auch Vertreter der Baath-Partei, der Muslimbruderschaft sowie Kubas eingeladen waren. Aus Großbritannien reisten der SWP-Funktionär John Rees und George Galloway an. ${ }^{43}$ Die Kairo-Konferenz war der Versuch, die linke, islamistische sowie arabisch-nationalistische Opposition gegen Israel und die amerikanische Irakpolitik zu vereinigen. Im Gegensatz zu ihren europäischen Genossen hielten viele ägyptische Linke jedoch merklich Abstand zur Konferenz. Sie wurden sowohl durch den antisemitischen Ton der Konferenz als auch durch glaubhafte Gerüchte abgeschreckt, wonach die Konferenz durch das Regime Saddam Husseins finanziert werde. ${ }^{44}$ Die Kairo-Konferenz verabschiedete schließlich eine Erklärung, die zum Boykott amerikanischer und israelischer Waren und zur Entsendung von menschlichen Schutzschilden in den Irak aufrief. Kritik am irakischen Regime wurde bewusst unterlassen. Das Dokument war von antisemitischen Vorstellungen einer jüdischen Weltverschwörung und einer jüdischen Kontrolle der USA geprägt: „Die USA wollen die arabischen Länder keineswegs heimlich in kleinere Einheiten auf ethnischer oder religiöser Basis aufteilen. Dies würde es Israel ermöglichen, die dominierende regionale Macht im Rahmen des Nahost-Projekts zu werden und das arabische Projekt der gerechten Entwicklung und der regionalen Einheit gefährden." ${ }^{45} \mathrm{Zu}$ den Unterzeichnern des Papiers gehörte, neben vielen anderen prominenten Linken, auch der britische Labour-Politiker Jeremy Corbyn, der später Vorsitzender der Partei geworden ist. ${ }^{46}$ Dies unterstreicht die fortwährende Kontinuität des Kairo-Programms in der Politik der britischen Linken.

An der zweiten Kairo-Konferenz im Dezember 2003 trat die MB erstmals als offizieller Partner der Konferenz auf. Die Konferenz stand unter den drei Schlagworten „Nein zur

41 Asef Bayat, The „Street“ and the Politics of Dissent in the Arab World, in: Middle East Report 226 (2003), [https://merip.org/2003/03/the-street-and-the-politics-of-dissent-in-the-arab-world/], eingesehen 1.2.2020.

42 Zur Ägyptischen Anwaltskammer siehe Jeffrey Haynes, Routledge Handbook of Religion and Politics, London 2008, S. 241.

43 Stan Crooke, The Cairo Declaration. Is it really a ,great opportunity“?, in: Workers' Liberty, 28.1.2003, [http://www.workersliberty.org/node/590], eingesehen 10.10.2017.

44 Ruth Reitan, The Global Anti-War Movement Within and Beyond the World Social Forum, in: Globalizations 6 (2009), Heft 4, S. 509-523, hier S. 519-520.

${ }^{45}$ Crooke, The Cairo Declaration.

46 Cairo motion is great opportunity, in: Socialist Worker online, 18.1.2003, [http://archive.is/4gpB2], eingesehen 10.10.2017. 
Grundlagen und Formen der Annäherung zwischen dem Islamismus und der radikalen ,globalen Linken“

kapitalistischen Globalisierung und US-Hegemonie“, „Nein zur Besetzung des Iraks und zu Zionismus in Palästina“ und „Nein zum Autoritarismus in der arabischen Region“. ${ }^{47}$ Erneut nahmen auch zahlreiche linke Organisationen und Aktivisten aus Europa und Nordamerika teil, besonders prominent die SWC. Die Anwesenheit islamistischer und terroristischer Organisationen wurde von diesen ausdrücklich begrüßt. In den Augen von John Rees bot die Konferenz generell eine einzigartige Gelegenheit für ein Zusammenkommen linker und islamistischer Kräfte:

„Wo sonst kannst du dich an einem einzigen Abend hinsetzen und den führenden Menschen der Hamas, der Hisbollah, der Muslimbruderschaft, der revolutionären Linken und der Anti-Kriegs-Bewegung rund um den Globus zuhören? Es gibt keinen anderen Ort. Also was auch immer die Kritik der Leute sein mag, [...] es ist [...] die beste Konferenz, die es im Nahen Osten zu dieser Frage gibt. Ich glaube auch, dass sie dazu beigetragen hat, der Demokratiebewegung in Ägypten einen gewissen politischen Raum zu eröffnen. Dies sind nicht unerhebliche Leistungen. “48

Trotzdem kam es gelegentlich zu Spannungen zwischen ägyptischen Linken und Islamisten. Die britische SWC Aktivistin Salma Yaqoob versuchte zu schlichten und forderte ,beide Seiten der Bewegung auf, Wege zu finden, enger zusammenzuarbeiten. Sozialisten, Nationalisten und Islamisten sollten einen gemeinsamen Nenner gegen einen gemeinsamen Feind suchen $[. . .]^{“ 4}{ }^{49}$ Die Linke realisierte dabei nicht, dass sie durch diese Politik ihre eigene Identität gefährdete. Prominente Vertreter der extremen Linken, wie der französisch-libanesische Aktivist Gilbert Achcar, kritisierten das Bündnis zwischen der SWP und der Muslimbruderschaft aus taktischen, aber nicht aus prinzipiellen Gründen. In einem Artikel aus dem Jahr 2005 beschuldigte er die trotzkistische Partei, die Grundlagen der Zusammenarbeit mit nicht-sozialistischen Verbündeten zu missachten, indem sie „Banner und Plakate mischte, [...] die Bedeutung der Elemente ihrer politischen Identität minimierte, die ihre fundamentalistischen Verbündeten des Tages in Verlegenheit bringen könnten; und schließlich [...] diese temporären Verbündeten so zu behandeln, als seien sie strategische Verbündete“ ${ }^{50}$ In der Tat - die Linke war der schwächere Partner in der links-islamistischen Allianz und wurde zunehmend von ihren islamistischen Verbündeten vereinnahmt.

\footnotetext{
47 Abdelrahman, With the Islamists?, S. 43-44.

${ }^{48}$ John Rees/Amira Howeidy, „Our opponents are on the defensive“, in: Ikhwanweb, 7.4.2007, [http://ikhwanweb.com/article.php?id=1899] (ursprünglich erschienen in: $A l$ Ahram), eingesehen 10.10.2017.

49 Anne Ashford, Cairo Conference: Middle Eastern Promise, in: Socialist Review (2004), Heft 281, [http://socialistreview.org.uk/281/cairo-conference-middle-eastern-promise], eingesehen 31.10.2015.

50 Gilbert Achcar, Marxists and Religion - yesterday and today, in: International Viewpoint, 16.3.2005, [http://www.internationalviewpoint.org/spip.php?article622], eingesehen 30.12.2015.
} 


\section{Der Islam als Partner gegen den Imperialismus?}

Die Unterstützung von Islamisten durch Linke wird in der Regel durch die gemeinsame antiimperialistische und antizionistische Agenda gerechtfertigt. Diese strategischen Gemeinsamkeiten würden die ideologischen Gegensätze überwiegen, die durchaus zur Kenntnis genommen wurden. Eddie Truman, der Betreiber des inzwischen eingestellten Blogs Islamophobia Watch, etwa schrieb 2004:

„Ungeachtet unserer Differenzen mit dem militanten Islam müssen wir der Tatsache ins Auge sehen, dass die islamischen Organisationen Massenparteien sind, die militanten Widerstand gegen die Unterdrückung der USA und Israels darstellen. Die Hamas in Palästina ist eine massive Macht, die die Palästinenser vor einem mörderischen Ansturm eines israelischen Staates schützt, der entschlossen ist, sie von der Erdoberfläche zu tilgen. " 51

Die Versuche linker Antiimperialisten nach dem 11. September, den Islam für ihre Politik zu instrumentalisieren, standen in einer langen, nicht exklusiv linken Tradition. Bereits die Großmächte im 19. und 20. Jahrhundert hatten dies versucht. Das bekannteste, aber nicht einzigartige Beispiel hierfür ist die Orientpolitik des Deutschen Kaiserreichs. ${ }^{52}$ Die sowjetische Außenpolitik stand ironischerweise ganz in dieser Tradition, obwohl sie sich selbst als antiimperialistisch darstellte.

Die Politik des Antiimperialismus war eine Folge der Turbulenzen des Weltkrieges und der bolschewistischen Machtergreifung 1917. Lenin argumentierte in seinem Buch „Der Imperialismus als höchstes Stadium des Kapitalismus“, dass die Revolution nur gelingen kann, wenn sich das Proletariat in den westlichen, fortgeschrittenen Ländern mit „nationalen Befreiungsbewegungen“ in der kolonialen Peripherie verbündet. Diese Politik führte einen grundlegenden Doppelstandard in die nationale Frage ein: Während der Nationalismus der Linken im Westen als reaktionär galt, wurde er in der Peripherie unterstützt und als progressiv dargestellt. Die Unterstützung für nationalistische Bewegungen ging jedoch oft auf Kosten der Kommunisten vor Ort. ${ }^{53}$ Dieser Antiimperialismus war im Grunde ein Ausdruck sowjetischer Realpolitik, der außenpolitischen und nicht ideologischen Maximen folgte. Wie die Deutschen zuvor, versuchten die Sowjets in den 1920er-Jahren mittels verschiedener Initiativen, den Islam als vermeintlich antiimperialistische Ideologie zu kooptieren. Ziel war es, durch die Revolutionierung der muslimischen Massen den geopolitischen und ideologischen Rivalen der Sowjetunion, insbesondere Großbritannien, in den Rücken zu fallen. ${ }^{54}$ Einer der Orte, an denen diese Politik verfolgt wurde, war Palästina.

${ }^{51}$ Eddie Truman, The Left and Islam, in: Islamophobia Watch, 16.7.2004, [http://www.islamophobiawatch.co.uk/theleft-and-islam/], eingesehen 1.6.2020. (Kopie des ursprünglich unter islamophobia-watch.com gehosteten Blogs.)

52 Siehe hierzu u. a. Wolfgang G. Schwanitz, „Der Geist aus der Lampe“. Fritz Grobba und Berlins Politik im Nahen und Mittleren Orient, in: Comparativ 14 (2004), Heft 1, S. 126-150.

53 Colin Shindler, Israel and the European Left. Between Solidarity and Delegitimization, New York 2011, S. $43-47$.

${ }^{54}$ Fred Halliday, ,Islam“ and Soviet Foreign Policy, in: Arab Studies Quarterly 9 (1987), Heft 3, S. $217-233$. 
Grundlagen und Formen der Annäherung zwischen dem Islamismus und der radikalen ,globalen Linken“

Der pro-islamische sowjetische Antiimperialismus verband sich hier mit der bolschewistischen Feindschaft gegen den jüdischen Nationalismus, d. h. den Zionismus. Gegen erheblichen internen Protest drängte die Komintern die fast ausschließlich jüdische Kommunistische Partei Palästinas sich zu arabisieren und ein unheiliges Bündnis mit arabischen nationalistischen und islamischen Elementen in Palästina anzustreben. ${ }^{55}$ Als 1929 eine antijüdische Revolte ausbrach, schlossen sich die Kommunisten zunächst den jüdischen Verteidigungskräften an. Gegen den Rat ihres Nahost-Gesandten, der Zeuge der antisemitischen Pogrome wurde, beschloss die Komintern, die Revolte als antiimperialistischen, revolutionären Aufstand zu begrüßen und zwang diese Haltung ihren Mitgliedsorganisationen auf. So glorifizierte die deutsche kommunistische Tageszeitung Die Rote Fabne die arabischen Nationalisten in Palästina, während sie den Zionismus als „parasitäre“, „faschistische“, imperialistische und kapitalistische Bewegung diffamierte, die von ,jüdischen Finanzmagnaten“ in Amerika kontrolliert werde. Diese antisemitische, verschwörungstheoretische Sprache zeigt, dass der linke Antisemitismus keine Erfindung der Neuen Linken war, sondern seit jeher tief im antiimperialistischen Denken verwurzelt war. ${ }^{56}$ Auf Geheiß der Komintern unterstützte die Kommunistische Partei Palästinas den arabischen Aufstand von 1936 bis 1939, wobei sie leugnete, dass die arabischen Führer Unterstützung aus dem nationalsozialistischen Deutschen Reich erhielten, und agitierte gegen die Aufnahme jüdischer Flüchtlinge aus Europa. Die arabische Bevölkerung wurde kollektiv als fortschrittlich und revolutionär erklärt, während die Juden als chauvinistisch und reaktionär gebrandmarkt wurden. Erst 1939 gaben die palästinensischen Kommunisten in internen Dokumenten ihre fehlerhafte Einschätzung zu. Die Komintern hatte mit ihrer Palästinapolitik in den 1920er und 1930er-Jahren ein Muster etabliert, das bis heute die antiimperialistische Linke kennzeichnet: Die Ignorierung, respektive sogar Unterstützung des Antisemitismus zur Aufrechterhaltung der antiimperialistischen Allianz. Die antiisraelische Wendung der Neuen Linken in Westeuropa und den USA in der Nachkriegszeit stellte eine Fortsetzung dieses Musters dar.

Die Ideologie des Antiimperialismus, die seit den 1960er-Jahren in der Bewegung der Neuen Linken erneut Fuß fasste, vermittelte einer Reihe von Linksaktivisten und Linksintellektuellen einen neuen, positiven Zugang zum Islam. Die beiden prägendsten Ereignisse im linken Verhältnis zum Islam waren der Algerische Bürgerkrieg und die Iranische Revolution. Nach der Iranischen Revolution in den Jahren 1978/1979 erhöhte sich das Renommee des Islam in antiimperialistisch gesinnten Kreisen. Im Nahen Osten und in Nordafrika wandten sich in den 1980er-Jahren unzählige ehemalige

55 Grigat, Einsamkeit Israels, S. 65-66.

56 Zit. n. Olaf Kistenmacher, Vom ,Judenkapital“ zur ,jüdisch-faschistischen Legion in Jerusalem“. Zur Entwicklung des „Antizionismus“ in der Kommunistischen Partei Deutschlands in der Weimarer Republik, 1925-1933, in: associazione delle talpa/Rosa Luxemburg Initiative Bremen (Hrsg.), Maulwurfsarbeit. Aufklärung und Debatte, Kritik und Subversion, Berlin 2010, S. 92-93. 
Linksaktivisten dem Islamismus zu. ${ }^{57} 1981$ warnte der linksliberale syrische Intellektuelle Sadiq al-Azm vor einem wachsenden Okzidentalismus in der arabischen Welt. Er beobachtete, dass nach der iranischen Revolution von 1979 viele arabische Linke, „ehemalige Radikale, Ex-Kommunisten, unorthodoxe Marxisten und desillusionierte Nationalisten der einen oder anderen Art", sich zum politischen Islam hingezogen fühlten. ${ }^{58} \mathrm{Al}$-Azm kritisierte deren „Beharren darauf, die vertraute Opposition der nationalen Befreiung gegen imperialistische Herrschaft durch die reaktionärere Opposition von Ost gegen West zu ersetzen“.59 Die Wiedererstarkung des politischen Islam als politische Kraft war auch im Westen spürbar. Viele Linksintellektuelle, unter ihnen der französische Philosoph Michel Foucault, sympathisierten nach der Iranischen Revolution mit dem politischen Islam. ${ }^{60}$

Eine Reihe von Linksaktivisten konvertierte in der Periode zwischen dem Beginn des Bürgerkrieges in Algerien und den Jahren nach der Iranischen Revolution gar zum Islam. Diese linken Konvertiten verstanden ihren Glaubenswechsel als politisches Statement und als Solidaritätsbekenntnis für den antikolonialen Kampf, insbesondere in Algerien. $\mathrm{Zu}$ den bekanntesten Linkskonvertiten zählen der Schweizer Ahmed Huber und die Franzosen Roger Garaudy und Jacques Vergès. Wie der französische Politologe PierreAndré Taguieff in Bezug auf Roger Garaudy beobachtete, begannen diese Bekehrten ihren Weg in Richtung islamischer Gläubigkeit in der Regel mit einer ideologischen Mischung aus Dritte-Welt-Begeisterung und antiwestlichem Ressentiment. ${ }^{61}$ Die Konversion zum Islam war eine Wegmarke auf einer langen Karriere der politischen Radikalisierung. Alle drei beendeten ihre Karrieren als „Querfrontler“: Figuren, deren Politik zwischen der extremen Linken und der extremen Rechten angesiedelt war. Sie machten sich einen Namen als Sympathisanten des Terrorismus, als leidenschaftliche Antisemiten und Holocaustleugner oder, wie im Fall Vergès, als Verteidiger von NaziKriegsverbrechern. ${ }^{62}$ Es ist auffallend, dass die Konversion zum Islam bei diesen ehemaligen Linksaktivisten in der Regel mit einem ausgeprägten Antisemitismus einherging.

In einigen Fällen entdeckten linke Konvertiten nach ihrer Bekehrung den Dschihadismus für sich. Dafür gibt es mehrere Beispiele. So verübten die Linksextremisten Bernhard

57 Siehe u. a. Manfred Sing, Brothers in Arms. How Palestinian Maoists Turned Jihadists, in: Die Welt des Islams 51 (2011), Heft 1, S. 1-44.

58 Sadik Jalal Al-Azm, Orientalism and Orientalism in Reverse [1981], in: Alexander Lyon Macfie (Hrsg.), Orientalism. A Reader, Edinburgh 2000, S. 217-238, hier S. 234.

59 Ebd.

${ }^{60}$ Janet Afary/Kevin B. Anderson, Revisiting Foucault and the Iranian Revolution, in: New Politics 10 (2004), Heft 1, [https://newpol.org/issue_post/revisiting-foucault-and-iranian-revolution/], eingesehen 4.6.2020.

${ }^{61}$ Pierre-André Taguieff, L'itinéraire du ,grand militant mujahid Roger Garaudy“: du communisme au négationnisme, in: Le Huffington Post, 17.6.2012,

[http://www.huffingtonpost.fr/pierreandre-taguieff/mort-roger-garaudy_b_1602735.html], eingesehen 16.4.2016.

62 Siehe u. a. Kevin Coogan, The Mysterious Achmed Huber. Friend to Hitler, Allah... and Bin Laden, in: Free Republic, April/Mai 2002; Bernard Violet/Robert Jegaden, Vergès. Le Maitre de l'ombre, Paris 2000; Michaël Prazan/Adrien Minard, Roger Garaudy, itinéraire d'une négation, Paris 2007. 
Grundlagen und Formen der Annäherung zwischen dem Islamismus und der radikalen ,globalen Linken“

Falk und Michael Steinau in den 1990er-Jahren mehrere Terroranschläge in Deutschland im Namen der Antiimperialistischen Zellen. Zunächst sympathisierten sie mit dem schiitisch-islamistischen Regime des Irans und konvertierten 1994 selbst zum Islam. In ihrem letzten Bekenntnisschreiben nach einem Terroranschlag im Jahr 1995 schrieben sie: „Wir haben den Islam als revolutionäre Waffe in voller Schärfe und Schönheit kennenlernen dürfen. “63 Bernhard Falk, mittlerweile ein Salafist und Anhänger der AlQaida, sieht durchaus eine Kontinuität in seinen Überzeugungen: „Antiimperialist bin ich immer noch,“ meinte er 2014.64 Ein anderes Beispiel für den Gang vom Linksextremismus zum Dschihadismus ist der Terrorist Carlos, auch er ein Konvertit zum Islam. Carlos lobte die Anschläge vom 11. September und forderte die Linke auf, Osama bin Laden als Vorkämpfer gegen den Imperialismus anzuerkennen. ${ }^{65}$

Parallel zu den genannten politischen Allianzbestrebungen ist seit dem 11. September 2001 auf Seiten der äußersten Linken auch das verstärkte Bestreben zu erkennen, den Islam als natürlichen Verbündeten zu konstruieren. Damit verbunden war auch ein erhöhtes Interesse an historischen Vorläufern der Zusammenarbeit zwischen der Linken und islamischen Bewegungen. Dies diente der Rechtfertigung aktueller Zustände. Linke Denker beantworteten Kritik an der links-islamistischen Bündnispolitik, indem sie Beispiele in der Geschichte aufzeigten, in denen sozialistische Parteien Allianzen mit nichtsozialistischen, ultrakonservativen Parteien geschlossen hatten. So rechtfertigte etwa der italienische Linksextremist Giuseppe Maj links-islamistische Bündnisse mit den Verweis auf die Geschichte: „Es gab in der modernen Geschichte [...] mehrere Male analoge Situationen, in denen fortschrittliche Bewegungen von Kräften mit rückwärtsgewandten Ansichten geführt wurden. "66 Der schottische Linksnationalist und Sozialist Eddie Truman argumentierte 2004 ähnlich: „Unterdrückte Völker haben auf verschiedenen Stufen der Geschichte religiöse Ideen und Institutionen als Waffen des Kampfes eingesetzt. [...] Die katholische Kirche in Irland kombinierte antiimperialen Widerstand gegen die englische Unterdrückung mit ultrakonservativen sozialen Einstellungen." 67 Während Truman und Maj die reaktionären Überzeugungen ihrer muslimischen Bündnispartner nicht leugneten, gingen andere weiter und erklärten den Islam zu einer progressiven, revolutionären Ideologie.

Zwei Artikel von Dave Crouch in der Zeitschrift Socialist Review aus den Jahren 2003 und 2006, die das Verhältnis zwischen Bolschewismus und Islam nach der Oktoberrevolution

63 Sabine am Orde, Der linke Salafist, in: die tageszeitung, 31.10.2014, [http://www.taz.de/!5029925], eingesehen 6.2.2016.

64 Ebd.

${ }^{65}$ Vgl. Ilich Ramírez Sánchez [Carlos]/Jean-Michel Vernochet, L’islam révolutionnaire, Monaco 2003.

${ }^{66}$ Giuseppe Maj, Il ruolo di Hezbollah nella rinascita del movimento comunista internazionale, in: Resistenza 9 (2006), zit. n. Lorenzo Vidino, The Italian radical Left's ambivalent fascination with Islamism, in: Dynamics of Asymmetric Conflict 5 (2012), Heft 3, S. 172-182, hier S. 178-179.

67 Maj, Il ruolo di Hezbollah; - Zu Eddie Truman siehe Phil, Remembering Eddie Truman, 3.7.2016, [http://averypublicsociologist.blogspot.com/2016/07/remembering-eddie-truman.html], eingesehen 13.10.2017. 
thematisieren, wurden besonders stark rezipiert. ${ }^{68}$ Einer der beiden Artikel wurde 2006 auch ins Deutsche übersetzt und 2010 in einem Sammelband zum Thema „Islam, Rassismus und die Linke“ erneut herausgegeben. ${ }^{69}$ Crouch vertritt darin die These, dass die Bemühungen der Bolschewiki, Russlands Muslime und die panislamische Bewegung für die Revolution zu gewinnen, nicht bloß taktischer Natur waren, sondern auf echter Sympathie für die Muslime beruhten. Der bolschewistische Doppelstandard in der Religionsfrage - Unterdrückung der russischen Orthodoxie versus Unterstützung des Islam - war eine Folge der Anerkennung muslimischen Leidens während der Zeit des Zarismus. Viele russische Sozialisten kritisierten diesen Doppelstandard der Bolschewiki und forderten ein einheitliches Vorgehen in der religiösen Frage. In den Augen von Dave Crouch setzten diese Kritiker damit die chauvinistische Politik des Zarismus fort:

„Diese Genossen unterschieden nicht zwischen dem Nationalismus des Unterdrückers und dem der Unterdrückten oder der Religion des Unterdrückers und der Unterdrückten. Für sie war jede Religion ein Feind. Lenin erkannte schon sehr früh, dass diese abstrakte Opposition zu nationalen und religiösen Rechten mit dem wiederauflebenden russischen Chauvinismus verschmelzen könnte. "70

Es ist klar erkennbar, dass diese Kritik vor allem gegen die zeitgenössischen linken Kritiker der links-islamistischen Allianz gerichtet war. Crouch argumentierte gezielt gegen den Laizismus und für die Unterstützung islamischer Institutionen. Nur so könne die Klassenstruktur der islamischen Gesellschaft öffentlich gemacht werden:

„Die offensichtliche Nachgiebigkeit, der Bolschewiki‘ gegenüber der Scharia spiegelte die Erkenntnis wider, dass der islamische Konservatismus nur dadurch in Frage gestellt werden konnte, indem man mit der großrussischen chauvinistischen Politik brach und dadurch sowohl die Fähigkeit der religiösen Eliten schwächte, alle Klassen um die Moschee herum zu vereinen, als auch die Grundlage dafür legte, dass die Klassenspaltungen in der muslimischen Gesellschaft an die Oberfläche kommen. "71

Crouchs Artikel zogen implizit eine Parallele zwischen der Zeit nach dem 11. September und jener nach der Oktoberrevolution. Dieses Mal waren Muslime die revolutionäre Klasse. Die Schlussfolgerungen der beiden Artikel lagen auf der Hand: Die zeitgenössischen Kritiker der links-islamistischen Annäherungspolitik begehen denselben Fehler wie die Kritiker der Islampolitik der Bolschewiki. Sie ignorieren, dass der Islam eine Religion der Unterdrückten sei und setzten dadurch angeblich das chauvinistische, antimuslimische Erbe des Imperialismus fort. Sie sind daher die Feinde der Revolution und der weltlichen Gerechtigkeit.

\footnotetext{
${ }^{68}$ Dave Crouch, Bolsheviks and Islam: Religious Rights, in: Socialist Review (2003), Heft 280, [http://socialistreview.org.uk/280/bolsheviks-and-islam-religious-rights], eingesehen 18.4.2016; Dave Crouch, „The Bolsheviks and Islam", in: International Socialism (2006), Heft 110, [http://isj.org.uk/the-bolsheviks-and-islam], eingesehen 24.3.2016.

${ }^{69}$ Yaak Pabst, Islam, Rassismus und die Linke, o. O. 2010.

${ }^{70}$ Crouch, Bolsheviks and Islam.

71 Ebd.
} 
Grundlagen und Formen der Annäherung zwischen dem Islamismus und der radikalen ,globalen Linken“

\section{Gemeinsame Deutungsmuster}

Wie der folgende Abschnitt zeigt, bestehen Übereinstimmungen in der linken und islamistischen Wahrnehmung des Verhältnisses zwischen Westen und Islam. Befürworter links-islamistischer Allianzen wie Crouch, Buck-Morss oder Giuseppe Maj nehmen die Rolle des Vermittlers oder Übersetzers ein. In dieser Funktion nehmen sie für sich in Anspruch, angebliche Vorurteile über den politischen Islam und seine Befürworter zu widerlegen und sein wahres Wesen einem westlichen, in der Regel linken Publikum verständlich zu machen. Der Politikwissenschaftler Karagiannis beobachtete, dass bei diesem Übersetzungsprozess islamistische Inhalte oft säkularisiert werden. Dabei werden problematische Aspekte des Islamismus, wie Antisemitismus oder religiöser Fundamentalismus, minimiert, während solche, die ihm mit Ideen der Linken gemeinsam sind, etwa antiimperialistische, antikapitalistische oder antirassistische Vorstellungen, hervorgehoben werden. Wie bereits beschrieben säkularisierte Susan Buck-Morss etwa den Islamismus, indem sie ihn mit der Kritik der Frankfurter Schule an der Aufklärung verglich. Giuseppe Maj tat dasselbe, indem er die Hamas als eine antirassistische, demokratische Organisation darstellte:

„Wir müssen die Verunglimpfung der Organisationen, die diesen Kampf führen, hinterfragen und ihre wirklichen Positionen bekannt machen: Die Hamas und die PFLP sind zwei Organisationen, die für ein demokratisches Palästina ohne Diskriminierung aufgrund von Rasse, Religion und Nationalität kämpfen." ${ }^{\text {"72 }}$

Doch wie ist es erklärbar, dass das angeblich echte Wesen des Islamismus sich so sehr von jenem Bild unterscheidet, dass sich seine Kritiker, inklusive einer großen Mehrheit der Bevölkerung in westlichen Staaten, von ihm machen? Diese Diskrepanz ist nur erklärbar durch die These, dass der politische Islam bewusst falsch dargestellt wird. Genau dies behauptet Giuseppe Maj. Gemäß dem italienischen Linksextremisten nutzen die Imperialisten bestehende antiislamische Gefühle, um die „demokratische und antiimperialistische Revolution, die in arabischen und muslimischen Ländern stattfindet, als Religionskrieg" falsch darzustellen. ${ }^{73}$ Maj insinuiert also, dass der Islamismus Opfer einer gezielten Verleumdungskampagne der Imperialisten sei.

Die These, dass westliche Medien und Forscher den Islam systematisch falsch darstellen würden, wurde im Westen von Edward Said in seinen bekannten Werken „Orientalism“ und „Covering Islam“ aus den Jahren 1978, respektive 1981 popularisiert. Insbesondere seine Kritik an westlicher Gelehrsamkeit war jedoch keineswegs neu. Vielmehr behaupteten islamische Ideologen seit den 1920er-Jahren, westliche Gelehrte seien Teil eines „kulturellen und geistigen Krieges gegen den Islam““.74 Diese Theorie wurde später auch von Said Qutb, dem führenden Ideologen der Muslimbruderschaft aufgenommen

72 Vidino, The Italian radical Left's, S. 178.

73 Ebd.

${ }^{74}$ Israel Gershoni/James P. Jankowski, Redefining the Egyptian nation. 1930-1945, Bd. 2, Cambridge 2002, S. 65-67. 
und verbreitet. Ironischerweise beschuldigte Qutb westliche Forscher, die politische Botschaft des Islam zu minimieren - also exakt das Gegenteil dessen, was linke Anhänger Saids der westlichen Islamforschung vorwerfen. ${ }^{75}$ Dieser angebliche geistige Krieg gegen den Islam ist Teil einer umfassenderen Verschwörungstheorie, wonach der Westen, in der Regel unter Anleitung der Juden, einen Krieg gegen den Islam führe, um ihn letztlich zu zerstören. Diese Theorie ist seit der jungtürkischen Revolution im Jahr 1909 im Umlauf und stellt einen der Kerninhalte islamistischer Propaganda dar. ${ }^{76}$ Edward Saids Thesen ähneln dieser Verschwörungstheorie frappant und stellen gewissermaßen ihre säkularisierte Form dar.

Die Theorie vom westlichen Krieg gegen den Islam wird immer wieder auch von linker und antirassistischer Seite in säkularisierter Form zitiert. Gemäß seinem Editorial hatte sich der Blog Islamophobia Watch zum Auftrag gesetzt, ,veröffentlichtes Material zu dokumentieren, das Angst und einen Hass gegenüber den muslimischen Völkern der Welt und dem Islam als Religion vertritt [...] [und] nicht zuzulassen, dass die rassistische Ideologie des westlichen Imperialismus in seiner Dämonisierung des Islam weitere Verbreitung findet" .77 Das Thema wiederholt sich auch in anderen Artikeln des Blogs. Lindsey German, eine Politikerin der SWC und der RP, behauptete ebenfalls, dass es eine Beziehung zwischen Kritik am Islam und westlicher Außenpolitik gebe, als sie beschuldigt wurde, mit extremistischen Muslimen zusammenzuarbeiten:

„Britische Muslime, so sehr wir auch mit einigen der Ansichten, die einige vertreten, nicht einverstanden sein mögen, kämpfen darum, ihre Rechte und Kultur in einem Umfeld von allgegenwärtigem Rassismus aufrechtzuerhalten - einem Rassismus, der dazu dient, die Politik des neuen Imperialismus aufrechtzuerhalten. ${ }^{678}$

Indem sie das an sich schon problematische antiimperialistische Modell von Unterdrücker- und Unterdrückten-Nationen auf die lokale Ebene übertragen, tendiert der Antirassismus zu einem Lagerdenken und zu einem manichäischen Weltbild. Muslimische Gemeinschaften werden so einseitig als die kollektiven Opfer von Islamfeindlichkeit wahrgenommen, der Staat und die Aufnahmegesellschaft dagegen als Täter. Kritische Aspekte, wie Hinweise auf einen überproportional unter Muslimen verbreiteten Antisemitismus, werden gezielt ausgeblendet. ${ }^{79}$ Auch ist die Erfahrung der Diskriminierung an sich nicht neutral. Wie Günther Jikeli herausgefunden hat, kann der Glaube an einen Krieg gegen den Islam und ähnliche antisemitische Verschwörungstheorien das Gefühl der Diskriminierung verstärken. ${ }^{80}$ Indem nicht sorgfältig zwischen

\footnotetext{
75 John Calvert, Sayyid Qutb and the Origins of Radical Islamism, New York 2009, S. 165-166.

76 Rickenbacher, Der jüdisch-westliche „Krieg gegen den Islam“.

77 Zit. n. Göran Larsson, Cyber-Islamophobia? The case of WikiIslam, in: Contemporary Islam 1 (2007), Heft 1, S. 5367, hier S. 64.

${ }^{78}$ Lindsey German, A badge of honour, in: The Guardian, 13.7.2004, [http://www.theguardian.com/politics/2004/jul/13/religion.world], eingesehen 7.11.2015.

${ }^{79}$ Neil Kressel, The Denial of Muslim Antisemitism, in: Journal for the Study of Antisemitism 2 (2010), Heft 2, S. $259-270$.

${ }^{80}$ Günther Jikeli, European Muslim Antisemitism. Why Young Urban Males Say They Don't Like Jews, Bloomington 2015, S. 50 .
} 
Grundlagen und Formen der Annäherung zwischen dem Islamismus und der radikalen ,globalen Linken“

Rassismus, legitimer Religionskritik am Islam und verschwörungstheoretisch motivierter Diskriminierungserfahrung unterschieden wird, laufen antirassistische Diskurse Gefahr, islamistische Deutungsmuster zu verstärken, statt sie zu hinterfragen.

In Anbetracht des ungelösten Verhältnisses des Antirassismus zum Islamismus mag es nicht erstaunen, dass antirassistische Organisationen wiederholt mit islamistischen Gruppierungen zusammenarbeiteten. So fungierte Amnesty International als Partner von Cage Prisoners, einer Organisation, die sich für Islamisten und Dschihadisten einsetzt, die des Terrorismus angeklagt sind. Moazzam Begg, ein ehemaliger Unterstützer der Taliban, leitete die Organisation. Als Gita Saghal, eine bekannte Feministin und hochrangige Vertreterin von Amnesty, 2010 Einwände gegen diese Zusammenarbeit erhob, wurde sie von Amnesty entlassen. ${ }^{81}$ Erst als 2015 bekannt wurde, dass der ISTerrorist Mohammed Emwazi aka Jihadi John, der für die Ermordung westlicher Geiseln verantwortlich war, ein ehemaliger Schützling von Cage Prisoner war, distanzierte sich Amnesty International von der islamistischen NGO. ${ }^{82}$ Auch in Frankreich arbeiteten Teile der antirassistischen Bewegung in den 2000er-Jahren offen mit islamistischen Organisationen zusammen, die dem Netzwerk der Muslimbruderschaft angehören. Dies führte schließlich zu einer Spaltung in der antirassistischen Bewegung zwischen den Gruppen, die den Islamismus und den muslimischen Antisemitismus als ernsthaftes Problem anerkannten, und jenen, die nicht darüber sprechen wollten. ${ }^{83}$ Solche Kollaborationen zwischen linken, antirassistischen NGOs und Islamisten waren auch im Jahr 2017 weiterhin eine Möglichkeit, wie der Fall der Amerikanerin Linda Sarsour zeigt, die am sogenannten Women's March eine promiente Rolle einnahm - trotz ihrer Unterstützung für die Scharia-Gesetzgebung in Saudi Arabien und ihre antisemitischen und antiisraelischen Statements. ${ }^{84}$

Die Vorstellung einer inhärenten westlichen Feindschaft gegenüber dem Islam in antirassistischen, linken und islamistischen Diskursen ist oft von einem tiefgründigen Ressentiment gegen den Westen inspiriert. Diesen Okzidentalismus definieren Buruma und Margalit als „das entmenschlichende Bild des Westens, das von seinen Feinden gemalt wird $[\ldots]$ “. ${ }^{85}$ Sie beschreiben den Okzidentalismus als globales Phänomen, das überall dort auftritt, wo Menschen mit dem Westen, seinen Ideen und Produkten konfrontiert werden. Der Okzidentalismus ist dabei keine in sich konsistente Ideologie,

${ }^{81}$ A reputation at risk, in: The Economist, 5.3.2015, [http://www.economist.com/news/britain/21645806-weightiesthuman-rights-outfit-has-waded-moral-quagmire-reputation-risk], eingesehen 19.4.2016.

82 Amnesty International responds to questions about Cage, 18.5.2020, [https://www.amnesty.org.uk/amnestyinternational-responds-questions-about-cage], eingesehen 1.7.2020.

${ }^{83}$ Timothy Peace, The French Anti-Racist Movement and the „Muslim Question“, in: Christopher Flood u. a. (Hrsg.), Political and Cultural Representations of Muslims. Islam in the Plural, Leiden u. a. 2012, S. 131-146, hier S. $133 \mathrm{f}$.

${ }^{84} \mathrm{Zu}$ Sarsour siehe u. a. James Kirchick, On Linda Sarsour's Politics of Hate and the Pathos of Her Jewish Enablers, in: Tablet Magazine, 15.6.2017, [http://www.tabletmag.com/jewish-news-and-politics/237149/linda-sarsour-jewishenablers], eingesehen 18.10.2017; Bari Weiss, When Progressives Embrace Hate, in: The New York Times, 1.8.2017, [https://www.nytimes.com/2017/08/01/opinion/womens-march-progressives-hate.html], eingesehen 18.10.2017.

85 Ian Buruma/Avishai Margalit, Occidentalism. The West in the Eyes of Its Enemies, New York 2005, Z. 99. 
sondern ein Rahmen, um die Welt zu begreifen und zu verstehen. Dennoch gibt es viele Überschneidungen zwischen den verschiedenen Erscheinungsformen des Okzidentalismus, wie die beiden Autoren überzeugend zeigen. Der Westen wird etwa als materialistisch und geistlos, sexuell verdorben und feige wahrgenommen. ${ }^{86}$

Okzidentalistische Bilder sind sowohl linken als auch in islamistischen Diskurs über den Westen und die islamische Welt häufig anzutreffen. Dies zeigt sich etwa beim Vergleich der Beurteilung nahöstlicher, pro-westlicher Eliten bei Said Qutb und bei Susan BuckMorss. Said Qutb kritisierte diese heftig und beschuldigte sie, sich an den Westen verkauft zu haben und die arabischen Länder in einen Zustand des Unglaubens zurückzuführen. ${ }^{87}$ Die Gründe, die von Susan Buck-Morss vorgebracht wurden, um den steigenden Erfolg des Islamismus im Nahen Osten zu erklären, ähneln in überraschender Weise der Analyse Qutbs. Sie schreibt in ihrem Buch „Thinking Past Terror“, die arabischen Regimes, „die behaupten, indigene, islamische Werte nicht aufgegeben $\mathrm{zu}$ haben, verletzen sie tatsächlich auf Schritt und Tritt. [S]ie setzen sich aus korrupten Machteliten zusammen, nominell muslimisch aber leidenschaftlich westlich-materialistisch in ihrem persönlichen Konsum, die auf Kosten einheimischer Bedürfnisse ausländische Interessen bedienen trotz der wachsenden Kluft zwischen Arm und Reich“. 88

Während Kritik an der Regierungsbilanz arabischer Regimes sicherlich berechtigt ist, tut Buck-Morss mehr als das. Sie konstruiert eine Dichotomie zwischen den korrupten, materialistisch-verwestlichten und von Fremdinteressen geleiteten Eliten einerseits und einem indigenen, sozial-gerechten Islam andererseits. Diese Zeilen sind charakteristisch für einen linken, essentialistischen und okzidentalistischen Diskurs über den Westen und den Islam. Der Islam wird hier als Gegenbild zu einem ausschließlich negativ wahrgenommenen Westen konstruiert. Eddie Truman etwa schrieb auf Islamophobia Watch, die Muslime „[...] sehen den christlichen Westen als eine Vision der Hölle, in der politische Führer wie Bush und Blair in Kirchen religiöse Gebete verrichten und Kinder auf der anderen Seite der Welt massakrieren. Sie sehen ein System, das Frauen, Kinder, Kranke und Arme mit Hass, Gewalt und Verachtung behandelt und die Reichen verherrlicht" ${ }^{89}$ Ein Ressentiment gegen den Westen wird hier offensichtlich in einen Diskurs über den Islam verpackt. Gemeinsame Deutungsmuster erleichtern die gegenseitige Sympathie und spielen eine entscheidende Rolle bei der Zusammenarbeit zwischen Linken und Islamisten.

\footnotetext{
${ }^{86}$ Ebd., Z. 417-425.

${ }^{87}$ Scott L. Montgomery/Daniel Chirot, The Shape of the New: Four Big Ideas and How They Made the Modern World, Princeton 2016, S. 404.

${ }^{88}$ Buck-Morss, Thinking Past Terror, S. 44.

${ }^{89}$ Maj, Il ruolo di Hezbollah.
} 
Grundlagen und Formen der Annäherung zwischen dem Islamismus und der radikalen ,globalen Linken“

\section{Ausblick}

Im Jahr 2010 organisierten linke und islamistische Kräfte die sogenannte Gaza-Flottille, um einen internationalen Vorfall mit Israel zu provozieren. Das Kalkül ging auf. Seither ist es jedoch spürbar leiser geworden. Während des Gaza-Krieges 2014 vermochten dieselben Kreise nicht mehr in demselben Maße zu mobilisieren wie früher. Das linksislamistische Bündnis steckt offenbar in einer Krise. Dafür gibt es mehrere Gründe. Die amerikanische Außenpolitik im Nahen Osten und Israel polarisieren die öffentliche Meinung nicht mehr in dem Maße wie während der 2000er-Jahre. Die Wahrnehmung des Nahen Ostens ist zunehmend komplexer geworden und andere Themen stehen heute im Fokus der öffentlichen Wahrnehmung. Eine antiimperialistische Sicht auf den Nahen Osten, die alle Konflikte einseitig als Folge amerikanischer und israelischer Politik zu erklären versucht, ist zunehmend unglaubwürdig. Der syrische Bürgerkrieg und der Aufstieg des Islamischen Staates haben die Kooperation zwischen Islamisten und Linksextremisten weiter verkompliziert. Die große Mehrheit der muslimischen Diaspora und der islamischen Organisationen in Europa sind sunnitisch und tendieren zur islamistischen Opposition gegen Assad. Die antiimperialistische Linke dagegen tendiert zur schiitischen Partei im Krieg, vertreten durch die Hisbollah, den Iran und Syrien. Dies stellt eine schwer überbrückbare Differenz zwischen Antiimperialisten und Islamisten dar. Die Teilnahme tausender junger europäischer Muslime am syrischen Dschihad und die Rückkehr vieler junger Europäer zu terroristischen Anschlägen in ihre Heimatländer haben das Bewusstsein für die Gefahren der muslimischen Radikalisierung geschärft. Häufig geschieht diese Radikalisierung in Bezirken, die von Linksparteien regiert werden, die dem Islamismus wohlgesonnen oder zumindest indifferent gegenüberstehen, wie etwa im Molenbeek-Quartier in Brüssel. ${ }^{90}$ Die Zusammenarbeit mit islamistischen Kräften ist daher politisch umstrittener geworden.

Das Risiko links-islamistischer Zusammenarbeit ist jedoch nicht gebannt. Mit der zwischenzeitlich wieder gescheiterten - Übernahme der Britischen Labour-Partei durch den radikalen Flügel Jeremy Corbyns und der politischen Polarisierung in den USA und dem zunehmenden Linkskurs in der Demokratischen Partei waren bzw. sind erneute Tendenzen erkennbar, dass extreme Linke den Islamismus wiederholt als Bündnispartner entdecken. Sollten sich auch die innerarabischen Konflikte entschärfen - etwa durch einen Friedenschluss in Syrien - ist eine erneute Annäherung zwischen Linken und Islamisten möglich.

90 Molenbeeks Ex-Bürgermeister: Ein Pate des Dschihad?, in: Audiatur-Online, 24.11.2015, [http://www.audiaturonline.ch/2015/11/24/molenbeeks-buergermeister-ein-pate-des-dschihad/], eingesehen 10.12.2015. 



\title{
Universalisierte Opferschaft. Über den Erfolg des islamischen Antisemitismus in Europa
}

\author{
Soma Mohammad Assad
}

Die Proteste gegen Israels „Operation Protective Edge“ im Sommer 2014 stellten einen Wendepunkt dar: sie zeigten, welche Massenbasis der offene Antisemitismus in Europa nach 1945 wieder errungen hatte. Das Kantor Center der Universität Tel Aviv, das den weltweiten Antisemitismus, der sich in Attacken gegen Juden und gegen jüdische Einrichtungen äußert, dokumentiert, stellte für das zweite Halbjahr 2014 einen rasanten Anstieg in Westeuropa und Nordamerika fest. ${ }^{1}$ Allein bezüglich der „,major cases“ stieg in Frankreich die Zahl der verbalen und tätlichen Übergriffe von 423 auf 851, in Deutschland von 788 auf 1076 und in Österreich von 137 auf 255 Vorfälle. In Großbritannien hatte sich im Vergleich zum Vorjahr die Zahl der gemeldeten Vorfälle sogar mehr als verdoppelt: von 535 im Jahr 2013 auf 1168. ${ }^{2}$ Auch wenn im Jahr 2013 und im ersten Halbjahr 2014 die Zahl bereits erschreckend hoch war, sehen die Studienautoren die Anti-Israel-Demonstrationen gegen den Gaza-Krieg im Sommer 2014 als einen wesentlichen Grund für den starken Anstieg.

„Kindermörder Israel“-Rufe und relativierende Gleichsetzungen Israels mit dem Nationalsozialismus wurden bereits vor den Pro-Gaza-Demonstrationen vermehrt skandiert, jedoch ist mit den Ereignissen im Sommer 2014 das antisemitische Tabu, das angesichts der Agitation antiimperialistischer Gruppierungen und rechtspopulistischer Organisationen und Parteien ohnehin ein oberflächliches war, damals unter großer Mitwirkung von Muslimen durchbrochen worden. Europaweit kam es im Sommer 2014 zu Angriffen auf Synagogen und Übergriffen auf Einzelpersonen, darunter auch Juden. Es herrschte wieder Mob-Stimmung gegen Juden auf den europäischen Straßen. Angesichts dessen ist es auffällig, dass weder die Verbrechen des sogenannten Islamischen Staats, dessen Opfer größtenteils Muslime sind und zu denen unter anderem auch der Angriff auf das palästinensische Flüchtlingslager Yarmouk in Syrien ${ }^{3}$ gehört, noch sonst andere Konflikte im Nahen Osten eine derart große Anzahl an Muslimen auf die europäischen Straßen gebracht hat wie die militärische Selbstverteidigung Israels.

In Gelsenkirchen in Nordrhein-Westfalen wurde „Hamas, Hamas, Juden ins Gas!“ skandiert. ${ }^{4}$ In Frankfurt eskalierte die Situation, als Polizisten gegen Ende der

${ }^{1}$ Kantor Center, Antisemitism Worldwide 2014, o. D.,

[http://mfa.gov.il/mfa/foreignpolicy/antisemitism/documents/kantorreportantisemitism2014.pdf], S. 5, eingesehen 9.11.2018.

2 Ebd., S. 6.

${ }^{3}$ Die Presse, 9.4.2015, S. 4.

${ }^{4}$ Die erwähnten antisemitischen Vorfälle und Übergriffe sind exemplarisch. Für eine weltweite Chronik siehe die 
Demonstration von jungen Männern mit Steinen beworfen und getreten wurden. Als die Demonstration bereits offiziell zu Ende war, formierte sich ein spontaner Protestzug und die Polizei überließ, nach Eigendarstellung, um deeskalierend $\mathrm{zu}$ wirken, einem Demonstranten den Lautsprecherwagen. ${ }^{5}$ Dieser durfte dann mit dem Polizeilautsprecher die Menge unter der Parole „Kindermörder Israel“ führen. In Berlin skandierten überwiegend junge muslimische Männer neben „Allahu Akbar!“ auch „Jude, Jude, feiges Schwein, komm heraus und kämpf allein!“. 6

\section{Das antisemitische Motiv jüdischer Allmacht}

Besonders anhand dieser und ähnlicher Parolen wird das dahinterliegende Motiv einer phantasierten jüdischen Allmacht deutlich, der hier mit Hilfe Allahs der Kampf angesagt wird. Zwar ist jede Religion politisch, jedoch zeigt die erwähnte Kampfansage, dass diese Religion in rein politischer Form und allein als politisches Engagement ihre einzige Gültigkeit haben soll. Der Erfolg der islamischen Ideologie in Europa begründet sich aus einem generellen Ungerechtigkeitsempfinden und einer Opferinszenierung, die - einmal mehr, einmal weniger offenkundig - die USA, den Westen und vor allem Israel als Übeltäter und Verursacher ausmacht. In den westeuropäischen Gesellschaften ist immer mehr zu erkennen, dass auch vonseiten progressiver Kräfte „den“ Muslimen eine entsprechende Opferrolle zugeschrieben wird.

In der erwähnten antisemitischen Parole wird das Stereotyp einer imaginierten jüdischen Allmacht erkennbar: über den Kafir (Ungläubigen), der in der islamischen Ideologie die Stellung des Gegners hat, wird es auf den Juden übertragen und letztendlich in ihm personifiziert. Der gläubige Moslem begeht nach den ideologischen Maßstäben eine Sünde, wenn er das Judentum nicht als monotheistische Religion akzeptiert, doch in dieser Feinderklärung wird der Mechanismus des Antisemitismus erkennbar: Er ist kein „gewöhnliches“ Vorurteil, strukturell liegt sein Unterschied zum Rassismus in der Vehemenz des Irrationalismus. Beides tritt bei autoritären Persönlichkeitsstrukturen auf, aber im antisemitischen Wahn wird der Jude zum absoluten Feind erklärt. Der Antisemitismus hat daher eine gesellschaftsaufhebende Intention. Antisemitismus müsste demzufolge mit mehr Ratio zu verhindern sein, doch gerade mit der Aufklärung im geschichtsphilosophischen Sinne hat sich die universelle Vernunft ihren eigenen „ideologischen Reflex“ geschaffen. Theodor W. Adorno und Max Horkheimer betonen in der „Dialektik der Aufklärung“, dass in der bürgerlichen Gesellschaft der

Reports des Kantor Centers. (Kantor Center, Antisemitism Worldwide, S. 53.)

5 Katharina Iskander/Hans Riebsamen, Anti-Israel-Parolen über Polizeilautsprecher verbreitet, 14.7.2014, [http://www.faz.net/aktuell/rhein-main/demonstration-eskaliert-anti-israel-parolen-ueber-polizeilautsprecherverbreitet-13044034.html], eingesehen 9.11.2018.

${ }^{6}$ Berlin, in: YouTube, 18.7.2014 [https://youtu.be/o4TWI1i4_Nk], eingesehen 9.11.2018. 
Antisemitismus einen „spezifischen ökonomischen Grund“ hat: „die Verkleidung der Herrschaft in Produktion".?

In der bürgerlichen Gesellschaft wurden Freiheit und Gleichheit zwar verankert, jedoch wurde die Herrschaft nicht abgeschafft, sondern durch ein universell geltendes Kapitalverhältnis vermittelt. Ihre Basis ist somit nicht Individualität im emphatischen Sinne, sondern ihre Nivellierung zum Zwecke der Produktion aus der nun eine zugerichtete Form von Individualität hervorgeht: das bürgerliche Subjekt. ${ }^{8}$ Ausbeutung und Herrschaft wurden vereinheitlicht und über den staatlichen Souverän vermittelt. Die nach der Verwertungslogik des Kapitals arbeitende Gesellschaft garantiert dem bürgerlichen Subjekt zwar formal Freiheit und Gleichheit, produziert aber, weil das Versprechen nicht eingelöst wird, gleichsam das Gefühl, betrogen worden zu sein. Hieraus resultiert eine Entfremdung des Subjekts zur Gesellschaft, deren Herrschaftscharakter zugleich verschleiert ist.

Aus dem Gefühl betrogen zu sein resultiert das Bedürfnis dieses Verhältnis aufzuheben, doch artikuliert es sich allzu häufig in Form antisemitischer Ranküne und der Konkretisierung einer personifizierenden Herrschaftskritik. Über den Mechanismus der antisemitischen Projektion, die Adorno und Horkheimer als „falsche Projektion“9 bezeichnen, schreiben sie weiter: „Regungen, die vom Subjekt als dessen eigene nicht durchgelassen werden und ihm doch eigen sind, werden dem Objekt zugeschrieben: dem prospektiven Opfer." ${ }^{10}$ Dabei fühlen sich Antisemiten stets selbst als Opfer und schaffen sich damit ihre eigene Rechtfertigung, ${ }^{11}$ um gegen den bereits als Feind wahrgenommenen Juden vorzugehen: „Die Störung liegt in der mangelnden Unterscheidung des Subjekts zwischen dem eigenen und fremden Anteil am projizierten Material.“12

Die negative Aufhebung des Kapitalverhältnisses hat daher immer einen antisemitischen Kern. Dieser ist nicht spezifisch islamisch, jedoch wird im Islam aufgrund der kollektivistischen Gesellschaftskonstitution jene „Störung“, also schlussendlich das Gefühl, Objekt von anonymen Machenschaften zu sein, bestärkt. Die Vorstellung von der „Ummah“ (der Gemeinschaft aller Muslime) beschränkt Freiräume für eine Bewusstseinsbildung, durch die individuelles Denken ermöglicht wird. Dieser

${ }^{7}$ Max Horkheimer/Theodor W. Adorno, Dialektik der Aufklärung. Philosophische Fragmente, Frankfurt a. M. 2008, S. 182.

8 ,Die Wohltat, dass der Markt nicht nach Geburt fragt, hat der Tauschende damit bezahlt, dass er seine von Geburt verliehenen Möglichkeiten von der Produktion der Waren, die man auf dem Markte kaufen kann, modellieren lässt.“ Ebd., S. 19.

${ }^{9}$ Ebd., S. 196.

10 Ebd.

11 Zur näheren Erläuterung des Ideologiebegriffs siehe Theodor W. Adorno, Beitrag zur Ideologienlehre, in: Ders., Gesammelte Schriften, Bd. 8, Frankfurt a. M. 1972, S. 457-477. - „Denn Ideologie ist Rechtfertigung. [Herv. i. O.] Sie erheischt ebenso Erfahrung eines bereits problematischen gesellschaftlichen Zustandes, den es zu verteidigen gilt, wie andererseits die Idee der Gerechtigkeit selbst, ohne die eine solche apologetische Notwendigkeit nicht bestünde, und die ihr Modell am Tausch von Vergleichbarem hat.“ Ebd., S. 465.

12 Horkheimer/Adorno, Dialektik der Aufklärung, S. 196. 
Kollektivismus erhält sich in Wechselwirkung mit der Aufrechterhaltung des Vollkommenheitsanspruchs des islamischen Sakralen. Das bedeutet aber nicht, dass der Islam außerhalb der Moderne steht, denn schließlich beansprucht heute das Kapitalverhältnis universelle Gültigkeit. Der Islamwissenschaftler Aziz Al-Azmeh schreibt in seinem 1993 veröffentlichten Buch „Islams and Modernities“ (deutscher Titel: „Islamisierung des Islam“), dass der Universalismus sich in den „Randzonen [...] wegen der Schwäche der ihm zugehörigen sozialen und kulturellen Bildungen unvollständig und ungleichmäßig“13 durchgesetzt hat. Diese Schwäche, so Al-Azmeh weiter, „findet ihr Gegenstück im Insistieren auf ,Authentizität"“.14

\section{Sehnsucht nach Authentizität und Wiedererweckungsbewegungen}

Letzteres zeichnet die erwähnte Sehnsucht nach der Konkretisierung des vermittelten Herrschaftsverhältnisses aus, ohne die Herrschaft aufzuheben. Die Forderung nach einer der Ummah entsprechenden Herrschaftsordnung - dem islamischen Kalifat - ist daher eine rückwärtsgewandte Utopie im Sinne der „Wiederherstellung einer Natur, die von der kontingenten Geschichte außer Kraft gesetzt war". ${ }^{15}$ Diese Forderung nach dem Kalifat funktioniert der Ideologie nach ähnlich den Wiedererweckungsbewegungen des arabischen Baathismus und des europäischen Faschismus. Im nicht nur von Islamisten offen geforderten Rückbesinnen auf den Islam als Urreligion, als das einzig Authentische, worin also ein vermeintlich volkstümliches und ursprüngliches Kollektiv - ähnlich der Volksgemeinschaft in der NS-Ideologie oder gegenwärtiger rechter Ideologien reaktiviert werden soll, wird eine ontologische Dichotomie geschaffen: Ein authentisches „,islamisches Selbst“ auf der einen Seite wird den Verfälschern der Geschichte, denen der „innere Wert“, also das Authentische, abhandengekommen sei, auf der anderen Seite gegenübergestellt. ${ }^{16}$ Der Islam ist daher gleichzeitig moderne und antimoderne Revolte: Modern ist er deshalb, weil er sich an Prämissen der Moderne entfaltet, um die Klassengesellschaft mit dem Ziel einer neuen Gesellschaft, der islamischen Ummah, aufzuheben. Antimodern ist er, weil er dieser Klassengesellschaft eine antiaufklärerische Bewegung utopischen Charakters entgegensetzt.

Die inhaltliche Bestimmung des Islam ändert sich daher auf Basis der gesellschaftlichen Ordnung. Es ist nicht möglich, von einem einheitlichen Islam im Sinne der Schriftenlehre auszugehen, da die bestimmenden islamischen Elemente je nach Ort und Kultur variieren. Im inhaltlichen Bestimmungsprozess des Islam allerdings werden die reaktionärsten Strömungen in der jeweiligen Kultur überhöht. Die Unmöglichkeit der

13 Aziz Al-Azmeh, Die Islamisierung des Islam. Imaginäre Welten einer politischen Theologie, Frankfurt a. M. 1996, S. 59 .

14 Ebd.

15 Ebd., S. 47.

16 Ebd. 
Herstellung einer einheitlichen Ordnung lässt sich anhand der Scharia, dem islamischen Recht, nachvollziehen. Bei der Scharia handelt es sich um keinen „Gesetzeskodex oder irgendwie Kodifizierbare[s]“, vielmehr stellt sie „willkürlich gesetzte Einzelexemplare“17 als ein Bündel an Rechts- und Sittenvorstellungen dar, deren Funktion als einheitsstiftende und -erhaltende Gesetzgebung damit obsolet wird. Als Sammelsurium an islamischen Handlungen und Aussprüchen ist ihre praktische Anwendung im Sinne eines allgemeinen Bezugspunkts daher gar nicht möglich. Die Forderung nach einer islamischen Ordnung läuft somit auf Willkürherrschaft hinaus, in der je nach realem politischen Kräfteverhältnis, einzig in Bezug auf den Namen Islam als dem Sakralen, eine allgemeine Verbindlichkeit hergestellt werden soll:

„Islam erweist sich demnach als ein selbstbezügliches Verhältnis, das mittels Übertragung funktioniert; jedes Element, auf das diese sakrale Qualität übertragen wird - der Schleier, verschiedene Vorschriften in Bezug auf Nahrungsverbote und Erbschaftsangelegenheiten [...] - verliert durch die Übertragung seine Neutralität und erhält einen besonderen Wert. Auf diese Weise wird jedes Element zu einem stellvertretenden Ausdruck für den Islam und steht voll und ganz für ihn ein." ${ }^{18}$

\section{Ungeglaubter Glaube}

Als ein selbstbezügliches System, dessen Anspruch nicht die Nachvollziehbarkeit im Sinne eines allgemeinen Reglements ist, worin sich, wenn auch nur formell, alle vertreten fühlen, braucht es daher nicht notwendigerweise eine Schriftenlehre, um als islamisch zu gelten. Der Islam ist in diesem Sinne ein ungeglaubter Glaube:

„Denn es ist diese Eigentümlichkeit alles Islamischen - dass es eine bloße nominalistische Setzung ist -, was dem symbolischen Zuschreibungsakt eine massive Bedeutung verleiht und was zugleich die ,Islamisierung von Dingen und Verhältnissen zu einer Handlung macht, die Privileg der zuschreibenden und sinnstiftenden Instanz bleibt. Das Repertoire, aus dem man auswählen kann, ist riesengroß; nur eine beschränkte Zahl an Elementen wird als Ausweis islamischer Rechtsgläubigkeit geltend gemacht - und die Entscheidung über diese Elemente ist ein politischer Akt." ${ }^{\text {"19 }}$

Das Verhandeln, was islamisch ist und was nicht, ist ein ewiger Prozess, der sich aber nicht als politische Verständigung, sondern als Aneinanderreihung politischer Akte vollzieht. Im Gegensatz zur Hervorbringung eines persönlichen Glaubens an Gott, in dessen Rahmen Subjektbildung noch möglich ist, bestimmt sich der Islam im Äußeren, dem Kollektiv. Innerhalb der islamischen Ideologie werden daher keine Formen von Subjektwerdung, in denen das Ich Hauptmovens jeden Handelns ist, ermöglicht. Die

${ }^{17}$ Ebd., S. 44-45.

18 Ebd.

19 Ebd., S. 45-46. 
Anerkennung von Eigenverantwortlichkeit wird daher nicht eingeräumt. Der Islam schafft somit tendenziell keine Verhältnisse, in denen Konflikte bewusst gemacht werden können. Man fühlt sich stets als Objekt und nicht als Subjekt. Damit führt jede Kränkung, jede Triebversagung, die man sich selbst auferlegt oder durch das islamische Kollektiv auferlegt bekommt, weder zu einer Auseinandersetzung und Hinterfragung seiner selbst noch zu einer Konfrontation mit den rigiden Werten innerhalb des Islam, sondern wird den Kafir zugeschrieben. Durch den islamischen „Zuschreibungsakt“ entsteht eine Dynamik, in der diejenigen Kräfte die Oberhand gewinnen, die sich auf die restriktivsten Elemente im Islam beziehen. Jeder, der sich auf diesen Allgemeinbegriff Islam bezieht und die politische Durchsetzungskraft hat, kann sich Moslem nennen. So setzte sich beispielsweise der damalige irakische Diktator Saddam Hussein, der selbst der pro forma säkularen, arabisch-faschistoiden Baath-Partei angehörte, in den 1990er-Jahren als Führer einer islamischen Gemeinschaft in Szene, um seine Herrschaft zu festigen. ${ }^{20}$ Seine Reislamisierungs-Kampagne erst hat die politische Voraussetzung für das Entstehen des sogenannten Islamischen Staats geschaffen. ${ }^{21}$

Genauso wenig, wie der Islam Einheit stiften kann, schafft er ein homogenes islamisches Kollektiv. Dies wird an der Barbarei des sogenannten Islamischen Staats am deutlichsten, insofern seine Mitglieder auch Muslime ermordeten, um sich ihre „Authentizität“ selbst zu beweisen. Es ist zwar nicht möglich, sich mit dem spontan wandelbaren Gebilde, dem Resultat dieser „nominalistischen Setzung“, als Einheit zu identifizieren, aber der Name Islam als Abgrenzung nach außen täuscht die Homogenität nach innen vor. Die Diffusion bei gleichzeitigem Anschein von Homogenität findet sich am radikalsten beim IS, ist aber bereits an der Vielzahl von Imamen zu sehen, die bei Fernsehdebatten darüber diskutieren, was islamisch verpönt ist und was nicht. Dabei bestimmt sich, wie erwähnt, in den einzelnen Aussagen selbst der islamische Glaubensinhalt immer wieder aufs Neue. Die innerislamischen Revolten sind daher eine Konsequenz dieser Ideologie und werden auch bei jungen Jihadisten offensichtlich. In ihrem Hass auf die westliche Gesellschaft begehren sie zuallererst gegen den Islam ihrer Eltern auf, weil ihnen dieser nicht islamisch genug ist. Bei diesem Aufbegehren geht es nicht um ein Brechen mit den elterlich vermittelten Werten, sondern um deren Überhöhung. Der Jihadismus ist keine Abspaltung des Islamismus vom Islam, sondern seine konformistische Aneignung. Daher ist eine klare Trennung zwischen Islam und Islamismus nicht möglich.

Der Bezug zum Islam von jungen Muslimen, die in Europa aufwachsen - also in Staaten, die zumindest formell säkular sind - ist anders bestimmt. Der islamische Wahrheitsanspruch, der innerhalb der islamischen Communities in Europa im Privaten reproduziert wird und der auch immer wieder in die politische Öffentlichkeit drängt,

20 Siehe Michael Weiss/Hassan Hassan, ISIS. Inside the Army of Terror, New York 2015, S. 23. - So wurde der irakischen Flagge, auf der zuvor die drei Sterne, welche den Baathismus mit den Schlagworten Einheit, Freiheit, Sozialismus symbolisieren sollten, „Gott ist groß“ hinzugefügt. Auch wurde vermehrt das Scharia-Recht angewendet. 21 Kyle W. Orton, How Saddam Hussein Gave Us ISIS, in: The New York Times, 23.12.2015, [https://www.nytimes.com/2015/12/23/opinion/how-saddam-hussein-gave-us-isis.html], eingesehen 9.11.2018; 
stößt in einer säkularen Gesellschaft bereits im Alltag an seine Grenzen. Damit ist der Islam im Sinne der erwähnten „,nominalistischen Setzung“ als Abgrenzungsmerkmal von der Mehrheitsgesellschaft bestimmt. Da es sich beim Islam um einen ungeglaubten Glauben handelt, muss die religiöse Identität nach außen umso präsenter auftreten: Um den Glauben für sich glaubhafter zu machen, muss umso mehr die Richtigkeit der rigiden Moral- und Sittenvorstellungen nach außen zur Schau gestellt werden. Der belgische Polizist Hamid Benichou bringt dieses Paradoxon auf den Punkt: „,Warum sollte ich mir auf die Fahne schreiben ,Schaut her, ich bin Moslem. [...] Heißt das ich bin nicht sicher, ob ich Moslem bin? Dass meine Eltern keine Moslems waren?" 22

Die Radikalisierung wird im Jihadismus am offensichtlichsten, aber diese Tendenz ist bereits bei jenen Migrantinnen der zweiten und dritten Generation zu sehen, die sich für die Verschleierung entscheiden. Der Islam ist hier politisches Statement der bewussten Abgrenzung von und Auflehnung gegen die als feindlich erklärte säkulare Gesellschaft allerdings auf Basis eben dieser Gesellschaft. Die Politologin Seyla Benhabib schreibt über Schülerinnen in Frankreich, die sich weigerten das Kopftuch abzulegen und damit eine Verschleierungs-Debatte auslösten, dass „es gerade die egalitären Normen des öffentlichen französischen Bildungssystems" waren, die den Mädchen das Selbstvertrauen gegeben haben, aus den „häuslich patriarchalen Strukturen“ auszutreten und öffentlich für ihr Recht auf freie Religionsausübung einzustehen. ${ }^{23}$ Obwohl laut dem Koran keine Pflicht zur Verschleierung besteht und es durchaus viele Frauen gibt, die kein Kopftuch tragen und sich trotzdem als Muslimas verstehen, deuteten diese jungen Mädchen das Tragen des Kopftuchs als ein Symbol des Protests gegen den säkularen Staat um.

Da sich die islamische Qualität durch politische (Abgrenzungs-)Akte bestimmt, führt jedes staatlich gesetzte Verbot zu einer weiteren Politisierung. ${ }^{24}$ Oft werden in Reaktion auf Gesetze, welche die Religionsfreiheit einschränken, von Islamverteidigern Partikularrechte gefordert, mit deren Gewährung der Staat seine Souveränität aufgeben würde. Nicht zufällig beziehen sich daher Islamkritiker auf ein einheitliches Gesetz und damit für staatlich gesetzte (Verschleierungs-)Verbote. Sie sind in ihren Anliegen nicht, wie ihnen oft von linker Seite vorgeworfen wird, gegen den Pluralismus in der Gesellschaft oder gar antidemokratisch, sondern wollen die Basis, auf der dieser Pluralismus gedeiht, also den bürgerlichen Staat, geschützt wissen.

22 Thomas Lauterbach, Europas Muslime. Auf Reisen mit Nazan Gökdemir und Hamed Abdel-Samad. Teil 2: Belgien, Frankreich und Spanien, ARTE/ZDF, $52 \mathrm{~min}$, 2017, 4:12-4:24 min., [https://youtu.be/97cRnJ26zds?t=4m12s], eingesehen 13.11.2018.

${ }^{23}$ Seyla Benhabib, Kosmopolitismus ohne Illusionen. Menschenrechte in unruhigen Zeiten, Berlin 2016, S. 248.

24 Ebd., S. $247 f$. 


\section{Universalisierte Opferschaft}

Gleichzeitig ist es allerdings auch dieser bürgerliche Staat, der seinen ideologischen Reflex, die modern-antimoderne Revolte hervorbringt. Die islamische Ideologie steht daher im Einklang mit all jenen Strömungen, die ebenfalls von einer grundlegenden Staats- und Kapitalismuskritik nichts wissen wollen. Ihre Wirkmächtigkeit liegt darin, dass sie erfolgreich die reaktionären Kräfte im allgemeinen Herrschenden anspricht. Die islamische Ideologie muss daher ähnlich wie rechte Ideologien begriffen werden. Der Anspruch auf Authentizität, also das Wieder-Natur-Werden in der unmittelbaren Übereinstimmung von Gesellschaft, Staatswesen und Kultur in der Gemeinschaft ist ebenso im rechten Gedankengut zu finden. Es ist daher kein Zufall, dass es Sympathien für den Islam seitens Rechtskonservativer gibt, auch wenn das heutzutage in Europa nur mehr selten offen propagiert wird. Beispielsweise bezeichnete Gabor Vona, der Chef der rechtsextremen ungarischen Jobbik, den Islam als „letzte Hoffnung des Konservativismus". 25

Sowohl den rechten als auch den linken Islamverteidigern ist gemein, dass sie in ihrer „Apologie des Anderssein“ 26 dem Islam und damit „den“ Muslimen ein unveränderliches Wesen attestieren. Rechte erkennen das Mobilisierungspotential des Islam und beneiden, sofern sie nicht sogar konvertieren, aus der Ferne jene islamischen Staaten, die ohne die Gebundenheit an demokratische Instanzen frei gegen Juden, Andersgläubige, Frauen und Homosexuelle hetzen. Sofern sie sich gegen den Islam aussprechen, dann nur als Konkurrenten gegenüber einer Ideologie, die erfolgreicher in der Bindung reaktionärer Kräfte ist. Dieses Mobilisierungspotential insgeheim beneidend, wird der eigene Antisemitismus externalisiert und „den“ Muslimen zugeschrieben. Sie sind daher keine Islamkritiker, sondern wollen sich eines Konkurrenten - im „Kampf“ um das für das eigene Kollektiv beanspruchte Herrschaftsgebiet in Form des Nationalstaats entledigen. Es ist die fatale Konsequenz dieses Konkurrenzverhältnisses, dass Menschen (unabhängig davon, wie diese es mit dem Islam halten), die auf der Flucht nationalstaatliche Grenzen überwinden müssen und damit ohnehin das Ressentiment völkischer Nationalisten auf sich ziehen, zu Muslimen gemacht werden.

Der Erfolg der islamischen Ideologie in Europa rührt aber nicht ausschließlich aus dem Konkurrenzverhältnis der Rechten zum Islam, denn auch linke bzw. sich als progressiv Verstehende brauchen die Konservierung der ,authentischen“ Kultur. Genauso wie auf der rechten Seite ist bei den Linken in Bezug auf den Islam eine „Ehrfurchtshaltung gegenüber dem Archaismus“ $27 \mathrm{zu}$ finden. Im Kultivieren der hiermit verbundenen Differenz werden universalistische Werte wie Gleichheit und Freiheit aufgegeben. Dennoch bezieht sich auch die Linke in der Verteidigung antidemokratischer

${ }_{25}$ Die Presse, 11.2.2016, S. 4.

26 Al-Azmeh, Islamisierung des Islam, S. 38.

${ }^{27}$ Ebd., S. 8. 
Strömungen und reaktionärer islamischer Werte oftmals auf die Menschenrechte und verkehrt den zugrundeliegenden Universalismus damit in sein Gegenteil.

Das heutige Verständnis von Menschenrechten in Europa wiederum entwickelte sich als scheinbare Lehre aus Nationalsozialismus und Holocaust. Dabei wurde der Holocaust örtlich, zeitlich und schlussendlich historisch entkontextualisert. Die Konsequenz war die Verwischung der Grenzen zwischen Tätern und Opfern:

„Der Preis der Entkontextualisierung führt auch dazu, dass es in diesem Diskurs keine Juden und keine Deutschen mehr geben darf. Es gibt nur Menschen und Menschheit, wie auch aus dem Begriff der, Verbrechen gegen die Menschheit' und der Entstehung eines moralischen und legalen Kodex gegen ,Völkermord' hervorgeht." 28

Das gemeinsame Maß für das europäische Projekt bildete daher eine unterschiedslose Opferschaft und der Holocaust wurde „zum Maßstab des eigenen Leidens stilisiert““ ${ }^{29}$ Mit der Universalisierung der Holocaust-Erinnerung wurde auch die Bedeutung des jüdischen Opfers universalisiert, wobei es nicht um eine Auseinandersetzung mit den nationalsozialistischen Verbrechen - das heißt dem zur Tat gebrachten Vernichtungsantisemitismus - ging. Somit war es nun ,vielen Opfergruppen erlaubt, sich in den jüdischen Opfern wiederzuerkennen“. ${ }^{30}$ Diese Auflösung von Geschichte drückt sich im Menschenrechtsdiskurs ${ }^{31}$ aus, in dem das Menschsein a-priori Opfer-Sein bedeutet. Im europäischen Gedächtnis ,geht es in erster Linie um Verfolgung, Demütigung, Hass. Jeder wird zum Opfer".32 Im Verteidigen des Islam seitens sich als progressiv Verstehender wurden zuerst die Palästinenser und später verallgemeinert die Muslime als Opferkollektiv gesetzt, was allzu gern von islamischen Verbänden in Europa übernommen wird. Immer öfter wird auch unter folgendem Slogan mobilisiert: „Du musst kein Moslem sein, um für Gaza einzustehen. Es reicht, ein Mensch zu sein“.33

Dabei darf nicht vergessen werden, dass in Europa in der Vergangenheit islamische Verbände mehr Anerkennung und Unterstützung durch die Staatsgewalt erfuhren als beispielsweise migrantische Interessensverbände, die sich für eine soziale und materielle Besserstellung einsetzten. Der in den europäischen Staaten unterschiedlich vorangetriebene Multikulturalismus bestärkt islamische Vereinigungen und ignoriert Säkulare und Ex-Muslime. In Wien organisierte eine dieser islamischen Vereinigungen, die AKPnahe Union Europäisch-Türkischer Demokraten, im Sommer 2014 eine Free-Gaza-

\footnotetext{
${ }^{28}$ Daniel Levy/Natan Sznaider, Erinnerung im globalen Zeitalter: Der Holocaust, Frankfurt a. M. 2007, S. $12 \mathrm{f}$.

${ }^{29}$ Ebd., S. 92.

${ }^{30}$ Ebd., S. 62.

31 „Wenn man verstanden hat, dass der Menschenrechtsdiskurs ein entkontextualisierter Diskurs ist - da er sich der historischen Einbettung von Menschen verweigern muss, sonst wäre es ja kein Menschenrechtsdiskurs, sondern ein Bürgerrechtsdiskurs -, dann wird man auch verstehen, warum der Holocaust als symbolische Repräsentation des Bösen entkontextualisiert wird.“ (Ebd., S. 15.)

32 Ebd., S.10.

33 Viele der Pro-Gaza-Demonstrationen verliefen unter diesem Slogan. Siehe exemplarisch eine Demonstration in der Frankfurter Innenstadt im Juli 2014: Peter Jülich, „Du musst kein Moslem sein um für Gaza einzustehen“, 13.7.2014, [https://peter-juelich.photoshelter.com/image/I000080fJVCiMgZA], eingesehen 13.11.2018.
} 
Demonstration, bei der unter anderem auch Fahnen der Terrororganisation Hamas zu sehen waren. ${ }^{34}$ Einen Tag zuvor hatte der damalige türkische Premierminister Recep Tayyip Erdogan, der sich zu dieser Zeit als Kandidat im Rennen um die türkische Präsidentschaft befand, bei einer Wahlkampfveranstaltung Israel ,barbarischer als Hitler" genannt. ${ }^{35}$ Er wusste, dass er auch die Muslime in Europa damit mobilisieren konnte. In der durch islamische Agitatoren vorangetriebenen Universalisierung des Opferstatus soll sich jeder mit „den“ Muslimen als entrechteten, betrogenen Menschen identifizieren, um schlussendlich gegen Israel vorzugehen. Leo Löwenthal, der in den 1940er-Jahren eine Untersuchung über Agitationsmechanismen durchgeführt hat, charakterisiert den Agitator folgendermaßen:

„Er steigert die Stimmung von Misstrauen bei seinen Hörern, indem er diese daran erinnert, dass sie ,einer Fremdherrschaft unterworfen' und dass sie ,ständig von schlimmen Machenschaften bedroht ${ }^{\star}$ seien. Sie alle, werden am laufenden Band betrogen': bei der Rationierung, im Krieg, durch die Presse und das Kino. Solch skrupellosen Taktiken steht, das schlichte, gewöhnliche, redliche Herdenvolk' hilflos gegenüber; es ist immer das Opfer, das ewig hereingelegte." 36

Das Heraufbeschwören dieser „unbewussten Mechanismen“37 zeichnet solche Agitatoren wie Recep Tayyip Erdogan und seine Vertreter in Europa aus. Sie verlassen sich auf das reproduzierte Opfer-Gefühl, wie man nicht nur an den Pro-GazaDemonstrationen im Sommer 2014, sondern auch den jährlich stattfindenden Al-Quds Aufmärschen sehen kann. Multikulturalismus-Verteidiger des Islam leugnen daher nicht das „grundlegende Opfergefühl europäischer Muslime“"38 oder die ,globale[n] muslimische[en] Opferrolle“"39, da sie die Muslime in dieser Opferrolle bestätigt wissen wollen. Sie selbst gehen in dieser Opferrolle auf und benutzen das klassenübergreifende islamische (Opfer-)Kollektiv, im Sinne eines antisemitischen Missbrauchs der Menschenrechte gegen „die“ Juden.

\section{Schlussbemerkung}

Der islamische Antisemitismus, dessen Erfolg in Europa spätestens seit den Pro-GazaDemonstrationen im Sommer 2014 offensichtlich ist, ist daher nicht nur eine Konsequenz der politischen Kräfteverhältnisse in den islamischen Ländern, sondern muss auch konkret auf den Diskurs der Linken und Rechten über den Islam sowie die

34 Teresa Eder/Jutta Berger, Tausende in Wien und Bregenz bei Demos gegen Israels Militäreinsatz, in: Der Standard, 20.4.2014, [https://derstandard.at/2000003312679/Israel-Proteste-in-Vorarlberg], eingesehen 13.11.2018.

35 Die Presse, 21.7.2014, S. 2.

${ }^{36}$ Leo Löwenthal, Falsche Propheten. Studien zum Autoritarismus (Schriften, Bd. 3), Frankfurt a. M. 1990, S. 36.

${ }^{37}$ Ebd., S. 12.

38 Timothy Garton Ash, Der Islam in Europa, in: Thierry Chervel/Anja Seeliger (Hrsg.), Islam in Europa. Eine internationale Debatte. Frankfurt a. M. 2007, S. 30-54, hier S. 34.

${ }^{39}$ Ebd., S. 42. 
Zugeständnisse der jeweiligen europäischen Regierungen an islamische Vereinigungen zurückgeführt werden.

Kritisiert man den Islam, unabhängig davon wie differenziert diese Kritik auch ist, wird häufig der Vorwurf der „Islamophobie“ erhoben. Die Verwendung des Begriffs „Islamophobie“, als vermeintlich antirassistisches Argument, kehrt jedoch die berechtigte Angst unter den Tisch, die viele Menschen, die in islamischen Ländern und Communities aufgewachsen sind und aus diesen fliehen, vor dem Islam haben. Das Appeasement der nur scheinbar Links-Progressiven überlässt diese Menschen, wie überhaupt die Kritik am Islam den Rechten, die das Thema für ihre Agitation gern aufgreifen. Eine progressive Linke sollte begreifen, dass es im Gegensatz zur rechten „Islamkritik“ auch eine emanzipatorische Islamkritik gibt, die nicht als antimuslimischer Rassismus abgetan werden kann. Essenzialismus von links, der eine indirekte Ungleichbehandlung fordert, ist mit dem Universalismus selbst entgegenzuhalten, dass überall Verhältnisse geschaffen werden müssen, die es ermöglichen, zum mündigen Denken zu gelangen. Ein Ansatz wäre, säkulare Kräfte und Initiativen kritisch-politischer Bildungsarbeit nicht nur in Europa zu fördern, sondern diese darüber hinaus auch in islamischen Ländern zu unterstützen. Dabei geht es nicht darum, dass man Menschen irgendeinen europäischen Wertekanon aufzwingt, sondern darum aufzuzeigen, dass das „Sapere Aude!“, das Kant'sche Diktum „Habe Mut, dich deines eigenen Verstandes zu bedienen“, jedem zumutbar ist. Das wäre die emanzipatorische Wendung des Universalismus. 



\title{
Antisemitismus unter Geflüchteten aus Syrien und dem Irak. Befunde einer qualitativen Erhebung
}

\author{
Günther Jikeli
}

\section{Einleitung und Forschungsstand ${ }^{1}$}

Die fast 1,5 Millionen Menschen, die von Anfang 2014 bis Juli 2017 in Deutschland einen Erstantrag auf Asyl stellten, sind individuell und nach Herkunft höchst unterschiedlich. Die mit Abstand meisten Anträge stellten in diesem Zeitraum Personen aus Syrien (34 Prozent), Afghanistan (12 Prozent) und dem Irak (10 Prozent). ${ }^{2}$ Von den syrischen Geflüchteten sind 29 Prozent Kurden und 91,5 Prozent muslimischer Herkunft. ${ }^{3}$ SyrerInnen stellen heute in Deutschland nach TürkInnen und PolInnen die drittgrößte Bevölkerungsgruppe mit ausländischem Pass. ${ }^{4}$ Aufgrund der andauernden Kriege und Konflikte, der Zerstörung ganzer Stadtteile und Dörfer in den Herkunftsländern sowie der besseren Lebensperspektiven in Deutschland ist davon auszugehen, dass ein Großteil, vielleicht die Mehrheit der Geflüchteten, auf absehbare Zeit in Deutschland bleiben wird.

Es ist unstrittig, dass antisemitische Vorstellungen in Syrien, Irak und anderen Ländern des Nahen Ostens sowie Nordafrika (MENA) weit verbreitet sind. Umfragen zeigen, dass die große Mehrheit der Bevölkerung antisemitischen Statements zustimmt. In vielen dieser Länder geben über 90 Prozent an, eine negative Meinung über Juden zu haben. ${ }^{5}$

1 Der vorliegende Beitrag ist die überarbeitete und gekürzte Fassung eines Forschungsberichts, der für das American Jewish Committee (AJC) Berlin, Ramer Institute for German-Jewish Relations und die zweite Konferenz des Netzwerks zur Erforschung und Bekämpfung des Antisemitismus (NEBA) erstellt und durch die großzügige Unterstützung des „Bennett Fund“ und des „Meyer Fund“ ermöglicht wurde. (Günther Jikeli, Einstellungen von Geflüchteten aus Syrien und dem Irak zu Integration, Juden und Shoah. Forschungsbericht Dezember 2017, Berlin 2017, [https://ajcberlin.org/sites/default/files/ajc_studie_gefluechtete_und_antisemitismus_2017.pdf], eingesehen 26.10.2018.)

2 Addierte Zahlen aus: Bundesamt für Migration und Flüchtlinge (BAMF), Aktuelle Zablen zu Asyl (2017), Heft 7; BAMF (Hrsg.), Das Bundesamt in Zahlen 2016. Asyl, Migration und Integration, Nürnberg 2017; BAMF (Hrsg.), Das Bundesamt in Zahlen 2014. Asyl, Migration und Integration, Nürnberg 2015. - Von den Personen, die in diesem Zeitraum einen Antrag stellten, befinden sich jedoch viele aufgrund von Rück- und Weiterwanderungen nicht mehr in Deutschland. (Herbert Brücker u. a., IAB-BAMF-SOEP-Befragung von Geflüchteten: Überblick und erste Ergebnisse (Forschungsbericht 29), Nürnberg 2016, S. 18-19.)

3 Zahlen für Erstantragsteller im Jahr 2016. (BAMF (Hrsg.), Das Bundesamt in Zahlen 2016, S. 24-25.)

4 Zahlen für den Stichtag 31.12.2017. (Statistisches Bundesamt, Migration \& Integration, o. D., [https://www.destatis.de/DE/ZahlenFakten/GesellschaftStaat/Bevoelkerung/MigrationIntegration/MigrationInte gration.html], eingesehen 26.10.2018.)

5 Eine Mitte 2013 durchgeführte Umfrage ergab, dass 92 Prozent der Befragten im Irak mindestens sechs der elf abgefragten antisemitischen Aussagen zustimmten. 75 Prozent hielten die Aussage für wahrscheinlich wahr, dass Juden für die meisten Kriege in der Welt verantwortlich seien. 84 Prozent meinten, Juden besäßen zu viel Macht in der Geschäftswelt. (Anti-Defamation League, ADL GLOBAL 100, 2014, [http://global100.adl.org], eingesehen 
Antiisraelische Einstellungen sind nicht weniger verbreitet, wie öffentliche Aufrufe zur Zerstörung Israels und Mobilisierungen gegen eine Normalisierung der Beziehungen mit Israel zeigen. Dies und die Tatsache, dass Antisemitismus, einschließlich Holocaustleugnung, von Regierungsvertretern, islamischen Würdenträgern oder regierungstreuen Medien meist unwidersprochen verbreitet wird, lässt auf eine antisemitische Norm in diesen Ländern schließen. ${ }^{6}$

Die sich als antiimperialistisch, revolutionär und arabisch-nationalistisch verstehende Baath-Partei im Irak betrieb jahrzehntelang antisemitische Propaganda und Hetze gegen Israel und Juden. Die regierende Baath-Partei in Syrien tut dies auch heute noch. Dies wirkte sich auch auf das Bildungssystem und auf die Gestaltung von Schulbüchern aus, die zumindest in Syrien bis heute antizionistische, antisemitische und antiamerikanische Hetze beinhalten. Problematisch ist auch das Geschichtsbild, das syrische Schulbücher von Deutschland vermitteln. Hitler wird hier als starker Führer porträtiert, der sich gegen die Juden zur Wehr setzte, die sich angeblich während der Weltwirtschaftskrise 1929 in Deutschland bereicherten. Juden werden als ewige Feinde der Muslime und Araber sowie der gesamten Menschheit dargestellt. Zionismus und Israel werden in diesen Schulbüchern als imperialistisch und Ursache aller Probleme im Nahen Osten dämonisiert. ${ }^{7}$ Das heißt allerdings nicht, dass alle aus diesen Ländern stammenden Menschen Antisemiten sind, aber diejenigen, die Antisemitismus öffentlich kritisieren, sind in diesen Ländern die Ausnahme.

Dies ist seit der militärischen Niederlage des Nationalsozialismus in Deutschland anders. Offen artikulierter Antisemitismus stößt in der Öffentlichkeit auf Widerspruch und wird im Extremfall, das heißt bei Aufruf zur Gewalt gegen Juden oder bei Verherrlichung des Nationalsozialismus, strafrechtlich geahndet. Ressentiments gegen Juden waren in der deutschen Bevölkerung auch nach 1945 nicht verschwunden, sie wurden aber seither meist über Umwege oder im Privaten geäußert. ${ }^{8}$ Politische Maßnahmen gegen Juden

26.10.2018.) In vielen anderen arabischen Ländern sind die Zahlen laut der ADL-Studie ähnlich. In dem Bericht der im Frühjahr 2009 von PEW erhobenen Umfrage heißt es: „In Arab nations, attitudes toward Jews remain extremely negative. More than $90 \%$ of Egyptians, Jordanians, Lebanese and Palestinians express unfavorable views toward Jews. Only 35\% of Israeli Arabs, however, express a negative opinion.“ (Pew Global Attitudes Project, Little Enthusiasm for Many Muslim Leaders, Washington D.C. 2010, S. 5.)

${ }^{6}$ Zahlreiche Beispiele, die ins Englische übersetzt wurden, können auf der Webseite des Middle East Media Research Institutes eingesehen werden. (MEMRI, 1998-2018, [https://www.memri.org/subjects/antisemitism-documentationproject], eingesehen 26.10.2018.)

7 Siehe u. a. Renate Heugel, Die deutsch-arabische Freundschaft. Deutsche Geschichte (1815-1945) in syrischen Schulbüchern, Hamburg 2013; Arnon Groiss, Jews, Zionism and Israel in Syrian School Textbooks. Report from June 2001, o. O. 2001, [http://www.impact-se.org/wp-content/uploads/2016/04/Syria2001.pdf], eingesehen 26.10.2018; Joshua Landis, Islamic Education in Syria: Undoing Secularism. Prepared for Constructs of Inclusion and Exclusion: Religion and Identity Formation in Middle Eastern School Curricula, Providence (RI) 2003, [http://joshualandis.oucreate.com/Islamic $\% 20$ Education $\% 20$ in $\% 20$ Syria.htm], eingesehen 26.10.2018. - Bezüglich der Schulbücher im Irak, die seit dem Fall Saddam Husseins geändert wurden, siehe Christine Asquith, A New History of Iraq, in: The Guardian, 24.11.2003.

${ }^{8}$ Werner Bergmann/Rainer Erb, Kommunikationslatenz, Moral und öffentliche Meinung. Theoretische Überlegungen zum Antisemitismus in der Bundesrepublik Deutschland, in: KZfSS 38 (1986), Heft 2, S. 223-246. 
wurden jedoch fast ausschließlich von rechtsextremen und linksradikalen Randgruppen gefordert. Dies hat sich sukzessive seit den 1970er-Jahren durch die inzwischen populärste antisemitische Umwegkommunikation in Deutschland, den Antizionismus, geändert. Forderungen nach Maßnahmen gegen den jüdischen Staat, die auf die Einschränkung seiner Fähigkeit hinausläuft, sich effektiv gegen antisemitisch-militante Gruppen zu verteidigen, finden sich heute zumindest vereinzelt bei Politkern aller Parteien. Die „Maßnahmen“ beschränken sich jedoch meist auf öffentliche Verurteilungen Israels und stehen engen Kooperationen auf wissenschaftlichem und kulturellem Gebiet gegenüber - wie auch einer „Staatsräson“, nach der für Deutschland das „Existenzrecht Israels unverhandelbar“ sei. ${ }^{9}$ Die öffentlichen Pauschalverurteilungen von Israel im Namen der Menschenrechte, die eben keine Kritik an bestimmten Regierungsentscheidungen sind, blenden den terroristischen Charakter von Hamas und anderen palästinensischen Gruppen aus, die zum Krieg gegen Israel und die Juden nicht nur aufrufen, sondern dies in die Tat umsetzen. ${ }^{10}$ Sie sind auch oft verbunden mit der Verwendung klassischer antisemitischer Stereotype wie ,jüdischer Rachsucht“ oder dem alten Ritualmordvorwurf in Form der Anschuldigung, (palästinensische) Kinder mit Absicht oder gar aus Lust zu töten. Darüber hinaus wirkt sich die Dämonisierung Israels direkt auf Jüdinnen und Juden in Deutschland aus, denn sie stehen unter Generalverdacht, Sympathien für den angeblich menschenverachtenden Staat Israel zu hegen und werden dafür angefeindet. Dabei ist es unerheblich, wie Jüdinnen und Juden in Deutschland zu Israel stehen, auch wenn es zutrifft, dass sich viele Jüdinnen und Juden aus historischen, religiösen und familiären Gründen mit Israel verbunden fühlen.

Vor diesem Hintergrund, der antisemitischen und antiisraelischen Norm in Ländern des Nahen Ostens und Nordafrika, einer weiten Verbreitung von antiisraelischen Einstellungen in der deutschen Bevölkerung, die meist mit Ressentiments gegen Jüdinnen und Juden einhergehen, sowie einer Häufung von öffentlich gewordenen antisemitischen Vorfällen, ist es nicht verwunderlich, dass VertreterInnen jüdischer Gemeinden Sorge über eine Zunahme von Antisemitismus auch aufgrund der

\footnotetext{
9 Bundeskanzlerin Angela Merkel bezeichnete schon 2006 während ihrer Reise in die USA das Eintreten für das Existenzrecht Israels als „unverrückbare Konstante deutscher Außenpolitik“ und betonte 2008 vor der Knesset: „die Sicherheit Israels ist für mich als deutsche Bundeskanzlerin niemals verhandelbar." Prinzipiell wird dies auch 2018 von allen im Bundestag vertretenen Parteien anerkannt, wie entsprechende Anträge im April 2018 zum 70. Jahrestag der Gründung des Staates Israel zeigen. (Siehe u. a. Deutscher Bundestag, Drucksache 19/1823, 24.4.2018, [http://dipbt.bundestag.de/doc/btd/19/018/1901823.pdf], eingesehen 26.10.2018; Deutscher Bundestag, Drucksache 19/1850, 25.4.2018, [https://dipbt.bundestag.de/doc/btd/19/018/1901850.pdf], eingesehen 26.10.2018.) - Doch bereits diese Formulierung weist auf ein gespanntes Verhältnis hin, denn es steht keineswegs im rechtlichen oder moralischen Kompetenzrahmen der Bundesrepublik, darüber zu befinden, ob Israel ein Existenzrecht hat oder nicht. Dass mit der Formel von der „Anerkennung des Existenzrechts“ keine militärische, finanzielle oder diplomatische Solidarisierung gemeint ist, wird beispielweise angesichts des Abstimmungsverhaltens Deutschlands in den Vereinten Nationen in Bezug auf einseitige Verurteilungen Israels oder auch angesichts der mangelnden Reaktion gegenüber wiederholten Vernichtungsdrohungen gegen Israel seitens des iranischen Regimes deutlich.

10 Alex Feuerherd/Florian Markl, Vereinte Nationen gegen Israel. Wie die UNO den jüdischen Staat delegitimiert, Berlin 2018, S. 193-219.
} 
Günther Jikeli

Zuwanderung hunderttausender Menschen aus Ländern wie Syrien, Irak und Afghanistan äußern. Eine Umfrage aus dem Jahr 2016 belegt, dass viele Jüdinnen und Juden sich vor antisemitischen Angriffen fürchten. ${ }^{11}$ Entsprechende Befürchtungen wurden bestärkt, als es im Dezember 2017 auf einer antiisraelischen Demonstration in Berlin zu antisemitischen Sprechchören in arabischer Sprache und zur Verbrennung einer israelischen Fahne kam, ${ }^{12}$ und im April 2018, als ein kippatragender Jugendlicher in Berlin von einem Geflüchteten aus Syrien beschimpft und geschlagen wurde. ${ }^{13}$ Im Juli 2018 wurde über einen antisemitischen Vorfall berichtet, bei dem ein Syrer, der aufgrund eines Kettenanhängers als Jude identifiziert wurde, von einer Gruppe junger Menschen zusammengeschlagen wurde, unter denen sich sechs Syrer befanden. ${ }^{14}$ Das Problem wird inzwischen auch von vielen PolitikerInnen und RegierungsvertreterInnen verschiedener Parteien erkannt, ${ }^{15}$ zugleich jedoch für pauschale Polemisierungen gegen Geflüchtete benutzt. Die Thematisierung von Antisemitismus unter Geflüchteten findet in einem gesellschaftlichen Rahmen statt, in dem zwar auf der einen Seite nach wie vor große Teile der deutschen Öffentlichkeit Sympathien gegenüber Geflüchteten bekunden und Integrations- und Hilfsprogrammen für Geflüchtete unterstützen, auf der anderen Seite aber ein nicht unbeträchtlicher Teil der Bevölkerung neuen (und alten) Migranten ablehnend gegenüber steht. Das zeigt eindrücklich die hohe Anzahl von Angriffen gegen

${ }^{11}$ Eine Befragung der Universität Bielefeld im Auftrag des vom Bundestag berufenen Unabhängigen Expertenkreises Antisemitismus im Mai und Juni 2016 ergab, dass sich 37 Prozent der befragten Jüdinnen und Juden besorgt vor körperlichen Übergriffen äußerten und 58 Prozent der Befragten aus Sicherheitsgründen bestimmte Stadtteile oder Orte vermeiden. 70 Prozent tragen aufgrund erwarteter Gefahren keine äußerlich erkennbaren jüdischen Symbole. (Andreas Zick u. a., Jüdische Perspektiven auf Antisemitismus in Deutschland. Ein Studienbericht für den Expertenrat Antisemitismus, Bielefeld 2017, S. 4.)

12 Demonstranten verbrennen israelische Flaggen in Berlin, in: Die Welt, 9.12.2017, [https://www.welt.de/politik/deutschland/article171430290/Demonstranten-verbrennen-israelische-Flaggen-inBerlin.html], eingesehen 26.10.2018. - Anlass der Demonstration war die Erklärung der amerikanischen Regierung, Jerusalem als Hauptstadt Israels anzuerkennen. Ob Geflüchtete an der Demonstration beteiligt waren ist allerdings nicht bekannt - mobilisiert wurde vor allem von der Muslimbruderschaft nahestehenden Organisationen. Der Rat der Imame und Gelehrten in Deutschland (RiGD), der mit dem Zentralrat der Muslime assoziiert ist, rief dazu auf, „Jerusalem als Besitz der Muslime zu betonen“. „Der östliche wie der westliche Teil Jerusalems sind als arabisches muslimisches Land zu betrachten, das nicht alleiniger Besitz der Palästinenser ist, sondern Besitz aller Muslime weltweit", hieß es weiterhin in einer Stellungnahme. (RiGD, Pressemitteilung vom 7.12.2017,

[https://www.facebook.com/698425836929834/photos/a.786083888164028.1073741829.698425836929834/13249 48617610883], eingesehen 26.12.2018.)

13 Der Vorfall ereignete sich am 17.4.2018 in Prenzlauer Berg (Berlin). Das Opfer, das beschimpft und mit einem Gürtel geschlagen wurde, war ein arabischer, nicht-jüdischer Israeli, der den Beweis antreten wollte, dass es ungefährlich sei, sichtbar mit Kippa, durch Berlin zu spazieren. Zahlreiche Medien berichteten über diesen Vorfall.

14 Attacke in Berlin - Gruppe prügelt auf Syrer ein, in: Frankfurter Rundschau, 7.7.2018.

${ }^{15}$ Die ehemalige Bundesjustizministerin Katarina Barley (SPD) nannte gegenüber Der Welt den „Flüchtlingszustrom“ als eine der Ursachen des Anstiegs des Antisemitismus. (Die Welt, 21.4.2018.) - Der Tagesspiegel zitierte die Bundeskanzlerin im April 2018 aus einer Stellungnahme gegenüber dem israelischen Nachrichtensender Channel 10 News: „Wir haben jetzt auch neue Phänomene, indem wir Flüchtlinge haben oder Menschen arabischen Ursprungs, die wieder eine andere Form von Antisemitismus ins Land bringen." (Der Tagesspiegel, 22.4.2018.) 
Geflüchtete und deren Unterkünfte, selbst wenn Kriminalstatistiken belegen, dass Geflüchtete auch häufig Opfer von Straftaten anderer MigrantInnen werden. ${ }^{16}$

Die hier vorgestellte (siehe unten) sowie zwei weitere empirische, aber nicht repräsentative Studien bestätigen, dass zumindest unter den interviewten Geflüchteten antisemitische und antiisraelische Vorstellungen weit verbreitet sind, dass es jedoch deutliche Unterschiede zwischen diversen religiösen und ethnischen Gruppen gibt.

Bei einer Umfrage aus Bayern unter 779 Geflüchteten aus Syrien, dem Irak, Eritrea und Afghanistan stimmten 52 Prozent der syrischen und 54 Prozent der irakischen Befragten der Aussage ,Juden haben auf der Welt zu viel Einfluss“ zu. Unter Afghanen waren dies 57 Prozent und unter Eritreern 5 Prozent. In der deutschen Bevölkerung schwanken die Zustimmungsraten zu dieser oder ähnlichen Aussagen in den letzten Jahren zwischen 15 und 25 Prozent. ${ }^{17}$ Das Ausmaß der Zustimmung ist in der Umfrage unter Geflüchteten nicht abhängig von Variablen wie Alter, Familienstand, Bildungsniveau, der bisherigen Aufenthaltsdauer in Deutschland oder dem Grad der Religiosität, wohl aber von der Religionszugehörigkeit. Muslime stimmten der Aussage mit über fünfzig Prozent deutlich häufiger zu als Christen mit 22 Prozent. Im Rahmen derselben Studie wurden auch qualitative Interviews mit zwölf Geflüchteten, darunter vier aus Syrien und vier aus dem Irak, geführt. Darin äußerten sich die Befragten nicht antisemitisch, verwiesen aber auf judenfeindliche Einstellungen in ihren jeweiligen Herkunftsländern. ${ }^{18}$ In einer anderen qualitativen Studie, in der 25 Geflüchtete aus Syrien, Afghanistan und dem Irak nach ihren Einstellungen zu Juden befragt wurden, stellen die Autorinnen einen „AlltagsAntizionismus“ fest, „der Israel für alle negativen Entwicklungen in der Region verantwortlich macht", sowie negative Einstellungen gegenüber Juden, die als selbstverständlich erachtet werden. ${ }^{19}$ Die Mehrheit der Befragten in dieser Studie äußerte sich antisemitisch, eine Interviewpartnerin sagte sogar explizit, sie hasse Juden.

Eine Studie des Londoner Pears Instituts im Auftrag der Stiftung Erinnerung, Verantwortung und Zukunft (EVZ) stellt in Bezug auf die Zuwanderung seit 2011 aus der MENA-Region (Länder des Nahen Ostens) keinen solchen Zusammenhang fest. ${ }^{20}$ Sie verwendet allerdings Methoden, mit der ein solcher auch gar nicht festgestellt werden

${ }^{16}$ Eine Chronik flüchtlingsfeindlicher Vorfälle ist auf einer gemeinsamen Webseite der Amadeu Antonio Stiftung und Pro Asyl einsehbar. (Mut gegen rechte Gewalt, o D., [https://www.mut-gegen-rechte-gewalt.de/service/chronikvorfaelle], eingesehen 26.10.2018.)

${ }_{17}$ Bericht des Unabhängigen Expertenkreises Antisemitismus, 7.4.2017, Deutscher Bundestag, Drucksache 18/11970, S. 63, [http://dip21.bundestag.de/dip21/btd/18/119/1811970.pdf], eingesehen 26.10.2018.; Anti-Defamation League, ADL GLOBAL 100.

18 Sonja Haug u. a., Asylsuchende in Bayern. Eine quantitative und qualitative Studie. Abschlussbericht, München 2017, S. 66-69.

19 Sina Arnold/Jana König, Flucht und Antisemitismus. Erste Hinweise zu Erscheinungsformen von Antisemitismus bei Geflüchteten und mögliche Umgangsstrategien. Qualitative Befragung von Expert_innen und Geflüchteten, Berlin 2016, S. 29.

20 Die Studie besteht aus fünf Länderberichten (Belgien, Deutschland, Frankreich, Großbritannien und Niederlande) und einem Gesamtbericht. (David Feldman: Antisemitismus und Immigration im heutigen Westeuropa. Gibt es einen Zusammenhang? Ergebnisse und Empfehlungen einer Studie aus fünf Ländern, Berlin-London 2018.) 
kann, geschweige denn das Gefahrenpotenzial, das möglicherweise von antisemitisch eingestellten Zuwanderern ausgeht. Mit Hilfe repräsentativer Umfragen soll belegt werden, dass es durch den Anstieg der Migration seit 2011 nicht zu einem Anstieg von Antisemitismus in Deutschland gekommen ist. Dies ist allerdings unsinnig, denn die Gruppe der neuen MigrantInnen, die nach 2011 nach Deutschland gekommen ist (insgesamt etwas über 1,5 Millionen Menschen und davon nur ein Teil aus der MENARegion) ist bei 83 Millionen Menschen in Deutschland zu gering, um in den für die Gesamtbevölkerung repräsentativen Umfragen erfasst zu werden. Die Gruppe der neuen MigrantInnen liegt prozentual deutlich unter der in Umfragen verwendeten statistischen Fehlervarianz zwischen drei und fünf Prozent. Das heißt, selbst wenn alle neuen MigrantInnen sich antisemitisch äußern würden, wäre das in den repräsentativen Umfragen nicht nachweisbar, wenn nicht speziell nach dieser Gruppe differenziert wird. Dass auch von einer relativ kleinen Gruppe eine Gefahr jetzt oder in Zukunft ausgehen kann, wenn besonders starke antisemitische Einstellungen vorhanden sind, wird nicht erörtert. Erstaunlicherweise zitiert der Autor für den Bericht für Deutschland zwar die von Julia Bernstein geleitete Umfrage unter jüdischen Betroffenen, der zufolge 81 Prozent der Befragten angaben, dass körperliche Angriffe von Muslimen ausgingen. Bei Beleidigungen oder Belästigungen waren dies 62 Prozent. Er kommt aber dennoch zu dem Schluss, dass „Täter immer noch vornehmlich nicht-Migranten, nicht-muslimische Deutsche mit einen rechtsextremen Hintergrund sind."21 Grundlage für diese Behauptung sind Polizei- und Verfassungsschutzstatistiken, die einen muslimischen Hintergrund gar nicht erfassen und beispielsweise Hakenkreuzschmierereien automatisch als rechtsextrem einordnen. ${ }^{22}$ Auch deshalb werden derzeit die Erfassungssysteme von antisemitischen Vorfällen reformiert, beziehungsweise neu aufgebaut. Die Datenlage ist zumindest nicht eindeutig und es ist unersichtlich, warum der Autor in diesem Punkt die Betroffenenperspektive in seiner Zusammenfassung unter den Tisch fallen lässt.

Im von David Feldman verfassten Gesamtbericht heißt es, im Widerspruch zum Teilbericht Deutschland, dass in Deutschland antisemitische Einstellungen insgesamt eher abnähmen. ${ }^{23}$ Während einige Umfragen eine Abnahme konstatieren, verweisen andere auf eine Zunahme ab 2014 - oder eine Fluktuation auf hohem Niveau. In Umfragen im Auftrag der Anti-Defamation League sind die Zustimmungsraten zur Aussage ,Juden haben zuviel Macht in der Geschäftswelt," seit 2002 wie folgt: Mai und September 2002: 32\%, März 2004: 24\%, April 2005: 20\%, März 2007: 21\%, Dezember 2008 bis Januar 2009: 21\%, Januar 2012: 22\%, August bis September 2013: 33\%, MärzApril 2015: 28\%. ${ }^{24}$ Ähnlich sieht es aus bei der Aussage ,Juden sprechen noch immer

21 Mathias Berek, Antisemitism and Immigration in Western Europe Today. Is there a connection? The case of Germany, Berlin-London 2018, S. 7.

22 Ist die Statistik zu antisemitischen Straftaten irreführend?, in: Badische Zeitung, 22.3.2018.

${ }^{23}$ David Feldman, Antisemitismus und Immigration im heutigen Westeuropa, S. 19 und 31.

${ }^{24}$ Siehe die Umfrageberichte ADL, European Attitudes Toward Jews, Israel and the Palestinian-Israeli Conflict, Juni 
zuviel über den Holocaust.“ Hier stimmten 2015 immerhin 51 Prozent zu. Eine Zu- oder Abnahme des Antisemitismus lässt sich jedoch nicht allein mit Einstellungsumfragen beurteilen. Zwei Umfragen unter Betroffenen werden zwar genannt, aber dann in den Schlussfolgerungen schlicht ignoriert: In der eingangs erwähnten Studie der Universität Bielefeld gaben 201678 Prozent der befragten Jüdinnen und Juden an, dass der Antisemitismus in den letzten fünf Jahren zugenommen habe. ${ }^{25}$ Ähnliches ergab schon eine Studie der Agentur der Europäischen Union für Grundrechte (FRA), nach der 2012 68 Prozent der befragten Jüdinnen und Juden in Deutschland eine Zunahme des Antisemitismus in den letzten fünf Jahren wahrnahmen. ${ }^{26}$

Die Daten des Bundeskriminalamts (wenn auch hinsichtlich der Tätergruppen unzuverlässig) zeigen keineswegs eine Abnahme der registrierten antisemitischen Straftaten seit 2011, sondern einen leichten Anstieg mit einem Peak jeweils 2012 und $2014 .^{27}$

Die Schlussfolgerungen der Studie des Londoner Pears Instituts sind wohl eher als politische Meinungsäußerung zu werten und nicht als Ergebnis fundierter Forschung. Schwerer wiegt vielleicht aber, dass der Gesamtbericht schlussfolgernd behauptet, dass der Antisemitismus abnehme. Einschlägige Umfragen unter jüdischen Betroffenen, die besagen, dass Antisemitismus in den letzten Jahren zugenommen habe und dass ein Großteil der Täter einen muslimischen Hintergrund habe, finden keine Berücksichtigung als Indikator für die weite Verbreitung von Antisemitismus. Implizit wird damit die Perspektive der Betroffenen delegitimiert. Dazu passt, dass Repräsentanten jüdischer Gemeinden, die vor Antisemitismus unter neuen MigrantInnen warnen, im öffentlichen Diskurs und in der EVZ-Studie häufig in einem Atemzug mit rechtspopulistischen Politikern genannt werden. Dies zeigt einmal mehr, wie sehr das Thema Antisemitismus unter (geflüchteten) Muslimen selbst in der Wissenschaft ideologisiert wird und wie wichtig es ist, der Fragestellung mit angemessenen Methoden zu begegnen und entsprechendes empirisches Material zu erheben.

2002; dies., European Attitudes Toward Jews. A Five Country Survey, August 2002; dies., Attitudes Toward Jews, Israel and the Palestinian-Israeli Conflict in Ten European Countries, August 2004; dies., Attitudes Toward Jews in Twelve European Countries, May 2005; dies., Attitudes Toward Jews and the Middle East in Five European Countries, May 2007; dies., Attitudes Toward Jews in Seven European Countries, February 2009; dies., Attitudes Toward Jews In Ten European Countries, March 2012; dies., ADL GLOBAL 100. 2015 Update Germany, o. D. [http://global100.adl.org/\#country/germany/2015], eingesehen 7.11.2018.

${ }_{25}$ Zick, Jüdische Perspektiven auf Antisemitismus, S. 13.

${ }^{26}$ European Union Agency for Fundamental Rights, Discrimination and hate crime against Jews in EU Member States: experiences and perceptions of antisemitism, Wien 2013, S. 17.

27 Siehe hierzu die Verfassungsschutzberichte der Jahre 2001 bis 2017. (Bundesamt für Verfassungsschutz, o. D., [https://www.verfassungsschutz.de/de/oeffentlichkeitsarbeit/publikationen/verfassungsschutzberichte], eingesehen 28.10.2018.) 


\section{Methoden der Studie und Sample}

Die hier vorliegende Studie hat keinen Anspruch auf Repräsentativität, sondern es werden vielmehr wiederkehrende Muster von Bildern über Jüdinnen und Juden untersucht: Welche Stereotype und Vorstellungen gibt es? Welche davon haben spezifische Bezüge zum jeweiligen Hintergrund der Zielgruppe? Welche Begründungsmuster und Zusammenhänge lassen sich feststellen?

Im Dezember 2016 wurden in Berlin in 16 Gruppeninterviews insgesamt 68 Geflüchtete aus Syrien und dem Irak befragt. Die Interviews dauerten durchschnittlich etwa neunzig Minuten und wurden mithilfe von drei Übersetzern und einer Übersetzerin geführt, die selbst Geflüchtete aus Syrien sind: einer muslimisch-arabischen Frau sowie einem christlich-arabischen Mann, einem muslimisch-arabischen und einem muslimischkurdischen Mann. Die Gespräche fanden, bis auf ein Gespräch auf Kurdisch und zwei auf Englisch, alle auf Arabisch statt. Teile der Gespräche wurden zudem auf Deutsch geführt. Fragen des Interviewers wurden ins Arabische beziehungsweise Kurdische sowie die Antworten der Befragten ins Englische übersetzt. Das Sample umfasst separate Gruppen von Geflüchteten: Geflüchtete über 27 Jahren, Geflüchtete unter 27 Jahren, Frauen, Männer, AraberInnen, KurdInnen, PalästinenserInnen (aus Syrien) sowie gemischte Gruppen. Alle Interviews wurden vom Autor geführt, der sich als Wissenschaftler der Indiana University und der Universität Potsdam vorstellte.

Die Interviewten wurden zum einen über Beschäftigte in der Flüchtlingsarbeit gewonnen und zum anderen über die vier ÜbersetzerInnen beziehungsweise deren Bekannte. Um nicht nur intrinsisch motivierte Personen $\mathrm{zu}$ befragen, wurde mit einer Aufwandsentschädigung von zwanzig Euro ein zusätzlicher Anreiz für die Teilnahme geschaffen. Laut der vermittelnden SozialarbeiterInnen gehört ein Großteil der Befragten zu den eher „aufgeschlossenen und toleranten“ Geflüchteten, die sich besonders um Integration und Kontakt mit der deutschen Bevölkerung bemühen. Erschwerend kommt hinzu, dass eine vom Staat unabhängige Forschung in den diktatorischen Regimen der Herkunftsländer unüblich ist und die Interviewten im Asylverfahren, das ebenfalls ein „Interview“ beinhaltet, stark abhängig vom deutschen Staat sind. Dies mag dazu geführt haben, dass Personen, die vermuten, dass sie sozial unerwünschte Einstellungen wie beispielsweise Islamismus und offener Judenhass teilen, im Sample unterrepräsentiert sind. ${ }^{28}$

${ }^{28}$ Für ein Folgeprojekt interviewte der Autor gemeinsam mit drei Wissenschaftlern der Indiana University, Haidar Khezri, Asaad al Saleh und Alvin Rosenfeld, im Sommer 2017 in Berlin, Greifswald und Köln weitere 85 Geflüchtete aus Syrien und dem Irak sowie zwanzig in der Flüchtlingsarbeit beschäftigte Personen. Diese ausführlicheren und größtenteils individuell geführten Interviews sind nicht Gegenstand dieses Berichts. Eine grobe Auswertung zeigt aber, dass die Interviews des Folgeprojekts den hier dargelegten Befunden nicht widersprechen. In einigen Bereichen, insbesondere in Bezug auf Einstellungen zu Juden, ist aber eine größere Vielfalt feststellbar, einschließlich radikalen, offen genozidalen Einstellungen. 
Einige der angesprochenen Themen wie islamistischer Terrorismus, Geschlechtergerechtigkeit, der Nahhostkonflikt oder Juden und Israel gelten als sensibel und der Interviewer und die ÜbersetzerInnen stießen folglich teilweise auf Zurückhaltung, Ablehnung und Misstrauen. Die zu Beginn des Interviews offengelegte Verbindung des Interviewers $\mathrm{zu}$ einer amerikanischen Universität mag darüber hinaus bei antiamerikanisch eingestellten Personen zu Zurückhaltung geführt haben. Möglicherweise wurden daher eventuell vorhandene antidemokratische und speziell antisemitische und antiamerikanische Einstellungen nicht offen im Interview geäußert. Zwei Gruppen wussten vor dem Interview, dass ein zentrales Thema Einstellungen zu Juden ist: offen antijüdische Einstellungen wurden in diesen Interviews nicht geäußert. Die übrigen interviewten Personen wussten im Vorfeld, dass die Interviews Teil einer wissenschaftlichen Befragung zu Einstellungen unter Geflüchteten in Deutschland waren.

Die Interviews wurden in ruhigen Cafés, Restaurants oder in verschiedenen Berliner Gemeinschaftsunterkünften, in Seminarräumen oder in den Zimmern der Befragten, durchgeführt. Im Anschluss an die Interviews wurden die Befragten gebeten, einen kurzen Fragebogen zu biografischen Daten auszufüllen (Alter, Beruf, Bildungsstand, Geburtsort, Religion, ethnischer Hintergrund, Sprachkenntnisse, derzeitige Beschäftigung, Aufenthaltsdauer in Deutschland). Die Interviews wurden aufgezeichnet, vollständig übersetzt und transkribiert. Die Auswertung erfolgte in Zusammenarbeit mit Dr. Lars Breuer und Dr. Matthias J. Becker anhand einer induktiven und deduktiven Kodierung der Interviews mithilfe der Auswertungssoftware MAXQDA in einem iterativen Prozess der Kategorienbildung.

Alle Interviewten, 14 Frauen und 54 Männer im Alter von 18 bis 52 Jahren, erreichten Deutschland seit Mitte 2014, die meisten kamen im Verlauf des Jahres 2015. 55 Geflüchtete identifizierten sich selbst als AraberInnen, davon elf als arabisch/syrischpalästinensisch $^{29}$ und 13 als KurdInnen aus Syrien. Die überwiegende Mehrheit ist muslimischen Glaubens, sechs bezeichneten sich als atheistisch (eine davon mit christlichem Hintergrund), vier als christlich und einer als Druse. Das Bildungsniveau und die Religiosität variierten erheblich. Die Befragten stammten aus kleineren und größeren Städten wie Aleppo, Bagdad, Damaskus, Hama, Homs, Idlib, Qamlishi und Raqqa oder deren Umgebung. Insgesamt hatten die Befragten ein positives Bild von der deutschen Bevölkerung. Ein Gefühl des Willkommenseins, zumindest am Anfang, war bei vielen verbreitet. Dies entspricht dem Empfinden einer Mehrheit der Geflüchteten in Deutschland, wie eine repräsentative Studie zeigt. ${ }^{30}$ Viele berichteten jedoch auch von Problemen, etwa der Sorge um den Aufenthaltstitel, Schwierigkeiten bei der Familienzusammenführung, der Suche nach einer Wohnung, dem Erlernen der deutschen Sprache, der Anerkennung von Papieren, diversen Behördengängen oder der

${ }^{29}$ Dabei handelt es sich um Personen, die in Syrien aufgewachsen sind.

${ }^{30}$ Brücker, IAB-BAMF-SOEP-Befragung, S. 32-36. 
Suche nach Arbeit beziehungsweise geeigneten Qualifizierungsmaßnahmen. Auch die Sorge um Familienangehörige im Herkunftsland spielten bei vielen Befragten eine große Rolle. Insbesondere die als undurchsichtig erlebte Bürokratie der Sozialämter und Ausländerbehörden sowie die Unterbringung in Gemeinschaftsunterkünften führten häufig zu Frustrationen. ${ }^{31}$ Die allermeisten Geflüchteten strebten eine Integration im Sinne gesellschaftlicher Teilhabe, Arbeitsaufnahme und Respektierung der Gesetze an. Unter den Jüngeren galt als selbstverständlich, dass dazu auch das Erlernen der deutschen Sprache gehört, auch wenn den allermeisten die Beibehaltung ihrer ethnischen Identität sowie ihrer Werte in Bezug auf Familie und Religion sehr wichtig war.

\section{Identitäten: Arabischer Nationalismus und Positionierungen gegen Jihadismus}

Keiner der Interviewten zeigte offene Sympathien für islamistische oder terroristischislamistische Gruppen. „Extremismus“ und „Terrorismus“ wurden weit von sich gewiesen und meist auch vom Islam an sich. Die Leugnung jeglicher Verbindung von Jihadisten zum Islam kann jedoch schnell in Verschwörungstheorien enden. Islamistischterroristische Gruppen wie der „Islamische Staat" (IS) und „al-Qaida“ wurden als unislamisch definiert. Zugespitzt kann diese Argumentationsstrategie dazu führen, dass andere, vorzugsweise Juden, Israel oder die USA, für islamistische Terrorgruppen verantwortlich gemacht werden: „Daesch [arabische Abkürzung für den IS; Anm. GJ] hat in keiner Weise etwas mit dem Islam zu tun [...]. Amerika hat Daesch geschaffen." (Sayyid, 21, arabisch-muslimischer Mann aus Raqqa/Syrien) ${ }^{32}$ Die Gruppe der fünf Interviewten war sich einig, dass Amerika die Anschläge auf das World Trade Center in New York am 11. September 2001 verübt hatte, und dass ,auch Juden etwas damit zu tun haben, da kein jüdischer oder israelischer Angestellter in dem Gebäude war.“ (Sayyid) Amerika und „die Juden" wurden für das Handeln islamistisch-terroristischer Organisationen verantwortlich gemacht und jegliche Verbindung islamistischer Gruppen zum Islam wurde geleugnet. Einige Befragte machten anstelle von Juden auch Israel verantwortlich. Für Yanes (32, arabisch/palästinensisch-muslimischer Mann aus Damaskus/Syrien) war der IS nichts weiter als eine Marionette der USA und Israels.

Unter weniger religiösen Interviewten fanden sich dagegen auch deutlichere Stimmen, die von „islamischen Extremisten“ sprachen und diese durchaus als eigenständige, gefährliche Akteure betrachteten, die es zu bekämpfen gilt. Aber auch unter den weniger Religiösen tendierten viele Befragte dazu, terroristisch-islamistischen Gruppen ihre islamische Identität abzusprechen. Dies führte zum Teil zu widersinnigen Behauptungen.

31 Die repräsentative IAB-BAMF-SOEP-Befragung zeigt ebenfalls eine relative Unzufriedenheit über die Wohnsituation in Gemeinschaftsunterkünften im Vergleich zu Privatwohnungen. (Ebd.)

32 Bei den angegebenen Namen der interviewten Personen handelt es sich um Pseudonyme. 
So meinte etwa die liberale, säkulare und ismailitische ${ }^{33}$ Aktivistin Tarana: „ISIS, das sind keine Muslime, [...] die sind Teil des [syrischen] Regimes." Sie sah die Kriege im Nahen Osten als Teil eines großen Plans, in dem die israelische Lobby die USA beherrsche. Erbitterte Gegner im syrischen Bürgerkrieg sind darin Teil derselben Macht und Muslime können gemäß dieses Narrativs keine Terroristen sein.

Arabische Interviewte waren oft stolz auf ihre arabische Identität und verorteten den Ursprung der menschlichen Zivilisation in Syrien und im Irak. Im Extremfall kamen dabei rassistische Gefühle der Überlegenheit und Abwertung von anderen zum Ausdruck. Diese Überlegenheitsgefühle eines arabischen Nationalstolzes werten nicht nur andere Menschen $a b$, sondern dienten paradoxerweise als Erklärung für das derzeitige Scheitern der arabischen Nationalstaaten Syrien und Irak. Die eigene Nation wurde als ganz besonders potent imaginiert, weshalb sie Ziel von Angriffen und Verschwörungen sei.

\section{Bilder von Jüdinnen und Juden: Von „Eine Religion wie unsere“ bis zu Weltverschwörern}

In den Interviews fand sich eine große Bandbreite von Einstellungen gegenüber Jüdinnen und Juden: Diese reichte von pro-jüdischen und pro-israelischen Bekenntnissen über Toleranz, Desinteresse, einzelne Stereotype bis hin zu antisemitischen Weltverschwörungsphantasien und genozidalen Einstellungen, die sich unter anderem in der Rechtfertigung der Shoah ausdrückten. Auffallend war dabei die Diskrepanz zwischen Angehörigen der Mehrheitsbevölkerung im jeweiligen Herkunftsland und den Angehörigen der jeweiligen ethnischen und religiösen Minderheiten. Insbesondere einige der interviewten syrischen KurdInnen zeigten deutlich pro-jüdische und pro-israelische Einstellungen. Teilweise waren diese jedoch philosemitisch durchsetzt, das heißt Juden wurden für ihre Macht und Cleverness bewundert. Einige der Interviewten mit syrischpalästinensischem Hintergrund zeigten sich hingegen besonders antisemitisch: sowohl in Bezug auf Israel als auch Verschwörungsphantasien.

Positiv zu vermerken sind vereinzelte Aussagen, die auf ein Aufbrechen des Feindbildes Israel verweisen: Einige Befragte sahen Israel im Vergleich zum IS oder zum syrischen Regime als deutlich humaner. Dies war freilich nur dann der Fall, wenn diese Personen nicht davon ausgingen, dass Israel für die Kriege im Irak und in Syrien verantwortlich ist. Jüdinnen und Juden wurden primär als religiöse Gemeinschaft und nicht als „Volk“ wahrgenommen. Letzteres wurde ausgeblendet oder explizit geleugnet und war eng verbunden mit der Ablehnung des Staates Israel als jüdischer Staat. Vor allem aber zeigten die Interviews, dass die allermeisten Befragten trotz verbreiteter

${ }^{33}$ Die schiitische Glaubensgemeinschaft der Ismailiten gilt als tolerant und offen. Sie wird von sunnitischen Muslimen oft als abtrünnig angesehen. 
verschwörungstheoretisch-antisemitischer Denkweisen zur Zeit des Interviews mit anderen Dingen beschäftigt waren, sodass Jüdinnen und Juden keinen zentralen Platz in ihrer unmittelbaren Gedankenwelt einnahmen.

Antisemitismus brach meist erst auf Nachfragen zu Themen wie Ursachen für Kriege im Nahen Osten, islamistische terroristische Angriffe wie am 11. September 2001, Ursachen für die Entstehung des IS, vorherrschende Bilder von Israel, die Shoah oder die Rolle von Juden vor dem Zweiten Weltkrieg in Deutschland hervor. Spontan wurden judenfeindliche Bilder im Zusammenhang mit der Erwähnung von Freimaurern, der Familie Rothschild, Zionismus sowie Banken und Finanzmärkten genannt. In Diskussionen zu traditionellen Beziehungen zwischen Juden und Muslimen fiel ein ambivalentes Verhältnis auf, in dem zum einen ein angebliches harmonisches Miteinander sowie religiöse Toleranz betont und zum anderen eine tiefgehende immerwährende Feindschaft zwischen Juden und Muslimen suggeriert wurde - teilweise von denselben Personen.

\section{Antisemitismus und Religion: Islamischer Antisemitismus}

Explizit religiös begründeter Antisemitismus wurde im Vergleich zu anderen Begründungen relativ selten geäußert. Generell waren die muslimischen Befragten darum bemüht, ein positives Bild des Islam zu zeichnen und diesen nicht als Ursache von potentiellen Konflikten darzustellen. Dennoch gaben die Interviewten auch Vorstellungen wieder, die islamisch-antijüdische Stereotype bedienen. Darunter fallen die Ansichten, dass Juden und Muslime generell Feinde seien, dass „die Juden“ die heiligen Schriften verfälscht hätten und dass sie versucht hätten, den Propheten Mohammed zu vergiften. ${ }^{34}$ Auch positive Stereotype begründeten Befragte mit Verweisen auf islamische Quellen: ,Juden sind fähig, Juden sind die Söhne Gottes, Juden ... das ist der Grund, warum sie Geld haben und der Koran besagt, dass sie hart arbeiten." (Nidal, 35, kurdischer Mann aus Aleppo/Syrien mit muslimischem Hintergrund)

Die Annahme einer generellen Feindschaft zwischen „den Juden“ und „den Muslimen“ hat ein radikales Potenzial, da sie essentialistisch auf die Gesamtheit der Jüdinnen und Juden, einschließlich in Deutschland, bezogen wird. Ein Beispiel ist die Reaktion von Yanes auf eine Äußerung Jalils, der in einem Gespräch über das Zusammenleben von Menschen unterschiedlicher Religionen in Deutschland betonte, dass der Islam eine friedliche Religion sei und dass ,unser Prophet Mohammed uns gesagt hat, dass wir alle

\footnotetext{
34 Entsprechende Interpretationen finden sich in vielen Strömungen des Islam. Der Koran und die Hadithen beschreiben die Beziehungen zwischen Juden und Muslimen ambivalent. Als Beleg einer grundsätzlichen Feindschaft werden verschiedene Stellen im Koran herangezogen, darunter: Sure 5, Vers 82; Sure 2, Vers 61 und Vers 96, sowie Sure 9, Vers 29. Der Vorwurf der Fälschung heiliger Schriften findet sich in Sure 4, Vers 46 und Sure 2, Vers 75. Eine Geschichte, in der eine Jüdin versucht habe, Mohammed zu ermorden findet sich in den Hadithen bei Sahih Muslim, Buch 026, Nr. 5430 und Sahih Bukhari, Band 3, Buch 47, Nr. 786.
} 
Religionen akzeptieren müssen. Und als sie Heiden bekämpften, wollte er keinen von ihnen töten, weil er dachte, dass es vielleicht ein Gläubiger sein könnte." (Jalil, 42, arabisch-muslimischer Mann aus Bagdad/Irak). Jalils Aussage entpuppt sich bei genauerem Hinsehen als Scheintoleranz, wenn sie wörtlich auf heutige Verhältnisse übertragen wird, insbesondere gegenüber Atheisten. Yanes war aber auch mit dieser Scheintoleranz nicht einverstanden und warf daraufhin ein: „Aber letztlich werden sie [die Juden; Anm. GJ] ${ }^{35}$ zu unseren Feinden. Laut Koran und dem Islam sagt Gott uns, wer die Feinde deiner Religion sind. Letztlich sagt uns Gott, dass dies deine Feinde sind." (Yanes, 32, arabisch/palästinensisch-muslimischer Mann aus Damaskus/Syrien) Yanes hat durchaus recht, dass es im Koran und auch in den Hadithen (Erzählungen über den Propheten Mohammed) Textstellen gibt, die insbesondere bei einer weitverbreiteten - ahistorischen, nicht kontextualisierten Interpretation nahelegen, dass Jüdinnen und Juden Feinde des Islam und der Muslime schlechthin seien. ${ }^{36}$ Verweise auf die Annahme einer entsprechenden Feindschaft machten auch Interviewte, die diese Ansichten selbst nicht teilten: „Es gibt ein Riesenproblem zwischen dem Islam und Juden. Und dieses Problem stammt aus der Zeit des Propheten.“ (Nidal, 35, kurdischer Mann aus Aleppo/Syrien mit muslimischem Hintergrund). Das in islamistischen Kreisen verbreitete Bild, Juden würden von Affen und Schweinen abstammen, ${ }^{37}$ war vereinzelten Interviewten aus YouTube-Videos von religiösen, öffentlichen Persönlichkeiten bekannt, stieß bei ihnen aber auf Ablehnung.

Als Beweis einer Feindschaft der Juden gegenüber Muslimen diente einigen Befragten die Annahme, Juden hätten versucht, Mohammed zu töten. So berichtete Abia (schätzungsweise Mitte 20, arabisch-muslimische Frau aus Bagdad/Irak) davon, dass die Mehrheit der Menschen im Irak keine Jüdinnen und Juden mag, da sie annähme, dass diese die Werte von Muslimen nicht respektierten und schlecht über den Islam redeten. Hayyan (schätzungsweise Ende 20, arabisch-muslimischer Mann aus Quneitra/Syrien) fügte daraufhin an, „die Juden“ hätten versucht, „den Gesandten“ zu töten. Dieses Gerücht lässt sich zurückverfolgen auf die kanonisierten Hadithe, die Erzählungen über das Leben Mohammeds, in denen es heißt, eine jüdische Sklavin habe Mohammed vergiftetes Fleisch zu essen gegeben. ${ }^{38}$ Islamisten, und in diesem Fall auch einer der

35 Auf Nachfragen des Übersetzers, wer der Feind sei, antwortete Yanes „Israel,“ womit klar wird, dass er nicht Ungläubige im Allgemeinen meint. Da es im Gespräch zuvor hauptsächlich um Juden ging und er an anderer Stelle äußerte, dass er keinen Unterschied zwischen Juden und Israelis sehe und darüber hinaus die Aussage mit dem Bezug zum Koran unsinnig wäre, wenn sie auf Israel und nicht auf Juden bezogen würde, kann geschlossen werden, dass hier Juden gemeint sind.

${ }^{36}$ Besonders relevant unter einer Anzahl von judenfeindlichen Stellen im Koran scheinen: Sure 5, Vers 82, der besagt, dass unter Juden die erbittertsten Gegner der Muslime zu finden sind, weit mehr als unter Christen; Sure 2, Vers 61, der beschreibt, dass Gott die Juden mit einem Fluch belegte; Sure 2, Vers 96, in dem Juden vorgeworfen wird, sie liebten das weltliche Leben; sowie Sure 9, Vers 29, der zum Kampf gegen Juden und Christen aufruft, bis sie Tribut zahlen und sich unterwürfig zeigen. Die kanonischen Hadithe enthalten noch explizitere judenfeindliche Stellen.

${ }^{37}$ Neil J. Kressel, ,The Sons of Pigs and Apes“. Muslim Antisemitism and the Conspiracy of Silence, Dulles 2012.

38 Sahih Muslim, Buch 26, Nr. 5430 und Sahih Bukhari, Band 3, Buch 47, Nr. 786. 
Interviewten, machen daraus den Vorwurf, dass schon seit Zeiten Mohammeds „die Juden“'Todfeinde der Muslime seien.

Einer der wirkmächtigsten Vorwürfe gegen „die Juden“ in der Tradition des Islam - in mancher Hinsicht vergleichbar mit dem Vorwurf im Christentum, „die Juden“ hätten Jesus getötet - ist die Vorstellung, sie hätten die heiligen Schriften gefälscht. Dieser Mythos findet sich an mehreren Stellen auch direkt im Koran. ${ }^{39}$ Damit verbunden sind Stereotype von „den Juden“ als Verrätern und Lügnern.

„Was wissen wir über Juden? Sicher, eine Religion, aber sie haben sie verfälscht. [...] Das wissen wir. Sie haben ein Buch wie unseres und sie haben einen Propheten und wir erkennen ihren Propheten an und alles, aber sie haben das Buch gefälscht, das von Gott offenbart wurde [...]. Der Koran besagt auch, dass es nicht dasselbe Buch ist." (Bader, 33, arabisch/palästinensisch-muslimischer Mann aus dem Flüchtlingslager Jarmuk bei Damaskus/Syrien)

Auch der Wunsch nach der Zerstörung Israels kann religiös begründet werden, indem Palästina, das in diesen Vorstellungen das Gebiet Israels mit umfasst, als muslimisches Territorium deklariert wird, auf dem Juden und damit der jüdische Staat keinen Hoheitsanspruch haben dürfen. ${ }^{40}$

„Letztendlich ist Palästina unser. Wir sind Muslime und wir wissen, dass Palästina den Muslimen und Arabern gehört und Aksa [am Tempelberg in Jerusalem; Anm. GJ] unser ist und eines Tages wird Palästina frei sein und $\mathrm{zu}$ uns zurückkehren." (Yasser, 41, arabisch/palästinensisch-muslimischer Mann aus Homs/Syrien)

Inas und Fatin, zwei junge, säkulare und wenig religiöse Frauen aus Damaskus, erwähnten eine in ihrem Bekannten- und Familienkreis sowie in Schulen und Schulbüchern in Syrien verbreitete Vorstellung: ,Ich habe gehört, im Islam, dass wir vor dem Jüngsten Tag Palästina zurückkriegen und den Krieg gewinnen werden." (Inas, schätzungsweise Mitte 20, arabisch-muslimische Frau aus Damaskus/Syrien). Diese Annahme zeigt die Verflechtung säkularer, islamischer und nationalistischer Deutungen des Krieges gegen Israel beziehungsweise gegen „die Juden“. Sie ist anschlussfähig an die in islamistischen Kreisen weitverbreitete Wahnvorstellung eines globalen Krieges gegen den Islam, der von ,den Juden“ angeführt würde, oder an dem sie zumindest mitwirkten. In dieser Vorstellung gibt es in der Zeit kurz vor dem Jüngsten Gericht einen

39 Theologisch stellt sich im Islam das Problem, dass der Koran als direktes Wort Gottes gilt und dass darin Geschichten aus der Thora beziehungsweise dem Alten Testament wiedererzählt werden, bei denen aber einige, teilweise wesentliche Details anders beschrieben werden. Wenn der Text des Korans als absolute Wahrheit gilt, muss die Thora eine Fälschung dieser Geschichten sein, auch wenn historisch unstrittig ist, dass die Thora lange vor dem Koran entstand und Niederschriften aus vorislamischer Zeit existieren. Der Vorwurf der Fälschung findet sich im Koran, so etwa in Sure 4, Vers 46 oder in Sure 2, Vers 75, in denen Juden vorgeworfen wird, wissentlich Gottes Wort entstellt zu haben.

${ }^{40}$ Eine entsprechende Logik lässt sich auch bei islamischen Organisation in Deutschland verzeichnen, die eine Nähe zum Islamismus zeigen, wie dem eingangs erwähnten Rat der Imame und Gelehrten. Dieser erklärte im Dezember 2017: „Der östliche wie der westliche Teil Jerusalems sind als arabisches muslimisches Land zu betrachten.“ (RiGD, Pressemitteilung vom 7.12.2017.) 
Religionskrieg, aus dem der Islam als Sieger hervorgehen werde. ${ }^{41} \mathrm{Gamal}$, ein ehemaliger Schuldirektor und Hochschullehrer, führte als Beleg für diese Position die „Protokolle der Weisen von Zion“ an, aus denen er frei zitierte: „Wir haben unser Bestes getan, um das Christentum in Europa zu erledigen und es innerhalb der Kirche zu beschränken. [...] Und wir werden nicht lange brauchen, um den Islam zu erledigen." (Gamal, 45, arabisch-muslimischer Mann aus Idlib/Syrien). Den in seinen Augen allgegenwärtigen Vorwurf, „der Islam“ sei die Ursache des Terrorismus, sah Gamal als Bestätigung für die Echtheit der „Protokolle“, die er als jüdisches Buch ansah und von denen er gleich zwei Exemplare besitzt, wie er berichtete.

Einige Interviewte begründeten ihre Abneigung gegenüber Jüdinnen und Juden auch mit muslimischen Traditionen. Inas etwa erinnerte sich an muslimische Verhaltensregeln gegenüber jüdischen und christlichen Menschen. „Was ich höre, ist, dass Juden wie wir sind. Sie sind sauber wie Muslime, [...] aber du darfst nicht in ihrem Haus schlafen, weil $\mathrm{du}$ [dort] nicht sicher bist. Christen sind nicht sauber, aber du kannst in ihrem Haus schlafen. Aber Juden sind unsere Cousins, sie sind wie wir, was Alltagsgewohnheiten betrifft." (Inas, schätzungsweise Mitte 20, arabisch-muslimische Frau aus Damaskus/ Syrien).

\section{Antiisraelismus: Gegen die Existenz Israels}

Negative Einstellungen gegenüber Israel und die Wahrnehmung, dass die Existenz des Staates prinzipiell unrechtsmäßig sei und beendet werden sollte, gehörten für die meisten der befragten Geflüchteten (mit Ausnahme vieler kurdischer) zur Norm. Dazu gehörte, dass Zionismus grundsätzlich negativ konnotiert war. Unter den Begriff Zionismus wurden jedoch auch viele Phantasien über angebliche israelische Einflüsse in der Welt sowie über vermeintliche Expansionspläne Israels gefasst - er wurde also keineswegs nur als Nationalbewegung zur Errichtung eines jüdischen Staates verstanden. Gerade das einfache Schwarz-Weiß-Denken und die Pauschalisierungen in Bezug auf Israel, verdeutlichen, dass es sich hierbei um eine grundsätzliche Opposition gegen Israel handelt - d.h., dass es sich eben nicht um Kritik, sondern vielmehr um ein antisemitisches Ressentiment handelt. Die Vorstellungen der Befragten von Jüdinnen und Juden einerseits sowie von Israel und Israelis andererseits gingen häufig ineinander über - auch bei denen, die eingangs betonten, dass es einen großen Unterschied zwischen Juden und Israelis gebe.

Interviewte, die sich antiisraelisch äußerten, positionierten sich zwar pro-palästinensisch (auch wenn sie keinen palästinensischen Hintergrund haben), ${ }^{42}$ begründeten ihre

${ }^{41}$ Ronald L. Nettler, Past Trials and Present Tribulations. A Muslim Fundamentalist's View of the Jews, Oxford 1987.

42 Interviewte mit palästinensischem Hintergrund hoben ihre palästinensische Identität oft hervor und empfanden es als selbstverständlich, dass mit dieser Identität israelfeindliche Einstellungen einhergehen, ohne dass auf konkrete Leiden von PalästinenserInnen und israelische Verantwortlichkeiten im Einzelnen eingegangen wurde. 
Ablehnung Israel gegenüber aber weniger mit dem Leid der PalästinenserInnen als vielmehr prinzipiell: Allein die Existenz eines jüdischen Staates auf vermeintlich arabischmuslimischem Territorium schien für sie nicht akzeptabel.

Für Gamal, den ehemaligen Schuldirektor und Hochschullehrer, war es eine Selbstverständlichkeit, Israel das Existenzrecht abzusprechen. Auf die Frage des Interviewers „Denken Sie, dass es eine schlechte Idee ist, dass Israel existiert?“ antwortete Gamal mit der knappen Antwort „Ja selbstverständlich.“ Doch dann schob er der Aussage den folgenden, relativierenden Satz hinterher: „Aber nicht schlimmer als Bashar Al Assad.“ (Gamal, 45, arabisch-muslimischer Mann aus Idlib/Syrien) Eine Reihe von syrischen Interviewten betonte, dass die Verbrechen des syrischen Regimes und des IS gravierender sind als die Israel zugeschriebenen Verbrechen. „Israel hat in seiner ganzen kriminellen Geschichte in Palästina nicht so viele Menschen getötet wie Bashar al-Assad in sechs Monaten in Syrien, “ sagte etwa Burhan (27, kurdisch-muslimischer Mann aus Damaskus/Syrien), der keineswegs frei war von antiisraelischen Verschwörungsphantasien. Allerdings ließ sich bei ihm eine Infragestellung des Feindbildes Israel beobachten. Andere Befragte wie Gamal sahen jedoch eindeutig ein Komplott am Werk: Gamal beschrieb Bashar al-Assad als „Partner“ des Islamischen Staates. Die Begründung: Beide würden Israel nicht bekämpfen, obwohl Israel doch Syrien angreife. Gamal vermutete daher, dass alle drei Akteure unter einer Decke steckten. Wieder andere gingen davon aus, dass Syrien angegriffen wird, „um Israel zu schützen." (Zaid, 29, arabisch-muslimischer Mann aus Syrien). Dass Israel hinter den Kriegen in Syrien und im Irak stecke, glaubten interessanterweise sowohl säkulare wie religiöse, christliche wie muslimische, männliche wie weibliche Interviewte. Manche betonten eher den (negativen) regionalen Einfluss Israels und hoben israelische Angriffe auf Syrien und die Besetzung der Golanhöhen oder des Südlibanons hervor, die sie als Teil eines Plans zur Errichtung eines Groß-Israels ansahen, der bis 1948 oder noch früher zurückreiche.

Der Hauptpunkt, mit dem die Befragten ihre antiisraelische Haltung begründeten und bei dem sie von einem allgemeinen Einverständnis auch des Interviewers ausgingen, ist die Verurteilung der „Besatzung Palästinas“, womit allerdings nicht die Besatzung des Westjordanlandes, sondern die Staatsgründung Israels gemeint ist. Dabei kann das vorherrschende Bild von Juden durch entsprechende Propaganda des syrischen oder irakischen Regimes geprägt sein. Dies reflektierte Assad rückblickend für die Zeit, bevor er nach Deutschland gekommen war: „Ich wusste so gut wie nichts über Juden. Alles, was ich wusste, ist, dass die Juden palästinensisches Land besetzen. “ (Assad, 31, arabischmuslimischer Mann aus Homs/Syrien) ${ }^{43}$

\footnotetext{
43 Assad widersprach antisemitischen Verschwörungsphantasien anderer Befragter und zeigte wenig Ressentiments gegenüber Juden. Er glaubte jedoch das Stereotyp, dass Juden reich seien und ihnen ,alles gehört“, von seinen jüdischen Bekannten in Deutschland als wahre Zuschreibung gelernt zu haben.
} 
Andere leugneten selbst die historische Tatsache, dass Jüdinnen und Juden bereits lange vor der Gründung des Staates Israel im Nahen Osten lebten. Juden wurden oft ausschließlich als Europäer und damit als Fremdkörper auf arabischem Territorium angesehen:

Interviewer: „Aber denken Sie nicht, dass Juden bereits dort waren [in Jerusalem und Hebron; Anm. GJ], auch schon vor zweitausend Jahren?“ Yasser: „Wer? Juden? Nein, Juden waren in Großbritannien, Juden sind nicht in Palästina zu Hause. [...] Juden haben kein Zuhause, sie haben kein Land." (Yasser, 41, arabisch/palästinensisch-muslimischer Mann aus Homs/Syrien)

Das Recht auf jüdische nationale Selbstbestimmung verneinte Yasser nicht nur mit dem Argument, dass es keine Geschichte jüdischen Lebens im Nahen Osten gegeben hätte. Ganz prinzipiell postulierte er, dass Jüdinnen und Juden gar kein eigenes Land hätten und griff damit auf das Stereotyp jüdischer Wurzellosigkeit und ewiger Wanderschaft zurück. ${ }^{44}$ Andere Interviewte akzeptierten zwar die historische Tatsache, dass Jüdinnen und Juden seit Jahrhunderten nicht nur in Jerusalem, sondern auch im Irak und in Syrien leben. Aus ihrer Perspektive bestätigte dies aber nur, dass ein harmonisches Zusammenleben am besten unter arabischer beziehungsweise muslimischer Herrschaft möglich ist. Letztlich wird daraus eine Forderung nach Auflösung des jüdischen Staates zugunsten eines muslimisch oder arabisch dominierten Palästinas, in dem Jüdinnen und Juden toleriert werden. Ein Vertreter dieser Position ist Zaid:

„In unserer arabischen Mentalität gibt es keinen Frieden, solange du nicht zurückgibst, was genommen wurde [...]. Was ich will, ist, dass deren Armee zerstört wird. Sie mögen dann weiter auf unserem Gebiet leben und ihre Religion ausüben [...]. Das ist, was wir für die nächsten 25 Jahre wollen, inschallah [so wahr Gott will; Anm. GJ]. Und ich wiederhole es zum dritten Mal, wir werden für die Zukunft der gesamten arabischen Nation entscheiden, auch wenn es einen dritten oder vierten Weltkrieg geben wird, weil wir eine große Generation haben, die in dieser Kultur groß geworden ist. Wir haben kein Problem mit den jüdischen Menschen, wir glauben, dass das [auch] deren Land, deren Region ist, aber wir wollen ein Ende der israelischen Armee und sie wird zerstört werden. Und sie mögen dann mit uns, unter der palästinensischen Regierung, leben und ihre jüdische Religion ohne Probleme ausüben. Wir wollen nur in Frieden und Sicherheit leben." (Zaid, 29, arabisch-muslimischer Mann aus Syrien)

44 Yasser ist ein gutes Beispiel für jemanden, der versuchte, zwischen Juden und Israel zu trennen. Die Fundamentalopposition gegen Israel, das Leugnen eines jüdischen Volkes und seiner Verbindung zu Israel sowie die Verwendung alter judenfeindlicher Stereotype hielten ihn nicht davon ab, an anderer Stelle zu sagen: „Wir sind nicht gegen Juden. Manche sind gut und manche sind schlecht. Netanyahu ist ein schlechter Mensch, aber das sind nicht alle Bürger." (Yasser, 41, palästinensisch-syrischer Herkunft aus Homs/Syrien) - Auch der oben mit einer Verschwörungstheorie in Bezug auf die angeblich von Israel initiierte Zerstörung Syriens zitierte Jaleel stellte an anderer Stelle seine nicht sehr originelle Verschwörungsphantasie zum 11. September 2011 vor, als angeblich 3.000 jüdische Angestellte nicht zur Arbeit erschienen, und ergänzte dann: „Ich habe hier drei sehr nette jüdische Freunde, also das ist in Bezug auf die Regierungen." (Jaleel, 31, Christ aus Damaskus/Syrien) 
„Frieden und Sicherheit“ ist in dieser Vorstellung also nur durch Unterwerfung unter den islamischen Herrschaftsanspruch zu haben. Die fundamentale Ablehnung des jüdischen Staats zeigte sich auch bei einigen sehr westlich orientierten Interviewten darin, dass sie die offizielle Bezeichnung Israel ablehnten und stattdessen den Begriff „Palästina“ verwendeten. Dazu die bereits zitierte Inas: „Mein Traum ist, dorthin zu fahren und Palästina zu sehen. Wirklich, das ist ein Traum von mir.“ Auf Nachfrage des Interviewers, ob sie Israel oder Palästina meine, kam die freundliche, aber bestimmte Antwort: „Nein, nein, das ist Palästina. Palästina und etwas, das Tel Aviv genannt wird.“ (Inas, schätzungsweise Mitte 20, arabisch-muslimische Frau aus Damaskus/Syrien).

Das seit dem Mittelalter im Christentum tradierte antisemitische Stereotyp von Juden als Kindermördern wird in medialen Diskursen in modernisierter Form häufig auf Israel übertragen. In den Interviews wurde nur vereinzelt auf dieses emotionalisierende Bild verwiesen. Das mag daran liegen, dass erstens zum Zeitpunkt der Interviews im Dezember 2016 die mediale Berichterstattung zum Nahostkonflikt kaum entsprechend interpretierbare Bilder lieferte, zweitens einigen die Bilder von an Giftgas erstickten syrischen Kindern noch sehr präsent sein mochten und drittens das Leiden der Palästinenser für viele nicht zentral war in ihrer Ablehnung von Israel. Insgesamt lässt sich beobachten, dass die Interviewten mit palästinensischem Hintergrund dem israelisch-arabischen Konflikt sehr viel mehr Bedeutung beimaßen und diesen auch emotionaler diskutieren als die anderen Befragten. Vielen Interviewten erschien der israelisch-arabische Konflikt angesichts der Kriege in Syrien und im Irak weniger bedeutsam.

Die Frage an die Interviewten, ob sie denken, dass das, was die Nazis mit den Juden gemacht haben, das Gleiche sei wie das, was Israel mit den Palästinensern mache, führte zu einer Reihe höchst unterschiedlicher Reaktionen. Der Vergleich stieß in gleichem Ausmaß auf Zustimmung und Ablehnung. Eine Zustimmung ging oft einher mit einer fundamentalen Ablehnung des Existenzrechts Israels - und scheint vielfach gerade in dieser Ablehnung des Existenzrechts motiviert zu sein, da gar nicht erst versucht wurde, bestimmte Aspekte des Holocausts mit der derzeitigen Situation in Israel zu vergleichen. Eine vage Gleichsetzung der Maßnahmen seitens der israelischen Regierung gegenüber Palästinensern mit der nationalsozialistischen Vernichtung der Juden kann aber auch in Unwissen - sowohl bezüglich des Holocausts als auch des israelisch-palästinensischen Konflikts - und einer generellen Ablehnung von Gewalt begründet sein. „Mord ist Mord“", antworteten viele, wenn sie nach ihrer Meinung zu dem Vergleich zwischen Nazis und Israelis gefragt wurden, was durchaus eine Basis für aufklärerische Bildungsarbeit sein könnte.

Umgekehrt bedeutet die Ablehnung einer Gleichsetzung jedoch nicht notwendigerweise, dass die Staatsgründung Israels grundsätzlich als legitim anerkannt wird - zumindest dann nicht, wenn noch prinzipielle Parallelen gesehen werden. Dila (26, atheistische Kurdin aus Syrien) war der Meinung, dass es ,die gleiche Idee [ist], aber in einer anderen Weise. Die Israelis stahlen das Land, auch wenn sie nicht so viele Menschen umbrachten 
und Hitler so viele Menschen umbrachte.“ Interessanterweise wurde der Vergleich oft von Angehörigen von Minderheiten abgelehnt, das heißt, vor allem von Kurden, aber auch von einigen Christen und Atheisten. Die Ablehnung oder Zustimmung zur Gleichsetzung von Israel mit NS-Deutschland schien weniger vom spezifischen Wissen über den Holocaust und über den israelisch-palästinensischen Konflikt abzuhängen, als davon, ob Ressentiments gegenüber Israel und Juden vorherrschten oder nicht.

Ein arabisch-muslimischer Mann aus Syrien, Hayyan, schätzungsweise Anfang dreißig, hatte einen ganz besonderen Grund, weshalb er die Gleichsetzung von Israel mit den Nazis ablehnte. Er stammt aus Quneitra in den Golanhöhen, direkt angrenzend an Israel. Sein Vater war zwei Jahre in Israel im Gefängnis, wurde dort aber gut behandelt. Und er wusste zu berichten: ,,auch heute, in den Gegenden, die nah an Israel sind, wann immer es verletzte Menschen an der Grenze gibt, nehmen sie [die Israelis; Anm. GJ] sie und geben ihnen medizinische Hilfe, was immer die Behandlung auch kosten mag." Hayyan schien zwar auch nicht mehr über den Holocaust zu wissen als andere Interviewte und er verurteilte Israel auch dafür, sein Heimatdorf (zeitweise) besetzt zu haben, eine Dämonisierung Israels mittels einer Gleichsetzung mit den Nazis hielt er aber dennoch für falsch. Die Einhaltung rechtsstaatlicher Normen in israelischen Gefängnissen und vor allem die israelische Hilfe für syrische Verletzte schienen einen nachhaltig positiven Effekt auf Hayyans Einstellungen zu Israel und Israelis bewirkt zu haben.

\section{Die „reichen Juden“ und Verschwörungsphantasien als Welterklärung}

Das weltweit wohl verbreitetste antisemitische Stereotyp vom reichen Juden kam auch in den Interviews sehr viel häufiger vor als andere Stereotype. ${ }^{45}$ Viele Interviewte nahmen wie selbstverständlich an, dass Juden reich seien. Diese vermeintliche Tatsache bewerteten sie aber nicht unbedingt negativ.

„Die Idee, dass Juden viel Geld haben, ist wirklich normal in unserer Gesellschaft. Und wo ist das Problem, wenn sie viel Geld haben? Syrischen Händlern wurde von jüdischen beigebracht, wie sie ihre Gewerbe managen." (Qadir, 31, arabisch-christlicher Mann aus Damaskus/Syrien)

Einige Befragte formulierten bewusst vorsichtig und zeigten damit ihre Unsicherheit: „Wir Araber denken, dass Juden die reichsten Leute der Welt sind, aber das mag falsch sein." (Maen, 23, arabisch-muslimischer Mann aus Khirbet Ghazaleh/Syrien) Andere hingegen führten vermeintliche Belege von einer angeblichen Dominanz von Juden in Banken oder der Geschäftswelt an. Das Bild von den reichen Juden wurde auch auf Israel

45 Nur in einem Interview sagten zwei syrisch-palästinensische Befragte (Suaad, 27, und Sabri, 41, aus dem Flüchtlingslager Jarmuk bei Damaskus beziehungsweise aus Homs/Syrien), dass sie von dem Stereotyp des reichen Juden noch nie gehört hätten. 
bezogen, eingebettet in Verschwörungsphantasien, in denen Israel und die Juden insgesamt die Welt durch Geld beherrschen:

„Israel, insbesondere Juden, sind bekannt dafür, dass sie die größte Finanzmacht in der Welt sind, also die beherrschen die Welt mit ihrem Geld. Gerade erst gestern habe ich gelesen, dass ein jüdischer Doktor [...] sagte, dass das Star Academy-Programm von uns gemacht wurde und wir es durch Europa in der arabischen Welt verbreiten, um die arabische Frau zu demütigen, weil der arabische Mann schon gedemütigt ist. Als ihm gesagt wurde, dass es das Programm im Libanon gibt, sagte er [der jüdische Doktor; Anm. GJ], dass es von ihnen gesponsert ist, von den Juden, Israel und Amerika. Also die beherrschen die Welt mit ihrem Geld.“ (Ratib, 36, arabisch-muslimischer Mann aus dem Irak)

Ratibs Zitat illustriert, wie das Stereotyp der reichen Juden mit „jüdischer Weltmacht“ assoziiert wird, die angeblich zersetzend und bedrohlich für die eigene Gemeinschaft ist. In unterschiedlichsten Kontexten sahen Interviewte geheime Machenschaften fremder Mächte am Werk. Vielfach - aber nicht immer - vermuteten sie dabei Juden als Drahtzieher. Dies zeigte sich auch bei der Frage nach Erklärungen für die Kriege in den Herkunftsländern der Befragten. Neben (realistischen) Einschätzungen, dass Länder wie Russland und die USA, aber auch der Iran, Saudi-Arabien und die Türkei, heute im Krieg in Syrien und dem Irak ihre Interessen vertreten, gab es Spekulationen zu den Ursachen, die von Verschwörungsphantasien gekennzeichnet sind. Fremde Mächte hätten die Kriege angezettelt, um den Islam zu zerstören, die arabischen Länder auszubeuten, an ihr Erdöl zu kommen, einen Markt für Waffen zu schaffen oder, um die schlauen Köpfe zur Auswanderung zu bewegen, um sie dann in ihren Ländern als Arbeitskräfte ausnutzen zu können. Diese fremden Mächte werden in den USA, Israel und „den Juden“, oder auch in einer ominösen globalen Waffenindustrie gesehen. Diese Erklärungsversuche zeugen von einem Weltbild, das die Ursache für negative Entwicklungen bei übermächtigen anderen sucht. Dabei wurde häufig eine selektive Geschichtsdarstellung bemüht, in der etwa die Aufteilung des Nahen und Mittleren Ostens nach dem Zusammenbruch des Osmanischen Reiches in französische und britische Einflusssphären 1:1 in die Gegenwart fortgeschrieben und als antiarabische beziehungsweise antimuslimische Verschwörung begriffen wurde:

„Einmal habe ich Hillary Clinton gehört, wie sie über das Ende des Sykes-PicotAbkommens sprach, das sich auf die Teilung der arabischen Länder bezieht und die Laufzeit von einhundert Jahren hat [...], sodass im Jahr 2011 die Menschen in arabischen Ländern revolutionieren und nach Ablauf des Abkommens einen anderen Arabischen Frühling hervorbringen. Also ich denke, das ist eine westliche, amerikanische und israelische Verschwörung gegen arabische Länder, um den israelischen Frieden zu erhalten." (Sayid, 20, arabisch-muslimischer Mann aus Hama/Syrien)

In solch einem Geschichtsbild handeln nicht unterschiedliche Akteure mit unterschiedlichen Interessen den Lauf der Dinge aus, sondern große, undurchsichtige Mächte planen den Lauf der Geschichte von langer Hand und über Generationen 
hinweg. Es ist daher nicht verwunderlich, wenn in diesem Denken auch auf die Tradition antisemitischer Verschwörungsphantasien wie die „Protokolle der Weisen von Zion“ zurückgegriffen wurde und „die Juden“ oder stellvertretend Israel beschuldigt wurden, das eigene Land als Spielball zu nutzen. Diese Verschwörungsphantasien stellten einen unhinterfragten Deutungsrahmen dar, mit dem nicht nur Politik und Geschichte, sondern auch beiläufige, nahezu alltägliche Phänomene interpretiert wurden, die als Bedrohung für die eigene Gesellschaft angesehen wurden. So war Burhan (27, kurdischmuslimischer Mann aus Damaskus/Syrien) überzeugt, dass das Computerspiel „CounterStrike“ von bösen Mächten nach Syrien gebracht wurde, um eine neue Generation kaltblütiger Krieger für den derzeitigen Bürgerkrieg heranzuzüchten. Burhan, der stolz ist auf die syrische Kultur, sah mit großem Bedauern auf die Zerstörung seines Landes, für die er den Mossad, den ,internationalen Zionismus“ und die Freimaurer verantwortlich machte. Interessanterweise war Burhans Weltbild zwar von (antisemitischen) Verschwörungsphantasien geprägt, aber an mindestens einer Stelle brüchig. Er war überzeugt, dass Juden die Banken dominieren und dass Juden vom Anschlag auf das World Trade Center am 11. September 2001 zumindest wussten, weil sie an diesem Tag angeblich nicht zur Arbeit erschienen. Als das Gespräch allerdings auf Israel kam, lobte Burhan die israelische Regierung, weil diese sich für ihre Bevölkerung einsetze und humaner sei als das Regime Bashar al-Assads.

In den verschwörerischen Weltbildern waren die Attentate vom 11. September 2001 häufig ein wichtiger Bestandteil, da sie angeblich von den Amerikanern und/oder den Juden zur Legitimierung der Angriffe gegen die Länder des Nahen Ostens, „die Muslime“ oder „den Islam“ orchestriert wurden. Die amerikanische Politik und der amerikanische Präsident wurden als stark abhängig von der jüdischen oder israelischen Lobby betrachtet.

Eine bei syrischen Interviewten verbreitete Verschwörungsphantasie war ein angeblich geheimes Bündnis Bashar al-Assads mit Israel: Das syrische Regime betreibe zwar nach außen hin antiisraelische Propaganda, verhindere aber tatsächlich jegliches effektive Vorgehen gegen Israel, weil es in Wirklichkeit mit Israel unter einer Decke stecke. Die antizionistische Ideologie des syrischen Regimes war bei einigen so stark verinnerlicht, dass sie diese trotz Opposition gegen das Regime nicht hinterfragten.

Es gab aber durchaus auch Anzeichen, dass selbst diejenigen, die krudesten antisemitischen Verschwörungsphantasien anhingen, zum Teil bereit waren, ihre Ansichten zu überdenken. Maen (23, arabisch-muslimischer Mann aus Khirbet Ghazaleh/Syrien) beispielsweise erzählte von dem ihm zu Ohren gekommenen Gerücht, dass Israel oder Juden die meisten Medien in der Welt und dass jüdische Familien die meisten Banken weltweit kontrollierten. Er erwähnte in diesem Zusammenhang „Die Protokolle der Weisen von Zion“" und ein weiteres verschwörungstheoretisches Buch. Im Anschluss daran gab er allerdings zu, dass dieses auf wenig Fakten beruhe und falsch sein könne. Auch die „Erziehung zum Hass gegen Israel“ in Syrien kritisierte er als Propaganda. 


\section{Distanzierung von antisemitischer Propaganda}

Einige Interviewte lehnten antisemitische Stereotype und Vorstellungen explizit ab. In ihrer Ablehnung wurde jedoch oft zum einen deutlich, dass entsprechende judenfeindliche Einstellungen in ihrem Herkunftsland zur gesellschaftlichen Norm und zur staatlichen Propaganda gehören und zum anderen, dass meist nur ein Teil der antisemitischen Vorstellungen hinterfragt wurde.

Die folgenden drei Beispiele von Fatin, Adnan und Maryam zeigen unterschiedliche Aspekte der Distanzierung von antisemitischen Einstellungen seitens der arabischen Befragten. Fatin studierte zum Zeitpunkt des Interviews in Deutschland, vertrat im Allgemeinen sehr säkulare und tolerante Positionen. Sie spricht hervorragend Englisch und gut Deutsch. Sie glaubte zwar, dass Israel hinter den Anschlägen vom 11. September 2001 stecke, aber sie begann, antisemitische Einstellungen zu hinterfragen. Dazu zählten judenfeindliche Stereotype in der Alltagssprache. Außerdem erkannte sie die staatliche Hetze in Syrien gegen Israel und Juden als Propaganda und bemühte sich um eine Trennung von Juden, Israelis und dem Staat Israel. Adnan, 36, hatte in Damaskus eine Filiale eines internationalen Modegeschäfts geleitet. Im Interview hob er hervor, dass man sich in Syrien im Zweifelsfall judenfeindlich zeigen müsse, um nicht in Schwierigkeiten mit dem Regime zu kommen. Er persönlich hege keine Feindschaft gegen Juden und der Koran schreibe, auch wenn er ihn nicht so genau kenne, Respekt gegenüber Juden vor. An anderer Stelle erklärte er jedoch, dass Juden durch die Besetzung Palästinas zu Feinden würden. Maryam, 35, eine arabisch-atheistische Frau mit christlichem Hintergrund aus Damaskus, sagte, „man kann das, was in der Schule gelehrt wurde, dass Juden habgierig sind und viel Geld haben“, nicht für bare Münze nehmen, denn „sie sind auch Menschen“, wie sie in Deutschland in Begegnungen erfahren habe.

Alle drei, Fatin, Adnan und Maryam, sind wenig religiös und kommen aus Damaskus, einer relativ pluralistischen Großstadt. Alle drei betonten, dass sich die syrische Propaganda nicht nur gegen Israel, sondern gegen Juden richtete. Fatin beschrieb außerdem einen Antisemitismus in der Alltagssprache. Räumliche Distanzierung (Fatin), das Wegfallen der Nötigung zum Antisemitismus durch das syrische Regime verbunden mit einem toleranten Islamverständnis (Adnan) und Begegnungen mit Jüdinnen und Juden in Deutschland (Maryam) führten zum Überdenken antisemitischer Positionen.

Unter kurdischen Interviewten waren antisemitische Stereotype und Verschwörungsphantasien generell weniger verbreitet, auch wenn es Gegenbeispiele gibt, wie es einige der oben zitierten kurdischen InterviewtpartnerInnen illustrieren. Wenn Kurden sich antisemitisch äußerten, dann geschah dies häufiger in gemischten arabischkurdischen Gruppen als in ausschließlich kurdischen Gruppen. Zum Teil mag das an einer instrumentellen Verwendung antisemitischer Bilder liegen: Die Anpassung an den herrschenden (antisemitischen) Diskurs ermöglicht es unter Umständen, bezüglich der 
Interessen der kurdischen Minderheit dem herrschenden Diskurs widersprechen zu können. ${ }^{46}$ In rein kurdischen Gruppen zogen einige Kurden Parallelen zwischen ihrem Volk und Juden beziehungsweise Israel aufgrund der Wahrnehmung eines gemeinsamen Feindes („die Araber“ oder die Staaten Irak, Syrien und die Türkei). Andere sahen Parallelen zwischen der Shoah und dem Giftgasangriff Saddam Husseins 1988 auf die kurdisch-irakische Stadt Halabaja und weitere Ortschaften. ${ }^{47}$

Der ehemalige Lehrer Nidal (35, kurdisch-muslimischer Mann aus Aleppo/Syrien) beschrieb nicht nur das Fehlen einer Feindschaft zwischen Kurden und Juden. Er sprach sogar von einer heimlichen Liebe, die sich daran zeige, dass Juden Kurden geholfen hätten. Er sah Parallelen in der Geschichte des kurdischen und jüdischen Volkes Saddam Husseins Giftgasangriffe und die Ermordung tausender Kurden setzte er mit der Shoah gleich. Sein Bild von Juden war eher philosemitisch geprägt: Gott habe sie mit besonderen Fähigkeiten wie Tüchtigkeit und Reichtum ausgestattet. Siwar (26, kurdischatheistischer Mann aus Qamishli/Syrien) beschrieb einen deutlichen Unterschied zwischen Arabern und Kurden. Während Araber den Juden feindlich gesinnt seien und deshalb sogar deren Ermordung befürworteten, teilten Kurden diese Feindschaft nicht. Dabei verwies er auch auf Unstimmigkeiten in syrischen Lehrinhalten in Bezug auf Israel, die zwar die historische jüdische Besiedlung Kanaans beschreiben, aber den heutigen Juden die Besetzung ,arabischen Landes“ vorwerfen würden.

Gleichsetzungen Israels mit dem Nationalsozialismus stießen bei Kurden meist auf Unverständnis. Sie verwiesen auf die völlig unterschiedlichen Formen von Diskriminierungen beziehungsweise Ermordungen. Siyamend erkannte entsprechende Gleichsetzungen wie auch die kollektive Verurteilung aller Juden für Taten der israelischen Armee als eine Ideologie, die ihm in der Schule beigebracht worden war: „Ich weiß, dass es diese Verallgemeinerungen gab, zum Beispiel, wenn wir sahen, dass die israelische Armee schreckliche Dinge tat, dachten wir, dass alle Israelis so sind. Und das ist etwas, was sie uns in den Schulen gelehrt haben, dass jeder Israeli, Jude, schlecht ist. Auch, weil sie einen kleinen Teil von Syrien besetzten, und solche Dinge werden

\footnotetext{
46 Antijüdische und antiisraelische Einstellungen sind, wie sich auch in den oben genannten Beispielen andeutet, zum Teil arabisch-nationalistisch oder muslimisch identitär aufgeladen und bilden die herrschende Norm im Herkunftsland. Sie können somit eine Signalfunktion übernehmen, um die Zugehörigkeit zur Mehrheitsgesellschaft im Herkunftsland anzuzeigen, welche gerade bei Kurden nach wie vor oft in Frage gestellt wird, wie sich anhand einer langen Diskriminierungsgeschichte sowohl in Syrien und im Irak zeigen ließe. Die antisemitische Norm zu hinterfragen und gleichzeitig für separate kurdische Interessen einzutreten, würde einen Kampf an zwei Fronten bedeuten, beziehungsweise umgekehrt signalisiert das Teilen der antisemitischen Norm, dass das Eintreten für kurdische Interessen nicht auf angeblich zersetzenden Machenschaften Israels besteht, wie dies von arabischen Antisemiten behauptet wird. (MEMRI, Arab Writers: Arab World's Opposition To Kurdish Independence Referendum Is Hypocritical (Special Dispatch 7246), 25.12.2017, [https://www.memri.org/reports/arab-opposition-to-kurdish-statehypocritical], eingesehen 28.10 .2018 .)

47 Ein christlicher Teilnehmer, vermutlich mit armenischem Hintergrund, sieht Parallelen zwischen der Shoah und dem Genozid an den Armeniern, was ihn aber nicht daran hindert, antisemitischen Verschwörungsphantasien über die angeblich von Juden dominierten Freimaurer anzuhängen.
} 
besonders hervorgehoben, während du jung bist, dass Israelis Juden sind und schlecht sind." (Siyamend, 22, kurdisch-muslimischer Mann aus Qamishli/Syrien)

Kurden wurden sowohl in Syrien als auch im Irak als Kurden diskriminiert. Die nationalistisch-arabische Ideologie und Praxis der jeweiligen Baath-Partei war auch gegen sie gerichtet. Dies mag ein entscheidender Grund sein, weshalb auch der antizionistischantisemitische Teil der arabisch-nationalistischen Ideologie abgelehnt wurde. Der morgendliche Treueeid im syrischen Schulsystem beinhaltete zumindest unter Hafez alAssad ein Bekenntnis zum Regime, zur arabischen Einheit sowie zum Kampf gegen die Muslimbruderschaft und gegen den zionistischen Imperialismus. Auch kurdische SchülerInnen wurden unter Androhung der Prügelstrafe gezwungen einen Schwur auf die arabische Einheit zu leisten. Die syrische Kurdin Bervian (26) berichtete: „Der wirkliche Feind für uns Schülerinnen und Schüler war nicht die Muslimbruderschaft oder Israel. Selbstverständlich sprachen sie von Imperialismus oder Zionismus, aber wenn sie darüber sprachen, dann sprachen sie auch über die Kurden [...]. Sie verbanden Kurden mit Imperialismus, dass sie Unterstützung bekämen vom Imperialismus oder imperialistischen Ländern. “ Das trug offensichtlich dazu bei, dass viele KurdInnen die Propaganda gegen den ,zionistischen Imperialismus“ nicht sehr überzeugend fanden.

\section{Schlussfolgerungen}

In fast allen Gruppeninterviews wurden deutlich antisemitische Stereotype geäußert. Die Position, die Welt würde von Juden oder Israel kontrolliert, wird oft als normal oder legitim empfunden. Das Welt- und Geschichtsbild vieler Interviewpartner ist geradezu strukturiert durch Verschwörungsphantasien, insbesondere hinsichtlich der Entwicklungen in der Region des Nahen und Mittleren Ostens. Antisemitische Denkweisen waren auch unter denjenigen verbreitet, die betonten, dass sie das Judentum „respektierten“ oder dass das Zusammenleben zwischen Muslimen, Christen und Juden in den Herkunftsländern und in Deutschland unproblematisch sei.

Ein grundsätzlich negatives Israelbild und eine Infragestellung des Existenzrechts Israels ist für fast alle arabischen Interviewten selbstverständlich. Das Feindbild Israel bricht jedoch vereinzelt auf, insbesondere angesichts der Verbrechen des IS und des syrischen Regimes. Kurdische Interviewte äußerten sich zumindest in rein kurdischen Gruppen des Öfteren neutral oder sogar positiv in Bezug auf Israel. Viele Interviewte betonten, dass sie zwischen Juden und Israel unterscheiden. Dies gelingt aber gerade bei einer starken Abneigung gegen Israel nur punktuell. Andere wiederum sahen explizit keinen Unterschied zwischen Israel und „den Juden“.

Auffallend war die Diskrepanz zwischen Angehörigen der Mehrheitsbevölkerung im jeweiligen Herkunftsland und den Angehörigen der jeweiligen ethnischen und religiösen Minderheiten. Insbesondere einige Kurden zeigten deutlich pro-jüdische und proisraelische Einstellungen. Teilweise waren diese jedoch philosemitisch durchsetzt, das 
heißt, „die Juden“ wurden bewundert für ihre Macht und Cleverness. Wie verbreitet Antisemitismus unter syrischen und irakischen Geflüchteten in Deutschland ist, kann jedoch anhand dieser Studie nicht beantwortet werden und muss in weiteren repräsentativen Umfragen erhoben werden.

An vielen Punkten wurde die antisemitische Norm innerhalb der jeweiligen Herkunftsgesellschaft deutlich. Die antisemitischen Vorstellungen - ob aus arabischnationalistischen, antiimperialistischen, islamistischen oder aus allgemein weltverschwörungstheoretischen ideologischen Versatzstücken gespeist - waren jedoch immer wieder brüchig. Bei einigen InterviewpartnerInnen konnten Ansatzpunkte zur Infragestellung dieser Vorstellungen verzeichnet werden.

Abschließend lassen sich sechs Einflussfaktoren erkennen: eine antisemitische Norm im gesellschaftlichen oder sozialen Umfeld im Herkunftsland; Propaganda im Herkunftsland, einschließlich der Schulbildung; alte und neue Medien, in denen insbesondere internationales antisemitisches „Kulturgut“ wie „Die Protokolle der Weisen von Zion“ und ähnliche Verschwörungsphantasien verbreitet werden; ein Palästinensismus, der per Identifikation mit PalästinenserInnen eine automatische Feindschaft gegen Israel und Juden verbindet; eine panarabische Ideologie mit dem Feindbild eines zionistischen Imperialismus sowie Auslegungen des Islam, die Juden zu Feinden des Islam erklären. Die Versatzstücke antisemitischer Ideologien bilden ein Potenzial für antisemitische Handlungen, die bei einer Radikalisierung oder politischen Betätigung mobilisiert werden könnten. 



\title{
Im „Namen der guten Sache“. Palästina-Solidarität, Antizionismus und Antisemitismus unter MuslimInnen im zeitgenössischen Frankreich
}

\author{
Alexandra Preitschopf
}

\section{Einleitung - die Pro-Palästina-Proteste im Sommer $2014^{1}$}

Anfang Juli 2014 reagierte Israel aufgrund verstärkten Raketenbeschusses durch die Hamas mit der Militäroffensive „Protective Edge“ im Gaza-Streifen. Dieser fielen auch viele palästinensische ZivilistInnen zum Opfer - nicht zuletzt aufgrund der Tatsache, dass die Hamas diese als Schutzschild benutzte - und in Reaktion hierauf fanden europaweit Proteste gegen das israelische Vorgehen statt, die in einigen Städten tausende Menschen mobilisieren konnten. ${ }^{2}$ Zwar verliefen diese oftmals friedlich, allerdings kam es immer wieder zu antisemitischen Manifestationen. ${ }^{3}$ Insbesondere in Frankreich war man auch mit gewalttätigen Ausschreitungen, bei denen mehrere Synagogen angegriffen und jüdische Geschäfte beschädigt wurden, konfrontiert. ${ }^{4}$ Am 13. Juli 2014 etwa blockierten mehrere Dutzend Demonstrierende eine Synagoge in Paris und hinderten die TeilnehmerInnen einer dort stattfindenden Zusammenkunft zur Unterstützung Israels bis zum Einschreiten der Polizei am Verlassen des Gebäudes. Mehrere Protestierende skandierten hierbei laut Medienberichten: „Tod den Juden! Hitler hatte Recht - wir werden euch abfackeln [...] Jihad! Jihad! Jihad! - Palästina muss die Arbeit [Hitlers] zu Ende bringen. "5 Im Pariser Vorort Sarcelles wiederum, wo eine der größten jüdischen Gemeinden Frankreichs lebt, wurden im Zuge einer nicht autorisierten Demonstration

1 Dieser Beitrag basiert auf meiner Dissertation: Alexandra Preitschopf, „Umkämpfter Raum“. Pro-PalästinaSolidarität, Antizionismus und Antisemitismus unter MuslimInnen im zeitgenössischen Frankreich, phil. Diss. Salzburg 2016.

2 Siehe zu Frankreich etwa Geoffroy Clavel, Manifestation pro-Palestine: un succès pour les organisateurs, malgré quelques dérapages isolés, in: Le Huffington Post, 24.7.2014,

[http://www.huffingtonpost.fr/2014/07/24/manifestation-pro-palestine-succes-organisateurs-derapages-

isoles_n_5615123.html], eingesehen 26.10.2018.

3 Siehe etwa Vladimir Vertlib, Der Tritt, in: Die Presse. Spectrum, 16.8.2014, S. III; Paul Lendvai, Judenhass gestern und heute, in: Der Standard, 5.8.2014, [http://derstandard.at/2000003981523/Judenhass-gestern-und-heute], eingesehen 26.10.2018;

4 Sylvie Corbet, Anti-Israel protesters clash with police outside Paris synagogue, in: Haaret\%, 13.7.2014, [https://www.haaretz.com/jewish/news/1.604879], eingesehen 26.10.2018

5 „Mort aux Juifs!- Hitler avait raison- On va vous cramer- [...] - Jihad ! Jihad ! Jihad !- La Palestine doit finir le boulot.“ (Zit. n. Frédéric Haziza, Israel-Palestine. Violences devant une synagogue à Paris: l'étrange réaction des médias, in: Le Nouvel Observateur, 15.7.2014, [http://leplus.nouvelobs.com/contribution/1223785-israel-palestine-violences-devantune-synagogue-a-paris-l-etrange-reaction-des-medias.html], eingesehen 26.10.2018. 
am 20. Juli u. a. eine jüdische Apotheke und ein koscherer Supermarkt ausgebrannt. ${ }^{6}$ Zuvor hatten Demonstrierende Jüdinnen und Juden vor einer Synagoge mit den Worten „Wir werden euch in Schutt und Asche legen“ bedroht. ${ }^{7}$ Jenseits der Demonstrationen wurden - allein im Monat Juli - in Frankreich insgesamt 201 antisemitische Vorfälle gemeldet, davon 61 Gewalttaten. ${ }^{8}$

Es stellt sich die schwierig $\mathrm{zu}$ beantwortende Frage, inwiefern diese Gewaltausschreitungen im Zuge mancher Proteste die Taten Einzelner blieben oder möglicherweise als repräsentativ für das Verhalten des Großteils der Demonstrierenden angesehen werden können. Zwar wurde von Seiten der Protest-Organisatoren sowie von zahlreichen Demonstrierenden immer wieder betont, nicht antisemitisch zu sein, sondern nur für die Rechte der PalästinenserInnen und die Beendigung der israelischen Militäroffensive eintreten zu wollen, ${ }^{9}$ nichtsdestotrotz waren die auf den Demonstrationen skandierten Parolen nicht immer unproblematisch. Neben der Solidaritätsparole „Nous sommes tous des Palestiniens“ („Wir sind alle Palästinenser“) wurde vielfach „Israël assassin, Hollande complice!“ („Mörder Israel, Komplize Hollande“) oder „Sionistes fascistes, c'est vous les terroristes“ (,Zionisten Faschisten, ihr seid die Terroristen“) skandiert, bis hin zu „Mort aux juifs“ („Tod den Juden“). Hinzu kamen Slogans wie „Nous sommes là pour lutter contre le nouveau nazisme“ („Wir sind hier um gegen den neuen Nazismus zu kämpfen“). Auf manchen Schildern war dementsprechend auch „Sionisme = nazisme“ zu lesen oder es wurden Hakenkreuz und Davidstern unmittelbar nebeneinandergestellt und mit einem Gleichheitszeichen verbunden. ${ }^{10}$ Manche Demonstrierende zeigten zudem den so genannten quenelle-Gruß, der auf den umstrittenen antisemitischen Komiker Dieudonné M'Bala M'Bala zurückgeht und von manchen französischen SozialwissenschaftlerInnen unter anderem als „umgekehrter Nazi-Gruß“" gedeutet wird. ${ }^{11}$

6 A Sarcelles, des dégradations après des manifestations interdites, in: Le Monde, 21.7.2014,

[http://www.lemonde.fr/societe/article/2014/07/20/a-sarcelles-des-degradations-apres-une-manifestationinterdite_4460283_3224.html]., eingesehen 26.10.2018.

${ }^{7}$ „On va vous mettre à feu et à sang“. (Zit. n. Anne Jouan, À Sarcelles: „Tu leur montres une carte, ils ne savent même pas où est la Palestine!“, in: Le Figaro, 21.7.2014, [http://www.lefigaro.fr/actualite-france/2014/07/21/0101620140721ARTFIG00348--sarcelles-tu-leur-montres-une-carte-ils-ne-savent-meme-pas-o-est-la-palestine.php], eingesehen 26.10.2018.)

8 Insgesamt registrierte das Service de Protection de la Communauté Juive, welches in Zusammenarbeit mit dem französischen Innenministerium antisemitische Vorfälle in Frankreich erfasst, für das erste Halbjahr 2014 insgesamt 326 Vorfälle und damit doppelt so viele wie im Zeitraum des Vorjahres. (Floriane Hohenberg/Ronald Eissens/Suzette Bronkhorst, Antisemitic Incidents in Europe before, during and after the Israel-Gaza conflict. A Report by The International Network Against Cyber Hate (INACH) and the Ligue Internationale contre le Racisme et l'Antisémitisme (LICRA), Amsterdam-Paris 2014, S. 10.)

${ }_{9}$ Mehdi Thomas Allal, Manif pro-Palestine: oui, on peut soutenir Gaza et critiquer Israël sans être antisémite, in: Le Nouvel Observateur, 26.7.2014, [http://leplus.nouvelobs.com/contribution/1227067-manif-pro-palestine-oui-on-peutsoutenir-gaza-et-critiquer-israel-sans-etre-antisemite.html], eingesehen 26.10.2018.

10 Nicolas Guégan, Manifestation pro-palestinienne: Nous sommes tous des Palestiniens, in: Le Point, 3.8.2014, [http://www.lepoint.fr/societe/manifestation-pro-palestinienne-nous-sommes-tous-des-palestiniens-03-08-20141851144_23.php], eingesehen 26.10.2018.

11 Nicolas Guégan, Affaire Dieudonné - Meyer Habib: La quenelle est le nouveau salut nazi, in: Le Point, 2.1.2014, 
Die Bandbreite an Parolen, Anspielungen auf Dieudonné bis hin zu antisemitischen Übergriffen gibt einen ersten Hinweis auf die heterogene Zusammensetzung der Demonstrierenden wie auch der OrganisatorInnen und der an den Demonstrationen teilnehmenden Gruppierungen: So waren zum einen linke bis linksradikale Organisationen und dezidiert pro-palästinensische Vereinigungen beteiligt, zum anderen nahmen zahlreiche Einzelpersonen ohne Zugehörigkeit zu einer bestimmten Organisation teil, darunter auch viele Demonstrierende mit muslimischem Hintergrund. ${ }^{12}$ Während der Protestzüge kam es immer wieder auch zu gemeinsamen Gebeten, manche Frauen demonstrierten im „Niqab“, auch Parolen wie ,allāhu akbar“ („Gott ist groß“) und vereinzelt „Djihad résistance“ waren zu hören. Dieser religiöse Aspekt der Proteste wurde zudem durch die Anwesenheit radikal-islamistischer und mitunter Hamas-naher Gruppierungen, wie das „Collectif Cheikh Yassine“, bestätigt insgesamt waren diese zahlenmäßig allerdings in einer deutlichen Minderheit. ${ }^{13}$ Die Präsenz radikal-islamistischer Vereinigungen auf Pro-Palästina-Demonstrationen lässt sich, dem französischen Politologen und Islamismus-Experten Jean-Yves Camus zufolge, in Frankreich vor allem seit der israelisch-palästinensischen Auseinandersetzung 2009 (Militäroperation „Gegossenes Blei“) und den damit verbundenen Protestveranstaltungen beobachten. ${ }^{14}$

\section{Ausgangssituation - innergesellschaftliche Spannungen und die Problematik des „neuen“ Antisemitismus im zeitgenössischen Frankreich}

Auch wenn sich im Nachhinein kaum näher bestimmen lässt, inwiefern die individuellen TeilnehmerInnen an den verschiedenen Pro-Palästina-Demonstrationen antizionistische und in manchen Fällen antisemitische Einstellungen vertraten, so stellt der Umstand, dass viele politisch eher der (radikalen) Linken zuzurechnen waren oder oftmals einen muslimischen Hintergrund hatten, doch einen wichtigen Anhaltspunkt hierfür dar. Diesbezüglich interessant sind auch die Ergebnisse einer aktuellen Studie zu antisemitischen Einstellungen in der französischen Gesellschaft von November 2014. Im Zuge der von der französischen Einrichtung Fondapol („Fondation pour l'innovation politique“, „Stiftung für politische Innovation“) durchgeführten Untersuchung waren

[http://www.lepoint.fr/societe/affaire-dieudonne-meyer-habib-la-quenelle-est-le-nouveau-salut-nazi-02-01-20141776259_23.php], eingesehen 26.10.2018.

12 Bernard Edinger, A worried community, in: The Jerusalem Report, 25.8.2014, S. 29.

13 Clément Parrot, Qui sont les participants aux manifestations pro-palestiniennes interdites?, in: franceinfo, 31.7.2014, [http://www.francetvinfo.fr/societe/manifestations-propalestiniennes-en-france/qui-sont-les-participants-auxmanifestations-pro-palestiniennes-interdites_658399.html], eingesehen 26.10.2018.

${ }_{14}$ Jean-Yves Camus, The French Extreme-Right, Anti-Semitism, and Anti-Zionism (1945-2009), in: Holocaust, Study and Research (Holocaust, Studii și cercetări) 5 (2012), S. 175-189, hier S. 182. 
zum einen 1.500 Personen als repräsentative Stichprobe für die französische Bevölkerung über 16 Jahre befragt worden, zum anderen als Vergleichsgruppe 575 Personen mit muslimischem Hintergrund (d. h. Personen, die angegeben hatten, in einer muslimischen Familie geboren worden zu sein). Bei den Befragungen war zudem ermittelt worden, welchem politischen Lager die jeweiligen Personen sich selbst zuordneten. Angesichts der erhobenen Datenlage zeichnen sich anhand der Ergebnisse der Studie Tendenzen ab, die sich in Frankreich bereits seit dem Jahr 2000 beobachten lassen: So war die Zustimmungsrate zu Items mit antizionistischen und antisemitischen Aussagen (1.) unter mit dem Front National sympathisierenden und Marine Le Pen wählenden Befragten erhöht, (2.) unter solchen, die sich der Front de gauche (eine Koalition verschiedener linksradikal, kommunistisch und antikapitalistisch geprägter Parteien) zuordneten sowie (3.) unter den befragten muslimischen Personen. Im Falle letzterer war zwischen Personen „muslimischer Herkunft“, „gläubigen MuslimInnen“ und „gläubigen und praktizierenden MuslimInnen“ unterschieden worden, wobei gläubige und zugleich praktizierende MuslimInnen antisemitischen Aussagen durchschnittlich stärker zustimmten als die beiden anderen Gruppen. ${ }^{15}$

Die genannte Studie gibt, wie bereits angedeutet, auch einen wichtigen Hinweis auf die generelle Problematik des ,neuen“ Antisemitismus, der in Frankreich verstärkt seit dem Jahr 2000 und dem Ausbruch der Zweiten Intifada in Israel zu beobachten ist. ${ }^{16}$ Manifest wurde dieser „neue“ Antisemitismus anhand einer deutlichen Zunahme und nach wie vor sehr hohen Zahl an antisemitischen Vorfällen, welche von Beschimpfungen, Schmierereien, Sachbeschädigungen bis hin zu Brandanschlägen auf Synagogen und andere jüdische Einrichtungen sowie tätlichen Übergriffen reichen. ${ }^{17}$ Traurige Kulminationspunkte waren hierbei drei islamistisch-jihadistisch motivierte Mordanschläge: Im März 2012 tötete der französische Jihadist Mohamed Merah drei jüdische Kinder und einen Lehrer in einer jüdischen Schule in Toulouse. Im Mai 2014 erschoss der französische Islamist Mehdi Nemmouche vier Menschen jüdischer Herkunft im Jüdischen Museum von Brüssel, im Januar 2015 tötete der sich zum Islamischen Staat bekennende Franzose Amedy Coulibaly im Zuge einer Geiselnahme

\footnotetext{
${ }^{15}$ Dominique Reynié, L'antisémitisme dans l'opinion publique française. Nouveaux éclairages, Paris 2014. - So hielten etwa 74\% der MuslimInnen die sich selbst als ,gläubig und praktizierend“ definierten, die Aussage, ,,die Juden“ hätten zu viel Macht und Einfluss im Wirtschafts- und Finanzbereich für zutreffend, im Gegensatz zu 52\% der befragten Personen „muslimischer Herkunft“ und $25 \%$ der befragten RepräsentantInnen der französischen Mehrheitsbevölkerung. (Ebd., S. 22.)

${ }^{16}$ Hierzu erschien ab dem Jahr 2001 eine Reihe an Publikationen. Siehe u. a. Raphaël Draï, Sous le signe de Sion. L'antisémitisme nouveau est arrivé, Paris 2001; Pierre-André Taguieff, La Nouvelle Judéophobie, Paris 2002; Alain Finkielkraut, Au nom de l'Autre. Réflexions sur l'antisémitisme qui vient, Paris 2003; Nicolas Weill, La République et les antisémites, Paris 2004; Michel Wieviorka, La tentation antisémite. Haine des Juifs dans la France d'aujourd'hui, Paris 2005; Ders., L'antisémitisme est-il de retour?, Paris 2008; Didier Lapeyronnie, Ghetto urbain. Ségrégation, violence, pauvreté en France aujourd'hui, Paris 2008.

17 Siehe u. a. Commission nationale consultative des droits de l'homme, La lutte contre le racisme, l'antisémitisme et la xénophobie. Année 2015. Les essentiels, Paris 2016, S. 6; Alexis Rosenbaum, L'antisémitisme, Levallois-Perret 2014, S. 8-9.
} 
vier jüdische Kunden eines koscheren Supermarkts in Paris. In zwei Fällen spielte auch die Bezugnahme auf Palästina eine nicht unwesentliche Rolle - Merah „rechtfertigte“ seine Tat damit, er hätte palästinensische Kinder rächen wollen, Coulibaly argumentierte ähnlich, er hätte „die unterdrückten Muslime in der Welt“, vor allem in Palästina, rächen wollen. ${ }^{18}$

Diese Denkweise, die jüdische Bevölkerung Frankreichs kollektiv und unmittelbar mit Israel zu identifizieren und in weiterer Folge als „feindlich“ zu betrachten, ist stark in islamistischen Milieus ausgeprägt, findet sich jedoch auch in weiteren sozialen und politischen Milieus. Generell ist im medialen und politischen Diskurs Frankreichs immer wieder die Rede von einem „Import des Nahostkonflikts“, welcher sich in „,interkommunitäre Spannungen“ zwischen der muslimischen und jüdischen Bevölkerung übersetze. ${ }^{19}$ Hierbei wird die Brisanz der Situation in demographischer Hinsicht auch durch den Umstand verstärkt, dass in Frankreich heute sowohl eine der größten muslimischen Bevölkerungsgruppen (fünf bis sechs Millionen MuslimInnen bzw. acht bis zehn Prozent der Bevölkerung) als auch die größte jüdische Bevölkerungsgruppe (etwa 500.000 Jüdinnen und Juden) in Europa lebt. ${ }^{20}$

Allerdings sind Solidarisierungs- und Identifikationsprozesse und mitunter damit einhergehende antisemitische Manifestationen unter MuslimInnen in Frankreich nicht nur im Kontext des Nahostkonflikts zu betrachten, sondern stehen auch in Zusammenhang mit innerfranzösischen Entwicklungen. Dies betrifft im Besonderen die französische Erinnerungspolitik und den Umgang des französischen Staates mit der eigenen Vergangenheit: Herrschte in Frankreich nach 1945 zunächst weitgehendes Schweigen über die Shoah und die Mitverantwortung des Vichy-Regimes, wurde diese „Phase der Verdrängung“ (H. Rousso) erst nach und nach von einer zögerlichen Aufarbeitung abgelöst - eine Aufarbeitung, welche sich heute in einer umfassenden und institutionalisierten Gedenkkultur manifestiert. ${ }^{21}$ Damit einhergehend ist in den letzten Jahren jedoch auch - im Zuge der stärkeren Differenzierung und „Ethnisierung“ der französischen Gesellschaft - das Phänomen einer so genannten „concurrence

18 Siehe u. a. Caroline Politi/Eric Pelletier, Merah, Kouachi, Coulibaly... D’incroyables similitudes, in: L'Express, 14.1.2015, [http://www.lexpress.fr/actualite/societe/merah-kouachi-coulibaly-d-incroyables-similitudes1640392.html], eingesehen 26.10.2018; Eric Hazan, Massacre antijuif de Vincennes: le terroriste a agi pour venger les Palestiniens, in: Le Monde juif, 9.1.2015, [https://www.lemondejuif.info/2015/01/massacre-antijuif-vincennesterroriste-agi-venger-les-palestiniens], eingesehen 26.10.2018.

${ }^{19}$ Siehe u. a. Sylvain Attal, Aux racines du nouvel antisémitisme, in: Revue internationale et stratégique 58 (2005), Heft 2, S. 57-66, hier S. 57; Eric Keslassy, Présentation. „Sociologiser“ le Proche-Orient pour renforcer la République, in: Frédéric Encel/Eric Keslassy (Hrsg.), Comprendre le Proche-Orient. Une nécessité pour la République, Paris 2005, S. 17-36, hier S. 30.

20 Siehe bzgl. dieser Problematik u. a. die Berichte zu den Jahren 2004 bis 2015 der Commission nationale consultative des droits de l'homme, La lutte contre le racisme, l'antisémitisme et la xénophobie (Paris 2005-2016) sowie Wolfram Stender, Konstellationen des Antisemitismus, in: Wolfram Stender/Guido Follert/Mihri Özdogan (Hrsg.), Konstellationen des Antisemitismus. Antisemitismusforschung und sozialpädagogische Praxis, Wiesbaden 2010, S. 738, hier S. 27; Danny Leder, Die Gefahr aus der Vorstadt. Bei Frankreichs Migrantenjugend greift altneuer Judenhass, in: Das Jüdische Echo 55 (2006), S. 135-145.

${ }^{21}$ Siehe exemplarisch Weill, La République et les antisémites, S. 13. 
mémorielle“, einer „Erinnerungskonkurrenz“ zu beobachten. So orientieren sich in Frankreich zunehmend Angehörige weiterer Minderheiten am Modell des nationalen Shoah-Gedächtnisses, um auf diese Weise die öffentliche Anerkennung „eigener“ historischer Traumata (beispielsweise im Kontext des Algerienkrieges, des französischen Kolonialismus oder der Sklaverei) ${ }^{22}$ einzufordern. ${ }^{23}$ Die öffentliche Thematisierung und Anerkennung wie auch das offizielle Gedenken an diese anderen Formen historischen Unrechts setzte ohnehin erst sehr verspätet ab den 2000er-Jahren ein. All dies wirkt sich auf die Wahrnehmung und die Einstellung zur jüdischen Bevölkerung Frankreichs aus, deren (scheinbar) „vorrangiger Opferstatus“ zum Teil im Sinne einer Opferkonkurrenz mit Ressentiments beargwöhnt wird. Dies artikuliert sich mitunter in einer Relativierung der Shoah, in Gleichsetzungen von nationalsozialistischer und israelischer Politik (wie in den eingangs erwähnten Demonstrationsparolen) oder in einer Delegitimierung Israels als „neue (rassistische) Kolonialmacht“. ${ }^{24}$ Werden die PalästinenserInnen auf diese Weise $\mathrm{zu}$ „den neuen Kolonisierten“ stilisiert, bietet dies wiederum für französische MuslimInnen mit maghrebinischem oder subsaharisch-afrikanischem Hintergrund insofern eine Identifikationsmöglichkeit, da deren eigene Vorfahren oftmals tatsächlich kolonisiert worden waren.

Jenseits der Nachwirkungen der französischen Kolonialvergangenheit und dem Konflikt um die französische Erinnerungspolitik sind weitere soziopolitische Entwicklungen in den Blick zu nehmen: Der Soziologe Didier Lapeyronnie etwa betrachtet antisemitische Manifestationen unter muslimischen Jugendlichen aus sozial prekären Banlieues französischer Großstädte vor allem als eine Ausdrucksform des städtischen „Ghettos“ und deutet diese als Folgewirkung verstärkter innergesellschaftlicher Rückzugs- und Abgrenzungstendenzen. ${ }^{25}$ So lässt sich in Frankreich - gerade in multiethnisch geprägten Vororten - seit einigen Jahren vermehrt ein so genannter „repli communautaire“, das heißt ein stärkerer Rückzug ethnischer oder religiöser Gemeinschaften auf sich selbst beobachten, ${ }^{26}$ der auch für den muslimisch-jüdischen Dialog ein Hindernis darstellt. ${ }^{27}$ Eine zum Teil ähnliche Argumentation verfolgt die französische Historikerin Esther

22 Sven Korzilius, Erinnerungsforderungen von descendants d'esclaves - Berechtigtes Anliegen oder Missbrauch der Geschichte?, in: Dietmar Hüser (Hrsg.), Frankreichs Empire schlägt zurück. Gesellschaftswandel, Kolonialdebatten und Migrationskulturen im frühen 21. Jahrhundert, Kassel 2010, S. 217-252.

${ }^{23}$ Siehe u. a. Pascal Blanchard/Isabelle Veyrat-Masson (Hrsg.), Les Guerres de mémoires. La France et son histoire. Enjeux politiques, controverses historiques, stratégies médiatiques, Paris 2008; Geoffrey Grandjean/Jérôme Jamin, La concurrence mémorielle, Paris 2011.

${ }^{24}$ Siehe exemplarisch Rosenbaum, L'antisémitisme, S. 60-61.

${ }^{25}$ Lapeyronnie, Ghetto urbain, S. 395.

${ }^{26}$ Siehe u. a. Mohand Khellil, Maghrébins de France. De 1960 à nos jours: la naissance d'une communauté, Toulouse 2004, S. 101-104; Dietmar Hüser, Plurales Frankreich in der unteilbaren Republik. Einwürfe und Auswüchse zwischen Vorstadt-Krawallen und Kolonial-Debatten, in: Deutsch-Französisches Institut (Hrsg.), Frankreich Jahrbuch 2006. Politik und Kommunikation, Wiesbaden 2007, S. 9-28, hier S. 23; Vincent Geisser/Aziz Zemouri, Marianne et Allah. Les politiques français face à la „question musulmane“, Paris 2007, S. 183-184.

${ }_{27}$ Siehe u. a. Gilles Kepel, Quatre-vingt-treize. Essai, Paris 2012, S. 95-96; Daniel Bensoussan-Bursztein, Étude 2011. Le dialogue judéo-musulman en France d'hier à aujourd'hui, in: Regards. Revue du Centre Communautaire Lä̈ Juif de Bruxelles. Etude annuelle de Regards (2011), S. 1-23. 
Im „Namen der guten Sache“

Benbassa, die in diesen Ethnisierungs- und Re-Religiösierungs-Tendenzen einen Ausdruck des Scheiterns des französischen Integrationsmodells sieht. Insbesondere unter einigen muslimischen Jugendlichen sei der „,nationalen Identität“ inzwischen eine „Diaspora-Identität“ und ein Gefühl der globalen Verbundenheit im Sinne einer transnationalen Religionsgemeinschaft (der „Umma“) entgegengetreten. Hierbei werde wiederum die ideelle Solidarisierung mit „muslimischen Brüdern und Schwestern“, insbesondere den PalästinenserInnen, zu einem wesentlichen identitätsstiftenden Faktor. $^{28}$

Angesichts dieser Diagnosen, die einen Verlust der Attraktivität des französischen Integrationsmodells konstatieren, stellt sich umso mehr die Frage, ab wann und inwiefern Palästina speziell für MuslimInnen in Frankreich eine wichtige identitätspolitische Rolle zu spielen begann.

\section{Pro-palästinensische „Tradition“ seit 1967 und neue Formen der Palästina-Solidarität}

Erste tiefgreifende Auswirkungen hatte in dieser Hinsicht der Widerhall des Sechstagekriegs von 1967 in Frankreich. Während Israel für französische Jüdinnen und Juden ab diesem Zeitpunkt zunehmend an Bedeutung gewann, ${ }^{29}$ versuchten andererseits Gruppierungen der radikalen Linken an französischen Universitäten und unter nordafrikanisch-muslimischen Immigranten für die Solidarität mit Palästina zu mobilisieren. ${ }^{30}$ Anfang der 1970er-Jahre nahmen diese Versuche noch weiter an Intensität zu, als von der maoistischen Gauche prolétarienne („Arbeiterlinke“) so genannte „Comités de soutien à la révolution palestinienne“ („Unterstützungskomitees für die palästinensische Revolution“) gegründet wurden, die nicht nur für die Rechte der PalästinenserInnen eintraten, sondern zugleich für jene der maghrebinischen Arbeiter in Frankreich. ${ }^{31}$ Die aus französischen Studierenden und arabischen Arbeitern zusammengesetzten Komitees positionierten sich sowohl für Palästina als auch gegen Rassismus und für eine Verbesserung der Lebensbedingungen der maghrebinischen Arbeitsimmigranten. ${ }^{32}$ Palästina-Solidarität im Frankreich der späten 1960er und frühen 1970er-Jahre ist somit weniger als Manifestation „muslimisch-jüdischer“ Divergenzen, sondern eher im Kontext eines linken Antizionismus zu sehen, der sich in dieser Zeit

${ }^{28}$ Esther Benbassa, Juifs et Musulmans: le modèle républicain renégocié, in: Mouvements 38 (2005), S. 60-67, hier S. 60. ${ }^{29}$ Esther Benbassa, Frankreich, in: Elke-Vera Kotowski/Julius H. Schoeps/Hiltrud Wallenborn (Hrsg.), Handbuch zur Geschichte der Juden in Europa. Band 1. Länder und Regionen, Darmstadt 2001, S. 387-418, hier S. 415.

${ }^{30}$ Maud S. Mandel, Muslims and Jews in France. History of a conflict, Princeton 2014, S. 98-101.

31 Olivia C. Harrison, Performing Palestine in Contemporary France: Mohamed Rouabhi's Transcolonial Banlieue, in: Modern \& Contemporary France 22 (2014), Heft 1, S. 43-57, hier S. 45-46.

32 Abdellali Hajjat, Les comités Palestine (1970-1972). Aux origines du soutien de la cause palestinienne en France, in: Revue d'études palestiniennes (2005), S. 9-27, hier S. 10. 
nicht nur in Frankreich innerhalb des Kampfes der radikalen Linken gegen „Imperialismus“, Kolonialismus und für „Dritte-Welt-Aktivismus“ ausbildete. ${ }^{33}$

In der maghrebinischen beziehungsweise muslimischen MigrantInnen-Community in Frankeich bestand Ende der 1960er-Jahre hingegen nur geringes Interesse für die „palästinensische Sache“ - trotz der Aufrufe und Mobilisierungsversuche, die an sie gerichtet wurde. ${ }^{34}$ Hierbei sollte jedoch bedacht werden, dass von MuslimInnen ausgehende politische Aktivitäten bis in die 1970er-Jahre ohnehin eher ein Randphänomen darstellten und dies schon allein dadurch bedingt war, dass die strukturellen Voraussetzungen hierfür weitgehend fehlten und die Mehrzahl erst im Laufe der 1960er-Jahre eingewandert war. Die Bedingungen änderten sich zu Beginn der 1980er-Jahre, als eine neue Generation an bereits in Frankreich geborenen jungen MuslimInnen hör- und sichtbarer wurde. Diese so genannte Beur ${ }^{35}$-Bewegung entstand im Kontext eines gesellschaftspolitischen Klimas, in welchem es, wie bereits erwähnt, zu einer schärferen religiösen und ethnischen Differenzierung der Gesellschaft kam, zugleich jedoch zu einem Anstieg an rassistischen Straftaten und zum Aufstieg der extremen Rechten, insbesondere des Front National. ${ }^{36}$ In Reaktion hierauf wurden einerseits mehrere antirassistische Organisationen (bspw. 1984 „SOS Racisme“) gegründet, die sich dem gemeinsamen Kampf gegen Rassismus und Antisemitismus verschrieben. ${ }^{37}$ Andererseits wurde die Solidarisierung mit dem Schicksal der PalästinenserInnen gerade für junge französische MuslimInnen zu einer Ausdrucksmöglichkeit von Frust und Unzufriedenheit, führte jedoch zugleich zu einer stärkeren Abgrenzung gegenüber der jüdischen Bevölkerung. ${ }^{38}$ Dies verstärkte sich insbesondere mit dem Libanonkrieg 1982, welcher politische Bruchlinien zwischen der jüdischen und muslimischen Bevölkerung in Frankreich erstmals umfassender deutlicher zu Tage treten ließ.39 Junge „Beur-AktivistInnen“ brachten ihre Unterstützung für Palästina vehement zum Ausdruck, wobei mitunter auch antisemitische Parolen wie ,jüdische Mörder“ und „Tod den Juden“ sowie verschwörungstheoretische Diktionen von der ,jüdischen Macht“ oder dem , jüdischen Geld“ zu hören waren. ${ }^{40}$

\footnotetext{
33 Siehe u. a. Michel Winock, La France et les Juifs. De 1789 à nos jours, Paris 2004, S. 319; Helga Embacher, Neuer Antisemitismus in Europa - Historisch vergleichende Überlegungen, in: Moshe Zuckermann (Hrsg.), Antisemitismus - Antizionismus - Israelkritik (Tel Aviver Jahrbuch für deutsche Geschichte 33), Göttingen 2005, S. 50-69, hier S. 65; Martin Kloke, Linker Antisemitismus, in: Wolfgang Benz (Hrsg.), Handbuch des Antisemitismus. Judenfeindschaft in Geschichte und Gegenwart. Band 3: Begriffe, Theorien, Ideologien, Berlin-New York 2010, S. 192-195, hier S. 193.

34 Siehe u. a. Mandel, Muslims and Jews, S. 111; Hajjat, Les comités Palestine, S. 10.

35 „Beur“ ist ein umgangssprachlicher Ausdruck für frz. „Arabe“ (dt. „Araber“).

${ }^{36}$ Mandel, Muslims and Jews, S. 128.

${ }^{37}$ Ebd., S. 136.

38 Diese Spannungen brachte, als einer der Ersten, der französisch-jüdische Intellektuelle Alain Finkielkraut zur Sprache. (Alain Finkielkraut, Le Juif imaginaire, Paris 1980.)

39 Bronwyn Winter, Walking the Middle of the Peace Road? The Emergence of JCall in France, in: Modern \& Contemporary France 22 (2014), Heft 1, S. 7-27, hier S. 15.

${ }^{40}$ Mandel, Muslims and Jews, S. 130 und 135.
} 
Unübersehbar und evident wurde diese Problematik jedoch erst um 2000. Seit dem Jahr 2001 waren und sind von Seiten pro-palästinensischer Organisationen immer wieder Boykottforderungen gegen israelische Produkte sowie gegen den Auftritt israelischer KünstlerInnen oder Vorträge von israelischen WissenschaftlerInnen in Frankreich zu vernehmen. ${ }^{41}$ Nachdem 2005 die umstrittene internationale Boykottkampagne BDS (kurz für Boycott, Divestment and Sanctions) ins Leben gerufen worden war, ${ }^{42}$ bildete diese kurze Zeit später auch Strukturen in Frankreich (verstärkt seit dem Gaza-Krieg 2008/09).43 Nimmt man zudem die wesentlichen französischen Pro-PalästinaOrganisationen näher in den Blick, so fällt auf, dass einige unter ihnen erst in den Jahren nach 2000 gegründet wurden. ${ }^{44} \mathrm{Zu}$ den Hauptaktivitäten dieser Vereinigungen zählen neben der Organisation von Demonstrationen auch die Publikation propalästinensischer Artikel und Protestschriften sowie die Organisation von Konferenzen, BenefizKonzerten oder Reisen in die palästinensischen Gebiete, womit sie zum Teil in der Tradition der erwähnten Palästina-Komitees der frühen 1970er-Jahre stehen und an deren politische Agitation anknüpfen. Hinzu kommen ganzjährige oder saisonale Hilfsaktionen vor Ort, insbesondere im Gaza-Streifen sowie im Westjordanland: Das seit 1990 bestehende „Comité de Bienfaisance et de Secours aux Palestiniens“ (CBSP; „Komitee zur Fürsorge und Hilfe für die Palästinenser") etwa gibt auf seiner Homepage an, in palästinensischen Gebieten Aktionen gegen Obdachlosigkeit und Kälte im Winter, für sauberes Trinkwasser oder zum Pflanzen von Olivenbäumen durchzuführen und macht hierzu in Frankreich regelmäßig Spendenaufrufe. ${ }^{45}$ Eine der federführenden französischen Pro-Palästina-Organisationen, die in ihrer jetzigen Form seit 2001 existente „Association France Palestine Solidarité“ (AFPS; „Frankreich Palästina

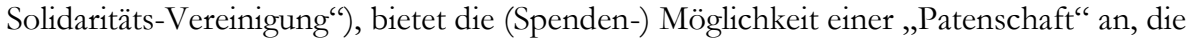
sich sowohl auf palästinensische Kinder (im Westjordanland, in Gaza und im Libanon) ${ }^{46}$ als auch auf palästinensische Gefangene in israelischen Gefängnissen bezieht. ${ }^{47}$ AFPS organisiert zudem regelmäßig Reisen in palästinensische Gebiete (etwa in Form von Sommercamps oder zur Hilfe bei der Olivenernte palästinensischer Bauern). ${ }^{48}$

41 Pascal Markowicz, La délégitimation de l'Etat d'Israël par la campagne de boycott BDS, Paris 2010, S. 1-13.

42 Siehe den Boykottaufruf Palestinian Civil Society Calls for Boycott, Divestment and Sanctions against Israel Until it Complies with International Law and Universal Principles of Human Rights, 9.7.2014,

[http://al-awda.org/pdf/boycotts.pdf], eingesehen 26.10.2018.

43 Winter, Walking the Middle, S. 13.

44 Marc Hecker, Intifada française. De l'importation du conflit israélo-palestinien, Paris 2012, S. 206-210.

45 Siehe etwa die Spendenaufrufe auf Comité de Bienfaisance et de Secours aux Palestiniens, o. D., [http://cbsp.fr], eingesehen 26.10.2018.

46 Association France Palestine Solidarité, o. D., [http://www.france-palestine.org/-Parrainages], eingesehen 26.10.2018.

47 Association France Palestine Solidarité, Parrainer un-e prisonnier-e politique palestinien-ne, 16.7.2012, [http://www.france-palestine.org/Parrainer-un-e-prisonnier-e-politique-palestinien-ne], eingesehen 26.10.2018.

48 Association France Palestine Solidarité, Missions en Palestine, o. D., [http://www.france-palestine.org/-Missionsen-Palestine], eingesehen 26.10.2018. 
Während es sich bei AFPS um eine säkular ausgerichtete Organisation handelt, finden sich auch pro-palästinensische Vereinigungen, die ihre Solidarisierung mit den PalästinenserInnen dezidiert auf den religiösen Bereich ausweiten. ${ }^{49}$ Die Organisation CBSP etwa, welche in Frankreich von der den Muslimbrüdern nahestehenden UOIF („Union des Organisations Islamiques de France“) unterstützt wird und selbst wiederum unter Verdacht steht die Hamas finanziell zu unterstützen, ${ }^{50}$ richtet anlässlich des Fastenmonats Ramadan jährlich an französische MuslimInnen Spendenaufrufe für palästinensische Familien. Gedacht sind die Spenden vor allem für Essenspakete zum „Iftar“ (Fastenbrechen) oder Geschenke für palästinensische Kinder zum „Id al-Fitr““ (Fest zum Ende des Ramadans). Zudem ruft CBSP dazu auf, den vorgeschriebenen „Zakāt al-Fitr" (Almosenabgabe am Ende des Ramadans) den PalästinenserInnen zu widmen..$^{51}$ Neben der Homepage der Organisation und Werbeeinschaltungen auf den muslimischen Online-Nachrichtenseiten SaphirNews und Oumma.com sowie Printwerbung in der muslimischen Monatszeitschrift Salamnews ${ }^{52}$ werden die Spendenaufrufe heute auch über Facebook verbreitet. Ähnliches gilt für die 2009 gegründete konservativislamische Hilfsorganisation „Ligue islamique française pour l'éducation“ (LIFE; „Islamische französische Liga für Bildung“). Während des Ramadans 2015 postete diese über die bekannte islamistische Website Islam \& Info beispielsweise: ${ }^{53}$

„Après la distribution dans les pays d'Afrique, LIFE n'a pas oublié nos frères et sœurs palestiniens. [...]. Il est temps pour nous de nous rapprocher de notre Seigneur en faisant une aumône qui restera inscrite pour le Jour du jugement.“ („Nach der Verteilung in den Ländern Afrikas hat LIFE unsere palästinensischen Brüder und Schwestern nicht vergessen. [...]. Es ist Zeit für uns, uns unserem Herrn zu nähern, indem wir ein Almosen geben, das angerechnet wird für den Tag des (Jüngsten) Gerichts.") Appelliert wird in diesem Posting sowohl an das Mitgefühl französischer MuslimInnen für die „palästinensischen Brüder und Schwestern“ als auch an ihre (religiösen) Pflichten als MuslimInnen an sich. Generell spiegelt die religiöse Durchdringung des Spendenaufrufs

49 Siehe exemplarisch Mérième Alaoui, Solidarité: associations et ONG sur le pont pour Ramadan, in: Salamnews 53 (2015), S. 10-11.

${ }^{50}$ Frank Peter, Die Union des Organisations Islamiques de France und die Tradition der Muslimbrüder im Zeitalter der Integrationspolitik, in: Dietrich Reetz (Hrsg.), Islam in Europa. Religiöses Leben heute. Ein Portrait ausgewählter islamischer Gruppen und Institutionen, Münster 2010, S. 145-169, hier S. 148.

51 Gemäß der Homepage von CBSP gab es für den Ramadan 2015 folgende Spendenmöglichkeiten: 100 Euro um eine Familie während des Ramadan zu unterstützen, 40 Euro für ein Essenspaket, 20 Euro für ein Geschenk an ein palästinensisches Kind und fünf Euro für den persönlichen „Zakāt al-Fitr“. (CBSP, o. D., [http://www.cbsp.fr/dons/index.php?lang=fr], eingesehen 20.6.2015.) Eine wichtige Bedeutung kommt Palästina zudem in den Hilfsaktionen der 1991 gegründeten NGO „Secours Islamique France“ („Islamische Hilfe Frankreich“) zu, welche auf ihrer Webseite ebenfalls zu Spenden aufruft. (Secours Islamique France, o. D., [http://www.secoursislamique.org/component/content/article.html?id=429], eingesehen 26.10.2018.)

52 Siehe Salamnews 53 (2015), S. 5.

${ }^{53}$ Siehe den Werbebanner auf Islam \& Info, Naplouse: LIFE n’a pas oublié nos frères et sœurs palestiniens, 22.6.2015, [http://www.islametinfo.fr/2015/06/22/naplouse-life-na-pas-oublie-nos-freres-et-soeurs-palestiniens], eingesehen 26.10.2018. 
die neuere Tendenz im Bereich der Palästina-Solidarisierungsaktionen wider, sich hierbei dezidiert auf den Islam zu berufen.

In diese Aktionen einzuordnen ist auch die französische Marke „Mecca Cola“. Das Softdrink-Label wurde während des Ramadan 2002 und in Reaktion auf die Zweite Intifada von dem französisch-tunesischen Geschäftsmann Tawfik Mathlouthi im Pariser Vorort Saint Denis nach dem Vorbild der iranischen Marke "ZamZam Cola“ gegründet. ${ }^{54}$ Initiiert wurde das heute weit über die Grenzen Frankreichs hinaus erhältliche Getränk vor allem als Gegenprodukt zu Coca-Cola und zum ,,amerikanischen Hegemonismus“ und gewann insbesondere während des Irakkrieges an Popularität. Ein wesentliches Prinzip von Mecca Cola ist es, zehn Prozent des Profits humanitären Projekten in den palästinensischen Gebieten und weitere zehn Prozent karitativen Organisationen in anderen Ländern zu widmen. ${ }^{55}$ Geprägt zu sein scheint das Firmenoberhaupt Mathlouthi hierbei jedoch nicht nur von antiamerikanischen, sondern auch von antiisraelischen Ressentiments - so ist auf der Webseite von Mecca Cola in Bezug auf die Initiierung der Marke in fehlerhaftem Englisch zu lesen:

„My main Goal also was at that time to point the unfair and unacceptable blind support of America to the Zionist Entity. I couldn't and still can't accept The Policy of Double Standards followed and continuing to be followed by the USA Administration. I Claim for Justice and Human treatment for Palestinians. [...] My Unique reason of strong opposition to these policies is my total rejection of INJUSTICE. I am not driven by hate or rejection of others or any racist feelings. " 56

Zum einen fällt an der Stellungnahme Mathlouthis auf, dass dieser nicht von Israel, sondern, wie für antizionistische Rhetorik charakteristisch, lediglich von einer „Zionist Entity“ spricht. Zum anderen ist die Betonung einer rein humanitären und antirassistischen Intention hinter dem Unternehmen - wohl auch in Abgrenzung zu möglichen Antisemitismusvorwürfen - bezeichnend für pro-palästinensische Initiativen dieser Art. Ähnlich betonte Mathlouthi auch in einem Interview mit der Zeitung Le Parisien im Jahr 2004, er sei „zutiefst antizionistisch“ und gegen den Staat Israel, jedoch ,nicht antijüdisch“. ${ }^{57}$

Wie die verschiedenen Solidaritätskampagnen und Spendenaktionen verdeutlichen, ist die Solidarisierung mit Palästina oftmals auch unmittelbar mit humanitären Aspekten

\footnotetext{
54 Siehe u. a. Bernard Pras/Catherine Vaudour-Lagrâce, Marketing et Islam. Des principes forts et un environnement complexe, in: Revue française de gestion 171 (2007), Heft 2, S. 195-223, hier S. 214; Amel Boubekeur, L'islam est-il soluble dans le Mecca Cola? Marché de la culture islamique et nouveaux supports de religiosité en Occident, in: Maghreb Machrek. 183 (2005), S. 45-65.

55 Siehe u. a. Christin Emrich, Interkulturelles Marketing-Management. Erfolgsstrategien - Konzepte - Analysen, Wiesbaden 2014, S. 16; Frédéric Pons, Mecca Cola à l'assaut du Golfe, in: Libération, 15.8.2003, [http://www.liberation.fr/futurs/2003/08/15/mecca-cola-a-l-assaut-du-golfe_442215], eingesehen 26.10.2018.

56 Tawfik Mathlouthi, The founer [sic] and you, o. D., [https://meccacolagroup.com/the-founer-and-you/], eingesehen 26.10.2018.

${ }^{57}$ „Je suis profondément antisioniste. Je revendique mon anti-Etat d'Israël. Mais je ne suis pas antijuif.“ (Zit. n. Vincent Mongaillard, La saga Mecca-Cola, in: Le Parisien, 16.4.2004, [http://www.leparisien.fr/seine-saint-denis/la-sagamecca-cola-16-04-2004-2004912449.php], eingesehen 26.10.2018.)
} 
verknüpft, deren Bedeutsamkeit hier nicht in Frage gestellt werden soll. Allerdings hat dies wohl auch zur Folge, dass die Israel-Palästina-Frage - unter anderem über gezielte Werbemaßnahmen, Spendenzahlungen oder den bewussten Konsum von Marken wie Mecca Cola - zusätzlich emotional aufgeladen und „personalisiert“ wird. Verbunden ist dies oftmals mit einer religiösen Komponente, insbesondere wenn Palästina-Solidarität in essenzielle Bereiche des Islam, wie die Almosenabgabe Zakāt oder den Ramadan und somit konkret in die religiöse Praxis eingebunden wird. Deutlich wird hieran auch die zentrale, „globalisierte“ Rolle Palästinas für die muslimische „Umma“.

\section{Konklusion}

Wie anhand der Pro-Gaza-Proteste des Sommers 2014 erneut deutlich wurde, werden die Auswirkungen des andauernden Nahostkonflikts in Europa mehr und mehr spürbar - in Frankreich vor allem seit dem Ausbruch der Zweiten Intifada im Jahr 2000, als es zu einem deutlichen Anstieg an antisemitischen Vorfällen kam. Die Proteste formierten sich mit dem offen artikulierten Ziel für die Rechte der Palästinenser und gegen die militärische Reaktion Israels einzutreten. Sie lassen sich schwer - wie die Pro-PalästinaBewegung allgemein - als unmittelbar offen antisemitisch charakterisieren, allerdings positionieren sich viele pro-palästinensische und linksradikale Akteure als offen antizionistisch. Hierbei handelt es sich wiederum um einen Antizionismus, der seit den späten 1960er-Jahren vielfach begleitet ist von Antirassismus, Antikolonialismus, Antiimperialismus und Menschenrechts-Aktivismus, wodurch er paradoxerweise im Namen der „guten Sache“ geäußert wird. ${ }^{8}$ In Anlehnung an Jean Amérys Überlegungen zum „ehrbaren Antisemitismus“59 lässt sich somit die aktuell zu beobachtende PalästinaSolidarität und in manchen Fällen regelrechte "Palästina-Obsession“ als eine Art „ehrbarer“ Antizionismus bezeichnen - im Sinne eines aktivistischen, vordergründig antirassistischen Antizionismus, hinter welchem sich nichtsdestotrotz auch ein mehr oder weniger subtiler Antisemitismus verbergen kann.

Welche Funktionen aber kann - abgesehen von Kanalisierung oder Verschleierung israelfeindlicher oder antisemitischer Ressentiments - ein derartiger Antizionismus erfüllen? Einen Ansatzpunkt hierfür liefert die Historikerin Shulamit Volkov, die ebenfalls in Bezug auf die Palästina-Solidarität der (radikalen) Linken der 1960er und 1970er-Jahre - von „Antizionismus als kulturellem Code“60 spricht: das heißt von Antizionismus als einem Signum kultureller Zugehörigkeit, mit welchem sich gegenüber dem eigenen Umfeld bezeugen lasse, dass man auf der "richtigen Seite“ (der

58 Kloke, Linker Antisemitismus, S. 193-194.

59 Jean Améry, Der ehrbare Antisemitismus. Die Barrikade vereint mit dem Spießer-Stammtisch gegen den Staat der Juden, in: Die Zeit, 25.7.1969, S. 16.

${ }^{60}$ In Anlehnung an ihre These über den Antisemitismus als kulturellen Code. (Shulamit Volkov, Antisemitismus als kultureller Code. Zehn Essays, München 2000.) 
Antiimperialisten, Antikolonialisten, Antirassisten, etc.) stehe. ${ }^{61}$ Die Vermittlung von Zugehörigkeitsgefühlen und eine zugleich nach außen getragene Selbstpositionierung über eine gemeinsam zum Ausdruck gebrachte, „globalisierte“ Palästina-Solidarität scheint heute insbesondere für muslimische Jugendliche in Frankreich und anderen europäischen Ländern von Relevanz zu sein. Dies kann identitätsstiftend wirken und das Gefühl verleihen - gemeinsam mit Gleichgesinnten im eigenen Land und weltweit - auf der moralisch „richtigen“, ,guten“ Seite zu stehen. Zugleich ermöglicht die Identifikation mit den „palästinensischen Brüdern und Schwestern“, das lautstarke Eintreten für deren Rechte auf Demonstrationen und anderswo auch Unzufriedenheit, Enttäuschung, Wut angesichts der eigenen sozialen Situation und Erfahrungen von Rassismus und Islamfeindlichkeit zum Ausdruck zu bringen. Hinzu kommt letztlich, dass die ProPalästina-Bewegung mittlerweile auch eine durchaus gut „vermarktete“ und relativ einfach zu „konsumierende“ Bewegung geworden ist (inklusive zu erstehender propalästinensischer Artikel wie T-Shirts, Fahnen, Schals und Ähnliches, propalästinensischer Rap-Musik ${ }^{62}$ oder Marken wie Mecca Cola etc.). Die Spannweite erstreckt sich hierbei vom politischen bis weit in den muslimisch-religiösen Bereich hinein und ermöglicht so wiederum auf vielfältige Weise, Anschluss zu finden und Zugehörigkeit zu erfahren.

${ }^{61}$ Shulamit Volkov, Readjusting Cultural Codes: Reflections on Anti-Semitism and Anti-Zionism, in: The Journal of Israeli History 25 (2006), Heft 1, S. 51-62, hier S. 60.

62 Ausführlich hierzu siehe Preitschopf, „Umkämpfter Raum“, S. 472-526. 



\title{
Zum Umgang mit Antisemitismus und anderen Formen Gruppenbezogener Menschenfeindlichkeit in der Berufsschule
}

\author{
Georg Lauss und Stefan Schmid-Heher
}

\section{Einleitung}

Am 20. Juni 2017 veröffentlichte eines der zentralen Publikationsmedien der USamerikanischen Alt-Right Bewegung Breitbart News einen Bericht mit dem Titel „Antisemitic views backed by half of Austria’s muslim youth“. Im Untertitel heißt es: „Almost 50 per cent of newly-arrived young Austrian Muslim migrants hold anti-Semitic views“". ${ }^{1}$ Illustriert wird der Bericht mit einem Foto, auf dem junge Palästinenser auf einer HamasDemonstration aus dem Jahr 2004 dabei zu sehen sind, wie sie einen Davidstern in Brand stecken.

Drei Tage zuvor war in der österreichischen Tageszeitung Der Standard ein Artikel mit dem Titel „Neue ,Gerüchte“ über Juden“ erschienen. ${ }^{2}$ Dieser Artikel wiederum bezieht sich (unter anderem) auf eine Studie über Haltungen zu Demokratie und Autoritarismus unter Wiener BerufsschülerInnen. ${ }^{3}$ Der Artikel präsentiert Antisemitismus als gesamtgesellschaftliches Problem. Zu lesen ist, dass $24 \%$ der SchülerInnen der Aussage zustimmen, dass Juden in Österreich zu viel Einfluss haben. Darüber hinaus wird die auffällig geringe Antwortbereitschaft bei dieser Frage thematisiert. Diskutiert werden auch gruppenspezifische Differenzen im Antwortverhalten. So weisen weibliche Befragte das antisemitische Klischee häufiger zurück als ihre männlichen Kollegen. Außerdem wird in der Tat darauf hingewiesen, dass $55 \%$ der muslimischen Jugendlichen, die sich positionieren, einen zu großen Einfluss von Juden in Österreich zu erkennen meinen. Sowohl in der Studie wie auch im Standard-Artikel wird vor Alarmismus gewarnt. Die Notwendigkeit von weiteren Untersuchungen wird hervorgehoben. Angesprochen wird auch, dass Prävention und Aufklärung über Antisemitismus in Schulen und darüber hinaus weiter einen hohen Stellenwert einnehmen müssen und keine Themen der Vergangenheit sind.

\footnotetext{
${ }^{1}$ Simon Kent, Antisemitic views backed by half of Austria's muslim youth, in: Breitbart News, [http://www.breitbart.com/jerusalem/2017/06/20/report-anti-semitic-views-backed-half-austrias-muslim-youth], eingesehen 23.10.2017.

2 Andras Szigetvari, Neue „Gerüchte“ über Juden, in: Der Standard, 17/18.6.2017, S. 4-5.

${ }^{3}$ Georg Lauss/Stefan Schmid-Heher, Politische Bildung an Wiener Berufsschulen. Demokratische und autoritäre Potentiale von Lehrlingen, in: Philipp Mittnik (Hrsg.), Empirische Einsichten in der politischen Bildung, Innsbruck 2017, S. 95-124.
} 
Nachdem die Verfasser des vorliegenden Beitrags auch die Autoren der von Breitbart zitierten Studie über Demokratie, Autoritarismus und Politische Bildung an Wiener Berufsschulen waren, werden im Folgenden einige für Theorie und Praxis der Politischen Bildung in der Migrationsgesellschaft dringliche Probleme behandelt. Im Zentrum steht dabei die Frage, wie im Rahmen von Politischer Bildung entschieden gegen Antisemitismus vorgegangen werden kann, ohne zugleich rassistischen und islamfeindlichen Diskursen Vorschub zu leisten. Welche Möglichkeiten gibt es, gegen bestimmte Formen Gruppenbezogener Menschenfeindlichkeit vorzugehen, die in manchen Bevölkerungsgruppen statistisch gesehen häufiger anzutreffen sind, ohne wiederum diese Gruppen insgesamt auf stereotype Weise zu stigmatisieren? Anders gefragt: Wie können sozialwissenschaftliche Studien dabei helfen, Probleme genauer zu beschreiben und zu lokalisieren, ohne dabei in die Falle einer „Versämtlichung “5 zu tappen, indem statistische Trends zu undifferenzierten und negativierenden Gruppenzuschreibungen werden?

Bei der Beantwortung dieser Frage wird folgendermaßen vorgegangen. Der zweite Abschnitt befasst sich mit didaktischen Zugängen zum Lerngegenstand Antisemitismus. Ohne die Notwendigkeit einer historischen Auseinandersetzung in Frage zu stellen, werden damit verbundene Probleme bei der Anknüpfung an die Lebenswelten von Jugendlichen aufgezeigt. Im Weiteren sollen Antisemitismus und Islamfeindlichkeit zueinander in Beziehung gesetzt werden, ohne sie dabei gleichzusetzen bzw. zu parallelisieren. Abschnitt drei beschreibt den methodischen Zugang von zwei quantitativen Erhebungen, deren Daten die empirische Grundlage der hier vorliegenden Überlegungen bilden. Im vierten Abschnitt werden die wichtigsten Ergebnisse der beiden Erhebungen zusammengefasst. In Abschnitt fünf vergleichen wir das Antwortverhalten von zwei Gruppen von BerufsschülerInnen. Die erste Gruppe setzt sich aus Befragten ohne Migrationshintergrund, in deren Haushalt ausschließlich Deutsch gesprochen wird, zusammen. Die zweite Gruppe umfasst Befragte, deren Haushaltssprache auf einen familiären Migrationshintergrund aus Ländern schließen lässt, in denen dem Islam eine gesellschaftlich und historisch prägende Rolle zukommt. Zuletzt wird geprüft, ob Antisemitismus in der Gruppe mit einem so verstandenen ,muslimisch geprägtem Familienhintergrund" weiter verbreitet ist, als in Gruppen, in deren Familien Serbisch oder Kroatisch gesprochen wird. Aufbauend auf den empirischen Ergebnissen werden in Abschnitt sechs didaktische Prinzipien für den Umgang mit Antisemitismus im Kontext von Berufsschulen dargelegt.

4 Ähnliche Artikel wie der oben zitierte in Breitbart News fanden sich auch in der Online Ausgabe der Jerusalem Post, wo dem Artikel ein Foto des Wachturms des ehemaligen Konzentrationslagers Mauthausen beigestellt war sowie im Daily Caller. - Benjamin Weinthal, Half of muslim youth in Austria hold antisemitic views, in: Jerusalem Post, 20.6.2017, [http://www.jpost.com/printarticle.aspx?id=497354], eingesehen 23.10.2017; Jake Rennie, Half of muslim minors in Austria hold Anti-Semitic views, in: The Daily Caller, 21.6.2017, [http://dailycaller.com/2017/06/21/half-of-muslimminors-in-austria-hold-anti-semitic-views-according-to-new-poll/], eingesehen 23.10.2017.

${ }_{5}^{5}$ Der Begriff wird Hedwig Dohm zugeschrieben. Vgl. Hedwig Dohm, Der Frauen Natur und Recht, Berlin 1876. 


\section{Didaktische Perspektiven auf Antisemitismus}

„Die Forderung, daß Auschwitz nicht noch einmal sei, ist die allererste an Erziehung. Sie geht so sehr jeglicher anderen voran, daß ich weder glaube, sie begründen zu müssen noch zu sollen." 6 Theodor W. Adorno formulierte seinen Anspruch an eine Erziehung nach Auschwitz als kategorischen Imperativ, als eine Maxime, die geltend macht, einzig aus menschlicher Vernunft zu resultieren. Daraus resultiert, dass die Infragestellung dieser Maxime bereits einen Tabubruch darstellt und sich somit moralisch delegitimiert. Keine der erdenklichen Rechtfertigungen, die mit der Verfolgung von Juden und Jüdinnen einhergingen und einhergehen, sollten damit Anspruch auf Gültigkeit erheben können. Sie alle haben gemeinsam, dass ,am Zusammenleben der Menschen einzig der Aspekt [interessiert], einen anderen dafür namhaft und schuldig zu machen, daß es nicht funktioniert“ und daher münden sie zwangsläufig , in einer Praxis der Verfolgung“. 7 So sehr die moralische Dimension von Antisemitismus in dieser Tatsache begründet ist, so herausfordernd ist eben diese moralische Dimension für einen pädagogischen Umgang mit dem Thema. Denn der Lerngegenstand Antisemitismus lässt sich nicht allein moralisch erschließen. Wenn historische Kontinuitäten und strukturelle Bedeutungen nicht wahrgenommen werden, ergibt sich auch aus einer moralischen Verurteilung keineswegs automatisch ein weiterer Reflexions- oder Handlungsbedarf. ${ }^{8}$ Barbara Schäuble konstatiert als Folge einer fehlenden Motivation zur Auseinandersetzung mit Antisemitismus eine „Spannung zwischen einem Sich-verpflichtet-Fühlen, VerpflichtetWerden und einer mangelnden Einsicht in Zusammenhänge "9, die durch das zwangsläufig damit verknüpfte Thema Holocaust zusätzlich aufgeladen wird. Auch von Borries stellt fest, dass der Holocaust angesichts seiner ,[[̈]]sthetisch-moralische[n] Widerlichkeit und kognitive[n] Unfassbarkeit“ aus geschichtsdidaktischer Sicht „zwar ein besonders wichtiger, aber kein lerngünstiger Gegenstand“ ist. ${ }^{10}$ Die Grundsätze des Beutelsbacher Konsens - Überwältigungsverbot, Kontroversitätsgebot und Interessenorientierung $^{11}$ - sind vor diesem Hintergrund nicht einfach einzulösen und dennoch muss sich jedes Bildungsangebot gegen Antisemitismus an ihnen messen lassen.

Schäuble macht vier zentrale Herangehensweisen antisemitismuskritischer Bildungsangebote aus: „Lernen über, Lernen aus, Lernen gegen und Lernen wegen

${ }^{6}$ Theodor W. Adorno, Erziehung zur Mündigkeit, Frankfurt a. M. 2013, S. 88.

7 Werner Konitzer, Einige Überlegungen. Antisemitismus und Moral, in: Mittelweg 3614 (2005), Heft 2, S. 24-35, hier S. 33 .

8 Barbara Schäuble, „Anders als wir“. Differenzkonstruktionen und Alltagsantisemitismus unter Jugendlichen, Berlin 2012, S. 412.

${ }^{9}$ Ebd., S. 411.

10 Bodo von Borries, Lernen und Lehren zum Holocaust - Konventionen, Irritationen, Provokationen?, in: epdDokumentation (2006), Heft 4/5, S. 48-65, hier S. 55.

${ }^{11}$ Hans-Georg Wehling, Konsens à la Beutelsbach? Nachlese zu einem Expertengespräch. Textdokumentation aus dem Jahr 1977, in: Benedikt Widmaier/Peter Zorn (Hrsg.), Brauchen wir den Beutelsbacher Konsens?. Eine Debatte der politischen Bildung, Bonn 2016, S. 19-27, hier S. 24. 
Antisemitismus". ${ }^{12}$ Während beim Lernen über Antisemitismus die Vermittlung von Wissen beispielsweise über Formen des Antisemitismus und die Verfolgungsgeschichte von Juden und Jüdinnen im Mittelpunkt steht, bezweckt der zweite Ansatz ein häufig von moralischen Erwartungen geprägtes „Lernen aus der Geschichte“. Die dritte Kategorie macht jene antisemitismusspezifischen Bildungsangebote aus, die sich zum Ziel setzen, gegen manifest oder latent antisemitische Einstellungen zu wirken bzw. eine entsprechende Prävention zu erzielen. Der vierte und letzte von Schäuble angeführte Bereich - Lernen wegen Antisemitismus - umfasst Bestrebungen im Zusammenhang mit verschiedensten Themen andere als antisemitische Deutungen und Orientierungsmuster anzubieten, „ohne dass dies notwendigerweise als ,Prävention’ ausgewiesen wird."13

Bildungsangebote der ersten beiden Kategorien bauen auf historischem Lernen. Dieses zielt darauf ab, „Kompetenz zur historischen Deutung“ zu gewinnen, sowie diese „historische Deutung in den Orientierungsrahmen der eigenen Lebenspraxis einzufügen und wirksam werden zu lassen“. ${ }^{14}$ Im Kontext des Unterrichtsfaches Politische Bildung an Berufsschulen stößt dieser grundsätzlich bedeutsame Zugang aber an seine Grenzen. Empirische Untersuchungen zeigen, dass die eigene Herkunft einen großen Einfluss auf die Wahrnehmung der NS-Geschichte hat und die Auseinandersetzung mit Geschichte in dieser Hinsicht der Migrationsgesellschaft Rechnung tragen muss. ${ }^{15}$ Für Jugendliche mit Migrationshintergrund ist der Nationalsozialismus in einem deutlich geringeren Ausmaß Teil ihrer eigenen Geschichte, als das für Jugendliche ohne Migrationshintergrund der Fall ist. ${ }^{16}$ Insbesondere in der Berufsschule erscheinen Bildungsangebote mit den Schwerpunktsetzungen Lernen über bzw. aus Antisemitismus aufgrund der mit ihnen verbunden Anforderungen an historisches Lernen weniger geeignet. Jugendliche, die nach der Erfüllung ihrer Schulpflicht eine Lehre im Dualen System beginnen, hatten nur von der sechsten bis zur achten Schulstufe Geschichtsunterricht. Im Rahmen des Pflichtgegenstandes Politische Bildung in der Berufsschule - für den über die zumeist dreijährige Lehrzeit hinweg insgesamt 80 Unterrichtsstunden vorgesehen sind - ist Geschichte nicht im Lehrstoff verankert, sondern lediglich als didaktisches Prinzip in den

12 Barbara Schäuble, „Über“, „aus“, „gegen“ oder „wegen“ Antisemitismus lernen? Begründungen, Themen und Formen politischer Bildungsarbeit in der Auseinandersetzung mit Antisemitismus, in: Richard Gebhart/Anne Klein/Marcus Meier (Hrsg.), Antisemitismus in der Einwanderungsgesellschaft. Beiträge zur kritischen Bildungsarbeit, Weinheim-Basel 2012, S. 174-191.

13 Ebd., S. 176

${ }^{14}$ Jörn Rüsen, Historisches Lernen. Grundlage und Paradigmen, Schwalbach/Ts. 2008, S. 64-65.

15 Viola Georgi, Entliehene Erinnerung. Geschichtsbilder junger Migranten in Deutschland, Hamburg 2003.

16 Während $29 \%$ der im Rahmen einer Studie zu Geschichtsbewusstsein und Identitätskonstruktionen von Jugendlichen mit Migrationshintergrund befragten Wiener SchülerInnen aus der AHS-Oberstufe bzw. aus berufsbildenden mittleren oder höheren Schulen mit zwei im Ausland geborenen Elternteilen kundtun, nichts mit dem Nationalsozialismus zu tun zu haben, weil sie sich nicht als ÖsterreicherIn fühlen, sind es unter jenen mit zumindest einem Elternteil aus Österreich nur $4 \%$. (Christiane Hintermann, Dissonante Geschichtsbilder? Empirische Untersuchung zu Geschichtsbewusstsein und Identitätskonstruktionen von Jugendlichen mit Migrationshintergrund in Wien, Wien 2007, S. 118.) 
Unterricht zu integrieren. ${ }^{17}$ Eine grundlegende historische Orientierung ist zwar für die Auseinandersetzung mit Antisemitismus ebenso wie für die Politische Bildung unverzichtbar, aber aufgrund der angeführten Rahmenbedingungen bleibt der Fokus im Weiteren auf Lernen ,gegen“ bzw. „,wegen“ Antisemitismus gerichtet.

Zur Erschließung von Antisemitismus als Lerngegenstand erscheinen die folgenden Fragen relevant: Wie kann dem „Brückenproblem“ - es bezeichnet die Schwierigkeit, eine „nachhaltige Begegnung zwischen Lernenden und Gegenstand anzubahnen, die an die Gesellschaftsbilder, Alltagstheorien und Erfahrungen von Lernenden anknüpft"18 _ entgegnet werden? Welche Rolle spielen Vorerfahrungen bzw. Voreinstellung der SchülerInnen?

Angesichts der oben beschriebenen Schwierigkeiten bei der Entwicklung von Lernmotivation verlangt eine didaktische Perspektive auf Antisemitismus eine lebensweltliche Orientierung im Sinne des didaktischen Prinzips der Adressatenorientierung. Dieses fokussiert auf ,interaktive ,Sinndeutung“ der ,miteinander handelnden Personen““. ${ }^{19}$ Warum man über bzw. aus Antisemitismus lernen soll, erschließt sich nicht allein aus moralischen Ansprüchen. Auch wenn Antisemitismus moralisch verurteilt wird, geht damit weder automatisch eine Lernmotivation noch ein Lernprozess einher. ${ }^{20}$ Die Beziehung zum Lerngegenstand Antisemitismus ist so zu gestalten, dass die SchülerInnen ihre Deutungen zum Ausdruck bringen können. Insofern anzunehmen ist, dass die Deutungen in der Regel auch antisemitisch bzw. von antisemitischen Stereotypen geprägt sind, muss zunächst vonseiten der PädagogInnen die moralische Dimension des Themas zugunsten einer rekonstruktiven Erkenntnishaltung hintangestellt werden. Sie sind gefordert, die „lebensweltgebundenen Topoi ihrer Adressatinnen und Adressaten [zu] analysieren“, um so „ein Wissen um subjektive Begründungen" $21 \mathrm{zu}$ erlangen und diese im Weiteren thematisieren $\mathrm{zu}$ können. Hinderlich wäre die Wahrnehmung solcher antisemitischer Deutungen als

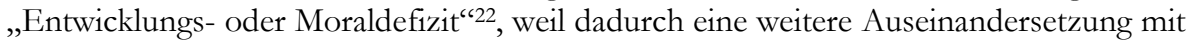
den Motiven und Interessenlagen der Jugendlichen blockiert wird. Genauso wenig, wie fachliche Fehlkonzepte aus der Lebenswelt „von wissenschaftlichen Konzeptionen einfach abgelöst werden“ 23 können, lässt sich ein antisemitisches Verständnis einfach durch ein anderes austauschen.

17 Unter „Besondere didaktische Grundsätze für den Pflichtgegenstand Politische Bildung“ ist angeführt, dass „,[z]eitgeschichtliche Entwicklungen [...] unter Beachtung der Bedeutung der historischen Dimension der zu behandelnden Themenbereiche, insbesondere der Demokratie und Menschenrechte, in den Unterricht zu integrieren [sind].“ (BGBl. II Nr. 211/2016)

18 Andreas Petrik, Der heimliche politikdidaktische Kanon, in: Ingo Juchler (Hrsg.), Unterrichtsleitbilder in der politischen Bildung, Schwalbach/Ts. 2012, S. 71-85, hier S. 72.

19 Andreas Petrik, Adressatenorientierung, in: Wolfgang Sander (Hrsg.), Handbuch politische Bildung, Bonn 2014, S.

241-248, hier S. 241.

20 Schäuble, Anders, S. 412

${ }^{21}$ Ebd., S. 428-429

22 Ebd., S. 419

${ }^{23}$ Dirk Lange, Kernkonzepte des Bürgerbewusstseins, in: Georg Weißeno (Hrsg.), Politikkompetenz. Was Unterricht 
Als Ergebnis mangelnder lebensweltlicher Anknüpfungspunkte in der schulischen Auseinandersetzung mit Antisemitismus bleibt in vielen Fällen, dass vor allem gelernt wird, sich entsprechend der Moralvorstellungen des jeweiligen Umfelds zu Antisemitismus zu äußern. ${ }^{24}$ In einer Migrationsgesellschaft gestaltet sich dieses Umfeld in einem zusätzlichen Maße divers und es lassen sich vielfältige Sinn- und Bedeutungszusammenhänge antisemitischer Einstellungen ausmachen. Solche könnten beispielsweise beabsichtigte Provokation, die Thematisierung des Nahostkonflikts, verkürzte Globalisierungskritik oder Verschwörungstheorien sein. Diesen Zusammenhängen kommt in Lernprozessen eine zentrale Bedeutung zu. Darüber hinaus ist ein gesellschaftlicher Diskurs, in dem die Thematisierung von antisemitischen Einstellungen bei MuslimInnen die Funktion erfüllt, die Mehrheitsgesellschaft und nichtmuslimische Minderheiten zu entlasten, in zweifacher Hinsicht problematisch: Er lagert das Problem aus, blockiert damit von vornherein Lernprozesse und dient der moralischen Empörung über „die Anderen“. Mit anderen Worten: Antisemitismus als Problem der Mehrheitsgesellschaft wird dadurch verdrängt und antimuslimische Ressentiments finden eine im öffentlichen Diskurs weithin akzeptierte Ausdrucksweise.

\section{Methode}

Die Umfragedaten, auf denen dieser Beitrag beruht, wurden im ersten Halbjahr 2016 erhoben. Befragt wurden einerseits Wiener BerufsschülerInnen ${ }^{25}$ und andererseits Studierende der Pädagogischen Hochschule Wien (PH Wien) ${ }^{26}$.

Zunächst wurden im Februar und März 2016 rund 700 Lehrlinge aus insgesamt 25 verschiedenen Lehrberufen an zehn Wiener Berufsschulen befragt. Bei der Zusammenstellung des Samples wurde darauf geachtet, dass aus Lehrberufen mit vielen Lehrlingen auch verhältnismäßig viele BerufsschülerInnen befragt werden und zugleich eine breite Streuung über verschiedenste Branchen erreicht werden kann. Aus rechtlichen Gründen waren alle TeilnehmerInnen mindestens 18 Jahre alt. Für die Auswertung wurden nur die Antworten jener 636 SchülerInnen herangezogen, die bis zur letzten Frage an der Umfrage teilnahmen. Eine Genehmigung des Stadtschulrats für Wien, sowie die Zusammenarbeit mit den Direktionen und Lehrenden der ausgewählten Schulen ermöglichte die Befragung während der Unterrichtszeit, wobei dafür nach Möglichkeit eine Stunde aus Politischer Bildung verwendet wurde. Vergleichsdaten zu den Antworten der BerufsschülerInnen wurden im März und April 2016 unter Studierenden der PH Wien erhoben. Insgesamt wurden 1006 Studierende, bei denen sichergestellt war, dass

zu leisten hat, Bonn 2008, S. 245-258, hier S. 246.

24 Schäuble, Über, S. 175

${ }^{25}$ Lauss/Schmid-Heher, Berufsschule.

26 Georg Lauss/Stefan Schmid-Heher, Politische Bildung und demokratierelevante Einstellungsmuster von angehenden Lehrenden. Eine quantitative Studie, in: R\&E Source (2017), Heft Tag der Forschung, S. 1-13. 
sie zum Zeitpunkt der Befragung schon eine Lehrveranstaltung zu Politischer Bildung besucht hatten, zur Teilnahme an der Studie aufgefordert. 334-mal wurde der Fragebogen aufgerufen und 302-mal bis zur letzten Frage beantwortet und abgeschickt. Die Daten wurden mittels Onlineumfrage via Limesurvey über Smartphones erhoben. Der Fragebogen war so konzipiert, dass das vollständige Ausfüllen zwischen zehn und 15 Minuten dauern sollte. Da die Fragen innerhalb der einzelnen Abschnitte jeweils per Zufallsgenerator gereiht wurden, sind Reihenfolgeeffekte auszuschließen. Die Datensätze wurden nach Beendigung der Erhebungsphase mittels SPSS statistisch ausgewertet.

Der Fragebogen besteht aus drei Abschnitten mit insgesamt 37 Items, wobei sich im Abschnitt A 17 Items mit politischen Einstellungen und sechs Items mit der politischen Aktivität befassen, im Abschnitt B acht Items mit der Wahrnehmung von Politischer Bildung und im Abschnitt $\mathrm{C}$ sechs Items mit demographischen Angaben zur Person. Die Abfrage politischer Einstellungsmerkmale baut in Grundzügen auf den Merkmalen der autoritären Persönlichkeit auf und gliedert sich in Konstrukte zu politischem Autoritarismus, Autoritarismus, Anomie und Gruppenbezogener Menschenfeindlichkeit. Einzelne Konstrukte sind in Dimensionen unterteilt, denen jeweils ein bis drei Items zugeordnet sind. Das Konstrukt Autoritarismus umfasst die Dimensionen Unterwerfung und Aggression; Anomie gliedert sich in Orientierungslosigkeit, politische Machtlosigkeit sowie Zukunftsperspektive und Gruppenbezogene Menschenfeindlichkeit wird in Anlehnung an Heitmeyer in den Dimensionen Zuwanderungsängste, Antisemitismus, Islamfeindlichkeit sowie Sexismus erfasst. ${ }^{27}$ Bei der Auswahl der Items wurde $\mathrm{zu}$ wesentlichen Teilen auf die Studie „NS-Geschichtsbewusstsein und autoritäre Einstellungen in Österreich“ 28 sowie auf die ländervergleichende Studie „Historical totalitarian experiences, authoritarian potential and democratic values in Austria, Poland, Hungary and the Czech Republic" ${ }^{\text {"29 }}$ zurückgegriffen. Ebenso wurde auf deutsche und österreichische Jugendwertestudien Bezug genommen. ${ }^{30}$

Die Fragebögen bestehen weitestgehend aus Likert-Skalen mit vier Antwortmöglichkeiten (stimme sehr zu ... stimme gar nicht zu) und der Möglichkeit ,keine Antwort“. Die überwiegende Mehrzahl der Konstrukte und Dimensionen besteht aus sowohl positiv als auch negativ formulierten Items. Dies ist vor allem im Bereich der Autoritarismusforschung ein entscheidender Punkt. Denn wenn man annehmen muss, dass autoritäre Charaktere dazu tendieren Fragen eher zustimmend zu beantworten,

${ }^{27}$ Wilhelm Heitmeyer, Gruppenbezogene Menschenfeindlichkeit (GMF) in einem entsicherten Jahrzehnt, in: Ders. (Hrsg.), Deutsche Zustände. Folge 10, Berlin 2015, S. 15-41

${ }^{28}$ Oliver Rathkolb/Martina Zandonelle/Günther Ogris, NS-Geschichtsbewußtsein und autoritäre Einstellungen in Österreich, Wien 2014, [http://www.sora.at/fileadmin/downloads/projekte/2014_Presseunterlage_Geschichtsbewusstsein-undautoritaere_Einstellungen.pdf], eingesehen am 2.11.2016

${ }^{29}$ Oliver Rathkolb/Günther Ogris, Historical totalitarian experiences, authoritarian potential and democratic values in Austria, Poland, Hungary and the Czech Republic, Wien 2008.

30 Bernhard Heinzlmeier/Phillip Ikrath, Jugendwertestudie 2011, Wien 2012, S. 55. 
würde man die Ergebnisse noch akzentuieren, wenn man StudienteilnehmerInnen überwiegend autoritäre Aussagen vorlegt.

\section{Demokratische und autoritaristische Potentiale von Wiener BerufsschülerInnen und Lehramtsstudierenden an der PH Wien}

Der folgende Abschnitt beginnt mit einer kurzen Einführung in das Konzept der autoritären Persönlichkeit. Danach werden zentrale Ergebnisse der oben beschriebenen Studien zusammengefasst und das Antwortverhalten von zumindest 18-jährigen BerufsschülerInnen und von Lehramtsstudierenden in Wien verglichen. In den Nachkriegsgesellschaften Europas und Nordamerikas, die den Umschlag demokratischer Systeme in Autokratie und Totalitarismus noch lebhaft vor Augen hatten, entstanden eine Reihe von Untersuchungen zur politischen Sozialisation von Kindern und jungen Erwachsenen. ${ }^{31}$ Diese erreichten in den 1970er-Jahren ihren Höhepunkt. ${ }^{32}$ Im deutschsprachigen Raum war es insbesondere die „Frankfurter Schule“ um Horkheimer und Adorno, die sich mit Fragen der politischen Sozialisation und demokratischer Erziehung in Gesellschaft, Schule und Familie auseinandersetzte. ${ }^{33}$ Grundlegend dabei war die erstmals im US-amerikanischen Exil entstandene Studie zum autoritären Charakter. ${ }^{34}$ Personen mit autoritären Einstellungsmustern bereitet es Schwierigkeiten, den grundlegenden Konflikt zwischen den Werten sozialer Anpassung und persönlicher Autonomie $\mathrm{zu}$ lösen. ${ }^{35}$ Das Vertrauen in demokratische Prinzipien ist schwach ausgeprägt. Dies wirkt sich in einer gesteigerten Bereitschaft zur Unterwerfung einerseits und aggressiv-dominantem Verhalten gegenüber Schwächeren andererseits aus. Kritiklose Befolgung der Anweisung von Autoritäten geht demnach einher mit einer idealisierenden Überbewertung der Eigengruppe und Abwertung des Fremden. Personen und Gruppen, die gesellschaftlich etablierten Normen widersprechen, werden zu Zielen von Aggression. Zukunftsangst und Orientierungslosigkeit steigern das Bedürfnis nach konformistischem Sozialverhalten. ${ }^{36}$

31 David Easton/Jack Dennis, Children in the Political System, New York 1969; Herbert Hyman, Political Socialization. A Study in the Psychology of Political Behavior, Glencoe 1959; Fred Greenstein, Children and Politics, New Haven 1965; Harold Lasswell, Democratic Character, in: Ders. (Hrsg.), Political Writings of Harold Lasswell, Glencoe 1951, S. 465-525.

32 Robert Dudley/Alan Gitelson, Civic Education, Civic Engagement, and Youth Civic Development, in: Political Science and Politics 36 (2003), Heft 2, S. 263-267; Richard Niemi/Mary Hepburn, The Rebirth of Political Socialization, in: Perspectives on Political Science 24 (1995), Heft 1, S. 7-16.

33 Theodor W. Adorno, Studien zum autoritären Charakter, Frankfurt a. M. 2013; Karlheinz Rebel (Hrsg.), ZwangAutorität-Freiheit in der Erziehung. Texte zum Autoritätsproblem, Berlin 1967.

34 Theodor W. Adorno u. a., The Authoritarian Personality, Oxford 1950.

35 Stanley Feldman, Die Konzeptualisierung und die Messung von Autoritarismus. Ein neuer Ansatz, in: Susanne Rippl/Christian Seipel/Angela Kindervater (Hrsg.), Autoritarismus, Wiesbaden 2000, S. 239-260; Stanley Feldman, Enforcing Social Conformity, in: Political Psychology 24 (2003) Heft 1, S. 41-74.

${ }^{36}$ Bob Altemeyer, The Authoritarian Specter, Cambridge (MA) 1996. 
Das Vertrauen in demokratische Prinzipien ist in der Gruppe der Lehrlinge insgesamt schwächer ausgeprägt als unter Lehramtsstudierenden. Lediglich $68 \%$ halten Demokratie für die beste Regierungsform. Unter Lehramtsstudierenden sind es immerhin 91 \%. Bei einer anderen Frage aus dem Konstrukt politischer Autoritarismus ergibt sich ein ähnliches Bild. Fast die Hälfte der Lehrlinge wünscht sich „an der Spitze eines Staates eine starke Persönlichkeit, die sich nicht um ein Parlament und Wahlen kümmern muss". Unter den Lehramtsstudierenden sind es mit $31 \%$ etwas weniger. Für die Vorstellung, dass ExpertInnen und nicht eine gewählte Regierung entscheiden sollen, was am besten für das Land ist, findet sich in beiden Gruppen eine deutliche Mehrheit. Demonstrationsverbote an neuralgischen Verkehrsadern, wie der Wiener Ringstraße, finden eine relative Mehrheit unter Wiener Lehrlingen. Unter PH-Studierenden stellen sich dreimal mehr Befragte gegen ein Verbot, als es befürworten.

\begin{tabular}{|c|c|c|c|c|c|}
\hline $\begin{array}{l}\text { Politischer Autoritarismus: } \\
\text { Lehrlinge (BS) und PH-Studierende (PH) im Vergleich }\end{array}$ & & ++ & + & - & $\mid--$ \\
\hline \multirow{2}{*}{$\begin{array}{l}\text { Die Demokratie ist die beste Regierungsform, auch wenn sie } \\
\text { Probleme mit sich bringen mag. }\end{array}$} & BS & 27 & 41 & 18 & 6 \\
\hline & $\mathrm{PH}$ & 56 & 35 & 6 & 1 \\
\hline \multirow{2}{*}{$\begin{array}{l}\text { An der Spitze eines Staates sollte eine starke Persönlichkeit } \\
\text { stehen, die sich nicht um ein Parlament und Wahlen } \\
\text { kümmern muss. }\end{array}$} & BS & 20 & 27 & 24 & 16 \\
\hline & $\mathrm{PH}$ & 11 & 20 & 26 & 33 \\
\hline \multirow{2}{*}{$\begin{array}{l}\text { ExpertInnen und nicht die Regierung sollten entscheiden, } \\
\text { was das Beste für das Land ist. }\end{array}$} & $\mathrm{BS}$ & 19 & 34 & 26 & 10 \\
\hline & $\mathrm{PH}$ & 16 & 39 & 24 & 10 \\
\hline \multirow{2}{*}{$\begin{array}{l}\text { Ein Demonstrationsverbot auf der Ringstraße halte ich für } \\
\text { gerechtfertigt. }\end{array}$} & BS & 20 & 21 & 20 & 18 \\
\hline & $\mathrm{PH}$ & 7 & 14 & 24 & 40 \\
\hline
\end{tabular}

Wie zuvor beschrieben, sind Aggression, Unterwerfung und Konventionalismus Kennzeichen für autoritäre Einstellungsmuster. Auch in diesem Bereich unterscheiden sich die befragten Gruppen durchgängig. Zwei Drittel der BerufsschülerInnen stimmen der Aussage zu, dass Disziplin und Gehorsam in der Gesellschaft wieder wichtiger werden müssen. Unter PH Studierenden sind es vier von zehn. Allerdings befürworten auch $51 \%$ der Studierenden härteres Vorgehen gegen Unruhestifter, um Recht und Ordnung zu bewahren. Unter Lehrlingen sind es mehr als $70 \%$. $41 \%$ der Lehramtsstudierenden können sich vorstellen, manchmal auch Gnade vor Recht ergehen zu lassen. Unter Wiener BerufsschülerInnen ist das für $26 \%$ der Befragten eine Option. 


\begin{tabular}{|l|l|l|l|l|l|}
\hline $\begin{array}{l}\text { Autoritarismus: } \\
\text { Lehrlinge (BS) und PH-Studierende (PH) im Vergleich }\end{array}$ & & ++ & + & - & -- \\
\hline $\begin{array}{l}\text { Es braucht Leute, die Neues ausprobieren, auch wenn sie } \\
\text { dabei Regeln verletzen. }\end{array}$ & BS & 22 & 33 & 26 & 11 \\
\cline { 2 - 6 } & PH & 16 & 38 & 27 & 8 \\
\hline $\begin{array}{l}\text { Disziplin und Gehorsam müssen in unserer Gesellschaft } \\
\text { wichtiger werden. }\end{array}$ & BS & 41 & 24 & 15 & 5 \\
\cline { 2 - 6 } & PH & 12 & 28 & 33 & 16 \\
\hline \multirow{2}{*}{$\begin{array}{l}\text { Um Recht und Ordnung zu bewahren, sollte man härter } \\
\text { gegen UnruhestifterInnen vorgehen. }\end{array}$} & BS & 36 & 35 & 15 & 6 \\
\cline { 2 - 6 } & PH & 20 & 31 & 30 & 10 \\
\hline $\begin{array}{l}\text { Anstatt hart zu strafen, sollte man manchmal Gnade walten } \\
\text { lassen. }\end{array}$ & BS & 8 & 18 & 30 & 33 \\
\cline { 2 - 6 } & PH & 7 & 34 & 29 & 19 \\
\hline
\end{tabular}

Eine Tendenz zur Gruppenbezogenen Menschenfeindlichkeit wurde in den Kategorien allgemeine Zuwanderungsängste, Islamfeindlichkeit, Antisemitismus und Sexismus abgefragt. Während sich eine relative Mehrheit der BerufsschülerInnen durch Zuwanderung beruflich bedroht fühlt, trifft das nur für $12 \%$ der PH-Studierenden zu. Mehr als die Hälfte der Lehrlinge sieht in Zuwanderung einen Nachteil für die österreichische Gesamtwirtschaft. Unter Lehramtsstudierenden teilen nicht ganz ein Drittel der Befragten diese Einschätzung. Weniger als ein Fünftel der Studierenden gibt an, mit Menschen aus dem eigenen Herkunftsland weniger Probleme zu haben als mit anderen. Unter BerufsschülerInnen sind beide Gruppen in etwa gleich groß. Sollten MuslimInnen in Österreich das Recht auf eigene Kulturorganisationen haben, solange sie sich an die Gesetze halten? Unter angehenden LehrerInnen sprechen sich immerhin $25 \%$ gegen dieses Recht aus. Unter Lehrlingen sind es sogar $45 \%$. Dies ist insbesondere deshalb bemerkenswert, weil hier durch die Verfassung geschützte Grundrechte wie das Recht auf Vereins- und auf Versammlungsfreiheit (Art. 12 StGG) und das Recht auf Glaubens- und Gewissensfreiheit einschließlich der Freiheit der Religionsausübung (Art 14 und 16 StGG; Art. 9 EMRK) berührt werden. Auch antisemitische Einstellungen sind unter den befragten Studierenden deutlich seltener anzutreffen. $5 \%$ finden, dass Juden in Österreich zu viel Einfluss haben. Unter BerufsschülerInnen vertreten immerhin ein Viertel der Befragten diese Ansicht. Und auch bei der Frage nach beruflicher Gleichstellung von Mann und Frau lassen sich Unterschiede feststellen. Während unter BerufsschülerInnen $29 \%$ der Befragten sich dagegen aussprechen, dass Frauen häufiger Führungspositionen übernehmen sollten, sind es unter PH-Studierenden nur $13 \%$. 


\begin{tabular}{|c|c|c|c|c|c|}
\hline $\begin{array}{l}\text { Gruppenbezogene Menschenfeindlichkeit: } \\
\text { Lehrlinge (BS) und PH-Studierende (PH) im Vergleich }\end{array}$ & & ++ & + & - & -- \\
\hline \multirow{2}{*}{$\begin{array}{l}\text { Meine beruflichen Chancen sinken durch steigende } \\
\text { Zuwanderung. }\end{array}$} & BS & 23 & 24 & 25 & 19 \\
\hline & $\mathrm{PH}$ & 5 & 7 & 32 & 53 \\
\hline \multirow{2}{*}{$\begin{array}{l}\text { ZuwandererInnen sind im Allgemeinen gut für die } \\
\text { österreichische Wirtschaft. }\end{array}$} & BS & 9 & 25 & 28 & 27 \\
\hline & $\mathrm{PH}$ & 16 & 40 & 25 & 7 \\
\hline \multirow{2}{*}{$\begin{array}{l}\text { Mit Menschen aus meinem eigenen Herkunftsland habe ich } \\
\text { weniger Probleme als mit anderen. }\end{array}$} & BS & 25 & 21 & 21 & 24 \\
\hline & $\mathrm{PH}$ & 7 & 12 & 24 & 51 \\
\hline \multirow{2}{*}{ Juden haben in Österreich zu viel Einfluss. } & BS & 15 & 9 & 20 & 35 \\
\hline & $\mathrm{PH}$ & 1 & 4 & 17 & 58 \\
\hline \multirow{2}{*}{$\begin{array}{l}\text { Muslime sollten das Recht haben eigene Organisationen zu } \\
\text { gründen, um ihre Kultur zu fördern, solange sie sich an die } \\
\text { Gesetze halten. }\end{array}$} & BS & 26 & 22 & 15 & 30 \\
\hline & $\mathrm{PH}$ & 34 & 34 & 17 & 8 \\
\hline \multirow{2}{*}{$\begin{array}{l}\text { Frauen sollten deutlich häufiger Führungspositionen } \\
\text { übernehmen. }\end{array}$} & BS & 29 & 30 & 17 & 12 \\
\hline & $\mathrm{PH}$ & 43 & 34 & 10 & 3 \\
\hline
\end{tabular}

Autoritaristische Einstellungsmuster sind in der Gruppe der Lehrlinge weiter verbreitet als unter Lehramtsstudierenden. Bildungshintergrund und Berufswahl wirken sich hier anscheinend deutlich auf das Antwortverhalten aus. So unterschiedlich sich das Antwortverhalten auf der Ebene der deskriptiven Statistik auch darstellt, gibt es zumindest drei für die Politische Bildung relevante Gemeinsamkeiten.

Erstens: Industrie und Wissensgesellschaft stellen teilweise unvereinbare Ansprüche an die Individuen. Erstere verlangt ein hohes Maß an Disziplin und Gehorsam. Zweitere animiert zumindest teilweise zum riskanten Bruch mit Regeln und etablierten Konventionen, um Neues auszuprobieren. In beiden Studien erhöht widersprüchliches Antwortverhalten die Wahrscheinlichkeit, dass sich eine Person an der Spitze eines Staates eine Persönlichkeit wünscht, die sich nicht um Parlament und Wahlen kümmern muss. Unabhängig vom Bildungsweg scheint die Sehnsucht nach einer starken Persönlichkeit, die in der Lage ist Ordnung in die Verhältnisse zu bringen, vor allem bei jenen vorhanden $\mathrm{zu}$ sein, die sich zwischen den teilweise widersprüchlichen Anforderungen der Wissensgesellschaft hin- und hergerissen fühlen. Mehr als die Hälfte der Lehrlinge stimmen sowohl der Aussage zu, dass „Disziplin und Gehorsam in der Gesellschaft wieder wichtiger werden müssen“ als auch, dass es Leute braucht, „die Neues ausprobieren, auch wenn sie dabei Regeln verletzen“. In dieser Gruppe sehnen sich $57 \%$ nach einer starken Persönlichkeit an der Spitze eines Staates, die sich um 
demokratische Institutionen nicht weiter kümmern muss, während es in der kongruent antwortenden Gruppe nur 38 \% sind. ${ }^{37}$ Auch bei den PH-Studierenden zeigt sich, dass jene, die sich sowohl für mehr Disziplin und Gehorsam aussprechen, als auch dafür, dass Neues trotz Regelverletzungen ausprobiert werden soll, mit $48 \%$ deutlich häufiger für eine autoritäre regierende Person an der Staatsspitze sind.

Zweitens: Es besteht ein deutlicher Zusammenhang zwischen autoritaristischen Einstellungsmustern und Gruppenbezogener Menschenfeindlichkeit. Personen die einen Mangel an Disziplin und Gehorsam in der Gesellschaft diagnostizieren, härter gegen Unruhestifter vorgehen wollen, um Recht und Ordnung zu bewahren, und weniger geneigt sind, härtere Bestrafungen auch einmal auszusetzen, fühlen sich häufiger von Zuwanderung bedroht und antworten tendenziell islamfeindlicher, antisemitischer und sexistischer. ${ }^{38}$

Drittens: Lehrlinge ${ }^{39}$ und Studierende ${ }^{40}$ bevorzugen Themen der Politischen Bildung, die sich an den Lebenswelten der Lernenden orientieren, gegenüber Zeitgeschichte. Zeitgeschichtliche Themen landen unter sieben Auswahlmöglichkeiten (Aktuelle Themen, Vorurteile und Minderheitenrechte, Politische Weltanschauungen, Staat Österreich, Arbeitswelt, Parteien und Interessenvertretungen) in beiden Gruppen auf dem letzten Platz. Bei der Hälfte der Befragten landet das Thema Zeitgeschichte auf einem der beiden letzten Plätze. So wichtig das Lernen über bzw. aus Geschichte auch ist, die Arbeit gegen Antisemitismus und andere Formen Gruppenbezogener Menschenfeindlichkeit muss sich - insbesondere außerhalb des Geschichtsunterrichts zunehmend auch neue thematische Zugänge suchen, um SchülerInnen zu erreichen.

\section{Autoritarismus und Gruppenbezogene Menschenfeindlichkeit unter Jugendlichen mit muslimisch geprägtem Familienhintergrund}

Wie im vorangegangenen Abschnitt gezeigt, unterscheidet sich das Antwortverhalten zwischen Jugendlichen ab 18 an Wiener Berufsschulen und Studierenden der PH Wien in vielen Bereichen maßgeblich voneinander. Die Variablen Bildungsgrad und Berufswahl haben demnach einen relativ starken Einfluss auf Einstellungsausprägungen in den Bereichen politischer Autoritarismus, Autoritarismus, Anomie und Gruppenbezogene Menschenfeindlichkeit. Autoritäre Einstellungsmuster zeigen sich dabei in der Gruppe der BerufsschülerInnen deutlicher als unter Studierenden der PH Wien. In diesem Abschnitt gehen wir nun der Frage nach, ob ein muslimisch geprägter Familienhintergrund Einfluss auf demokratische Grundhaltungen und autoritäre

${ }^{37}$ Lauss/Schmid-Heher, Berufsschule, S. 106.

38 Ebd., S. 118; Lauss/Schmid-Heher, PH Wien, S. 12.

${ }^{39}$ Lauss/Schmid-Heher, Berufsschule, S. 114.

${ }^{40}$ Lauss/Schmid-Heher, PH Wien, S. 11. 
Einstellungen hat. Zu diesem Zweck wurden zwei Subgruppen aus der Gruppe der BerufsschülerInnen verglichen. Einerseits junge Erwachsene mit muslimischem Familienhintergrund $(\mathrm{n}=102)$, andererseits junge Erwachsene ohne Migrationshintergrund, bei denen in der Familie ausschließlich Deutsch gesprochen wird $(\mathrm{n}=310)$. Die Zuteilung erfolgte aufgrund der Antworten auf zwei Items im soziodemografischen Teil des Fragebogens. Die Vergleichsgruppe mit muslimisch geprägtem Familienhintergrund setzt sich aus Personen zusammen, in deren Haushalt ausschließlich oder zum Teil eine der folgenden Sprachen gesprochen wird ${ }^{41}$ : Arabisch, Albanisch, Bangla, Bosnisch, Dari, Farsi, Kurdisch, Somali, Tschetschenisch, Türkisch. Im Weiteren wollen wir prüfen, ob gefundene Unterschiede zwischen den Gruppen in einem Zusammenhang mit einem so definierten muslimisch geprägten Hintergrund stehen. Zu diesem Zweck haben wir eine dritte Gruppe von Personen gebildet, die angeben im eigenen Haushalt (auch) Serbisch oder Kroatisch zu sprechen ( $\mathrm{n}=88$ ).

Die Variable „muslimisch geprägter Familienhintergrund“ hat bei der großen Mehrzahl der Fragen keinen signifikanten Einfluss auf das Antwortverhalten. Sowohl die Gruppe der ausschließlich Deutschsprachigen ohne Migrationshintergrund als auch die Gruppe mit muslimisch geprägtem Familienhintergrund fühlen sich in ähnlichem Maß orientierungslos und sehen ähnlich zuversichtlich in ihre berufliche bzw. private Zukunft. Sowohl das Bekenntnis zur Demokratie als Regierungsform, als auch der Wunsch nach einer von Parlament und Wahlen unabhängigen, starken Führungspersönlichkeit ist unter BerufsschülerInnen mit und ohne Migrationshintergrund in der Familie in etwa gleich stark ausgeprägt. BerufsschülerInnen mit muslimischem Familienhintergrund bringen einer demokratisch legitimierten Regierung tendenziell mehr Vertrauen entgegen als solche ohne Migrationshintergrund. $60 \%$ (24\% sehr/36 \% eher) der Letzteren finden, dass ExpertInnen und nicht die Regierung entscheiden sollen, was das Beste für das Land ist. Nur $39 \%$ (14/25) aus der Gruppe mit muslimischem Migrationshintergrund votieren tendenziell für eine Expertokratie. Ein unterscheidbares Antwortverhalten gibt es auch bei zwei Fragen aus dem Konstrukt Autoritarismus, wobei die Unterschiede relativ gering sind: $30 \%$ (5/25) der SchülerInnen mit muslimischem Familienhintergrund finden, dass man manchmal Gnade walten lassen sollte, anstatt hart zu strafen. Befragte ohne Migrationshintergrund antworten hier in der Tendenz autoritärer. Nur 24 \% (7/17) neigen dazu, in manchen Fällen Gnade vor Recht ergehen zu lassen. Geringe Unterschiede lassen sich noch bei einer zweiten Frage aus dem Bereich Autoritarismus

\footnotetext{
41 Augenscheinlich lässt die im Haushalt gesprochene Sprache keinen direkten Rückschluss auf ein wie auch immer geartetes religiöses Bekenntnis bzw. individuelle religiöse Praxis zu. Die Gruppenkonstruktion beruht demnach auf dem Vorhandensein eines familiären Einflusses, der sich in zuhause gesprochenen Sprachen manifestiert und aufgrund der gesellschaftlichen Bedeutung von Religion als ,muslimisch geprägt' verstanden wird. Die in der Folge aufgezeigten Unterschiede sind demnach auf ein breites Spektrum von Sozialisierungsvorgängen zurückzuführen, unter denen eine solche „muslimische Prägung“ lediglich einen Faktor unter mehreren darstellt. Diese Gruppenkonstruktion erscheint insofern als aussagekräftig, als - wie in der Einleitung exemplarisch dargestellt - im gesellschaftlichen Diskurs um Antisemitismus in der Migrationsgesellschaft ZuwandererInnen aus muslimisch geprägten Herkunftsländern unabhängig von ihrem religiösen Selbstverständnis im Fokus stehen.
} 
erkennen. Hier sind allerdings SchülerInnen ohne Migrationshintergrund zu $75 \%$ (43/32) der Ansicht, dass Disziplin und Gehorsam in der Gesellschaft wieder wichtiger werden müssen. Immerhin 80 \% (46/34) der jungen Erwachsenen mit muslimischem Migrationshintergrund stimmen dieser Ansicht zumindest in der Tendenz zu.

Lediglich in einem Konstrukt finden sich durchgängig Unterschiede im Antwortverhalten zwischen Jugendlichen mit und ohne muslimischem Familienhintergrund: Gruppenbezogene Menschenfeindlichkeit. Wenig überraschend zeigen sich große Abweichungen im Antwortverhalten bei der Frage, ob Muslime das Recht haben sollten, eigene Organisationen zur Förderung ihrer Kultur zu gründen, solange sie sich an die Gesetze halten. Lediglich 38 \% der Befragten ohne Migrationshintergrund in der Familie teilen diese Einschätzung tendenziell, wohingegen in der Gruppe mit muslimisch geprägtem Hintergrund $76 \%$ der Befragten dieser Aussage zustimmen, davon nahezu alle $(66 \%)$,sehr stark“. Im Umkehrschluss bedeutet das, dass eine deutliche Mehrheit der ÖsterreicherInnen ohne Migrationshintergrund und immerhin noch ein knappes Viertel der SchülerInnen mit muslimisch geprägtem Familienhintergrund das Recht auf Versammlungsfreiheit für Muslime in Österreich einschränken wollen. In der Gruppe der Kroatisch bzw. Serbisch sprechenden Befragten befürworten 44 \% das Recht von MuslimInnen, eigenen Kulturorganisationen zu gründen.

Nicht ganz so groß, aber immer noch deutlich sind die Unterschiede bei der Frage, ob Zuwanderung im Allgemeinen gut für die österreichische Wirtschaft ist. Dies bejahen in der Tendenz fast die Hälfte (48 \%) der BerufsschülerInnen mit muslimischem Hintergrund und nicht einmal ein Drittel (26\%) der Befragten aus der Gruppe ohne Migrationshintergrund. In der dritten Gruppe von Personen, also jene mit kroatischem bzw. serbischem Hintergrund, denken $28 \%$, dass Zuwanderung überwiegend positive ökonomische Effekte hat. Auch bei einer anderen Frage, die auf Zuwanderungsängste abzielt, sind Ressentiments in der Gruppe ohne Migrationshintergrund weiter verbreitet. $52 \%$ geben an, mit Menschen aus ihrem eigenen Herkunftsland weniger Probleme zu haben als mit anderen. Mit $42 \%$ etwas weniger weit verbreitet ist dieser Eindruck unter jungen Erwachsenen mit muslimischem Familienhintergrund. Serbisch und Kroatisch sprechende Befragte antworten hier in der Tendenz ähnlich wie ihre ausschließlich Deutsch sprechenden MitschülerInnen. 


\begin{tabular}{|c|c|c|c|c|c|}
\hline $\begin{array}{l}\text { Items Gruppenbezogene Menschenfeindlichkeit: } \\
\text { ausschließlich deutschsprachige Lehrlinge ohne } \\
\text { Migrationshintergrund (a), Lehrlinge mit muslimisch } \\
\text { geprägtem Familienhintergrund } \quad \text { (b) und Lehrlinge mit } \\
\text { kroatischem bzw. serbischem Familienhintergrund } \\
\text { Vergleich }\end{array}$ & & ++ & + & - & -- \\
\hline \multirow{3}{*}{$\begin{array}{l}\text { Meine beruflichen Chancen sinken durch steigende } \\
\text { Zuwanderung. }\end{array}$} & (a) & 28 & 23 & 26 & 19 \\
\hline & (b) & 18 & 29 & 23 & 23 \\
\hline & (c) & 26 & 22 & 21 & 15 \\
\hline \multirow{3}{*}{$\begin{array}{l}\text { ZuwandererInnen sind im Allgemeinen gut für die } \\
\text { österreichische Wirtschaft. }\end{array}$} & (a) & 7 & 19 & 28 & 37 \\
\hline & (b) & 18 & 30 & 29 & 15 \\
\hline & (c) & 5 & 23 & 34 & 25 \\
\hline \multirow{3}{*}{$\begin{array}{l}\text { Mit Menschen aus meinem eigenen Herkunftsland habe ich } \\
\text { weniger Probleme als mit anderen. }\end{array}$} & (a) & 32 & 20 & 19 & 19 \\
\hline & (b) & 17 & 25 & 21 & 31 \\
\hline & (c) & 27 & 22 & 23 & 18 \\
\hline \multirow{3}{*}{ Juden haben in Österreich zu viel Einfluss. } & (a) & 10 & 6 & 23 & 43 \\
\hline & (b) & 28 & 18 & 17 & 21 \\
\hline & (c) & 24 & 16 & 17 & 25 \\
\hline \multirow{3}{*}{$\begin{array}{l}\text { Muslime sollten das Recht haben eigene Organisationen zu } \\
\text { gründen, um ihre Kultur zu fördern, solange sie sich an die } \\
\text { Gesetze halten. }\end{array}$} & (a) & 17 & 21 & 18 & 38 \\
\hline & (b) & 66 & 10 & 10 & 12 \\
\hline & (c) & 16 & 28 & 15 & 33 \\
\hline \multirow{3}{*}{$\begin{array}{l}\text { Frauen sollten deutlich häufiger Führungspositionen } \\
\text { übernehmen. }\end{array}$} & (a) & 32 & 33 & 15 & 8 \\
\hline & (b) & 23 & 25 & 20 & 19 \\
\hline & (c) & 24 & 19 & 27 & 17 \\
\hline
\end{tabular}

Während Ängste vor (weiterer) Zuwanderung unter BerufsschülerInnen mit muslimischem Hintergrund tendenziell weniger stark ausgeprägt sind, finden sexistische und antisemitische Vorbehalte anscheinend weitaus größeren Anklang. Rund zwei Drittel (65\%) der Befragten ohne Migrationshintergrund befürworten das Voranschreiten der beruflichen Gleichstellung von Männern und Frauen. In der Gruppe mit muslimischem Familienhintergrund findet sich dafür keine Mehrheit. Nur $48 \%$ stimmen der Aussage zu, dass Frauen deutlich häufiger Führungspositionen übernehmen sollten. Als besorgniserregend muss auch das Antwortverhalten bei einem Item bezeichnet werden, das auf antisemitische Vorurteile abzielt. Der Aussage, dass Juden in Österreich zu viel 
Einfluss haben, stimmen $16 \%$ der BerufsschülerInnen ohne Migrationshintergrund zu. In der Gruppe mit muslimischem Familienhintergrund vertritt nahezu die Hälfte (46\%), die Meinung, dass der Einfluss der Juden in Österreich zu groß ist. Dabei bejahten $28 \%$ die Aussage sehr stark und $17 \%$ eher. Weitere $17 \%$ haben keine Antwort abgegeben. Aber ist der muslimisch geprägte Familienhintergrund hier wirklich entscheidend? Die an Wiener Berufsschulen erhobenen Daten sprechen eher gegen diese These. Kroatisch bzw. Serbisch sprechende Jugendliche stehen der beruflichen Gleichstellung von Mann und Frau am skeptischsten gegenüber. Nur $43 \%$ finden, dass Frauen häufiger Führungspositionen übernehmen sollen. Außerdem stimmen auch in dieser Gruppe $40 \%$ dem antisemitischen Klischee zu, dass Juden in Österreich zu viel Einfluss haben. Die Daten legen nahe, dass Antisemitismus unter muslimischen Jugendlichen in Österreich ein Problem ist, dem größere Aufmerksamkeit gewidmet werden sollte. Allerdings scheint das Problem auch in Familien, in denen Kroatisch bzw. Serbisch gesprochen wird, ähnlich groß zu sein. Dieser Befund ist ein deutlicher Auftrag für die Politische Bildung in Berufsschulen. Das folgende Kapitel widmet sich der Frage, wie Gruppenbezogener Menschenfeindlichkeit im Allgemeinen und Antisemitismus im Speziellen im schulischen Kontext nachhaltig begegnet werden kann. Konventionelle, auf homogene Lerngruppen ausgerichtete und primär an der österreichischen Geschichte orientierte Vermittlungsansätze stoßen hier an ihre Grenzen.

Ohne die grundlegende Bedeutung der Auseinandersetzung mit der Geschichte des Antisemitismus und dem Holocaust als wichtige Aufgabe der Schule infrage zu stellen, liegt der Fokus in diesem Beitrag auf der Einbeziehung lebensweltlich orientierter Erfahrungen. Der im folgenden Abschnitt entwickelte Ansatz findet seinen Ausgangspunkt für das Lernen gegen Antisemitismus und andere Differenzkonstruktionen in der Schilderung und wechselseitigen Anerkennung von (durchaus sehr unterschiedlichen) Ausgrenzungserfahrungen, mit denen Jugendliche in ihrem Alltag konfrontiert sind.

\section{Diskussion der Ergebnisse und Ableitungen für die Praxis Politischer Bildung an Berufsschulen}

Das Ausmaß antisemitischer Einstellungen unter Jugendlichen mit Migrationshintergrund muss zunächst als Problem wahrgenommen werden, um pädagogische Strategien bzw. entsprechende Bildungsangebote entwickeln zu können. Für deren Aussicht auf Erfolg sind bereits die Beschreibung sowie die Kontextualisierung des Problems entscheidend. Abstand zu nehmen ist von einer Betrachtung, die geeignet ist, wiederum ausgrenzende Stereotype - im aktuellen Diskurs insbesondere gegen MuslimInnen - zu reproduzieren. Das liefe nicht nur den Prinzipien einer an demokratischen Werten orientierten Politischen Bildung entgegen, sondern wäre darüber 
hinaus aus zwei Gründen falsch. Erstens ist Antisemitismus auch in der Mehrheitsgesellschaft verwurzelt. Jeder fünfte Jugendliche ohne Migrationshintergrund (19\%) stimmt der Aussage zu, dass Juden in Österreich zu viel Einfluss haben. Wie groß der Einfluss einer gesellschaftlichen Ächtung von offenem Antisemitismus in Österreich ist, kann nicht beziffert werden und eine moralische Empörung über offenen Antisemitismus schließt latenten keineswegs aus. Zweitens ist es aus mehreren Gründen erforderlich, Antisemitismus im Zusammenhang mit anderen Formen Gruppenbezogener Menschenfeindlichkeit zu betrachten. Einerseits ist Antisemitismus gerade als „dynamisches Phänomen“42 zentral für ausgrenzende und Fremdgruppen abwertende Identitätskonstruktionen. Antisemitismus zeigt sich anschlussfähig zu verschiedenen Einstellungsmerkmalen und Weltanschauungen. Er erfüllt dabei immer die Funktion, ein auf nebulose Rechtfertigungen gestütztes Feindbild zu konstruieren und bleibt dabei als „Gerücht über die Juden“43 von Erfahrungen weitestgehend unabhängig. Andererseits würde in der Berufsschule ein ausschließlicher Fokus auf antisemitische Einstellungen von Jugendlichen mit Migrationshintergrund dem Umstand nicht gerecht, dass für Jugendliche ohne Migrationshintergrund augenscheinlich Islam- und Fremdenfeindlichkeit eine deutlich größere Rolle für ausgrenzende Identitätskonstruktionen haben.

Ein spezifisch auf MigrantInnen ausgerichtetes Bildungsangebot gegen Antisemitismus ließe sich in der Schule schon aufgrund heterogener Klassenzusammensetzungen nicht realisieren und dennoch bzw. gerade deshalb zeigt sich vor dem Hintergrund des komplexen Verhältnisses zwischen Antisemitismus und anderen Differenzkonstruktionen die Notwendigkeit, verschiedene Diskriminierungserfahrungen sowie Ausgrenzungsmuster in pädagogische Bemühungen gegen Antisemitismus einzubeziehen.

Antisemitismusprävention kann sich - insbesondere unter den spezifischen Bedingungen in der Berufsschule im Hinblick auf den fachlichen Rahmen und die zur Verfügung stehende Unterrichtszeit - nicht in einer gezielten, historisch fundierten Auseinandersetzung entfalten. Der Lehrplan für den Pflichtgegenstand Politische Bildung ist in die drei Kompetenzbereiche „Lernen und Arbeiten“, „Leben in der Gesellschaft" und „Mitgestalten in der Gesellschaft“ gegliedert. (BGBl. II Nr. 211/2016) Vielmehr muss demnach jeglichen Differenzkonstruktionen ein grundlegendes Demokratie- und Politikverständnis entgegengestellt werden, das dem Ziel der politischen Mündigkeit förderlich ist und an die Lebenswelt der Jugendlichen anknüpft. Das für die schulische Politische Bildung zentrale Kompetenz-Strukturmodell versteht politische Mündigkeit als Maßstab für die Ausformung von politischen Kompetenzen. Ebenso verlangt es, die „Berücksichtigung der Erfahrungs- und Lebenswelt der SchülerInnen [...] insofern als vorrangig anzusehen, als dadurch die Relevanz politischen

${ }^{42}$ Konitzer, Moral, S. 33.

43 Theodor W. Adorno, Minima Moralia, Frankfurt a. M. 2001, S. 200. 
Lernens für die Lernenden gesichert wird“. 44 Auf Grundlage der in Kapitel vier und fünf beschriebenen Daten wird deutlich, dass die Forderungen nach Disziplin und Gehorsam und nach Härte gegenüber UnruhestifterInnen sowohl für die Gruppe der BerufsschülerInnen als auch für die Gruppe der PH-Studierenden ein verlässlicher Prädiktor für das Ausmaß Gruppenbezogener Menschenfeindlichkeit ist. Mit Adorno ist autoritären Denkmustern einzig Mündigkeit entgegenzusetzen, „die darin besteht [...], daß die Erziehung eine Erziehung zum Widerspruch und zum Widerstand ist“ “. 45 „Lernen wegen Antisemitismus" (und ebenso wegen anderer antidemokratischer, auf Ab- und Ausgrenzung beruhender, Differenzkonstruktionen) verlangt nach einer kritischen Politischen Bildung, die sich parteilich am Demokratiepostulat orientiert, und dabei nicht nur die Möglichkeit zur Wahlbeteiligung, sondern darüber hinaus die Möglichkeit zur Teilhabe an gesellschaftlichen Auseinandersetzungen zum Ziel hat. ${ }^{46}$ Die zunehmende Bedeutung einer diffusen gesellschaftlichen Unzufriedenheit, die den vermeintlichen Wunsch nach Veränderung ebenso wie die Verteidigung althergebrachter Konventionen miteinschließt, verdeutlicht den Stellenwert von Kritik für die Demokratie. Wer nicht in der Lage ist, kritische Perspektiven gegenüber Autoritäten einzunehmen, Kritik zu formulieren und an AdressatInnen zu richten, kann empfundene Unzufriedenheit bzw. Strategien zum Umgang damit nur an Autoritäten delegieren bzw. geeignete Sündenböcke suchen.

Da auch Politische Bildung an der Berufsschule im Rahmen der Berufsausbildung im Dualen System stattfindet, stehen von Seiten der Lehrlinge Erwartungen im Hinblick auf das Arbeitsleben im Vordergrund und die Identität als Lehrling ist zentral für die Lebenswelt der BerufsschülerInnen. Der Arbeitsalltag ist von hierarchischen Verhältnissen geprägt und bietet in der Regel keine Gelegenheit zum kritischen Hinterfragen von Autoritäten. Zwar ist auch die Schule ohne Zweifel ein grundsätzlich autoritäres System, doch zu den Aufgaben der Schule zählt nicht nur die Heranbildung von jungen Menschen zu ,arbeitstüchtigen, pflichttreuen und verantwortungsbewussten Gliedern der Gesellschaft", sondern auch die Befähigung zur politischen und weltanschaulichen Aufgeschlossenheit sowie zum selbstständigen Urteil und zum sozialen Verständnis. ${ }^{47}$ Wenn Sekundärtugenden wie Fleiß und Pflichttreue die politische Mündigkeit nicht einschränken sollen, muss auch der kritischen Reflexion von Macht, Hierarchien und Diskriminierung ein Stellwert eingeräumt werden. Im Hinblick auf Diversity-Konzepte, die nicht zuletzt vor dem Hintergrund einer Migrationsgesellschaft für ein diskriminierungsfreies Miteinander stehen, unterscheidet Albert Scherr zwischen

${ }^{44}$ Reinhard Krammer, Die durch politische Bildung zu erwerbenden Kompetenzen. Ein Kompetenz-Strukturmodell, Wien 2008.

45 Adorno, Erziehung, S. 145.

${ }^{46}$ Frank Nonnenmacher, Analyse, Kritik und Engagement. Möglichkeiten und Grenzen schulischen Politikunterrichts, in: Bettina Lösch/Andreas Thimmel (Hrsg.), Kritische Politische Bildung, Ein Handbuch, Bonn 2011, S. 459-470, hier S. 465.

${ }^{47}$ Schulorganisationsgesetz, \2, Aufgabe der österreichischen Schule, BGBl. 242/1962. 
solchen Konzepten, „, die allein Unterschiede in den Blick nehmen und jenen, die Vielfalt im Zusammenhang mit Macht- und Herrschaftsverhältnissen [...] thematisieren “. ${ }^{48}$ Während in der Politischen Bildung an Berufsschulen die Aufklärung über Rechte und Pflichten von Lehrlingen zu den thematischen Säulen des Unterrichts zählt, fehlen vielfach kritische Perspektiven auf die „Fragestellung [...], wodurch Herrschaft und Autorität von der Gesellschaft als rechtmäßig anerkannt werden. “49 Der Zusammenhang zwischen Herkunft, Geschlecht und sozialökonomischem Status sowie von Stereotypen, Vorurteilen und Diskriminierung ist hier vor dem Hintergrund der lebensweltlichen Bezüge der Lehrlinge in den Mittelpunkt zu stellen. Eine auf ein kritisches Demokratieverständnis und eine Stärkung der politischen Mündigkeit ausgerichtete Politische Bildung, die an die Lebenswelt der Jugendlichen anknüpft und demokratische Teilhabe fördert, erscheint als zielführendste Strategie gegen Antisemitismus wie auch Islamfeindlichkeit, Sexismus oder andere Formen Gruppenbezogener Menschenfeindlichkeit.

Ansätzen, die dabei Antisemitismus und z. B. Islamfeindlichkeit als austauschbare Phänomene gleichsetzen oder Islamfeindlichkeit als den neuen Antisemitismus darstellen, werden dem Verhältnis von eigenen antimuslimischen Diskriminierungserfahrungen und Antisemitismus von MuslimInnen nicht gerecht. ${ }^{50}$ Trotzdem muss herausgearbeitet werden, dass Differenzkonstruktionen sowohl bei Islamfeindlichkeit als auch bei Antisemitismus eine zentrale Rolle zukommt. Als Konstrukte, die auf Fremdzuschreibungen aufbauen, ermöglichen sie die Aufwertung der Eigengruppe (,Wir") durch die Abwertung der Fremdgruppe. Vor dem Hintergrund eigener Diskriminierungserfahrungen von MuslimInnen als Minderheiten in der Migrationsgesellschaft dient der Antisemitismus der „Verschiebung des Gegners, der dann nicht die Mehrheitsgesellschaft ist, sondert etwas Drittes, etwas, das von zwei Seiten als fremd markiert wird, von der Seite der Dominanzgesellschaft wie von ihren Minderheiten“ .51 Im Hinblick auf die Vorerfahrungen und Voreinstellungen der SchülerInnen ist aus pädagogischer Perspektive von generalisierenden Vorstellungen von Antisemitismus bzw. AntisemitInnen Abstand zu nehmen. Gerade das Thema des „migrantischen Antisemitismus"52 birgt eine Gefahr. Eine solche Wahrnehmung schränkt den Handlungsspielraum ein, weil sie Stereotype reproduziert. ${ }^{53}$ Das gilt insbesondere, wenn

48 Albert Scherr, Diversity im Kontext von Machtbeziehungen und sozialen Ungleichheiten, in: GPJE (Hrsg.), Diversity Studies und politische Bildung, Schwalbach/Ts. 2008, S. 53-64, hier S. 57.

${ }^{49}$ Unterrichtsprinzip Politische Bildung, Grundsatzerlass 2015, 22.6.2015. Bundesministerium für Bildung und Frauen, [https://www.bmb.gv.at/ministerium/rs/2015_12.pdf?61edq7], eingesehen 25.10.2017.

50 Thomas Schmidinger, Antisemitismus und Islamophobie. Einige Neuerscheinungen zum Vergleich von Antisemitismus und antimuslimischen Ressentiments, in: Österreichische Zeitschrift für Geschichtswissenschaften 22 (2011), Heft 3, S. 153-165.

${ }^{51}$ Astrid Messerschmidt, Bildungsarbeit in der Auseinandersetzung mit gegenwärtigem Antisemitismus, in: Aus Politik und Zeitgeschichte 64 (2014), Heft 28-30, S. 38-44, hier S. 42.

52 Wolfram Stender, Der Antisemitismusverdacht. Zur Diskussion über einen „migrantischen Antisemitismus“ in Deutschland, in: Migration und Schule 30 (2008), Heft 3-4, S. 284-291.

53 Heike Radvan, Pädagogisches Handeln und Antisemitismus. Eine empirische Studie zur Beobachtungs- und 
PädagogInnen ohne Migrationshintergrund mit Jugendlichen mit Migrationshintergrund arbeiten. Im Unterschied zu antirassistischen Bildungsangeboten kommen MigrantInnen im Zusammenhang mit Antisemitismus nicht als Objekte der Abwertung, sondern als „Subjekte von Diskriminierung und Ausgrenzung“54 in den Blick. Die eigenen Ausgrenzungserfahrungen können allerdings in Verbindung mit einem Perspektivenwechsel zum Ansatzpunkt für Lernprozesse gegen Antisemitismus werden. In der Praxis der Politischen Bildung an Berufsschulen werden in verschiedensten Situationen und thematischen Zusammenhängen immer wieder latente oder offene antisemitische Einstellungen - von Jugendlichen mit und ohne Migrationshintergrund geäußert, die ein „Lernen gegen Antisemitismus“ im Sinne einer Intervention und Prävention notwendig machen. ${ }^{55}$ SchülerInnen müssen dabei in die Lage versetzt werden, über ihre - bloß subjektiv empfundenen oder auch intersubjektiv nachvollziehbaren - Ausgrenzungserfahrungen zu reflektieren. ${ }^{56}$ Wenn beispielsweise geäußert wird, dass „Juden“ zu viel Einfluss hätten, sind dazu zunächst Fragen aufzuwerfen: Wer ist konkret gemeint bzw. was haben "Juden“ in diesem Zusammenhang gemeinsam? Wer hat welchen Einfluss worauf und wie ist dieser Einfluss legitimiert? Worauf habe ich welchen Einfluss und welchen Einfluss hätte ich gerne bzw. sollte ich haben? Dieses Nachfragen dient dazu, die Deutungsmuster und den Orientierungsrahmen der Jugendlichen zu erschließen. Seitens der PädagogInnen ist für diese Auseinandersetzung mit den Deutungsmustern von SchülerInnen eine rekonstruktive Erkenntnishaltung gefordert, die von stereotypisierenden Zuschreibungen und moralischen Verurteilungen Abstand nimmt. Pädagoginnen müssen distanziert beobachten und dabei zugleich den Jugendlichen die in der pädagogischen Arbeit stets nötige persönliche Anerkennung, sowie ein grundlegendes Verständnisinteresse für ihre Perspektive entgegenbringen, ohne dabei antisemitischen Einstellungen bzw. Deutungen selbst Verständnis oder gar Akzeptanz entgegen zu bringen. ${ }^{57}$ So kann vor diesem Hintergrund beispielsweise ein kritischer Diskurs die Bedeutung von Demokratie als Herrschafts-, Gesellschafts- und Lebensform eröffnet werden. Als Herrschaftsform in einem Staat setzt Demokratie freie Wahlen, rechtsstaatliche Ordnung und ein Bekenntnis zu Menschrechten voraus. Demokratie als Gesellschaftsform baut auf Pluralismus, konstruktiver Konfliktregelung und einer handlungsfähigen Zivilgesellschaft. Als Lebensform verlangt Demokratie auch von jedem und jeder Einzelnen ein gewisses Maß an Toleranz, Solidarität und nicht zuletzt

Interventionsformen in der offenen Jugendarbeit, Bad Heilbrunn 2010.

${ }_{54}$ Messerschmidt, Bildungsarbeit, S. 42.

55 Szigetvari, Gerüchte, S. 9-10.

56 Schäuble, Anders, S. 427.

57 Heike Radvan, Zum Zusammenhang von Ethnisierungen und antisemitischen Konstruktionen in Beobachtungshaltungen heutiger Jugendpädagog/innen, in: Richard Gebhart/Anne Klein/Marcus Meier (Hrsg.), Antisemitismus in der Einwanderungsgesellschaft. Beiträge zur kritischen Bildungsarbeit, Weinheim-Basel, S. 144161. 
die grundsätzliche Bereitschaft zur demokratischen Teilhabe. ${ }^{58}$ Ein solcher, am Verständnis von Jugendlichen orientierter, Diskurs auf der Grundlage lebensweltlicher Erfahrungen hat das Potential, implizites Wissen zugänglich zu machen, auf Aus- und Abgrenzung beruhende Deutungsmuster zu dekonstruieren und Alternativen zu erschließen. ${ }^{59}$ Eine Belehrung durch die Vermittlung von richtigem Wissen bzw. moralisch angemessenen Perspektiven kann sich schnell als kontraproduktiv erweisen und auf eine Überwältigung hinauslaufen, die dem Schüler bzw. der Schülerin die Möglichkeit nimmt, sich ein eigenständiges Urteil zu bilden.

Bildungsarbeit ist „kein Allheilmittel gegen Antisemitismus.“60 Insbesondere subjektorientierte Bildungsangebote können niemandem aufgezwungen werden und sind deshalb auf leichte Zugänglichkeit und Attraktivität angewiesen. Die Auseinandersetzung mit Antisemitismus bei SchülerInnen mit Migrationshintergrund stellt im Hinblick auf die oben beschriebene Ausrichtung subjektorientierter Bildung hohe Anforderungen an LehrerInnen. Insbesondere dann, wenn sie häufig selbst keinen Migrationshintergrund haben. Potenzielle Probleme liegen dabei insbesondere in kulturalisierenden Zuschreibungen, die Differenzkonstruktionen zwischen der Dominanzgesellschaft als „Wir-Gruppe“ und Minderheiten reproduzieren. Bezüge zu lebensweltlichen Erfahrungen von Jugendlichen herzustellen, ist für LehrerInnen schon an sich eine Herausforderung. Im Fall von Jugendlichen mit Migrationshintergrund kommt gerade im Zusammenhang mit Antisemitismus der Einbeziehung der selbsterfahrenen rassistischen Diskriminierung eine zentrale Bedeutung zu. Lehrlinge ohne Migrationshintergrund sind zwar in den meisten Fällen nicht unmittelbar von Rassismus betroffen, aber auch ihren Perspektiven auf beispielsweise als diskriminierend empfundene Ausgrenzung von politischen Prozessen sind hier relevant.

\section{Schlussbemerkungen}

Sozialwissenschaftliche Studien haben den Anspruch dabei zu helfen, gesellschaftlich relevante Probleme genauer zu beschreiben und zu lokalisieren. Gleichzeitig besteht die Gefahr, dass statistische Aussagen wie die, dass z. B. Antisemitismus in bestimmten Bevölkerungsgruppen häufiger auftritt als in anderen, wiederum Nährboden für undifferenzierte, negativierenden Gruppenzuschreibungen werden. Umschreiben wir eine Gruppe und definieren diese als Risiko, dann verschwinden oftmals die

58 Gerhard Himmelmann, Demokratie Lernen. Als Lebens-, Gesellschafts- und Herrschaftsform, Ein Lehr- und Arbeitsbuch, Schwalbach/Ts. 2016.

59 Schäuble, Anders, S. 425

${ }^{60}$ Albert Scherr, Aufgabenstellungen, Möglichkeiten und Grenzen der Bildungsarbeit gegen Antisemitismus in der Einwanderungsgesellschaft, in: Richard Gebhart/Anne Klein/Marcus Meier (Hrsg.), Antisemitismus in der Einwanderungsgesellschaft. Beiträge zur kritischen Bildungsarbeit, Weinheim-Basel, S. 15-28, hier S. 26. 
Eigenschaften, welche die betroffenen Menschen sonst auszeichnen. Als Sicherheitsmaßnahme droht Exklusion. ${ }^{61}$

Die zentrale Frage in diesem Beitrag war, ob sich Jugendliche mit migrantisch geprägtem familiären Hintergrund in ihren Haltungen zu Demokratie und Gruppenbezogener Menschenfeindlichkeit unterscheiden. Zudem wurde der Frage nachgegangen, ob BerufsschülerInnen mit muslimisch geprägtem Familienhintergrund stärker zu bestimmten Formen Gruppenbezogener Menschenfeindlichkeit (z. B. Antisemitismus) neigen als ihre MitschülerInnen. Zu guter Letzt sollte geklärt werden, wie im schulischen Kontext mit identifizierten Gruppenunterschieden pädagogisch und didaktisch adäquat umgegangen werden kann.

Es ist festzustellen, dass autoritaristische Potentiale unter Lehrlingen stärker ausgeprägt sind als in der Vergleichsgruppe von Wiener Lehramtsstudierenden. BerufsschülerInnen aus muslimisch geprägten Familien unterscheiden sich von ihren MitschülerInnen in Bezug auf Haltungen zu Demokratie und autoritaristischen Einstellungen nicht systematisch. Bei der Ablehnung von Menschen aufgrund gruppenspezifischer Zuschreibungen unterscheidet sich jedoch das Antwortverhalten muslimischer BerufsschülerInnen von demjenigen der Gruppe ohne Migrationshintergrund. Zweitere stehen Zuwanderung insgesamt und muslimischer Zuwanderung im Speziellen eher ablehnend gegenüber. Erstere sind tendenziell reservierter gegenüber beruflicher Gleichstellung von Mann und Frau. Außerdem positionieren sie sich deutlich seltener gegen antisemitische Stereotype. BerufsschülerInnen mit muslimisch geprägtem Familienhintergrund unterscheiden sich allerdings in ihrem Antwortverhalten in diesem Bereich nicht maßgeblich von ihren ausschließlich deutschsprachigen KollegInnen ohne Migrationshintergrund. Jugendliche, die in ihrem Alltag selbst Vorurteilen ausgesetzt sind und Erfahrung mit Diskriminierung machen, sind anscheinend ihrerseits anfälliger für antisemitische Botschaften. Insbesondere dort wo eine soziale Grammatik der Härte auf Strukturen trifft, die strikte Ein- und Unterordnung verlangen und sich mit einer strikten Logik des „Wir“ und „Die“ überlappt, ist der Nährboden für unterschiedliche Arten von Rassismen, Sexismus und Antisemitismus bereitet.

Jede Form von Antisemitismus ist ein Problem für ein demokratisches Zusammenleben und kann deshalb nicht hingenommen werden. Ein betont moralischer Zugang zum Lerngegenstand Antisemitismus erscheint allerdings wenig erfolgsversprechend. Um Vorurteile - die zweifelsfrei vorhanden sind - bearbeitbar zu machen, müssen sie auch zur Sprache gebracht werden können. Auch ausschließlich historische Zugänge greifen zu kurz. Die Geschichte von Ausgrenzungen zu thematisieren, bleibt eine wichtige Aufgabe. Dies gilt natürlich insbesondere für die Geschichte des Antisemitismus und des Holocaust in Österreich und Deutschland. Nichtsdestotrotz sollten gegen Antisemitismus gerichtete Lernprozesse in einem schülerInnenorientierten Unterricht die lebensweltlichen Erfahrungen von Jugendlichen aufnehmen und zum Thema

${ }^{61}$ Ulrich Beck, Weltrisikogesellschaft, Frankfurt a. M. 2007, S. 334. 
machen. Dies gilt vor allem für die österreichische Berufsschule, wo historisches Lernen kein eigenständiger Teil des Unterrichtsfaches Politische Bildung ist.

Der hier vorgestellte Ansatz findet seinen Ausgangspunkt für das Lernen gegen Antisemitismus, Fremdenfeindlichkeit und Sexismus in der Schilderung und wechselseitigen Anerkennung von (durchaus unterschiedlichen) Ausgrenzungserfahrungen, mit denen Jugendliche in ihrem Alltag konfrontiert sind. Politische Bildung sollte dazu beitragen, reflektierte Ordnungs- und Deutungsmuster an die Stelle von ausschließenden Differenzkonstruktionen („Wir“ sind so und „die“ sind so!) treten zu lassen. Es geht um die Kritik von Verhältnissen, die durch systematisch versagte Anerkennung die menschliche Würde verletzen. ${ }^{62}$ Dies sollte geschehen, indem nahe an der Lebenswelt von jungen Menschen mit ihren jeweiligen Ausgrenzungserfahrungen gearbeitet wird. Was wir bei aller Unterschiedlichkeit gemeinsam haben, sind unsere individuellen und gesellschaftlichen Verletzungen, mit denen wir umgehen lernen müssen. Aus pädagogischer Sicht ist es wichtig, Räume zu eröffnen, in denen die Anerkennung verschiedener Diskriminierungserfahrungen möglich wird und Vorurteile abgebaut werden können.

${ }^{62} \mathrm{Vgl}$. Axel Honneth, Verdinglichung. Eine anerkennungstheoretische Studie, Frankfurt a. M. 2005, S. $46 \mathrm{ff}$. 



\title{
Nach der Erziehung zur Mündigkeit. Anmerkungen zu Antisemitismus und Pädagogik
}

\author{
Michael Fischer
}

An einem spätherbstlichen Abend im November 2017 riefen einige hundert Menschen wütende Parolen in Richtung der US-Botschaft in Wien. Mitgebracht hatten die Demonstranten neben Palästina- und Türkeifahnen auch den Hass auf den israelischen Staat. Anlass für die Versammlung war die angekündigte Verlegung der US-Botschaft in Israel von Tel Aviv nach Jerusalem. ${ }^{1}$ An der Lage der Menschen in Israel und Palästina änderte diese symbolische Aktion der Vereinigten Staaten, die inzwischen rechtlich umgesetzt wurde, de facto rein gar nichts. Jerusalem war ohnedies bereits die israelische Hauptstadt, auch wenn die meisten arabischen und islamischen Staaten diese Tatsache, wie auch insgesamt die Existenz eines souveränen jüdischen Staates nicht anerkennen wollen. Der türkische Präsident Tayyip Recep Erdogan ergriff Ende 2017 dennoch die Chance und setzte sich rhetorisch an die Spitze einer Bewegung empörter Muslime. Niemals werde er die Entscheidung der USA anerkennen, verlautete Erdogan. Mit ihr habe Donald Trump Jerusalem zum Kerker für Muslime und andere Religionen gemacht. Der Kampf der Muslime werde erst enden, wenn ein palästinensischer Staat errichtet sei, so Erdogan. ${ }^{2}$

In Erdogans Rede und den Botschaften der antiisraelischen Demonstranten bricht sich ein irrationaler Erlösungsglaube Bahn, der in Israel das alleinige Hindernis für den Weltfrieden zu erkennen glaubt. Friede auf der gesamten Welt gibt es in diesem teleologischen Weltbild erst dann, wenn ein eigener palästinensischer Staat gegründet worden ist: ein großpalästinensischer Staat - nicht neben, sondern anstelle des israelischen versteht sich -, ein Staat, in dem Juden bestenfalls noch als Minderheit geduldet würden. Die bestehenden Probleme der islamischen Welt, wie unzählige interne und externe bewaffnete Konflikte, Bürgerkrieg, islamischer Radikalismus, wirtschaftliche und gesellschaftliche Stagnation würden selbstverständlich auch nach Errichtung eines solchen Staates weiterbestehen, doch die Frage um den Status von Jerusalem scheint offensichtlich mehr Menschen zu bewegen, als die Lösung solch weltlicher und ganz realer Probleme. Statt über die Fehler und Probleme der eigenen Gesellschaft zu reflektieren, erkennt man in Israel den Schuldigen.

\footnotetext{
${ }^{1}$ Die Botschaft wurde inzwischen offiziell nach Jerusalem verlegt. De facto wurde dazu das dortige Generalkonsulat umbenannt, während die meisten Einrichtungen der Botschaft nach wie vor in Tel Aviv sind. Siehe auch U.S. Embassy in Israel, o. D., [https://il.usembassy.gov/], eingesehen 1.6.2020.

${ }^{2}$ Jerusalem-Streit, Erdogan gibt USA Mitschuld an Gewalt, in: Die Zeit, 11.12.2017,

[http://www.zeit.de/politik/ausland/2017-12/jerusalem-streit-recep-tayyip-erdogan-israel-usa], eingesehen 1.6.2020.
} 
Man kennt diese Reaktion aus der Geschichte des Antisemitismus. Für Theodor W. Adorno und Max Horkheimer beruht der Antisemitismus auf falscher Projektion: Regungen in einem selbst, die nicht als die eigenen akzeptiert werden können, werden jemand anderem zugeschrieben; dem, der nun zum Opfer wird. ${ }^{3}$ Das Subjekt verliert die Fähigkeit zur Reflexion in zwei Richtungen: „,[...] da es nicht mehr den Gegenstand reflektiert, reflektiert es nicht mehr auf sich und verliert so die Fähigkeit zur Differenz. Anstatt der Stimme des Gewissens hört es Stimmen; anstatt in sich zu gehen, um das Protokoll der eigenen Machtgier aufzunehmen, schreibt er die Protokolle der Weisen von Zion den anderen zu. "“4

Anhand Erdogans Rede und der Rhetorik seiner Sympathisanten in Wien, die vor der US-Botschaft demonstrierten, lässt sich dieses simple Projektionsmuster nachzeichnen: Israel wird vorgeworfen, an einem Großreich zu arbeiten, dabei hängen der türkische Präsident und viele seiner Anhänger selbst dem Traum einer imperialistischen neoosmanischen Ideologie an. ${ }^{5}$ Man wirft Israel „Kindermord“ vor, während die türkische Armee Kriegsverbrechen begeht und kurdische Dörfer bombardiert. ${ }^{6}$

Nicht nur in Israel werden Juden immer wieder Opfer der islamischen „Israel-Kritik“, die sich dort regelmäßig wiederkehrend in Messer- oder Bombenattentaten äußert. Auch in Schweden wurde die sogenannte „Kritik“ im Dezember 2017 praktisch: Jugendliche warfen Brandsätze auf eine Synagoge in Göteborg. ${ }^{7}$ Auch hier wurden in den Medien Zusammenhänge mit den Protesten gegen die Botschaftsverlegung der USA thematisiert, die in den Tagen zuvor in vielen schwedischen Städten abgehalten worden waren. In Malmö hatte sich diese „Kritik“ an der Botschaftsverlegung in antisemitischen Parolen geäußert, wie die Tageszeitung Die Welt berichtete. ${ }^{8}$

Zur Rechtfertigung derartiger Hass- und Gewalttaten werden die Juden und Israel als besonders mächtig imaginiert, um mit gutem Gewissen zuschlagen zu können. Das Opfer wird zum Täter umgedeutet: „Stets hat der blind Mordlustige im Opfer den Verfolger gesehen, von dem er verzweifelt sich zur Notwehr treiben ließ, und die mächtigsten Reiche haben den schwächsten Nachbarn als unerträgliche Bedrohung empfunden, ehe sie über ihn herfielen." In Wien blieb am eingangs beschriebenen Novemberabend alles ruhig, vermeldete die Polizei. Laut Zeugenaussagen skandierte die

\footnotetext{
${ }^{3}$ Max Horkheimer/Theodor W. Adorno, Dialektik der Aufklärung, in: Max Horkheimer, Gesammelte Schriften, Band 5. Dialektik der Aufklärung und Schriften 1940-1950, Frankfurt a. M. 2003, S. 217.

${ }^{4}$ Horkheimer/Adorno, Dialektik der Aufklärung, S. 219-220.

${ }_{5}^{5}$ Siehe bspw. Mustafa Türkeş, Decomposing Neo-Ottoman Hegemony, in: Journal of Balkan and Near Easter Studies 18 (2016), Heft 3, S. 191-216.

${ }^{6}$ Amnesty wirft Türkei Kriegsverbrechen vor, in: tagesschau.de, 18.10.2019, [https://www.tagesschau.de/ausland/amnesty-tuerkei-kriegsverbrechen-101.html], eingesehen 4.6.2020.

${ }^{7}$ Maskierte werfen Molotowcocktails auf Synagoge in Göteborg, in: Die Welt, 10.12.2017, [https://www.welt.de/politik/ausland/article171441557/Maskierte-werfen-Molotowcocktails-auf-Synagoge-inGoeteborg.html], eingesehen 11.12.2017.

8 Ebd.

${ }^{9}$ Horkheimer/Adorno, Dialektik der Aufklärung, S. 219-220.
} 
Menge jedoch „Schlachtet die Juden“. Es blieb der Wiener FPÖ überlassen, eine Anzeige bei der Staatsanwaltschaft einzubringen. ${ }^{10}$

Mit dieser hier skizzierten Konstellation ist auch schon ein Dilemma beschrieben, in dem sich all jene wiederfinden, die sowohl Fremdenfeindlichkeit als auch den Antisemitismus ablehnen. Weil die meist türkischen und arabischen Demonstranten in Wien selbst fremdenfeindlich diskriminiert werden, scheut man im linken oder progressiven Milieu vielfach vor der Kritik am islamischen Antisemitismus zurück. Das ist einerseits ein Schweigen aus taktischen Überlegungen, freilich sind andererseits Teile der Linken in Form der „Israel-Kritik“ ihrerseits dieser Spielart des Antisemitismus verfallen. ${ }^{11}$ Wie es sich im Einzelnen auch verhält: Die Kritik des islamischen Antisemitismus gilt als Thema, welches man in der Öffentlichkeit besser nicht anspricht. Oft besteht die Angst, der FPÖ bzw. der Rechten damit argumentative Munition zu liefern oder die latente Fremdenfeindlichkeit in der Gesellschaft zu befeuern. Dabei weiß in Österreich, nicht zuletzt durch mediale Berichterstattung, ${ }^{12}$ bereits jetzt schon fast jeder über die islamische Judenfeindschaft Bescheid und diese Thematisierung wird wohl kaum jemand zum Fremdenfeind machen, der es nicht schon davor war. Fremdenfeindlichkeit äußert sich schließlich nicht in der Einstellung zu Ideologien wie dem Islam oder im Grad der Ablehnung des islamischen Antisemitismus, sie äußert sich in einem biologistischen und essentialistischen Menschenbild. ${ }^{13}$ In diesem sind Menschen durch ihre Geburt an eine bestimmte Kultur gebunden. Für einen Fremdenfeind ist ein Muslim folglich von Geburt an Muslim und dieses Charakteristikum ist auch nicht veränderbar. Wer jedoch nicht von dieser Unveränderlichkeit der Menschen ausgeht, wer nicht davon ausgeht, dass die Kultur angeboren ist, hegt die Hoffnung, die Kritik könnte manche vom Antisemitismus abbringen. Die Kritik des islamischen Antisemitismus ist deshalb auch ein notwendiges Mittel, um das friedliche Zusammenleben der Menschen in Österreich zu garantieren.

\section{Antisemitismus bei muslimischen Jugendlichen}

In den letzten Jahren beschäftigten sich mehrere Studien in Österreich implizit oder explizit mit dem islamischen Antisemitismus. ${ }^{14}$ So wollten Georg Lauss und Stefan

10 Zeugen geschockt über „Schlachtet die Juden“-Ruf, in: Heute, 9.12.2017,

[http://www.heute.at/oesterreich/wien/story/Zeugen-geschockt-ueber--Schlachtet-die-Juden--Ruf-48060169], eingesehen 11.12.2017.

11 Zum linken Antisemitismus siehe David Hirsh, Contemporary Left Antisemitism, Abingdon-on-Thames 2017. Vergleiche auch den Beitrag von Daniel Rickenbacher zu links-islamistischen Allianzen in diesem Band.

12 Siehe bspw. Merkel räumt Problem des Antisemitismus unter Geflüchteten ein, in: Der Standard, 22.4.2018, [https://www.derstandard.at/story/2000078433573/merkel-raeumt-problem-des-antisemitismus-untergefluechteten-ein], eingesehen 1.6.2020.

13 Siehe bspw. Anti-Defamation League, Racism, [https://www.adl.org/racism], eingesehen 1.6.2020.

${ }^{14}$ Eine Überblicksstudie über die Situation in mehreren europäischen Ländern bietet: Günther Jikeli, European Muslim Antisemitism. Why Young Urban Males Say They Don't Like Jews, Bloomington 2015. 
Schmid-Heher in zwei Studien wissen, wie groß die Zustimmung zum demokratischen System unter Wiener Berufsschülern und Lehramtsstudenten ist. ${ }^{15}$ Von beiden Studien wurde bisher nur eine vollständig veröffentlicht. ${ }^{16}$ Zumindest in der Studie zu den Lehramtsstudenten finden sich einige diskussionswürdige Abschnitte.

Im Teilbereich „Politischer Autoritarismus“ wurden die Teilnehmer mit folgender Aussage konfrontiert: „Die Demokratie ist die beste Regierungsform, auch wenn sie Probleme mit sich bringen mag. " 17 Wer dies verneinte bzw. ablehnte, wurde in der Auswertung dem politischen Autoritarismus zugeschlagen. Selbst wenn mit der Ablehnung gemeint gewesen sein könnte - was als mögliche Antwort durchaus plausibel erscheint -, eine noch menschenfreundlichere Form des gesellschaftlichen Zusammenlebens sei denkmöglich. Für die Auswertung der Studie galt den Autoren allerdings nur die Affirmation der bestehenden Verhältnisse als progressiv. Im Sinne Adornos würde eine derartige Affirmation hingegen eher auf einen autoritären Charakter hinweisen. ${ }^{18}$ Auch die Zukunftsangst, die bei der aktuellen Weltlage vielmehr eine realistische Einschätzung der gesellschaftlichen Entwicklung ist, als eine unbegründete Angst, wird in dieser Studie letztlich zum Indikator für Autoritarismus. Zudem nimmt die Studie theoretisch Bezug auf Denktraditionen, die inhaltlich wenig gemeinsam haben und nicht einfach unwidersprochen nebeneinanderstehen können. Adorno und Karl Popper werden gleichzeitig bemüht, doch beide waren im Positivismusstreit der deutschen Soziologie nicht ohne Grund Widersacher. ${ }^{19}$

Die zweite Studie über die politischen und gesellschaftlichen Einstellungen der Berufsschüler in Wien ist noch unveröffentlicht. ${ }^{20}$ Einige Ergebnisse drangen durch einen Artikel der Tageszeitung Der Standard jedoch bereits 2017 an die Öffentlichkeit. Dieser titelte: „Starke antisemitische Vorurteile bei muslimischen Jugendlichen. “21 Eine Frage, die Lauss und Schmid-Heher den Probanden stellten, war, ob die Juden in Österreich zu viel Einfluss hätten. Dem stimmten $24 \%$ der Befragten zu. Ein nicht zu unterschätzend hoher Prozentsatz. Noch höher ist der Glaube an den zu großen Einfluss der Juden in Österreich bei Berufsschülern, die zuhause türkisch, bosnisch, albanisch

\footnotetext{
15 Vergleiche den Beitrag der Autoren in diesem Sammelband.

16 Georg Lauss/Stefan Schmid-Heher, Politische Bildung und demokratierelevante Einstellungsmuster von angehenden Lehrenden. Eine quantitative Studie, in: R\&E-SOURCE (2017), [https://journal.phnoe.ac.at/index.php/resource/article/view/350], eingesehen 11.12.2017, S. 5.

17 Ebd., S. 5.

18 Theodor W. Adorno u. a., The Authoritarian Personality, New York 1950.

19 Hans-Joachim Dahms, Der Positivismusstreit der 60er Jahre: eine merkwürdige Neuauflage, in: Jahrbuch für Soziologiegeschichte 1991, Opladen 1992, S. 119-182.

${ }^{20}$ Inzwischen ist ein Pre-Print über Research Gate abrufbar: Georg Lauss/Stefan Schmid-Heher, Politische Bildung an Wiener Berufsschulen: Demokratische und autoritäre Potentiale von Lehrlingen, Wien 2017 [https://www.researchgate.net/publication/324755324_Politische_Bildung_an_Wiener_Berufsschulen_Demokratis che_und_autoritare_Potentiale_von_Lehrlingen], eingesehen 1.6.2020.

21 András Szigetvari, Starke antisemitische Vorurteile bei muslimischen Jugendlichen, in: Der Standard, 17.6.2017, [https://www.derstandard.at/story/2000059359305/starke-antisemitischen-vorurteile-bei-muslimischenjugendlichen], eingesehen 1.6.2020.
} 
oder arabisch sprechen. Dort vertraten $48 \%$ der Befragten dieses Weltbild. Sehr subtil wurde hier von den beiden Studien-Autoren nicht nach dem Antisemitismus gefragt. ${ }^{22}$ Die Zustimmungsraten bei derartig offen antisemitischen Aussagen sind in der Regel gering. In der Mehrheitsgesellschaft ist ein solch offen vorgetragener Antisemitismus verpönt. Hier greift man stattdessen mit gutem Gewissen zur „Israel-Kritik“, beschimpft den jüdischen Staat pseudo-antifaschistisch als rassistisch und ruft zum Boykott israelischer Waren auf. ${ }^{23}$ Personen, die sich selbst als progressiv sehen, fasziniert von fremden Kulturen sind und einen Hang zu den beschriebenen antisemitischen Denkmustern aufweisen, werden diese Frage nach der Macht der Juden höchstwahrscheinlich negativ beantworten. $\mathrm{Zu}$ sehr klingt sie nach klassisch nationalsozialistischem Antisemitismus, der in der Regel abgelehnt wird. Umso verwunderlicher sind die $48 \%$ Zustimmung bei jenen Kindern, bei denen die Eltern auch eine andere Sprache als Deutsch sprechen. Auch bei ihnen muss man von einem Hang zur gesellschaftskonformen Beantwortung der Frage ausgehen. Doch dürfte der Bezugsrahmen nicht die österreichische Mehrheitsgesellschaft sein, sondern vielfach ein islamisch-konservatives Milieu. Vieles deutet deshalb auf eine hohe Verbreitung antisemitischer Denkmuster in diesem gesellschaftlichen Umfeld hin. Denn trotz der recht mageren Datenmenge ist eine Tendenz klar zu erkennen.

Wie sehr der Antisemitismus speziell unter muslimischen Berufsschülern verbreitet ist, kann aus diesen Daten jedoch letztlich nicht herausgelesen werden. Abgefragt wurde nur die „Muttersprache“ und nicht die Religionszugehörigkeit. Doch von der Muttersprache kann selbstverständlich nicht darauf geschlossen werden, wie es jemand mit der Religion bzw. dem Islam hält. ${ }^{24}$ Es würde folglich nicht überraschen, wenn der Antisemitismus unter islamisch-religiösen Jugendlichen in dieser Gruppe der „Nicht-DeutschenMuttersprachler" deutlich höher wäre, als unter tendenziell nichtreligiösen und säkularen bzw. Nichtmuslimen, die sich in der Gruppe ebenfalls finden dürften. Die Studie gibt darauf allerdings keine Antwort. Diese Tendenz lässt sich zumindest aus einer Studie des Soziologen Kenan Güngör herleiten. ${ }^{25}$ Sie hatte die Einstellung zu gesellschaftlichen Fragen der Jugendlichen in Wiener Jugendhäusern zum Gegenstand und wurde 2016 durchgeführt. Ein Drittel der befragten Jugendlichen zeigte gegenüber Juden negative Einstellungen. Nach Religionszugehörigkeit ergab sich folgendes Bild: $47 \%$ der Muslime

22 Ähnlich plump fragt die Autoritarismusstudie der Österreichischen Hochschülerschaft nach dem Antisemitismus: „Wenn es zu Auswüchsen des Kapitalismus kommt, dann sind daran meistens die Juden/Jüdinnen Schuld“, ist das entsprechende Item in deren Studie von 2018. Petra Ziegler, Befragung von Studierenden in Österreich zu Autoritarismus, Geschichtsbildern und demokratischer Disposition, Wien 2018, S. 31, [https://www.oeh.ac.at/file/2086/download?token=nt9ZraU9], eingesehen 1.6.2020.

23 Siehe bspw. Bildungsstätte Anne Frank (Hrsg.), 4 Grüne, warum BDS antisemitisch ist, [https://www.bs-annefrank.de/fileadmin/user_upload/Slider/Publikationen/BDS_Kritik_Broschuere.pdf], eingesehen 1.6.2020.

${ }^{24}$ In der Medienberichterstattung, u. a. im Standard, wurde auf diese Diskrepanz allerdings keine Rücksicht genommen. ${ }^{25}$ Kenan Güngör/Caroline Nik Nafs, Jugendliche in der offenen Jugendarbeit. Identitäten, Lebenslagen \& abwertende Einstellungen, Wien 2016, [https://www.wien.gv.at/freizeit/bildungjugend/pdf/studie-1.pdf], eingesehen 11.12.2017. 
lehnten Juden ab, bei den Orthodoxen Christen waren es $27 \%$ und unter den Katholiken waren es $7 \%$.

Für Güngör speist sich dieser islamische Antisemitismus vor allem aus der Rezeption des Nahostkonflikts. Als Muslime solidarisierten sie sich mit ihren „Brüdern und Schwestern“ in Palästina. Bei vielen Menschen im und aus dem Nahen Osten herrsche die Vorstellung vor, der Westen habe sie immer schon unterdrückt und die Speerspitze dieser westlichen Unterdrückung sei Israel. In den meisten arabischen Medien erhalte Israel den Platz des globalen Bösewichts. Ein Unterschied zwischen Juden und Israel werde dabei nicht gemacht. Diese Sendungen würden auch in Österreich über Onlineplattformen wie YouTube oder Satellitenfernsehen konsumiert. Viele Jugendliche aus islamischen Familien hätten folglich das Gefühl, es sei gesellschaftlich akzeptiert, antisemitische Einstellungen zu vertreten. Jugendliche aus der Mehrheitsbevölkerung sind hier dagegen schon vorsichtiger. ${ }^{26}$ Der Hang dazu, Fragen gesellschaftlich erwünscht zu beantworten, könnte auch hier eine Erklärung des großen Unterschieds zwischen Katholiken und Muslimen sein. Nämlich die unterschiedlichen sozialen Referenzrahmen. Den massiven Unterschied von gleich $40 \%$ kann das jedoch allein nicht erklären. Für Güngör ist dieser islamische Antisemitismus deshalb so gefährlich, weil er mit dem israelisch-arabischen Konflikt in Verbindung steht. Immer wenn in Nahost etwas passiere, flamme auch der Antisemitismus in Österreich auf.

Dementsprechend wird der islamische Antisemitismus in naher Zukunft wahrscheinlich auch ein drängenderes Problem werden. Es gibt immer mehr Schüler mit Migrationshintergrund in den Klassenzimmern und 2015 kamen viele neue Menschen aus Syrien, dem Irak und Afghanistan nach Österreich. In diesen Ländern wird und wurde der Antisemitismus lange Zeit politisch eingesetzt und staatlich gefördert. Es wäre also ein Wunder, wenn 2015 nicht auch Menschen nach Österreich kamen, die antisemitischen Welterklärungen anhängen. ${ }^{27}$

\section{Die spezifische Verantwortung als Österreicher}

Der Wiener Zeithistoriker Oliver Rathkolb empfahl als Reaktion auf die genannten Studienergebnisse bereits im Kindergarten und in der Volksschule Maßnahmen gegen Vorurteile zu ergreifen. Ein Fokus solle dabei auf die Berufsschulen gelegt werden, diese seien bisher vergessen worden. Dabei besuchen beinahe $40 \%$ der 15-Jährigen eine solche Lehranstalt. Gerade in Wien hätten viele Lehrlinge einen sogenannten Migrationshintergrund. In der Schule werden Antisemitismus und der Holocaust bislang meist gleichzeitig behandelt. Darin liegt für Rathkolb ein Problem, weil sich diese Art des Unterrichts explizit an die Nachfahren der Täter des Holocausts richte. Diese

${ }^{26}$ Szigetvari, Starke antisemitische Vorurteile.

${ }^{27}$ Siehe dazu auch den Beitrag von Günther Jikeli in diesem Band. 
„Betroffenheitspädagogik“ werde Schulklassen auch in Gedenkstätten, wie dem Mauthausen Memorial, vermittelt. Türkische und arabische Jugendliche erreiche man damit nicht, für sie sei der Holocaust eine europäische Angelegenheit und damit hätten sie nichts zu schaffen. ${ }^{28}$ Damit spricht Rathkolb einen wichtigen Punkt an. Die Aufklärung über den Antisemitismus darf nicht auf Betroffenheit oder einem schlechten Gewissen aufbauen. Denn auch Schülerinnen und Schüler, die sich selbst als Österreicher verstehen, wird man damit kaum noch nachhaltig erreichen.

Aufgrund der spezifischen österreichischen Geschichte müsse man entschieden gegen Antisemitismus und Rassismus vorgehen, forderte noch im November 2017 die damals scheidende Bildungsministerin Sonja Hammerschmid von der SPÖ. ${ }^{29}$ Der kategorische Imperativ Adornos lautete dagegen: „Hitler hat den Menschen im Stande ihrer Unfreiheit einen neuen kategorischen Imperativ aufgezwungen: ihr Denken und Handeln so einzurichten, daß Auschwitz nicht sich wiederhole, nichts Ähnliches geschehe." ${ }^{30}$ Nicht nur den Österreichern (oder Deutschen) qua ihrer spezifischen Geschichte, sondern der Menschheit allgemein fällt die Aufgabe zu, etwas Ähnliches wie Ausschwitz zukünftig zu verhindern. Selbst in einem Text, in dem es um die Aufarbeitung der Vergangenheit in Deutschland geht, begrenzte Adorno das Nachleben des Faschismus nicht nur auf jene Länder, in denen er zur Macht kam: „Das faschistische Wunschbild heute verschmilzt ohne Frage mit dem Nationalismus der sogenannten unterentwickelten Länder, die man bereits nicht mehr solche, sondern Entwicklungsländer nennt.“" ${ }^{\text {31 }}$ Zur Macht kam der Nationalsozialismus zwar zuvorderst in Deutschland und schließlich auch in Österreich, Sympathien flossen ihm jedoch aus der ganzen Welt zu. Insofern handelt es sich auch nicht um ein Phänomen, das nur auf Mitteleuropa beschränkt war. Bereits in den 1930erJahren berichtete Alexander Stein von den Versuchen der Nationalsozialisten, in anderen Ländern Fuß zu fassen, und zwar mithilfe des Antisemitismus. Stein war Sozialdemokrat und schrieb sein Buch „Adolf Hitler. Schüler der, Weisen von Zion““ im Exil in Prag. Die Nationalsozialisten betrieben bereits in den 1930ern in Nordafrika, dem arabischen Raum und am Balkan antisemitische Hetzpropaganda. ${ }^{32} \mathrm{Ab}$ den 1940er-Jahren gab es in Berlin Zeesen einen nationalsozialistischen Radiosender, der im arabischen und islamischen Raum Propaganda verbreitete. Geleitet wurde dieser Radio-Sender von Amin El-Husseini, Mufti von Jerusalem, der nach dem Zweiten Weltkrieg dem alliierten Kriegsgericht entkam und seine antisemitische Ideologie nach 1945 gegen Israel fortführen konnte. ${ }^{33}$ Der Antisemitismus ist ein heute globales Problem und war es, wie diese Beispiele zeigen, schon vor und während des Zweiten Weltkriegs. So gab es am

\footnotetext{
28 Szigetvari, Starke antisemitische Vorurteile.

${ }^{29}$ Bundesministerium für Bildung, Hammerschmid: Feindbilder können mit Bildung überwunden werden, 23.11.2017, [https://www.bmb.gv.at/ministerium/vp/2017/20171123.html], eingesehen 11.12.2017.

30 Theodor W. Adorno, Negative Dialektik, Frankfurt a. M. 1975, S. 358.

31 Theodor W. Adorno, Was bedeutet: Aufarbeitung der Vergangenheit, in: Ders., Kulturkritik und Gesellschaft II. Eingriffe Stichworte, Frankfurt a. M. 2003, S. 565.

32 Alexander Stein, Adolf Hitler. Schüler der „Weisen von Zion“, Freiburg i. Br. 2001, S. 149.

33 Vgl. den Beitrag von Michel Wyss in diesem Band.
} 
Balkan und in Osteuropa muslimische SS-Divisionen und Freiwilligenbataillone, die in den Genozid an den europäischen Juden involviert waren. Im Irak kam es 1941 zu einem prodeutschen Putsch und infolgedessen zu einem Pogrom gegen die irakischen Juden. Auch darüber wäre im Geschichtsunterricht zu sprechen. Die Beschäftigung mit dem Nationalsozialismus und dem Holocaust muss sich von ihrer eurozentristischen Sicht lösen. ${ }^{34}$

Es lässt sich kein vernünftiges Argument anführen, warum sich 75 Jahre nach dem Ende des nationalsozialistischen Völkermordes an den Juden heutige Kinder und Jugendliche aufgrund einer spezifischen österreichischen Geschichte in besonderem Maße dafür verantwortlich fühlen sollten. Egal ob es sich dabei um türkische, arabische oder österreichische Jugendliche handelt. Damit keine Missverständnisse aufkommen: Der Kampf gegen und die Aufklärung über den Antisemitismus sind dringend notwendig. Dieser sollte nur nicht aus einer wie auch immer gearteten Verantwortung der Österreicher abgeleitet werden, denn damit wird mit gutem Gewissen der Irrglaube an überzeitliche Kollektive und unveränderliche Volkssubjekte konserviert. Zudem geht es beim Kampf gegen den Antisemitismus nicht um die Imagepflege Österreichs. Stattdessen sollten Schülern die psychosozialen Mechanismen bewusst gemacht werden, die in ihnen selbst den Antisemitismus erzeugen. Um dazu in der Lage zu sein, müssten Lehrkräfte, wie Adorno bereits 1964 vorgeschlagen hat, die gängigsten Propagandatricks der Antisemiten analysieren und den Schülern erklären, warum sie funktionieren und was falsch an ihnen ist. Das wäre insbesondere angesichts der massenhaften Verbreitung und Nutzung von „Sozialen Medien“ notwendig. Vor allem aber muss, so Adorno, das Selbstbewusstsein der Kinder und Jugendlichen gestärkt werden, um den Antisemitismus bekämpfen zu können. ${ }^{35}$

Der Antisemitismus ist nicht nur „das Gerücht über die Juden“, wie es oft aus dem Zusammenhang gerissen zitiert wird. Die antisemitische Ideologie enthüllt auch, was der Antisemit insgeheim wünscht. So definiert Adorno den Antisemiten und seine Wirkung auf andere folgendermaßen: „Paranoia, der Verfolgungswahn, der die anderen verfolgt, auf die er projiziert, was er selber möchte, steckt an."36 Rathkolb übergeht diesen spezifischen Charakter des Antisemitismus und empfiehlt die Dekonstruktion von Vorurteilen ausgehend von selbst erlebten Diskriminierungserfahrungen. Muslimische Jugendliche sollen zuerst über ihre eigene Ausgrenzungserfahrung reden. In einem späteren Schritt soll durch diese Thematisierung der eigenen Ausgrenzung auch Empathie für andere ausgegrenzte Gruppen geweckt werden. Ausgrenzung persönlich

\footnotetext{
34 Nähere Informationen zum Verhältnis von Islam und Nationalsozialismus finden sich in folgenden Werken: Matthias Künzel, Von Zeesen bis Beirut. Nationalsozialismus und Antisemitismus in der arabischen Welt, in: Doron Rabinovici/Ulrich Speck/Natan Sznaider, Neuer Antisemitismus?, Frankfurt a. M. 2004; Jeffrey Herf, Nazi Propaganda for the Arab World, New Haven-London 2009; Klaus-Michael Mallmann/Martin Cüppers, Halbmond und Hakenkreuz. Das Dritte Reich, die Araber und Palästina, Darmstadt 2011.

35 Theodor W. Adorno, Zur Bekämpfung des Antisemitismus heute, in: Ders., Gesammelte Schriften, Band 20, Frankfurt a. M. 1985, S. 371.

36 Adorno, Aufarbeitung, S. 566.
} 
zu erfahren, macht jedoch niemanden zu einem besseren oder reflektierten Menschen. Vermutlich ist eher das Gegenteil der Fall. Die subjektiv erfahrende Ausgrenzung wird selbst oft wieder menschenfeindlich verarbeitet. Davon berichtet auch Adorno in seinem Aufsatz „Zur Bekämpfung des Antisemitismus heute“ von 1964, in dem er sich explizit mit der pädagogischen Praxis im Kampf gegen Antisemitismus auseinandersetzte. Für den Antisemitismus seien vor allem die Gruppen von sehr schlechten Schülern anfällig, analysierte Adorno. Die Lehrpersonen würden auf diesen von vornherein herumhacken. Diesen Schülern würden Fragen in der Erwartung gestellt, dass sie diese nicht beantworten können. Ihre eigene Situation als Stigmatisierte wälzten diese Schüler auf andere, noch schwächere Gruppen ab. Weit entfernt davon dumm zu sein, seien diese Kinder in bestimmten Bereichen sogar sehr begabt. Sie fühlten das Potential in sich. Wenn man diese Kinder nicht mehr durch Erziehung erreiche, weil sich bereits eine autoritäre Charakterstruktur herausgebildet habe, müsse man sie die Autorität spüren lassen. Die Verbreitung des Antisemitismus solle in der Schule unter Strafe gestellt werden. Noch wichtiger aber sei es, diese Kinder zum Sprechen zu bringen. Sie sollten lernen, sich richtig auszudrücken, denn Gefühle benennen zu können und auch auszusprechen ist heilsam. Doch nicht nur deshalb sei diese Maßnahme wichtig: Wer selbst gelernt habe sich gut auszudrücken, werde keinen unbewussten Hass auf redegewandte Kinder ausbilden. ${ }^{37}$ Adornos Beispiele mögen zeitbedingt antiquiert wirken. In der pädagogischen Praxis hat sich seit den 1960er-Jahren wohl einiges geändert, aber Diskriminierungs- und Ausgrenzungserfahrungen - darunter auch durch Lehrpersonen verursachtes Mobbing - sind in der Gegenwart nach wie vor Teil des schulischen Alltags. In ihnen liegt oftmals der Keim für die Ausbildung menschenfeindlicher Ressentiments.

Was Rathkolb wohl implizit kritisieren wollte, ist eine gesellschaftlich weit verbreitete Fremdenfeindlichkeit. Diese richtet sich heute vor allem gegen Migranten und Migrantinnen aus mehrheitlich islamischen Ländern. Die Fremdenfeinde greifen diese Menschen meist pauschal als „Muslime“ an, unabhängig davon, wie es diese Einzelpersonen selbst mit der Religion halten. Gegen diese Fremdenfeindlichkeit die Vorzüge des Islam in Anschlag zu bringen, wäre allerdings nicht nur falsch, sondern aus vielen Gründen kontraproduktiv. Für Adorno war es selbstverständlich, jeder Art von Stereotypenbildung entgegenzutreten. Er warnte deshalb eindringlich davor, negative Gruppenurteile durch positive Gegenbeispiele zu ersetzen. Dagegen wären Urteile über Gruppen von Menschen an sich in Frage zu stellen. ${ }^{38}$ Dem negativen Islambild ein positives Bild entgegenzusetzen, ist selbst wieder eine Stereotypbildung, die Gruppenurteile verfestigt. Zudem werden migrantische Jugendliche aus islamischen Ländern dadurch in Gruppenidentitäten gezwängt. Fatal ist dies deshalb, weil religiöse oder nationale Gruppen die Tendenz haben, sich über den Ausschluss von Fremden oder

37 Ebd., S. 376-377.

38 Adorno, Zur Bekämpfung, S. 378 
Anderen zu definieren. Statt nun das Selbstbewusstsein zu stärken, was geboten wäre, empfiehlt man Kindern und Jugendlichen die Identifikation mit einem Kollektiv. Weder gegen Antisemitismus noch gegen Fremdenfeindlichkeit kann unter diesen Voraussetzungen vorgegangen werden.

Schüler und Schülerinnen müssen auch in diesem Fall völlig unabhängig von ihrer Herkunft im Unterricht über die Mechanismen von Fremdenfeindlichkeit aufgeklärt werden. Die Lehrpersonen sollten sich dabei nicht die Illusion machen, Kinder und Jugendliche, die selbst diskriminiert werden oder wurden, seien von solchen Denkmustern frei. Dies lässt sich auch aus der schon genannten Studie von Güngör ablesen; $20 \%$ der befragten Muslime äußerten sich negativ gegenüber anderen (nichtjüdischen) ethnischen oder religiösen Gruppen.

\section{Was ist Antisemitismus? Die Kritik des Antisemitismus bei Adorno und Horkheimer}

Um dem Antisemitismus entgegentreten zu können, muss man wissen, womit man es zu tun hat. Im April 2017 wurde im österreichischen Ministerrat die Arbeitsdefinition der International Holocaust Remembrance Alliance (IHRA) angenommen. Sie lautet wie folgt:

„Antisemitismus ist eine bestimmte Wahrnehmung von Juden, die sich als Hass gegenüber Juden ausdrücken kann. Der Antisemitismus richtet sich in Wort oder Tat gegen jüdische oder nicht-jüdische Einzelpersonen und/oder deren Eigentum, sowie gegen jüdische Gemeindeinstitutionen oder religiöse Einrichtungen. “39

Wirklich viel schlauer wird man aus dieser Definition allerdings nicht: Antisemitismus wird hier als Hass gegenüber Juden oder deren Institutionen beschrieben. Darauf wäre man wohl auch von selbst gekommen. Deshalb werden der tautologischen Definition insgesamt elf Beispiele für Antisemitismus zur Seite gestellt: Ein Beispiel ist dem christlichen Antisemitismus entlehnt; es ist der Vorwurf an die Juden, Jesus getötet zu haben. Fünf der Beispiele thematisieren die Feindschaft gegen Israel, den zeitgemäßen Ausdruck des Antisemitismus. Die Definition verharrt damit auf einer rein beschreibenden Ebene und lässt jede Erklärung vermissen. Damit bleibt auch völlig unklar, wie sie als Grundlage für eine Pädagogik gegen Antisemitismus dienen könnte. Will man mehr über die Ursache des Antisemitismus erfahren, lohnt ein Blick in die Werke der kritischen Theorie. In Fragen der Pädagogik, dem Nachleben des Faschismus in der Demokratie und der Aufklärung über den Antisemitismus wird gerne auf Theodor W. Adorno verwiesen. Wer sich mit bestimmten Themen beschäftigt, kommt nicht

39 Was ist Antisemitismus. Österreich nimmt IHRA-Arbeitsdefinition von Antisemitismus an, in: erinnern.at, o. D. [http://www.erinnern.at/bundeslaender/oesterreich/e_bibliothek/antisemitismus-1/was-ist-antisemitismus-

oesterreich-nimmt-ihra-arbeitsdefinition-von-antisemitismus-an], eingesehen 11.12.2017. 
darum herum, diesen Autor zu zitieren, gilt er doch als großer Denker. Leider dient dieser Verweis auf Adorno häufig nicht dem Erkenntnis- sondern rein dem Distinktionsgewinn. Unterschlagen wird dabei in der Regel, was Adorno wirklich geschrieben hat und worauf seine Schriften hinauslaufen. Gerade für das Verständnis des Antisemitismus ist dies aber unabdingbar.

Während des Zweiten Weltkriegs verfassten Adorno und Max Horkheimer ihre wohl berühmteste Schrift: Die Dialektik der Aufklärung. Darin findet sich das Kapitel „Elemente des Antisemitismus“. Der Untertitel lautet vielsagend „Grenzen der Aufklärung“. Denn über den Antisemitismus aufzuklären, ist schwierig, entspringt er doch Regungen und Bedürfnissen, die im Unbewussten liegen. Um über die Mechanismen des Antisemitismus aufzuklären, bedienten sich die beiden Autoren der Psychoanalyse von Sigmund Freud. ${ }^{40}$ Nach Freud ist der Mensch nicht der Herr im eigenen Haus, also der Psyche. Die Gründe für das Tun und Handeln der Menschen bleiben ihnen selbst oft verborgen. Doch auch über die Gesellschaft bestimmen die Menschen nicht bewusst, es verhalte sich vielmehr umgekehrt: die Logik der Gesellschaft bestimmt, wie die Menschen agieren. Über die unbewussten Triebkräfte der Gesellschaft und die des einzelnen Individuums wollten Adorno und Horkheimer aufklären. Sie bedienten sich dazu nicht nur Freud, sondern auch der Kritik der politischen Ökonomie von Karl Marx. ${ }^{41}$

Der Antisemitismus hat für Adorno und Horkheimer ökonomische und psychologische Gründe und dies gleichzeitig. Gerade von marxistischer Seite gab es immer wieder Versuche, den Antisemitismus rein ökonomisch zu erklären. Das musste misslingen. Denn die Antisemiten folgten keinen rationalen ökonomischen Zielen. Vom deutschen Beamten bis zum Bewohner von Harlem wüssten alle Antisemiten, so schrieben Horkheimer und Adorno in den 1940ern, dass er sich letztlich nicht auszahle. Doch der Gedanke daran, andere hätten es noch schlechter, reicht dem Antisemiten als Motivation. Der Antisemitismus zielt nicht auf die Verbesserung der materiellen Lage von einzelnen Menschen, er zielt ausschließlich auf die Vernichtung der Juden. ${ }^{42}$

Marx und Freud zusammendenken heißt: Die Psychoanalyse muss den Menschen untersuchen, der unter bestimmten ökonomischen Verhältnissen lebt. Verändern sich die ökonomischen Verhältnisse, verändern sich auch die Charaktere jener Menschen, die in diesen leben. Deshalb sind Erkenntnisse, die Freud im frühen 20. Jahrhundert machte, an die spezifischen gesellschaftlichen und ökonomischen Bedingungen der damaligen Zeit in Wien geknüpft. Das Über-Ich ist bei Freud jene Instanz im Menschen, die über Verbote, Gebote und Werte des Individuums wacht. Dieses Über-Ich bildete sich im 19. Jahrhundert in der Auseinandersetzung mit dem Vater aus. Dies hatte ein ökonomisch starkes und autonomes Bürgertum zur Voraussetzung. Denn nur unter diesen

$40 \mathrm{Zu}$ den Verbindungen der beiden Ansätze siehe auch: Christine Kirchhoff/Falko Schmieder (Hrsg.), Freud und Adorno. Zur Urgeschichte der Moderne, Berlin 2015.

${ }^{41}$ Karl Max, Zur Kritik der Politischen Ökonomie [1859] (Marx-Engels-Werke 13), Berlin 1971.

42 Horkheimer/Adorno, Dialektik der Aufklärung, S. 199. 
Verhältnissen konnte der Vater als stark und autonom erscheinen. Dies galt nur in der liberalen Phase des Kapitalismus. Freud erlebte in Wien gerade noch dessen Ausläufer mit. Im Spätkapitalismus bildet sich das Über-Ich nicht mehr am Vater, sondern an gesellschaftlichen Institutionen wie Schule, Sportverein, Arbeit oder Peer-Groups. Diese haben zu einer radikalen Veränderung des aktuellen Menschentypus geführt. Diese hierarchische Gesellschaftsform, welche sich in Institutionen und der Selbstzurichtung der Subjekte äußert, müsse die Menschen irrational machen. ${ }^{43}$

Für den Antisemitismus heißt dies nun: Er hat ökonomische Gründe, die mithilfe der Psychoanalyse besser verstanden werden können. Wünsche und Regungen im Einzelnen, die gesellschaftlich tabuisiert sind, werden jemand anderem zugeschrieben.

Nach Adorno und Horkheimer produziert die falsch eingerichtete Gesellschaft den Vernichtungswillen gegen die Juden aus sich heraus. ${ }^{44}$ Die ökonomische Ordnung verdamme die Mehrheit der Menschen zur Abhängigkeit von Bedingungen, über die sie nicht verfügten. Damit aber nicht genug: Um in dieser Ordnung leben zu können oder gar erfolgreich zu sein, müssen sich die Menschen anpassen. Ihre Autonomie wird dabei durchgestrichen, also genau jener Moment, an den die Demokratie appelliert. Dem zu widerstehen verlangt neben einer Ich-Stärke auch die Kraft, nicht um jeden Preis mitmachen zu wollen. Verstärkt wird das totalitäre Potential durch die Wut und Unzufriedenheit, die der schmerzhafte Zwang zur Anpassung an Verhältnisse produziert, die nicht glücklich machen. Weil der autoritäre Charakter realisiert, dass er selbst in der Anpassung um das versprochene Glück der Gesellschaft betrogen wurde, hasst er nun jeden Gedanken an eine Welt, in der das Glück möglich wäre. Diese Sehnsucht nach Glück, Einkommen ohne harte Arbeit, eine Gesellschaft ohne Druck verschwindet im Einzelnen nicht einfach. Diese Regungen werden verleugnet und den Juden zugeschrieben. Alles was die Antisemiten insgeheim wünschen, lasten sie den Juden an: Sowohl den Reichtum, der ihnen vorenthalten bleibt, die sexuelle Freizügigkeit als auch den Gedanken an eine befreite Gesellschaft. Für die Anpassungsleistung an die falsche Gesellschaft wollen die Betrogenen belohnt werden, zwar nicht mit Reichtum, aber mit der Zusage, ewig ausgebeutet zu werden. Insgeheim weiß der Betrogene, wie überflüssig und austauschbar er in der Arbeit ist. Deshalb fordert er das Vorrecht der Nationalität und argumentiert mit der Herkunft. Die Gesellschaft, die er selbst nicht durchschauen will, weil dies ihm die Nutzlosigkeit seiner Anpassung vor Augen führt, muss um jeden Preis affirmiert werden. Für das Schlechte auf der Welt sind nicht die elenden Verhältnisse verantwortlich, sondern bestimmte gierige Menschengruppen. Dies ist der gesellschaftliche und ökonomische Grund des Antisemitismus. ${ }^{45}$

In der Unterdrückung von Wünschen liegt auch der Grund für den islamischen Antisemitismus begraben. Der Islam verlangt dem Namen nach Unterwerfung und

43 Max Horkheimer, Der soziologische Hintergrund des psychoanalytischen Forschungsansatzes, in: Ernst Simmel (Hrsg.), Antisemitismus, Frankfurt a. M. 1993, S. 32-33.

${ }^{44}$ Horkheimer/Adorno, Dialektik der Aufklärung, S. 197.

45 Adorno, Aufarbeitung, S. 560-567. 
zwingt seinen Anhängern den Triebverzicht auf. Der Westen führt sie nun immerzu in Versuchung, in Sünde zu leben, die sie selbst begehren, sich jedoch nicht eingestehen dürfen. Ansonsten würden sie vom wahren Glauben abkommen. Gehasst werden nun jene, die für gesellschaftliche Libertinage stehen. Es ist das Bild des Juden, der hinter den Verführungen des Westens stehen soll. Auch der islamische Antisemit hasst seine eigenen Wünsche.

\section{Wie gegen Antisemitismus vorgehen?}

In Graz beschäftigte sich der Verein JUKUS - Verein zur Förderung von Jugend, Kultur und Sport im Jahre 2017 mit dem Thema Antisemitismus. Zu diesem Zweck wurde auch eine Broschüre mit dem Namen ,Jugend, Migration und Antisemitismus. Präventive Arbeit zu menschenfeindlichen Haltungen "veröffentlicht. ${ }^{46}$ Diese Broschüre nimmt sich explizit dem Thema des Antisemitismus unter Migranten an. Dieser äußere sich vielfältig: Israel oder die Juden insgesamt werden als Feinde gesehen. Das Wort ,Jude“ wird auf dem Schulhof als Schimpfwort verwendet. ${ }^{47}$ Manche Jugendliche vertreten sogar die Position, die Muslime und die Juden seien schon immer Feinde gewesen. Womit sie sich auf einige Koranstellen stützen können, die von der Vernichtung jüdischer Stämme durch Mohamed berichten. ${ }^{48}$ Auch der Nationalsozialismus versuchte bei seiner Propaganda in der islamischen Welt an diese Argumentationsfigur anzuschließen.

Die meisten muslimischen Jugendlichen wurden in Österreich selbst schon diskriminiert, betont die Autorin. Auch in dieser Broschüre empfiehlt man, an diesen Erfahrungen anzuknüpfen. Wer selbst nicht gerne ausgegrenzt wird, der wird besser verstehen, warum er selbst niemand ausgrenzen soll, so zumindest der Gedanke hinter diesem Ansatz. Bei Jugendlichen, die für Erfahrung noch offen sind, kann dies sogar funktionieren. Doch wahrscheinlich waren genau diese Jugendliche, bei denen es noch funktioniert, gar nie anfällig für die antisemitische Ideologie. Wer an Unterdrückungserfahrungen anschließt, läuft oft Gefahr eine gewisse Opfer-Identität zu stärken. Diese Gefahr darf keinesfalls unterschätzt werden. Wer sich als Opfer übermächtiger Gegner empfindet, fühlt sich zum besinnungslosen Zuschlagen legitimiert. An den nichtigsten Ereignissen entlädt sich dann die Gewalt. Ob der Anlass nun die Verlegung der US-Botschaft nach Jerusalem oder die Veröffentlichung von Mohammed-Karikaturen in dänischen Zeitungen ist.

Allgemein wird in der Broschüre die Wirkmächtigkeit von Erziehung und Pädagogik überschätzt. Adorno reflektiert auf diese Grenze der Pädagogik und gibt einige praktische

\footnotetext{
${ }^{46}$ Johanna Stadelbauer, Jugend, Migration und Antisemitismus. Präventive Arbeit zu menschenfeindlichen Haltungen, Graz 2017, [http://jukus.at/sites/default/files/uploads/broschuere_web.pdf], eingesehen 1.6.2020.

47 Siehe dazu auch Franziska Pröll, Wenn Schüler einander als „Du Jude!“ beschimpfen, in: Die Zeit, 21.12.2019, [https://www.zeit.de/gesellschaft/schule/2019-12/antisemitismus-beleidigung-schulhof-paedagogik-lehrerausbildung], eingesehen 1.6.2020.

48 Vgl. den Beitrag von Michel Wyss in diesem Band.
} 
Ratschläge, wie gegen den Antisemitismus vorzugehen sei. Zuerst müsse erforscht werden, wo und wie der faschistische Antisemitismus nachlebt. Diese Forschungsarbeit werde vom Gedanken geleitet, die Mechanismen des Antisemitismus zu begreifen und darauf zu reflektieren. Der falsche Weg sei dagegen, sich ausschließlich moralisch über den Antisemitismus und die Antisemiten zu entrüsten. ${ }^{49}$

Für Adorno muss auf zwei verschiedene Arten gegen Antisemitismus vorgegangen werden. Da wären die Langzeitprogramme, die durch Erziehung verhindern sollen, dass Kinder einen autoritätsgebundenen Charakter ausbilden. Doch ab einem gewissen Alter seien die Würfel in diese Richtung gefallen und mit Erziehung und Pädagogik ist dem Antisemitismus nicht mehr beizukommen. Deshalb empfiehlt Adorno Kurzzeitprogramme zur akuten Abwehr des Antisemitismus. Diese Programme können auf Autorität nicht verzichten. ${ }^{50}$ Das mag widersprüchlich erscheinen. Auf der einen Seite soll die Herausbildung autoritärer Charakterstrukturen durch Erziehung verhindert werden, auf der anderen Seite soll man gegen den Antisemitismus mit autoritären Mitteln vorgehen. Adorno plädiert nun dafür, Phänomene nicht dort zu vereinfachen, wo die Realität den Menschen Widersprüche aufzwingt. In der Erziehung muss der Herausbildung eines autoritätsgebundenen Charakters entgegengearbeitet werden. Abgebaut werden soll jede Autorität, die sich nicht durch Vernunft oder Sachautorität legitimiert lässt. ${ }^{51}$ Dies ist ein erster Schritt zur Entbarbarisierung. Denn der autoritäre Charakter ist anfällig für das antisemitische Vorurteil. Wenn sich dagegen nichts mehr machen lässt, weil die Charakterstruktur sich schon zu einer autoritären verfestigt hat, bleibt als Mittel gegen den Antisemitismus nur mehr die Autorität. Denn diese Personen sind für Erfahrung nicht mehr offen, sie lassen sich nicht mehr einfach so verändern. ${ }^{52}$ Adorno berichtete in einer längeren Passage von einem Aufeinandertreffen mit Antisemiten:

„Ich sagte Ihnen bereits, dass ich bei Menschen, bei denen das Vorurteil bereits etabliert ist, von der Herstellung sogenannter Kontakte und ähnlichem nicht viel halte. Bei ihnen ist die Erfahrungsfähigkeit bereits abgestumpft. Antisemitischen Äußerungen ist sehr energisch entgegenzutreten: sie müssen sehen, dass der, welcher sich gegen sie stellt, keine Angst hat. Man imponiert einem bissigen Hund, sobald er merkt, dass man sich nicht vor ihm fürchtet, aber es ist verloren, wenn er innerviert, dass man eigentlich vor seinem Gebiss zittert; so ist es in solchen Fällen auch. Ich habe nach meiner Rückkehr nach Deutschland mit solchen Menschen unmittelbare Erfahrung gemacht. Einmal bin ich an einer Gruppe von Chauffeuren vorbeigekommen, die damals in dem Pool für die amerikanische Besatzungsmacht beschäftigt waren. Sie schimpften untereinander wüst auf die Juden. Ich ging zum nächsten Schutzmann und ließ sie verhaften. Auf der Wache habe ich mich lange und eingehend vor allem mit dem Rädelsführer unterhalten und habe

49 Adorno, Bekämpfung, S. 362.

50 Ebd., S. 372.

51 Theodor W. Adorno, Erziehung zur Mündigkeit, Frankfurt a. M. 1971, S. 131.

52 Adorno, Bekämpfung, S. 363-364. 
von ihm einen Satz gehört, der sich mir sehr eingeprägt hat: ,Ach wissen Sie, gestern waren wir Nazi, heute sind wir Ami und morgen sind wir Kommi` Er hat mir damit ungewollt eine tiefe Weisheit über die ganze Charakterstruktur seines Typus verraten. Bei ihm überwiegt das Motiv der Anpassung um jeden Preis alles andere. Wenn man in solchen Fällen ohne Angst zugreift und dann auf die Argumente solcher Personen in allem frank antwortet, kann man etwas erreichen. Ich hatte jedenfalls das Gefühl, dass jene Chauffeure, jedenfalls ihrer bewussten Überzeugung nach, ein wenig anderen Sinnes von der Polizeiwache weggegangen sind. Begegnet man expliziten und fixierten Vorurteilen, so ist auf eine Art Schocktherapie zu vertrauen. Man muss die allerschroffsten Gegenpositionen beziehen. Schock und moralische Kraft gehen dabei zusammen. Schlecht ist das Zurückweichen. "53

Allgemein war Adorno kein Befürworter unreflektierter antiautoritärer oder pazifistischer Erziehung. Auch wenn Kinder dazu erzogen werden sollten, Abscheu gegenüber jeder Art von psychischer Gewalt zu empfinden ${ }^{54} \mathrm{zu}$ „Lämmchen“ sollen sie keinesfalls werden. Denn „Lämmchen“ wären wahrscheinlich bereit, so Adorno, das Abscheuliche ohne Gegenwehr hinzunehmen. ${ }^{55}$

\section{Aufklärung statt Propaganda}

Wer gegen Antisemitismus vorgeht, muss auf alles reklameähnliche verzichten, so die Forderung Adornos. Stattdessen müssten Kinder und Jugendliche immer mit der ungeschönten und ganzen Wahrheit konfrontiert werden. Aufgeklärt werden muss vor allem über die Struktur und die Motivation des antisemitischen Denkens. Wer sich dagegen auf Diskussionen innerhalb einer antisemitischen Argumentation einlässt, also antisemitische Behauptungen mit Gegenbehauptungen kontert, steht schon von Beginn an auf verlorenem Posten. Wer nun bspw. als Lehrperson mit der Behauptung konfrontiert wird, am 11. September 2001 seien gar keine Juden in den New Yorker Twin Towers gewesen, weil sie wohl selbst die Drahtzieher hinter den Anschlägen waren, sollte sich gar nicht erst auf Zahlenspiele einlassen. Offenzulegen wäre hier vielmehr die zugrundeliegende Struktur des antisemitischen Verschwörungsdenkens. Die pathische Projektion, die den Juden ein Verbrechen andichtet, welches von Anhängern des Islam verübt wurde (und von diesen auch durchaus für sich reklamiert wurde). Derartige Projektionen können mehrere, sich überlagernde Gründe haben: Man will beweisen, dass auch die Juden bösartig sind, womit der Antisemitismus der Nazis im Nachhinein legitimiert oder relativiert werden soll (sogenannter ,sekundärer Antisemitismus“56).

53 Ebd., S. 379-380.

54 Adorno, Erziehung, S. 130-131.

55 Ebd., S. 128-129.

56 Juliane Wetzel, Antisemitismus heute - klassische und neue Erscheinungsformen, in: bpb.de, 23.11.2017, [https://www.bpb.de/politik/extremismus/rechtsextremismus/260281/antisemitismus-heute-klassische-und-neue- 
Oder aber es wird als Plan der Juden verkauft, den Islam schlecht dastehen zu lassen und die USA in einen Krieg gegen islamische Länder zu zwingen. Muslime könnten dies nämlich nie tun, für sie sei es verboten Unschuldige zu töten usw.

Ein anderes Beispiel, das Adorno selbst anführte, stammt noch aus dem Arsenal des nationalsozialistischen Antisemitismus. Die Behauptung, die Juden drückten sich vor harter Arbeit. Dem entgegen zu halten, viele Juden in Osteuropa seien Arbeiter gewesen, ist für Adorno der falsche Weg. Dagegen sollte offengelegt werden, was hinter diesem Vorwurf eigentlich steckt: Die eigene uneingestandene Abscheu gegen die Arbeit. Diese darf man sich nicht offen eingestehen, verlangt doch die Gesellschaft von jedem Einzelnen, dass er hart arbeitet. Deshalb hasst man jene, die angeblich schon ohne harte Arbeit leben: Die Juden. Die einzige richtige Entgegnung wäre hier für Adorno: Harte Arbeit alten Stils sei heute gar nicht mehr nötig. Dank der Entwicklung der Wissenschaft, der Technik und der Maschinen könnte man die harte Arbeit von heute auf morgen abschaffen. ${ }^{57}$ Auch dem Antisemitismus soll kein Idealbild des Juden gegenübergestellt werden. Der Antisemitismus entspringt den Projektionen der Antisemiten. ${ }^{58}$ Wer gegen den Antisemitismus vorgehen will, muss immer bei der Wahrheit bleiben. Deshalb wäre es auch nicht die richtige Strategie, den jüdischen Beitrag zum kulturellen und politischen Leben der Weimarer Republik zu leugnen. Auch wer sich auf diese Diskussion einlässt, hat verloren. In einer liberalen Demokratie verletzt schon diese Diskussion darüber, welche Bevölkerungsgruppen in welchen Berufen überrepräsentiert seien, das Gesetz der Gleichheit. ${ }^{59}$

Wie nun gegen den Antisemitismus vorgehen? Auch wenn sie gut gemeint sind, für Adorno sind Freundschaftsprogramme zwischen Juden und Nicht-Juden im Kampf gegen Antisemitismus meist wirkungslos. Die Antisemiten sind zu keiner Erfahrung fähig. Sie können deshalb nicht durch Begegnungsprogramme mit Juden von ihrem Antisemitismus abgebracht werden. Die Geschichte des Antisemitismus zeigt, dass Begegnungen zwischen Juden und Nicht-Juden letztlich eben diesen nicht verhinderten. Auch die Präsentation von Fakten wird im Kampf gegen den Antisemitismus zahnlos bleiben. Stattdessen muss man den Einzelnen bewusstmachen, welche Mechanismen den Antisemitismus vielleicht auch in ihnen selbst erzeugen. ${ }^{60}$ Und wenn dies alles nichts mehr hilft, muss entschieden gegen den Antisemitismus vorgegangen werden, wenn nötig auch mit den Mitteln der Autorität.

erscheinungsformen-einer-ideologie], eingesehen 1.12.2019.

57 Adorno, Bekämpfung, S. 369-370.

58 Ebd., S. 369.

${ }^{59}$ Ebd., S. 362-363.

60 Ebd., S. 371. 


\title{
Opfergemeinschaften und Verschwörungsphantasmen. Reflexionen über pädagogische Praxis in der postnazistischen Gesellschaft
}

\author{
Enno Stünkel
}

\section{Turning a blind eye}

Der britische Psychoanalytiker John Steiner hat mit der Formulierung ,turning a blind eye" einen Mechanismus benannt, der es ermöglicht, ein anscheinend schon erkanntes Problem der Wahrnehmung zu entziehen. Das, was bewusst scheint, vielleicht sogar im Mittelpunkt der Aufmerksamkeit steht, verschwindet in dem Moment, da es angeschaut wird:

„I refer to this mechanism as turning a blind eye because I think this conveys the right degree of ambiguity as to how conscious or unconscious the knowledge is. At one extreme we are dealing with simple fraud where all the facts are not only accessible but have led to a conclusion which is then knowingly evaded. More often, however, we are vaguely aware that we chose not to look at facts without being conscious of what it is we are evading. These evasions may lead to a sense of dishonesty and to various manoeuvres which deny or conceal what has happened by creating a cover up."1

Manchmal bedarf es einer Gesellschaft, um ein Problem derart in den Blick zu nehmen, dass es darüber unsichtbar wird. Steiner zeigt das an Sophokles' König Ödipus. Dazu liest er das Drama nicht als Geschichte einer Aufklärung, sondern als Darstellung einer kollektiven Anstrengung, das, was offenkundig ist, nicht zu sehen. Ödipus ist hier nicht der Analytiker seiner Schuld, der, nach Wahrheit suchend, erkennt, dass er mit seiner Mutter geschlafen und seinen Vater getötet hat, vielmehr unternimmt Ödipus alles, um nicht zu wissen, was doch zu wissen wäre. Er verzichtet auf naheliegende Fragen und stellt Verbindungen nicht her. Eben dadurch vollzieht sich das Drama. Damit dieses Vermeiden von Wissen gelingen kann, müssen alle, müssen Iokaste und Kreon, muss der Chor sich auf entsprechende Weise verhalten. So entsteht in Steiners Aufsatz das Bild einer Gesellschaft, die gemeinsam und arbeitsteilig Einsicht vermeidet. Mit diesem Modell lässt sich beschreiben, wie die postnazistischen Gesellschaften ihren Antisemitismus vor sich selbst verborgen halten - den gegenwärtigen ebenso wie den geschichtlichen. Methodisch kann das Modell dazu anregen, für die Wahrnehmung und für die Analyse des Antisemitismus gerade auf die Abwehr- und Vermeidungs-

${ }_{1}^{1}$ John Steiner, Turning a blind Eye. The Cover Up for Oedipus, in: The International Review of Psycho Analysis 12 (1985), S. 161-172, hier S. 161. 
mechanismen $\mathrm{zu}$ achten und so besser $\mathrm{zu}$ erkennen, unter welchen Bedingungen Aufklärung nicht gelingt.

Zum Komplex des Antisemitismus gehören auch die Schwierigkeiten, ihn als solchen zu erkennen. Ein Bekenntnis ,gegen Antisemitismus“ geht nicht zwangsläufig mit einer Erkenntnis, was Antisemitismus geschichtlich und aktuell bedeutet, einher. Insbesondere die Vorstellungen ,jüdischer Macht“, die seit dem 19. Jahrhundert das Zentrum antisemitischer Projektion bestimmen und heute in Form von neuen Verschwörungsphantasmen und moralischen Erzählungen über das Böse in der Welt, in der Angst vor dem mächtigen Israel und der Verfolgung durch Juden wiederkehren, werden aber nicht als das erkannt was sie sind. Diese Vorstellungen sind in einem Maße irrational und gleichzeitig so sehr mit historischer und aktueller Gewalt verbunden, dass man den Eindruck gewinnen mag, dass dem gesellschaftlichen Wahngeschehen mit verdinglichendem und isolierendem Gestus begegnet wird, der bannen soll, was an Unheimlichem sonst unfassbar, tatsächlich aber unerträglich bekannt erschiene.

Diese Beobachtung möchte ich im Folgenden an zwei Begebenheiten entwickeln und auf ihre Auswirkungen auf eine mögliche pädagogische Praxis hin befragen, die sich bewusst sein muss, in einer Öffentlichkeit stattzufinden, in der auch die kritische Aufmerksamkeit auf Antisemitismus zu seiner Verstetigung beitragen kann. Es ist, als wirke die realitätszerstörende Macht des antisemitischen Ressentiments auch in den Bemühungen, diesem Ressentiment etwas entgegenzusetzen. Die großen, medialen Debatten - von der Paulskirchenrede Martin Walsers, über Günter Grass’ Gedicht „Was gesagt werden muß“ bis zu den Diskussionen um Jakob Augstein oder Xavier Naidoo - scheinen kaum Einsichten zu vermitteln. Das Modell des „,turning a blind eye“ mag eine Möglichkeit eröffnen, das nicht intendierte Zusammenwirken von Verleugnungen, Abspaltungen und Abwehrgesten so zu interpretieren, dass ein angemesseneres Verständnis der aktuellen Dynamik des Antisemitismus und der Gesellschaft, in der dieser wirkt, gelingt. Das sollte für eine pädagogische Praxis, die die antisemitische Tradition unterbrechen will, gerade in dem Moment wichtig sein, da sie sich als reflektierte Praxis zu verbreiten beginnt. ${ }^{2}$ Denn mit dem Zugewinn an historischem und sozialpsychologischen Wissen, das wir in den letzten Jahren erleben, geht eine Neuformierung des Widerstands gegen diese Einsichten einher - das zumindest legen die Erfahrungen aus der „Aufarbeitung“Geschichte der postnazistischen Gesellschaften nahe. Die verbreitete Unkenntnis von Wirkung und Funktion des Antisemitismus muss wohl noch immer (oder immer wieder) als Schutz vor gesellschaftlicher Selbsterkenntnis verstanden werden.

2 Vgl. dazu einführend und mit weiteren Hinweisen Meron Mendel/Astrid Messerschmidt (Hrsg.), Fragiler Konsens.

Antisemitismuskritische Bildung in der Migrationsgesellschaft, Frankfurt a. M. 2017. 


\section{Phantasien über Antisemiten - Wiederholungen}

Unter dem Titel „Heiliger Durchblick“ veröffentlichte die Cellesche Zeitung am 7. Juni 2014 eine Pfingstandacht des protestantischen Theologen Otmar Schulz. Der Text erschien unter der farbigen Reproduktion des Gemäldes „Pfingsten“ von Emil Nolde aus dem Jahr 1909. Damit bezog sich Schulz auf eine Debatte, die anlässlich der großen NoldeRetrospektive im Frankfurter Städel Museum zum wiederholten Mal sich an der Rolle Noldes im Nationalsozialismus entzündete. Der (postume) Erfolg des Malers Nolde beruhte nach 1945 darauf, dass der als im Nationalsozialismus verfemter Künstler galt; eine Legende, die ein Beispiel für die Leugnung und Umdeutung von nationalsozialistischer Geschichte ist. Den 2014 in Ausstellung und Katalog präsentierten Forschungsstand fasste die FAZ zusammen: „Nolde, in summa, war bis zum Kriegsende ein überzeugter Nationalsozialist und glühender Bewunderer Hitlers. Er war ein entschiedener Antisemit. Er hielt seine Verfemung durch die Kunstbürokratie für ein schreckliches Missverständnis, gegen das er beständig kämpfte. “3

Das ist der Hintergrund, vor dem die Pfingst-Andacht über das Nolde-Gemälde steht. In dem mit „Nachwort“ betitelten Teil, der fast die Hälfte des Textes umfasst, bezieht Schulz sich darauf: „Die Frage, ob Nolde Nazi war oder gar Antisemit, wird in jüngster Zeit wieder heftiger diskutiert. [...] Sie lässt sich auch in diesem Beitrag nicht umgehen. “4 Warum ist diese Frage nicht zu umgehen? Die Frage, ob „Nolde Nazi war“", bietet wenig Spielraum für die Diskussion. Seine Mitgliedschaft in der NSDAP bis 1945 ist dokumentiert. Auch die Zuspitzung, „Nazi oder gar Antisemit“ ist bemerkenswert, scheint sie doch zu implizieren, dass die Gruppe der Nazis größer war als die der Antisemiten. Der letzten zuzugehören, das insinuiert das ,gar", ist kaum denkbar. Ein Abwehrsignal ist gesetzt, das die folgenden Überlegungen leitet. Es geht Schulz um die Berechtigung des Begriffs „Antisemitismus“. Wir erfahren: „Noldes vermeintlicher „Antisemitismus' hatte eine Vorgeschichte." Schulz fasst sie so zusammen: Noldes „Gemälde Pfingsten wurde 1910 auf Anweisung von Max Liebermann aus der Ausstellung der Berliner Secession verbannt. Nolde lieferte sich anschließend einen heftigen Briefwechsel mit Liebermann, der ihn daraufhin aus der Secession ausschloss. Er hatte die Macht dazu, er war der Präsident.“ Es ist hier nicht der Ort, die kunsthistorische Geschichte des Konfliktes zwischen der Berliner Secession und den sich um 1910 entwickelnden Strömungen der (expressionistischen) Malerei nachzuzeichnen. Wichtig für unseren Zusammenhang ist, dass Schulz einen persönlichen und künstlerischen Konflikt zwischen Nolde und Liebermann als „Vorgeschichte“ eines schon in Anführungszeichen gesetzten Antisemitismus deutet, in diesem also Ausdruck

${ }^{3}$ Jochen Hieber, Der Erzähler Siegfried Lenz und sein Modell Emil Nolde, in: Frankfurter Allgemeine Zeitung, 26.4.2014, S. 9.

${ }^{4}$ Otmar Schulz, Heiliger Durchblick, in: Cellesche Zeitung, 7.6.2014, S. 1. So auch für die folgenden Zitate, wenn nicht anders angegeben. 
einer lebensgeschichtlichen Erfahrung sieht. Diese Lebensgeschichte wird von Schulz typisierend nachgezeichnet. Wir erfahren, dass Noldes Jugendjahre geprägt waren von „harter Arbeit und kargem Leben. Erst 1899 mit 32 Jahren, konnte er sich eine Malerschule leisten.“ Ganz anders sein Gegenspieler: „Liebermann, 20 Jahre älter als Nolde, stammte aus einem reichen Elternhaus, hatte alle Möglichkeiten, gute Schulen zu besuchen und sorglos zu studieren." Eine idealtypische Gegenüberstellung: Macht, Reichtum, Sorglosigkeit auf der einen, harte Arbeit und karges Leben auf der anderen Seite. Auch steht alt gegen jung. Schulz erklärt, was weiter geschah:

„Seinem Rauswurf aus der Berliner Secession wegen seines Pfingstbildes folgten weitere Auseinandersetzungen mit Max Liebermann und Paul Cassirer, dem führenden Kunsthändler, wie Liebermann ebenfalls aus reichem jüdischen Hause. Das waren die dominierenden Kräfte des damaligen Kunstmarktes, Liebermann als Maler, Cassirer als mächtiger Kunsthändler. Überdies war Liebermann eifriger Vertreter des französischen Impressionismus, den Nolde als ,undeutsch“verabscheute. Er suchte vielmehr nach einer eigenständigen ,deutschen' Ausdrucksform und meinte, sie im Expressionismus gefunden zu haben. Und eckte damit auch bei anderen (jüdischen) Kunsthändlern an. Es ist tragisch, dass diejenigen, die Nolde in seiner Karriere behinderten, Juden waren. Und das in einer Zeit, wo der Antisemitismus politisch gewollt war. Wir, die wir das Glück der späten Geburt haben, haben schnell den Stempel ,Antisemit‘ bei der Hand. Er muss nicht stimmen.“

Das ist die „Vorgeschichte“ des „,vermeintlichen ,Antisemitismus““. Aber der „Stempel ,Antisemit“ stimmt nicht. Warum nicht? Offenbar deswegen, weil das, was Nolde bestimmt, keine Ideologie war, sondern eine persönliche Erfahrung. Damit übernimmt Schulz selbst eine zentrale Rechtfertigungsfigur des Antisemitismus. Julijana Ranc hat deren Wirken, unter dem Begriff der „Kausaltäuschung“, so beschrieben:

„Wie alle Ressentimentgeleiteten [...] wollen Antisemiten deshalb auch das, was sie umtreibt, als etwas anderes verstehen oder verstanden wissen als das, was es ist: Nämlich als unvermittelte und kausal begründbare Reaktion auf ein Sosein oder Verhalten derjenigen, die sie in Wirklichkeit bereits durch das ,Giftauge des Ressentiments“ abschätzen und gegen die ihre Aversion - via Projektion - bereits disponiert ist. Die Genese ihrer Aversion (und der Aversion ihrer Brüder und Schwerstern im Geiste) gegenüber Juden machen sie kausal an diesen selbst fest und dichten ihnen dergestalt, implizit oder explizit, zugleich die Schuld am Antisemitismus an."

Warum aber greift Schulz zu einer solchen Argumentation, die darauf zielt, den „Stempel des Antisemitismus" als falsch zu erweisen und warum nimmt er in Kauf, dafür selbst noch einmal antisemitisch konnotierte Muster zu wiederholen? Es fällt auf, dass Schulz keine Argumente vorweist, die sich mit dem Begriff Antisemitismus auseinandersetzen und etwa einen Vergleich vornähmen zwischen dem, was eine antisemitische Position

${ }^{5}$ Julijana Ranc, „Eventuell nichtgewollter Antisemitismus“. Zur Kommunikation antisemitischer Ressentiments unter deutschen Durchschnittsbürgern, Münster 2016, S. $21 \mathrm{f}$. 
wäre und dem, was Nolde selbst vertritt. Nolde selbst kommt bei Schulz nicht zu Wort. Der Frage, worin Noldes Antisemitismus sich äußerte, wird ausgewichen, stattdessen wird dieser biografisch gerechtfertigt. Und als durch Erfahrung gerechtfertigt wird er abgetrennt von dem, was als ,politisch gewollter Antisemitismus“ firmiert. Behauptet wird, gegen die offensichtlichen Zeugnisse, dass Nolde mit diesem Antisemitismus nichts zu tun gehabt habe. Noch einmal, warum?

Würde Schulz mit seiner Argumentation durchdringen, dann wäre das Wissen, das mühsam und nach einer Geschichte des Ausblendens und des Umschreibens, der Lüge und der Auslassung verfügbar ist, wenigstens für den Fall Nolde, wieder zurückgenommen und der Stand der 1950er-Jahre wäre wiederhergestellt. Zu fragen ist aber, ob Argumentationen, die wie eine Wiederholung der Abwehrhaltungen der 1950erJahre anmuten, heute die gleiche Bedeutung haben wie damals. Jede Wiederholung verändert. Wenn es darum geht, die „überwertige Identifikation“ aufrechtzuerhalten, dann gilt diese jetzt der Gesellschaft, die für sich in Anspruch nimmt, Geschichte in einer vorbildlichen Weise „aufgearbeitet“ zu haben. Die Figur des Malers Emil Nolde selbst spielt eine Rolle in der Geschichte dieser Aufarbeitung. Sie ist, in der literarischen Umformung, die ihr Siegfried Lenz in dem 1968 erschienenen Roman „Deutschstunde“ gab, für Generationen in Westdeutschland Schullektüre gewesen. Im Roman wird aus dem immer durchscheinenden Vorbild Noldes der widerständige und vom Nationalsozialismus verfolgte Maler Max Ludwig Nansen. Lenz hat den Anspruch dieses Romans damit bezeichnet, Antworten zu finden auf die Frage, ,wie geschehen konnte, was in diesem Land geschehen ist" "6. Aber gerade in dem Anspruch, verstehen zu wollen, wie ,geschehen konnte, was in diesem Land geschehen ist", wird Wesentliches ausgeblendet. Fragen werden nicht gestellt, Umdeutungen akzeptiert, und das „was in diesem Land geschehen ist“ verändert seine Bedeutung ins Ungewisse. „Auf den sechshundert Seiten der ,Deutschstunde‘ fällt das Wort Jude nicht einziges Mal - und dies, obwohl die im bäuerlichen und kleinbürgerlichen Milieu angesiedelte Handlung sonst nichts und niemanden vergisst, nicht den Landpfarrer und den Dorfschullehrer, nicht den Parteibonzen und den Kriegsversehrten, nicht den Briefträger, den Kneipenwirt und den Heimatforscher [...] Norddeutsche Landjuden aber gibt es ebenso wenig wie völkischen Antisemitismus. "7 Wenn man das Bild der Schullektüre und das der geschichtlichen Realität übereinanderlegt, wird aus dem Antisemiten und Nationalsozialisten der in seiner Kreativität und seiner rebellischen Unangepasstheit vorbildliche Maler.

Schulz' späte Wiederholung der Schuldabwehrgeste muss verstanden werden als Versuch, diese Ausblendung und Umdeutung aufrechtzuerhalten. Sie aufzugeben würde etwas verändern. Die Frage, warum die „Aufarbeitung des Nationalsozialismus“ so wenig zu einem angemessenen Verständnis von Antisemitismus beigetragen hat, sollte hier

${ }^{6}$ Hieber, Der Erzähler.

${ }^{7}$ Ebd. 
nach Antworten suchen. Schulz formuliert in vorgeblicher Selbstanklage: „Wir, die wir das Glück der späten Geburt haben, haben schnell den Stempel ,Antisemit ' bei der Hand.“8 Das ,schnell bei der Hand“ formuliert ein Verbot, das die meisten, die in erster, zweiter oder dritter Generation nach der NS-Zeit in den postnazistischen Gesellschaften aufgewachsen sind, kennen. Es ist das intergenerationell ausgesprochene Verbot, über eine Zeit zu urteilen, die man nicht erlebt hat. Ein moralischer vorgetragener Anspruch darauf, nicht moralisch beurteilt zu werden, mit Folgen, die als Beschädigung des moralischen Urteilsvermögens weiterwirken. Moralische Fragen aber sind es, um die es Schulz in seiner Pfingstandacht geht.

Obwohl die Ausführungen zu Nolde als Nachwort abgesetzt sind, bilden sie einen integralen Teil der Andacht. Erst wenn man den ersten Teil hinzunimmt, wird deutlich, welche religiöse und moralische Bedeutung der Entgegensetzung von Nolde und Liebermann zukommt. Denn tatsächlich ist sie bereits in der Pfingstgeschichte, wie Schulz sie erzählt, vorweggenommen. Sie beginnt damit, dass die Jünger Jesu sich nach dessen Tod „hinter verschlossenen Türen“ verbergen, „während draußen ihre jüdischen Verwandten ,Schawuot ' feiern“. Der Geist kommt über die Jünger und sie verlassen ,ihr verschlossenes, enges Haus, treten hinaus in die Weite des Tempelberges und erzählen den Tausenden da draußen von Jesus, vom Kommen des Reiches, wo Frieden und Gerechtigkeit herrschen, wo Barmherzigkeit stärker ist als Gier, Zuversicht stärker als Hoffnungslosigkeit“.?

Wie ein Echo verhalten sich diese Entgegensetzungen zu dem, was wir über Noldes Leben erfahren haben. Draußen die heimlich feiernden Jünger, eingesperrt erst, dann heraustretend, die wie Nolde die „Frömmigkeit“ besitzen, die sich „aus Fantasie und Ekstase speist“. Damit ist eine Entgegensetzung etabliert, die, wie in alter Ersetzungstheologie, die Pole des Guten und Verworfenen auf Kirche und Synagoge, auf Christen und Juden verteilt. In einer Anwendung für heute wird diese Polarisierung im Text in Frageform aufgenommen:

„Wer hat zum Beispiel recht: Der Geist des Geldes, der Märkte, der Massentierhaltung, der Atomlobby? Oder der Geist des einfachen Lebens, der Bescheidenheit, des ehrenamtlichen Einsatzes? Oder hat das eine mit dem anderen nichts zu tun? Gilt nun der Geist der Konkurrenz und des Individualismus oder doch der einer gemeinsamen Suche nach gangbaren Wegen in eine gemeinsam gestaltete Zukunft?" 10

Die Fragen sind rhetorisch, der „Geist der Wahrheit“ und der „Geist des Lebens“ stehen gegen den „Geist des Geldes“. Über die Frage, so Schulz, wie man vom Geist des Geldes zum Geist der Wahrheit komme, „müssten wir gemeinsam nachdenken. Der Sache auf den Grund gehen - wie Nolde.“ Und genau das geschieht dann in dem „Nachwort: Nolde - ein Nazi?“ Hier erfolgt die Einsetzung. Mit dem Geist des Geldes sind „die

8 Schulz, Heiliger Durchblick.

${ }^{9}$ Ebd.

10 Ebd. 
dominierenden Kräfte des damaligen Kunstmarktes, Liebermann als Maler, Cassirer als mächtiger Kunsthändler" gemeint. Dagegen steht der Geist des einfachen Lebens: „Noldes Frömmigkeit, die sich aus Fantasie und Ekstase speiste, aus einer tiefen Innerlichkeit."11 Die Behauptung, Nolde sei kein Antisemit gewesen, dient offenbar dazu, den moralischen Impuls, den Schulz in Nolde sieht, aufrechterhalten zu können er soll als moralische Person gerettet werden.

Nolde selbst übrigens hat seine Auseinandersetzung mit Liebermann anders geschildert; er nannte sie „meine um 1910 geführten Kulturkämpfe gegen die herrschende Überfremdung in allem Künstlerischen und gegen die alles beherrschende jüdische Macht“. ${ }^{12}$ Dass Schulz das auslässt, scheint mir entscheidend. Was nicht in den Blick geraten soll, ist der Antisemitismus, der sich selbst als moralisch überlegen gegen die „allesbeherrschende jüdische Macht“ rechtfertigte.

Nichts davon steht für sich allein oder ist untypisch. Ähnliches z. B. geschieht in Silvio Viettas mit weitaus höherem intellektuellen Anspruch unternommenen Versuch zur Rettung von Martin Heideggers „Globalisierungskritik“, die auf die Diskussion um die postum veröffentlichten „Schwarzen Hefte“13 reagiert. Den dort offen zutage tretenden Antisemitismus deutet Vietta um in ,Judenkritik“. Auch dazu muss der paranoidideologische Kern des Antisemitismus - die Verschwörung des Weltjudentums ausgespart werden. So wird die Geschichte zu etwas, das beiseitegelassen werden kann, und wichtig wäre allein die Intention dessen, was Heidegger dachte oder meinte und nicht seine Zeitgenossenschaft zum Mord an den europäischen Juden. Es mag so aussehen, als wiederhole Vietta hier nur die Darstellung, die Heideggers Apologeten nach 1945 verbreiteten und nach der auf die kurzzeitige Nähe zum Nationalsozialismus eine innere und äußere Distanzierung folgte. Die Neufassung des Antisemitismus, nach der Shoah und im Wissen um sie, die Heidegger nach 1945 betrieben hat, wurde nicht benannt, ja vielleicht nicht einmal erkannt. Sie verfiel dem blinden Blick. Heidegger schrieb auf die Vorhaltungen Herbert Marcuses, dass ein Philosoph sich nicht täuschen könne „über ein Regime, das Millionen von Juden umgebracht hat - bloß weil sie Juden waren“ am 13. Mai 1948: „[...] ich kann nur hinzufügen, daß statt ,Juden“, Ostdeutsche“ zu stehen hat und das dann genauso gilt für einen der Alliierten" ". ${ }^{14}$

Diese Täter-Opfer-Umkehr ist nicht ungewöhnlich, Heidegger bei weitem nicht der Einzige, der darauf verfiel, aber offenbar ist das Wissen und das Bewusstsein davon, in welchem Ausmaß das geschah, nicht nur bei „Meisterdenkern“, sondern spontan überall im besiegten Deutschland, etwas, das immer noch abgewehrt wird. Was Donatella Di Cesare über Heidegger schreibt, charakterisiert eine verbreitete Haltung der unmittelbaren Nachkriegszeit: „Die Juden werden nazifiziert, während die Deutschen

11 Ebd.

12 Zit. n. Hieber, Erzähler.

13 Silvio Vietta, „Etwas rast um den Erdball...“ Martin Heidegger: Ambivalente Existenz und Globalisierungskritik, Paderborn 2015.

${ }^{14}$ Ebd., S. 80. 
gleichsam hebräisiert und zu Opfern gemacht werden - in einer Rollenverdrehung, die nach der Shoah auch in anderen Zusammenhängen erfolgreich wiederholt wurde." 15 Diese Umkehr wird bei Heidegger noch weiter aufgeladen und begründet. Seine „Zivilisationskritik“, von der Vietta spricht, setzt Heidegger fort. In den Bremer Vorträgen von 1949 erklärt er: „Ackerbau ist jetzt motorisierte Ernährungsindustrie, im Wesen das Selbe wie die Fabrikation von Leichen in Gaskammern und Vernichtungslagern, das Selbe wie die Blockade und Aushungerung von Ländern, das Selbe wie die Fabrikation von Wasserstoffbomben. "16 In dieser „Zivilisationskritik“ sind "Juden" Agenten der Moderne, oder in Heideggers Worten: „Die zeitweilige Machtsteigerung des Judentums hat aber darin ihren Grund, daß die Metaphysik des Abendlandes, zumal in ihrer neuzeitlichen Entfaltung, die Ansatzstelle bot für das Sichbreitmachen einer sonst leeren Rationalität und Rechenfähigkeit“. ${ }^{17}$ „Genau besehen“, schreibt Vietta dazu, ,ist dies - wie auch die frühere Juden-Kritik Heideggers - ein Stück Kulturkritik, kein biologischer Antisemitismus [...]." ${ }^{18}$ Der Zeitpunkt der Notiz über das „Sichbreitmachen“ fällt zusammen mit dem Beginn der Vernichtung des europäischen Judentums, etwas, worauf Vietta nicht hinweist, was er auch nicht zu bedenken scheint. Und er erwähnt nicht, welche Konsequenz diese „kulturkritische“ Identifizierung von Judentum und moderner „Rationalität und Rechenfähigkeit“ hat. Di Cesare fasst die Absicht dieser Argumentation, die Heidegger nach verlorenem Krieg fortspinnt, so zusammen: „Die Juden haben sich selbst vernichtet."19 In Heideggers eigenen Worten: „Wenn erst das wesenhaft ,Jüdische“ im metaphysischen Sinne gegen das Jüdische kämpft, ist der Höhepunkt der Selbstvernichtung in der Geschichte erreicht." 20

Das Anfang der 1950er-Jahre durchgeführte „Gruppenexperiment“ des Frankfurter Instituts für Sozialforschung bewahrte nicht nur entsprechendes Material, es bleibt ein methodisches Vorbild, wie auch heute an und mit den kurrenten Äußerungen zu arbeiten wäre, um Funktion und Wirkung des antisemitischen Syndroms in seiner gesellschaftlichen Dimension erkennen und bearbeiten zu können. ${ }^{21}$ Die Befassung mit dem historischen Material kann dann helfen, die Kontinuität des Antisemitismus zu verstehen, die darin besteht, die stereotypen Bilder über den Wandel der Zeiten konstant zu halten, sie aber aufzuladen mit der (verleugneten) Macht des Geschehenen. Die Juden

${ }^{15}$ Donatella Di Cesare, Heidegger, die Juden, die Shoah, Frankfurt a. M. 2016, S. 321.

16 Martin Heidegger, Bremer und Freiburger Vorträge (Gesamtausgabe 79), Frankfurt a. M. 2005, S. 27.

${ }_{17}$ Martin Heidegger, Überlegungen XII-XV. Schwarze Hefte 1939-1941 (Gesamtausgabe 96), Frankfurt a. M. 2014, S. 46, zit. n. Vietta, Etwas rast, S. 171.

18 Ebd.

${ }_{19}^{19}$ Di Cesare, Heidegger, S. 310.

${ }^{20}$ Martin Heidegger, Anmerkungen I-V. Schwarze Hefte 1942-1948 (Gesamtausgabe 97), Frankfurt a. M. 2015, S. 20, zit. n. ebd.

${ }_{21}$ Friedrich Pollock, Gruppenexperiment. Ein Studienbericht, Frankfurt a. M. 1955; Vgl. zu dem hier angerissenen Sachverhalt Jan Lohl, „Deutsche fordern: Juden raus“. Antisemitismus nach Auschwitz im Alltagsdiskurs der 1950er Jahre, in: Charlotte Busch/Martin Gehrlein/Tom David Uhlig (Hrsg.), Schiefheilungen. Zeitgenössische Betrachtungen über Antisemitismus, Wiesbaden 2016, S. 131-153. 
des antisemitischen Bedürfnisses sind so gleichzeitig Phantasien der Macht, als deren eigentliches Opfer der Antisemit sich imaginiert, und Erinnerung an die Schwäche derer, die umgebracht wurden. Diese widersinnige Vorstellung enthält die destruktive Macht des Antisemitismus, in der der Nationalsozialismus weiterwirkt. Wir müssen an aktuellen Äußerungen zu verstehen versuchen, was Saul Friedländer über den „Widerschein des Nationalsozialismus" formuliert hat:

„In erster Linie geht es mir um eine Form, der Realität sich zu stellen, die zugleich ein Ausweichen vor ihr ist, um die Neutralisierung der Vergangenheit, um die Verschleierung - ob nun bewusst oder nicht - dessen, was an dieser Vergangenheit unerträglich bleibt. Hauptsächlich geht es also um einen Vorgang in der Gegenwart. Doch so seltsam es auf den ersten Blick scheinen mag: Auch der Nazismus selbst verstand es, sich der Realität zu stellen und ihr gleichzeitig auszuweichen. "'22

Die Bereitschaft, das Verbrechen zu leugnen, die Opfer als Sieger und als Täter zu imaginieren, lässt sich als Wunsch nach Wiederholung verstehen. Deswegen auch ist die Ähnlichkeit zwischen Äußerungen der Nachkriegszeit und heutigen Argumentationen kein Hinweis auf geschichtliche Kontinuität, sondern als Aktualisierung zu verstehen. Der Wunsch besteht fort und im Versuch der Abwehr erneuert er sich - und damit auch die Schuld. Dunkel ist das dem antisemitischen Wahn bewusst: deutlich wird das in der Abwehr, mit dem die Kritik am Antisemitismus als Verfolgung wahrgenommen wird. Methodisch aber bedeutet das, dass für die Wahrnehmung und für die Analyse des gegenwärtigen Antisemitismus immer auf die Abwehr- und Vermeidungsmechanismen $\mathrm{zu}$ achten ist, um zu verstehen, was dem Blick entzogen wird. In Schulz’ „Heiliger Durchblick“" war es das Phantasma der , jüdischen Macht“.

\section{„Die sind doch selber schuld.“ - Opfervorstellungen}

Eine ähnliche Konstellation in einem völlig anderen Setting: Teilnehmende in einem von mir geleiteten Lehrgang des zweiten Bildungsweges sollten im Unterrichtsgespräch den Begriff „Satire“ klären. In diesem Zusammenhang fiel der Name der Zeitschrift Charlie Hebdo. Der Anschlag auf die Redaktion lag drei Monate zurück. Ein junger Mann, der im folgenden N. genannt wird, reagierte auf den Namen und rief: „Die sind doch selber schuld!“ Mit „die“" waren die Opfer des Attentats gemeint.

Ich hatte Gelegenheit, diese Unterrichtssituation in Workshops nachzustellen. Beobachtungen aus dieser Rekonstruktion fließen in meine Überlegungen zu dem ein, was dort geschah, was gesagt, was gemeint und was verstanden wurde. Auf mich wirkte dieses „Die sind selber schuld!“ wie ein Schlag. Die sofortige Folge der Äußerung (vielleicht auch eine Reaktion auf meine nicht geäußerte, aber vielleicht sichtbare oder spürbar Emotion) war Stille im Raum. Eine anhaltende Stille, in der sich ein Gespräch

22 Saul Friedländer, Kitsch und Tod. Der Widerschein des Nazismus, München 1986, S. 74f. 
entspann, an der sich außer N. und mir nur noch eine weitere Person beteiligte: ein Mann, der sich in eine solidarische Gemeinschaft mit N. begab. Zunächst fragte ich nach: „Wie meinen Sie das, selber schuld?“, worauf N. entgegnete: „Die wussten doch, was ihnen droht.“ Auf die anschließende Frage: „Wie hätten sie das wissen sollen?“ antwortete er: „Das ist wie an einem Becken mit Piranhas. Wer da den Fuß reinhält...“

Ich fühlte mich unsicher, ein Gefühl, das auch die Teilnehmenden der Workshops erlebten. Die Unsicherheit führt zu Fragen wie diese: Sollte man N. dazu bringen, dass er diese Äußerung zurücknimmt? Würde er dadurch zu einer Rechtfertigung seiner Position verleitet? Wollen wir noch verstehen, wollen wir urteilen oder ausschließen? Ich werde diese Fragen hier nicht beantworten, auch wenn sie berechtigt sind. Interessant ist, wie sich die Haltung zu N. veränderte, je nachdem, welche Informationen über ihn die Teilnehmenden erhielten (oder sich ausmalten). Die Frage aber, die ich in den Workshops stellte, lautete: Ist das eine antisemitische Äußerung?

Einig waren sich die Teilnehmenden über zweierlei: dass es sich um eine Rechtfertigung von Gewalt handelte und dass sie deswegen in einer Unterrichtssituation nicht unwidersprochen stehen bleiben dürfe. Ziemlich schnell wurde spekuliert, dass es sich um einen muslimischen Schüler handelt, der religiös sei. Wahrscheinlich teile er die Empörung oder die Wut über die Karikaturen, die den Propheten Mohammed verspotteten. - Aber Antisemitismus? Mancher fiel dann ein, dass der Anschlag, der sich am Tag nach den Morden in der Reaktion von Charlie Hebdo ereignete, auf einen koscheren Supermarkt zielte und dort Juden traf. Aber das war ja nicht das, was bei Charlie Hebdo geschah. Was macht einen Anschlag zu einem antisemitischen Anschlag? Und wie vermittelt sich das im Reden über den Anschlag?

Den Zusammenhang hatte - in der Unterrichtssituation - N. selbst hergestellt. Mein Ziel war zunächst, wenig reflektiert, eine Art Einigung darauf zu erzielen, dass es nicht richtig und auch nicht zu rechtfertigen sei, Menschen wegen ihrer Äußerungen umzubringen. N. wechselte die Argumentation. „Überall sonst werden Menschen umgebracht und das kümmert hier keinen. Muslime werden umgebracht, aber das ist egal. Und außerdem: Es ist doch klar, wer dahinter steckt: Das weiß doch jeder. Das waren die Juden."

Schilderte ich diesen Fortgang, oder spielte die Rekonstruktion die Situation bis zu diesem Punkt weiter, wurde der Bezug zum Antisemitismus offensichtlich. Aber musste dafür das Wort „die Juden“ tatsächlich fallen? Meinem Eindruck nach stand der Antisemitismus ähnlich offen im Raum wie die Bejahung der Gewalt. Denn als solches habe ich dieses „Die sind doch selber schuld“ verstanden. Nicht allein des Inhalts der Worte wegen, sondern wegen einer schwer zu beschreibenden emotionalen Tönung, mit der sie ausgesprochen wurden: aufgeregt und kalt. Danach überraschte mich die Aussage, „die Juden“" steckten dahinter, nicht mehr. Mit Methoden der Vorurteilsforschung aber wäre an der Aussage „Die sind doch selbst schuld“ Antisemitismus nicht zu erkennen. Meine Beobachtungen bei den Diskussionen, die ich über diese Szene führen konnte, verdichten sich zu folgender Vermutung: Der Versuch, mit einer Äußerung wie der geschilderten umzugehen, die eigene Irritation zu bewältigen und der Störung, die mit 
dieser Äußerung einhergeht pädagogisch zu begegnen, führt leicht zu Interpretationen, in denen Abspaltungen und Trennungen die Wahrnehmung des Antisemitismus verhindern. Der Fokus auf N., seine Intentionen und seine Biografie, verstellt den Blick auf das Wesentliche.

Genauer gesagt: Das geschah bereits in der ursprünglichen Unterrichtssituation. Da war es N. selbst, der versuchte, den mit seiner Äußerung „Das waren doch die Juden“ manifest gewordenen Antisemitismus wieder unsichtbar werden zu lassen. N. griff zu einer sprachlichen Korrektur: „Entschuldigung, nicht Juden. Ich habe Israel gemeint. Israel steckt dahinter.“ Ändert das etwas? Und hängt das von der Biografie, von seinen Erlebnissen ab? ,Jetzt stehe ich hier als der einzige Antisemit da“, sagte er etwas später. In der Rekonstruktion der Szene habe ich eine anrührende Geste erlebt. Eine Frau wandte sich demjenigen zu, der die Rolle des N. spielte, beugte sich zu ihm, machte sich klein und redete ihn mit einer Freundlichkeit an, in der ich Traurigkeit hörte und die mitfühlend gemeint war: „Du bist sicher auch mal Opfer gewesen“, sagte sie. Ich bin mir nicht sicher, ob das Mitgefühl oder die Trauer richtig zugeordnet war: Bewusst schien sie bezogen auf seine Vergangenheit. Die Deutung, von der sie ausging, lautete, dass seine Aggression, seine Lust an der Beschuldigung der Juden aus seinen Erfahrungen von Ausgrenzung und Diskriminierung rührte.

Auch scheint mir fraglich, ob die Geste und die damit verbundene Intervention helfen kann: denn das setzte voraus, dass N. das Hilfsangebot darin erkennen würde und nicht allein die Schwäche des sich Kleinmachens. Aber könnte es sein, dass die Trauer, unbewusst, nicht der Vergangenheit galt, sondern dem Ziel, das in der Äußerung lag: dass N. Teil einer Opfergemeinschaft werden würde, bereit, zu opfern und geopfert zu werden. Dazu kann einem ein Bild einfallen, wie das, das in Schulbüchern der palästinensischen Autonomiebehörde verbreitet wird. Es zeigt Jungen und Mädchen, gemeinsam in einer Klasse. Sie alle haben die Augen gerichtet auf den einzig leeren Platz, einen leeren, mit Blumen geschmückten Stuhl, ein Ort der Bewunderung und der Sehnsucht, bezeichnet mit dem Wort: Märtyrer. ${ }^{23}$

Die Trauer sollte, so denke ich, der Rechtfertigung des Mordes gelten und der Opferbereitschaft, die darin anklingt. Das heißt nicht, darin eine Drohung oder die Gefahr einer „Radikalisierung“ zu erkennen und den jungen Mann auf dem Weg in den Dschihad zu sehen. Auch das wäre eine Möglichkeit, sich durch übertriebene Angst, durch Hysterie und Zuschreibung der Wahrnehmung zu entziehen. Wahrzunehmen wäre: die Faszination für die Wiederholung von Gewalt und Opfer und gleichzeitig die Leugnung davon: es waren die Juden und es werden die Juden sein.

In der Äußerung von N., das war mein unmittelbarer und nachhaltiger Eindruck, ist Gewalt spürbar geworden. Aber zu unterscheiden ist zwischen der emotional verstandenen Bedeutung und der tatsächlichen Qualität in der äußeren Realität. Und da

${ }^{23}$ Eldad J. Pardo, Palestinian Elementary School Curriculum 2016-17. Radicalization and Revival of the PLO Program, Jerusalem 2017, S. 9. 
gilt: Die Äußerung selbst ist - in diesem Raum und in diesem Umfeld - keine Gewalt. „Die sind selber schuld“ und „das waren die Juden“ sind Äußerungen, die darauf hinweisen, dass in der Verschwörungsbehauptung die Freude über die Gewalt und die Leugnung der Täterschaft zusammengehen. Das lässt sich verallgemeinern: Verbalantisemitismen sind an die Gewalttat historisch gebunden. Diese Verbindung ist ain den psychischen Repräsentanzen bewahrt, auch wenn das Bewusstsein sie verneint. Das erklärt, warum diese Verbindung so leicht in den Fokus des blinden Blicks gerät. Beispielhaft ist das zu erkennen, wenn der Philosoph Georg Meggle in seinem den Antisemitismus definitorisch entwirklichenden Text „Wer ist Antisemit“ schreibt: „Zur Erinnerung: Ein Antisemit sein heißt, eine Einstellung zu haben, die zu Recht absolut moralisch verwerflich ist. Das direkte Spiegelbild davon ist: Einen anderen als ,Antisemiten` zu bezeichnen, ist einer der schlimmsten Vorwürfe, die man einem Mitmenschen gegenüber erheben kann. Vor dem Hintergrund von Auschwitz vielleicht der schlimmste überhaupt. Was man dabei fast immer vergisst, aber nie vergessen sollte: Auch Worte können töten. Rufmord - das ist keine bloße Metapher. TotschlagArgumente schlagen nicht nur Argumente tot. “24

In dieser Umkehr (Antisemiten haben eine Einstellung, wer jemanden einen Antisemiten nennt, tötet ihn) ist das Verhältnis zwischen Antisemitismus und Gewalt bewahrt, wird aber durch die Umkehr unkenntlich, das Opfer ist der, der (fälschlich?) als Antisemit bezeichnet wird. In anderen Verneinungen wird die Tat von der Intention getrennt oder übersehen, dass antisemitische Vorstellungen auch Folge, nicht allein Motiv von antisemitischen Taten sind. Die Annahme, dass Aufklärung über die Shoah allein geeignet sei, Antisemitismus zu verhindern, übersieht, dass Gewalt und Vernichtung Faszination und Ziel des Antisemitismus sind. Gerade deswegen könnte es wichtig sein, das cover up, das über der Verbindung von Antisemitismus und Gewalt liegt - und seit der Shoah über jener von Antisemitismus und Vernichtung - aufzuheben. Statt der verleugnenden Trennung zwischen Antisemitismus und Vernichtung, die typisch für die postnazistischen Gesellschaft ist, wäre es wichtig, die psychische Freiheit zu erlangen, in der zwischen Gedanke, Wort und Tat zu unterscheiden ist und die es ermöglicht, die magische Verbindung zwischen Gedanke und Tat zu lösen, die auch dem Verschwörungsglauben zugrunde liegt und stattdessen die Realgeschichte der Gewalt als Grund der eigenen Phantasien zu erkennen. Das wäre eine Möglichkeit, antisemitische Ressentiments aufzugeben. Forderungen aber, Äußerungen zu strafen, kommen dem autoritären Wunsch entgegen, der vom Antisemitismus nicht zu trennen ist.

In der (ursprünglichen und reinszenierten) Unterrichtssituation blieb die Unsicherheit, wie angemessen zu reagieren wäre. Heike Radvan hat Fragen, die sich in diesem Zusammenhang stellen, zusammengestellt:

24 Georg Meggle, Wer ist Antisemit?, 2008, S. 14f., [https://www.sozphil.uni-leipzig.de/cm/philosophie/ files/2013/01/Wer-ist-Antisemit-08.pdf], eingesehen 13.7.2020. 
„Wie reagiere ich als Pädagogin auf eine antisemitische Aussage? Ist es sinnvoll, deren Ursprung und Motivation zu ergründen? Verbiete ich solche Äußerungen generell oder ist es zielführender, auf deren ,falsche Inhalte ${ }^{6} \mathrm{zu}$ verweisen? Ist es eine Option, das Statement zu ,überhören', da es sich um eine ,schlichte Provokation' gehandelt haben kann?" 25

Darin liegt der verständliche Wunsch nach einer Handlungsanweisung oder einem Rezept: Was wäre die richtige Verhaltensweise? Die Gefahr eines solchen Rezeptes liegt darin, anzunehmen, wir - nicht nur die pädagogisch Handelnden in der postnazistischen Gesellschaft - hätten im Wesentlichen schon verstanden, was Antisemitismus heute meint.

Die Metapher vom „blind eye“ lenkt aber demgegenüber die Aufmerksamkeit gerade auf die Möglichkeiten, die Bedeutung einer Äußerung tatsächlich zu überhören und den Antisemitismus damit zugleich zu übersehen. Naheliegend ist es, die Selbstrechtfertigung des N. aufzugreifen. Ändert sich nicht der Gehalt seiner Aussage tatsächlich, wenn nicht von Juden, sondern von Israel die Rede ist?

Macht die Formulierung nicht den Unterschied zwischen Kritik und Antisemitismus aus? Die scheinbar so schwierige Trennung von „Kritik an Israel“ und Antisemitismus bestimmt die gesellschaftliche Debatte über Antisemitismus in einer Vehemenz, dass die Frage danach zu einem bestimmenden Motiv der Abwehr geworden ist. Im hier geschilderten Fall verändert das Ersetzen des einen Worts durch das andere nichts am Gehalt der Aussage. Der Gehalt ist fixiert in der Phantasie, in der ein islamistischer Anschlag verschwindet und an seine Stelle eine Verschwörung tritt. Das aber zu verstehen fällt immer dann schwer, wenn Antisemitismus rationalisierend und verengend verstanden wird als die (mehr oder minder) hasserfüllte Ablehnung von realen Jüdinnen und Juden, die auf Vorurteilen oder auf falsch verallgemeinerter Erfahrung beruhe - und eben nicht als eine falsche und auf Gewalt zielende Scheinerklärung von Gesellschaft durch das Wirken geheimer und zu enttarnender Kräfte. Ob in antisemitischer Rede „Juden“ oder „Zionisten“ benannt werden, macht keinen Unterschied. Es scheint aber genau diese Phantasie von der Verschwörung zu sein, die Irritationen auslöst und (nicht nur) Pädagoginnen und Pädagogen überfordert.

Juljana Ranc hat in ihrer wichtigen Studie darauf hingewiesen, dass in den Gruppengesprächen, die sie auf antijüdische Ressentiments untersucht hat, „[o]ffenkundig verschwörungstheoretische Themensetzungen über Juden [...] gruppenübergreifend nur wenig resonanz- und interaktiv nicht etablierungsfähig" 26 waren. Dies deckt sich auch mit meiner Beobachtung bei Workshops mit Pädagoginnen und Pädagogen, bei denen zunächst kaum Wissen um „Verschwörungstheorien“

\footnotetext{
${ }^{25}$ Heike Radvan, Die Bedeutung von Kommunikation im Umgang mit Antisemitismus am Beispiel der offenen Jugendarbeit, in: Maron Mendel/Astrid Messerschmidt (Hrsg.), Fragiler Konsens. Antisemitismuskritische Bildung in der Migrationsgesellschaft, Frankfurt a. M. 2017, S. 43.

${ }^{26}$ Ranc, „Eventuell nichtgewollter Antisemitismus"rhebun, S. 48.
} 
vorhanden schien. Doch diese Beobachtung täuscht und es scheint sich eher um ein tabuisiertes Wissen zu handeln. Auch Ranc beobachtete hellhörig weiter:

„Allerdings schienen die meisten weitaus mehr über die Existenz und den Inhalt antijüdischer Verschwörungstheorien zu wissen als sie zuzugeben bereit waren. Dafür spricht eine oft schon im Ansatz, nach den ersten vagen Andeutungen greifbare atmosphärische Anspannung, eine vorausahnende Wachsamkeit in den Gesichtern so mancher Mitdiskutanten, sprechen kommunikative Verhaltenheit sowie sichtlich peinlich berührtes Schweigen. Auch kam es vor, daß man denjenigen, die sich gar zu weit aus dem Fenster zu lehnen drohten, eilfertig zur Seite sprang, etwa durch raschen Themenwechsel. Oder man ruderte gemeinsam ein Stück zurück. Wer ihrer Verpöntheit dergestalt Rechnung trägt, der kennt antijüdische Verschwörungstheorien. "27

Das muss, wie auch Ranc betont, nicht als Einverständnis gewertet werden. Ich schlage aber vor, es als Wunsch zu interpretieren, davon nichts wissen zu müssen, eben als ein Mechanismus des blinden Blicks. ${ }^{28}$ Das Wissen um die Virulenz antisemitischer Verschwörungsideologien, um ihre Quellen und jene, die sie propagieren, muss vorhanden sein, um in angemessener Weise einer Äußerung wie der von N. zu begegnen. Sie kommt weder aus dem Nichts noch ist sie das originelle Produkt der Phantasie dieses individuellen jungen Mannes. Wer nicht weiß, oder nicht wissen will, in welchen Zusammenhängen diese Verschwörungsbehauptungen kursieren, wird sie in ihrer gesellschaftlichen Bedeutung und Dynamik nicht verstehen. Trennungen und Zuweisungen liegen dann nahe, ähnlich der, die Otmar Schulz vornahm zwischen dem „politisch gewollten Antisemitismus“ und dem, was Nolde antrieb. Im Falle von N. und seiner Äußerung wäre es falsch, von einem importierten Antisemitismus zu sprechen, und zwar obwohl die Behauptung, Israel stecke hinter dem Anschlag, in Medien des Nahen Ostens prominent verbreitet wird.

Tatsächlich sieht das, was N. sagte, als Karikatur dargestellt so aus: Vor dem Hintergrund einer Stadtsilhouette, durch den Eiffelturm als Paris kenntlich, gehen zwei schwarz gekleidete und vermummte Männer, die gerade ein Auto verlassen haben, mit ihren Gewehren im Anschlag auf ein Tor zu, über dem der Schriftzug „Charlie Hebdo“ den Ort des Anschlags bezeichnet. An den Männern und an dem Auto sind Fäden befestigt, die zu einem einfachen hölzernen Spielkreuz führen und das von der Hand eines Marionettenspielers gehalten wird. Der Spieler selbst ist nicht zu sehen, der Arm ragt aus dem Himmel in den Bildraum und ist am Revers mit dem Davidstern kenntlich gemacht. Eine derartige Karikatur wurde über die iranische Seite irib.ir verbreitet.

${ }^{27}$ Ebd., S. 49, Hervorh. im Original.

28 Die Gespräche wurden 2005 bis 2007 geführt. Es ist zu vermuten, dass gesellschaftliche Veränderungen und die mediale Verfügbarkeit von Verschwörungsideologien das Sprechen darüber in den letzten Jahren verändert haben. Das ist ein Hinweis darauf, wie wichtig es für die kritische Auseinandersetzung mit Antisemitismus ist, seismisch genau Veränderungen zu registrieren und den Antisemitismus gerade nicht für etwas Unveränderliches zu nehmen - entgegen allem Augenschein. 
Die Behauptung, bei dem Anschlag auf Charlie Hebdo handele es sich nicht um das, was uns glauben gemacht wird, findet sich auch auf den Seiten eines im Sommer 2017 gegründeten Internetmagazins, das sich selbst als „Magazin für die kritische Masse“ bezeichnet:

„Bei Charlie Hebdo öffnen sich zufällig drei Mal sonst verschlossene Türen, und dieses Wunder muss geplant gewesen sein. Andernfalls, bei Türsprengungen, Geballer, Geiselnahmen und Geschrei, wären ja der Wachmann alarmiert worden, die Redaktionsmitglieder auf das Dach geflüchtet, die allgegenwärtige Polizei im Herzen der Hauptstadt Paris alarmiert worden. Kinder würden sagen: also ein Märchen..."29 Eine Andeutung genügt - wer das „Wunder“ geplant hat, wird nicht benannt. In welchem Verhältnis steht sie zu der manifest antisemitischen Verschwörungstheorie? Wahrscheinlich würde sich der Verfasser dagegen verwahren, wollte man ihm die antisemitische Intention unterstellen, die der anonyme Zeichner in der Karikatur offenbart. Mit der vorgeblichen Naivität eines Kinderblicks weist der Autor nur auf offenkundige Ungereimtheiten hin, die schon ein Kind erkennen ließen, dass hier etwas nicht stimme. Die Leichtigkeit, mit der die Lüge aufgedeckt wird, der große Plan durchschaut wird, erreicht der Autor durch die Perspektive eines Kindes. Dahinter steht eine Infantilisierung, die durch ihr Ausstellen überspielt wird. Denn die Bereitschaft, an Verschwörungsbehauptungen dieser Art zu glauben setzt tatsächlich eine Regression voraus: rationale Techniken verlieren an Bedeutung. Sprachliche und argumentative Mängel, die offenkundig sind, werden nicht mehr wahrgenommen und die Fähigkeit zur Realitätsprüfung lässt nach. Dem mit Medienkritik und Aufklärung entgegenzuwirken, stößt schnell an Grenzen. Wer Verschwörungsideologien anhängt, spielt mit oder verfällt magischem Denken. Aggression gegen die, die einen manipulieren, wird zur Selbstverteidigung. Der autoritäre Glaube an beliebige Experten geht einher mit einer Absage an Rationalität und Wissenschaft und verrät, dass der rationale, planende, verändernde Eingriff in die Welt für unmöglich oder für ethisch verboten gehalten wird. So sehr anzunehmen ist, dass all das Resultat einer Gesellschaft ist, in der Eigenwirksamkeit, Selbstbestimmtheit und Handlungsfreiheit real nicht erfahren werden, kritisiert eben Verschwörungsideologie jene Unfreiheit nicht, sondern behauptet eine Welt, in der der Ausweg in der Demaskierung der manipulierenden und herrschenden Kräfte liegt: dieser Ausweg aber ist selbst nichts anderes als magisches Denken. Enthüllen und das Brechen der Macht fallen zusammen, aber nur in der Phantasie. Daher ist der Verschwörungsglaube stete Quelle von Frustration - oder Erinnerung an und Versprechen von Gewalt. Der Aufstand, der geträumt oder geführt wird, richtet sich real gegen Schutzlose. Das ist die historische Wahrheit des Antisemitismus, um die alle wissen. Er richtet sich auch gegen die psychischen Repräsentanzen von Macht, die gefürchtet werden (als Manipulation, als Versagung, als Strafe), die aber als Rationalität,

29 Andreas Hauß, Terror-Logik, in: rubikon.news, 7.6.2017, [https://www.rubikon.news/artikel/terroralarm], eingesehen 13.7.2020. 
als Gesetz und als Empathie tendenziell fähig wären, als Bündnispartner für Aufklärung und $\mathrm{zu}$ erreichende Freiheit $\mathrm{zu}$ wirken. Das beschädigt auch die Fähigkeit zum moralischen Urteilen.

\section{Die moralische Geste}

Die Vorstellung einer umfassenden, die Geschichte bestimmenden, die Welt bedrohenden Macht steht im Zentrum des modernen Antisemitismus. Für den postnazistischen Antisemitismus bedeutet das, dass die Leugnung der Shoah die originäre Verschwörungsphantasie nach 1945 wird: die Phantasie des triumphierenden, des mächtigen Juden entsteht in ihr gegen alle Tatsächlichkeit neu. Und daher ist das Motiv der Schuldumkehr so zentral: es entlastet nicht nur die Täter und die, die mit ihnen familiär, generationell, gesellschaftlich und moralisch verbunden sind. Es stellt auch den wahnhaften Charakter des Antisemitismus (wieder) her. Worin besteht die Macht - nicht die Macht der imaginierten Juden, sondern die Macht dieser Vorstellung? Was erhält sie, ihrer Unsinnigkeit zum Trotz, am Leben? Und wie geht man heute mit dieser Vorstellung um? Ich habe mit zwei Beispielen zu zeigen versucht, dass das „blind eye“ angewiesen ist auf genau die Ausblendung dessen, was den modernen Antisemitismus ausmacht: die Vorstellung von der geheimen, erst aufzudeckenden jüdischen Macht. Dieses Tabu schützt den Antisemitismus. Es blendet aus, was die antisemitische Vernichtungswut im Nationalsozialismus antrieb, jene pervertierte Moral, die in den Juden die Feinde schlechthin ausmachte, die Feinde nicht allein der Deutschen, sondern aller Völker, als Kriegstreiber, als die Macht hinter dem Finanzkapital, den Plutokratien und dem Bolschewismus. Ausgeblendet wird so die Selbstwahrnehmung der Antisemiten: für eine Erlösung der Welt zu kämpfen, sich gegen die Mächtigen aufzulehnen. Unverstanden bleibt das Rebellische des antisemitischen Affekts. Was bleibt, ist ein Zerrbild des Antisemitismus. Und leicht wird aus der gesellschaftlichen Ablehnung des Antisemitismus, wie sie seit 1945 gilt, die Ablehnung allein dieses Zerrbildes von Antisemitismus, das so erfolgreich ist, weil es den historischen Antisemitismus vom heutigen trennt, und den historischen um seinen Kern bringt. Dieses Zerrbild ist gleichermaßen falsch für die NS-Zeit wie für die heutigen, postnationalsozialistischen Zeiten. Es entzieht die andauernde Verschmelzung von Ideologie und Gewalt dem Blick. Der übermächtige Feind, den es zu enttarnen gilt, war real schutzlos. Dieses Wissen ist - maskiert aber verfügbar - in die heutigen antisemitischen Verschwörungsideologien eingegangen. Das könnte erklären, warum der offenkundig unsinnige Gestus, der in der behaupteten kinderleichten Enttarnung der doch überaus Mächtigen besteht, so attraktiv ist. Ein NS-Propagandaplakat von 1943 zeigt, wie ein Arm einen Vorhang beiseite zieht, der das Gesicht eines als „Kriegsanstifter“ und „Kriegsverlängerer“ bezeichneten Juden 
entblößt und dem entschlossen die Fäuste drohen. ${ }^{30}$ Diese Geste des Enttarnens ist das, was Verschwörungsideologien ausmacht. Man muss das Zusammendenken mit dem Morden der Wehrlosen, das gleichzeitig stattfand. Es ist diese Verbindung, die in unserer Wahrnehmung tabuisiert wird. Mit den Bildern der Opfer, der Überlebenden verbinden wir das Wissen um die absolute Hilflosigkeit. Der Wahn, in ihnen die Herren der Welt zu sehen, bedarf der Trennung und der neuen Codierung. Die Geschichte der Verwendung des Begriffs „Zionismus“ in der Nachkriegszeit ist ein beredtes Beispiel für eine solche Neu-Codierung. Noch im Angesicht der Bilder aus den Vernichtungslagern beginnt eine „neue“ Geschichte der Umkehrungen, die bis heute fortgeschrieben wird. Ein aktuelles Beispiel für eine solche Neu-Codierung - das als gesprochenes Dokument mehr an Einsicht vermitteln kann, als die folgende Transkription - stammt aus der Tonne des verschwörungstheoretischen „Mülltrenners“31 KenFM. Der emotionale Gehalt, im Text zu erkennen, wird von der Stimme übertragen, die in einem knapp einstündigen Stakkato Auskunft über das Verhältnis von Hass und Kälte sowie von Phantasie und Moral gibt:

„Zionismus ist im Kern eine Ideologie, die der der Herrenrasse verdammt ähnlich ist. Beide Ideologien gehen und gingen davon aus, man selber würde den Übermenschen darstellen, der das von Gott gegebene Recht besäße, sich über andere, also Restmenschen zu erheben, um diese zu beherrschen. Das auserwählte Volk ist die andere Seite einer Medaille, der in Nazi-Deutschland die Aufschrift ,Herrenrasse‘ eingraviert war. Heil Hitler und Heiliges Land sind primitive Blut-und-Boden-Betriebssysteme. "32

Ken Jebsen, Autor und Sprecher dieses Textes, geriert sich in den letzten Jahren regelmäßig als Opfer unbegründeter oder falscher Antisemitismusvorwürfe. Diejenigen, die ihn verteidigen, vermeiden es, sich mit Aussagen wie den zitierten auseinanderzusetzen. Jebsens Internetprojekt KenFM ist gleichzeitig eines der Zentren, um die sich der vielgestaltige Verweisstruktur der Verschwörungsszenen dreht. Wenn auch die Intentionen der Schuldabwehr, die Täter-Opfer-Umkehr unübersehbar den Text strukturieren, sollte der aggressive Charakter, der auf die Gegenwart zielt, nicht übersehen werden. Ken Jebsen betreibt nicht vorrangig Geschichtspolitik, auch dann nicht, wenn er die USA und die Federal Reserve Bank als Drahtzieher hinter den Weltkriegen darstellt. ${ }^{33} \mathrm{Zu}$ erkennen ist hier vielmehr die Ähnlichkeit, in der die Umkehr, auch wenn sie unterschiedlichen Intentionen folgt, in der antisemitischen Aufladung übereinstimmt. Nicht zufällig steht der Massenmord, den Islamisten (und damit Anhänger einer Ideologie, in der Antisemitismus zentral ist) am 11. September 2001 in

\footnotetext{
${ }^{30}$ Hans Schweitzer [Mjölnir], Der Jude: Kriegsanstifter, Kriegsverlängerer, ca. 1943, [https://www.warmuseum.ca/collections/artifact/1023686], eingesehen 13.7.2020.

${ }^{31}$ Kurze Beschreibung über das Portal KenFM.de, in: KenFM.de, o. D., [https://kenfm.de], eingesehen 13.7.2020.

32 Die deutsch-israelische Freundschaft, in: KenFM.de, 20.11.2012, [https://kenfm.de/deutsch-israelische], eingesehen 13.7.2020.

33 Siehe exemplarisch: Schein-Demokratie, in: KenFM.de, 31.4.2014, [https://kenfm.de/kenfm-ueber-scheindemokratie], eingesehen 13.7.2020.
} 
den USA begingen, am Beginn einer neuen Virulenz von Verschwörungsideologien, mit denen die Täterschaft (oder gleich die Tat) in Abrede gestellt wird. Auch für KenFM ist das ein zentrales Thema - und es bedarf einer blindäugigen Trennung der Themen, um nicht den Antisemitismus als verbindendes Motiv zu erkennen. ${ }^{34}$

In der postnationalsozialistischen Ablehnung des Antisemitismus wird die gesellschaftliche Einigkeit erkauft durch das gemeinsame Nicht-Hinsehen auf diesen Zusammenhang. So bleibt unbegriffen, dass eben der Hass auf Israel, die Leugnung der Täterschaft von Islamisten und die Mobilisierung gegen die „Globalisten“" zusammengehören - und eine klar erkennbare gemeinsame inhaltliche Bestimmung aufweisen. In dieser Neuerfindung antisemitischer Topoi für unsere Zeit sind nicht die Motive neu - neu aber ist ihre gesellschaftliche, geschichtliche und emotionale Aufladung. Sie zu verstehen, kann nicht Aufgabe der Pädagogik allein sein. Ihre Rolle wäre es aber, Reflexionsräume zu eröffnen, in der die Wahrnehmung blinder Flecken möglich wird. Dazu muss aber die Abwehr, die sich in der Leugnung der Zusammenhänge ausdrückt, gezielt in den Blick genommen werden.

\section{Schluss}

Die moralische Rettung der eigenen Haltung - das sollten die Beispiele zeigen - verkennt den Antisemitismus, um ihn nicht in den eigenen Motiven erkennen zu müssen. So wird ein Text wie jener von Jebsen, genauso wie das pfingstliche Plädoyer gegen den „Geist des Geldes, der Märkte, der Massentierhaltung, der Atomlobby“ und für den „Geist des einfachen Lebens, der Bescheidenheit“ nicht einfach durch die vorgebrachten Antisemitismen kontaminiert - sondern sie erscheinen als moralisch richtig und als Ausdruck kritischen Denkens. Dadurch aber, dass in diesem Sprechen antisemitisches Denken neu aufgeladen und geprägt wird, geht Gegenwärtiges in die Stereotype ein und wird von denen, die ihm anhängen, wider die geschichtliche Erfahrung rationalisiert und verteidigt. Heute sehen wir, gerade in den Debatten um den Antisemitismus, dass unter der Forderung, man müsse doch sagen dürfen, moralische Ansprüche formuliert werden. „Beunruhigend an der neuen Debatte ist jedoch,“ schrieb Werner Konitzer bereits 2005, „dass diese Operation scheinbar unlösbar verknüpft ist mit der Frage danach, ob man überhaupt, und wenn ja, was man gegen Israel, gegen das Judentum oder gegen Juden sagen darf. Diese Verknüpfung geht, so vermute ich, auf die enge Verschränkung von Moral und Verfolgung zurück, die der Nationalsozialismus nicht erst geschaffen, sondern nur radikalisiert hat. Auf sie reagierte nach dem Ende des Zweiten Weltkriegs jenes ,kommunikative Beschweigen' [...], in dem sich trotz gleichzeitiger ideologischer

${ }^{34}$ Für das Verhältnis von Verschwörungsideologie und (verdrängter) Gewalt ist der Effekt lehrreich, den Daniele Ganser bei seinen Vorträgen erzielt. Das Bild der Trümmerstätte im Stadtzentrum New Yorks löst bei den Zuhörerinnen und Zuhörern Lachen aus. Daniele Ganser, Wir wurden alle getäuscht, in: YouTube, 25.4.2017, [https://youtu.be/klYEWL-81GE], eingesehen 13.7.2020. 
Distanzierung unschwer eine Modifizierung der alten Komplizengemeinschaft unter den Gegebenheiten eines reformierten Moralsystems erkennen lässt. In den letzten Jahren wurde diese Symptomatik zusehends durch eine Konzeption ersetzt, die Auschwitz zu einer Art von Gründungsmythos der Bundesrepublik Deutschland adelt. An die Auseinandersetzung mit der alten, tradierten Moral trat etwas, das man als das ,Tabu des Antisemitismus' bis heute zu bezeichnen nicht aufgehört hat. " 35

Dieses Tabu, das aus der ausgebliebenen Auseinandersetzung folgt, könnte sich heute als der blinde Fleck entpuppen, der die Errungenschaften auch der kritischen pädagogischen Intervention gegen den Antisemitismus verunmöglicht. Der sich quer zu politische Zuordnungen und über unterschiedliche Intentionen hinweg herstellende Zusammenhang des antisemitischen Syndroms tritt als moralische Befreiung auf. Die gesellschaftlichen und psychologischen Bedingungen, die es erlauben, Befreiung als Opfer zu ersehnen, bilden immer wieder einen erneuerten Anreiz, dessen Dynamik nicht absehbar ist, sich in die antisemitische Tradition einzureihen. Sie erlaubt es, die eigenen Vernichtungswünsche als moralische Geste zu erleben. Der wahnhafte Blick auf jüdische Israelis, wie er in Jebsens Text aufscheint, ist unschwer als Beschwörung von Gewalt gegen das „,auserwählte Volk“ zu dechiffrieren. Nichts daran ist, was zu sein die Rede vorgibt: Kritik. Es handelt sich um eine Phantasie, in der das Böse enttarnt wird - die Macht, die uns alle im Griff hält und die uns manipuliert, findet ihren Widerpart in einem Wir, das sich als Opfer wähnt.

Auch wenn das Wissen um die historische Realität der Vernichtung aus dem Bewusstsein verdrängt und abgewehrt wird, so kann der antisemitische Wahn im Postnazismus dennoch nicht mehr hinter diese historische Erfahrung zurück. Kritik, die es ermöglicht, der antisemitischen Tradition $\mathrm{zu}$ entgehen, muss diesen Zusammenhang von Irrationalität und Gewalt benennen, um ihn zu unterbrechen. Dazu bedarf es der gesellschaftlichen Reflexion, für die, kontrastierend zu den Fortschritten, die es gerade in der Pädagogik gegen Antisemitismus in jüngster Zeit gibt, die Gelegenheiten in der Gesellschaft spärlicher werden. Immerhin gibt es mittlerweile methodisch kluge, reflektierte Modelle eines kritischen Umgangs mit Antisemitismus in Bildungseinrichtungen. In verschiedenen gesellschaftlichen Milieus gelingt es, Haltungen zu entwickeln, die antisemitische Reflexe und Traditionen unterbrechen. Dagegen aber entwickeln sich wieder Abwehrbewegungen - weswegen die scheinbare Wiederkehr des Überholten und Obsoleten eben keine Wiederholungen sind, sondern jeweilige Aktualisierungen aus gegenwärtiger schlechter Vergesellschaftung. Der Begriff des Antisemitismus bezeichnet das Wirken eines Wiederholungszwangs, dessen Dynamik zu verkennen eine weitere Möglichkeit ist, dem Irrationalen auszuweichen, anstatt sich ihm zu widersetzen.

35 Werner Konitzer, Antisemitismus und Moral. Einige Überlegungen, in: Mittelweg 3614 (2005), Heft 2, S. 24-35, hier S. 35 . 



\section{Autorinnen und Autoren}

Soma Mohammad Assad ist Politikwissenschaftlerin und arbeitete unter anderem zu Einstellungen junger Muslime in Österreich und für den Thinktank Mena-Watch.

Michael Fischer hat in Innsbruck Politikwissenschaft studiert und absolviert derzeit das Lehramtsstudium Geschichte, Sozialkunde und Politische Bildung sowie Deutsch an der Universität Wien.

Nikolaus Hagen ist Postdoctoral Fellow am Wiener Wiesenthal Institut für HolocaustStudien (VWI) und am Fortunoff Video Archive for Holocaust Testimonies der Yale University.

Günther Jikeli ist Erna B. Rosenfeld Professor am Institute for the Study of Contemporary Antisemitism der Indiana University Bloomington sowie Fellow der Groupe Sociétés, Religions, Laïcités am Centre National de la Recherche Scientifique (GSRL/CNRS) in Paris und am Moses Mendelssohn Zentrum der Universität Potsdam.

Georg Lauss ist Hochschullehrperson für Politische Bildung und empirische Sozialforschung an der Pädagogischen Hochschule Wien.

Manuel Mayrl ist Doktorand am Institut für Politikwissenschaft und Mitglied des Doktoratskollegs Political Institutions and Agency in a Contingent World an der Universität Innsbruck. Zuvor absolvierte er Bachelorstudien in Wirtschaftswissenschaften und in Politikwissenschaften sowie das Masterstudium Gender, Kultur und Sozialer Wandel.

Tobias Neuburger ist Soziologe und Kulturwissenschaftler. Er forscht derzeit am Leibniz Center for Inclusive Citizenship an der Leibniz Universität Hannover zu Mechanismen und Effekten des institutionellen Rassismus in urbanen Räumen und ist Lehrbeauftragter an der Hochschule Hannover. Er promoviert mit einer kulturhistorischen Arbeit über (theatrale) Aufführungen des Antiziganismus an der Universität Innsbruck.

Alexandra Preitschopf studierte an der Universität Salzburg Französisch und Geschichte und promovierte dort 2016 mit einer Dissertation zu Palästina-Solidarität, Antizionismus und Antisemitismus unter MuslimInnen im zeitgenössischen Frankreich. Derzeit ist sie OeAD-Lektorin am Germanistik-Institut der Universität Sofia. 
Daniel Rickenbacher ist Postdoctoral Fellow am Ben-Gurion Research Institute for the Study of Israel and Zionism an der Universität Beer Sheva. Zuvor war er unter anderem am Institute for Canadian Jewish Studies in Montreal tätig.

Gerhard Scheit lebt als freier Autor und Essayist in Wien. Er ist Gründer und Redaktionsmitglied von sans phrase - Zeitschrift für Ideologiekritik.

Stefan Schmid-Heher ist Berufsschullehrer und dienstzugeteilte Hochschullehrperson für Politische Bildung an der Pädagogischen Hochschule Wien.

Wolfram Stender ist seit 2003 Professor für Soziologie an der Hochschule Hannover. Davor arbeitete er viele Jahre als politischer Bildungsreferent und war Leiter von „Miteinander. Netzwerk für Weltoffenheit und Demokratie in Sachsen-Anhalt“.

Enno Stünkel hat Kunstgeschichte, Philosophie und Geschichte studiert und ist in der Erwachsenenbildung in Niedersachsen tätig.

Michel Wyss ist Doktorand am Institut für Geschichte der Universität Leiden und Wissenschaftlicher Assistent an der Dozentur Strategische Studien der Militärakademie an der Eidgenössischen Technischen Hochschule (ETH) Zürich. 
Der Antisemitismus hat wieder Konjunktur und scheinbar überwunden geglaubte antisemitische Verschwörungstheorien drängen zurück in die politische Arena: die "Protokolle der Weisen von Zion“ als Erzählung vom "großen Austausch", völkische Kapitalismuskritik in Form von Hetzkampagnen gegen George Soros oder sogenannte "Globalisten". Rechte Agitatoren und Neonazis spüren in diesem Klima Aufwind und schreiten zur Tat. Auch linker Antisemitismus artikuliert sich zunehmend unverstellt und findet neue Bündnispartner - als hätte es eine diesbezügliche innerlinke Kritik niemals gegeben. Und der in Europa beheimatete islamistische Terrorismus hat Jüdinnen und Juden sowie jüdische Einrichtungen zu bevorzugten Zielen seiner Gewaltexzesse erkoren. Eine Herausforderung besteht zudem auch in dem weitverbreiteten Unvermögen den modernisierten und sich wandelnden Antisemitismus überhaupt als Antisemitismus zu erkennen. Dieser Sammelband vereint Beiträge, die sich in diesem Sinne den Fragen und Problemstellungen des zeitgenössischen Antisemitismus aus unterschiedlichen Blickwinkeln annähern.

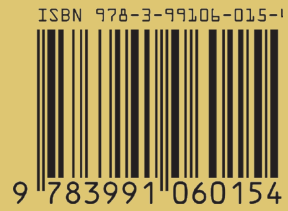

